Rhode Island College

Digital Commons @ RIC

6-2006

\title{
The Incorporation of Communicative Language Teaching into the Elaboration of Interactive Software for ESL/EFL Learning
}

Vladia Borges

Rhode Island College

Follow this and additional works at: https://digitalcommons.ric.edu/etd

Part of the Bilingual, Multilingual, and Multicultural Education Commons, Instructional Media Design Commons, Reading and Language Commons, and the Software Engineering Commons

\section{Recommended Citation}

Borges, Vladia, "The Incorporation of Communicative Language Teaching into the Elaboration of Interactive Software for ESL/EFL Learning" (2006). Master's Theses, Dissertations, Graduate Research and Major Papers Overview. 2.

https://digitalcommons.ric.edu/etd/2

This Dissertation is brought to you for free and open access by the Master's Theses, Dissertations, Graduate Research and Major Papers at Digital Commons @ RIC. It has been accepted for inclusion in Master's Theses, Dissertations, Graduate Research and Major Papers Overview by an authorized administrator of Digital Commons @ RIC. For more information, please contact digitalcommons@ric.edu. 
THE INCORPORATION OF COMMUNICATIVE LANGUAGE TEACHING INTO THE ELABORATION OF INTERACTIVE SOFTWARE FOR ESL/EFL LEARNING

BY

VLADIA BORGES

A DISSERTATION SUBMITTED IN PARTIAL FULFILLMENT OF THE REQUIREMENTS FOR THE DEGREE OF DOCTOR OF PHILOSOPHY

IN EDUCATION

UNIVERSITY OF RHODE ISLAND

AND

RHODE ISLAND COLLEGE

2006 
DOCTOR OF PHILOSOPHY DISSERTATION

OF

VLADIA BORGES

APPROVED:

Dissertation Committee:

Major Professor

DEAN OF THE GRADUATE SCHOOL - RIC

DEAN OF THE GRADUATE SCHOOL - URI

UNIVERSITY OF RHODE ISLAND

AND

RHODE ISLAND COLLEGE

2006 


\section{ABSTRACT}

This study investigated the extent to which ESL/EFL software programs currently available on the market develop language skills according to the principles of Communicative Teaching and an interactive approach to computer use for language learning. A software evaluation instrument was developed and validated. The validated instrument was used to evaluate fifteen ESL/EFL software programs currently available on the market for the technological, pedagogical and individualization features that would account for the incorporation of Communicative Language Teaching principles and an interactive approach to computer use in language teaching. Results indicated that only three programs incorporated more than seventy-five percent of the technological features, four programs incorporated more than seventy percent of the pedagogical features, and only one program contained more than seventy percent of the features that allow for individualization of instruction. Overall, only two programs incorporated more than seventy percent of the technological, pedagogical and individualizing features and created environments that developed language skills according to the principles of Communicative Language Teaching and an interactive approach to computer use for language learning. The use of the ESL/EFL software evaluation instrument for evaluating the programs provided evidence that the key differentiating factor in ESL software programs lies not only in their pedagogical orientation, but also in how and the extent to which they incorporate Communicative Language Teaching principles and an interactive language learning approach into their design. Although all programs claimed to incorporate communicative theories of language learning into their elaboration, they had to a lesser or greater degree difficulty in elaborating activities that would develop language skills according to this approach. 


\section{ACKNOWLEDGEMENTS}

Appreciation goes to the faculty of the URI/RIC Ph.D. Program in Education, whose expertise provided much help in my completing the program.

I am grateful to Julie Wollman-Bonilla, Willis Poole, JoAnn Hammadou, and Peter Adamy, members of my dissertation committee, who all shared with me their knowledge, and whose relevant questions and comments helped me shape this study.

Special thanks to my Major Professor, Dr. Julie Wollman-Bonilla, for her encouragement and the valuable feedback she provided throughout the doctoral program.

I am also indebted to the participant teachers. Part of this study could not have been done had it not been for them.

I am eternally thankful to my parents, for the encouragement and unconditional belief in my potential.

For the time my books took me away from them, I beg forgiveness of my children, and thank them for their support and encouragement. Their love has made all difficulties worthwhile. 


\section{TABLE OF CONTENTS}

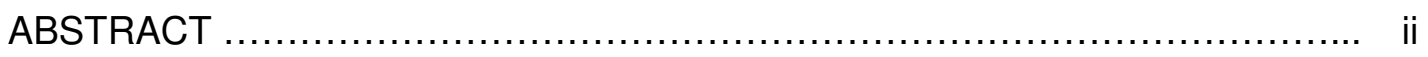

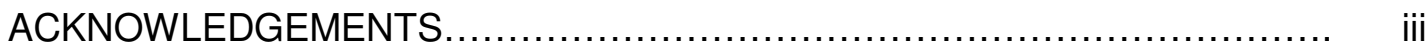

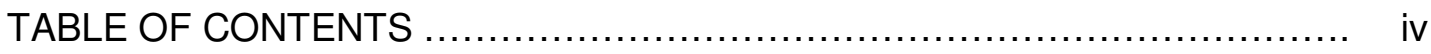

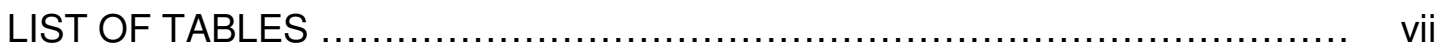

CHAPTER 1: INTRODUCTION

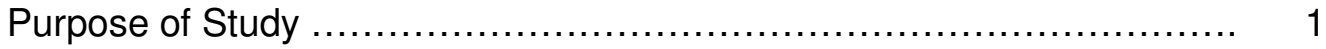

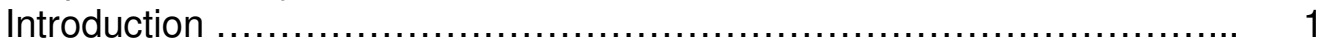

Statement of the Problem .............................................. 6

Research Questions ….............................................. 7

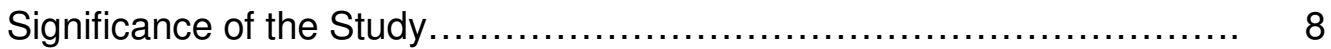

CHAPTER 2: LITERATURE REVIEW

Communicative Language Teaching ...................................... 10

Theories of Learning and of Language Learning supporting CLT... $\quad 16$

An Interactive Approach to Computer Use for Language Learning ......... 22

The Uses of Multimedia for Second Language Learning .................... 33

Evaluating ESL/EFL Software ........................................... 45

CHAPTER 3: METHODOLOGY

Overview of the Study ................................................ 56

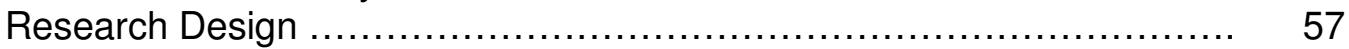

Elaboration and Validation of the ESL/EFL Software Evaluation Instrument 58

Elaboration of the ESL/EFL Software Evaluation Instrument........... 59

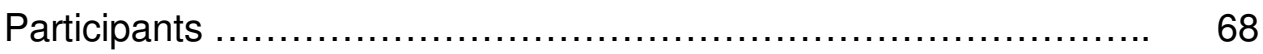

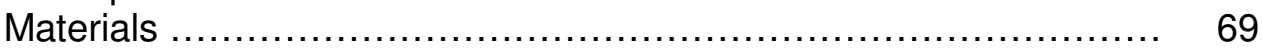

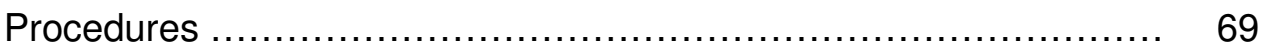

Method of Data Collection and Analysis .............................. $\quad 70$

Analysis of ESL/EFL Software Programs 72

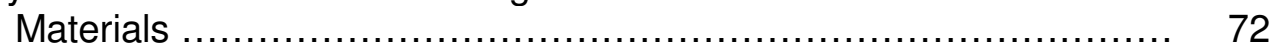

Procedures ........................................................... 74

Method of Data Collection and Analysis ............................... 75

CHAPTER 4: RESULTS OF THE RELIABILITY AND VALIDATION ANALYSES

Research Questions Restated ........................................... 78

Results for Face Validity and Content Validity ........................... 79

Results of Inter-Rater Reliability Measures …........................... 80

Pearson-Coefficients …............................................ 80

Intra-Class Coefficients …........................................ 81

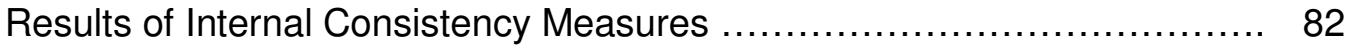

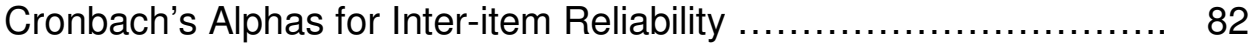

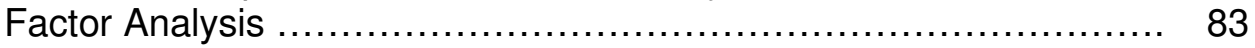

Summary of Results ........................................................ 89

CHAPTER 5: RESULTS OF THE ANALYSIS OF THE PROGRAMS

Research Questions Restated .......................................... 91

Analysis of the Incorporation of Technological Features ..................... 92 
Analysis of the Incorporation of the Principles of CLT

Analysis of How the Programs Incorporate the Principles of CLT and an Interactive Approach to Computer Use for Language Learning......

\section{CHAPTER 6: DISCUSSION AND IMPLICATIONS}

Major Findings and Discussion ........................................... 134

Reliability of the ESL/EFL software evaluation instrument ............ 134

Validity of the ESL/EFL software evaluation instrument .............. 138

Technological Features …......................................... 139

Simplicity of Installation and Navigation ...................... 140

Feedback ................................................... 143

Integration of Media ........................................ 146

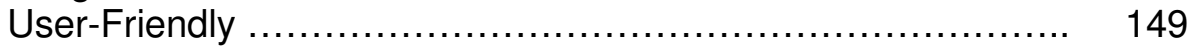

Individualization of Instruction ....................................... 154

Allowing for Different Routes of Learning ....................... 155

Allowing Learners to Move Through Content at Own Rhythm.... 157

Adapting to Learner's Needs, Interests, and Styles ............... 158

Principles of CLT ...................................................... 159

Theory of Language Learning and Teaching ...................... 159

Content Presentation and Sequencing ........................... 162

Activities ....................................................... 163

Facilitation of Language Skills Development..................... 166

Principles of CLT and an Interactive Approach to Computer Use for

Language Learning......................................................... 175

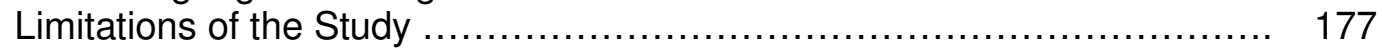

Limitations of the Validation Measures ............................. 177

Participants .............................................. 177

Study Design ....................................... 177

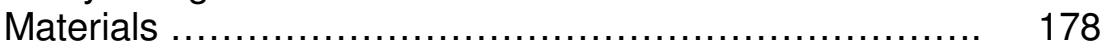

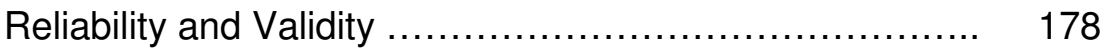

Limitations of the Evaluation of the Programs $\quad 179$

Study Design ............................................ 179

Materials .............................................. 179

Implications for Further Research ....................................... 180

Implications for the Development of ESL/EFL Software Programs ............ 181

Appendix A: Pilot Study .................................................. 191

Appendix B: ESL/EFL Software Evaluation Instrument ..................... 213

Appendix C: Informed Participant Consent Form ......................... 218

Appendix D: Evaluation Instrument Forms of the Software Programs ....... 219

Evaluation Instrument Form of "Asterix" ............................ 219

Evaluation Instrument Form of "Discoveries" ....................... 224

Evaluation Instrument Form of "Dynamic English" .................. 229

Evaluation Instrument Form of "ELLIS" ............................. 234

Evaluation Instrument Form of "Issues in English" ................... 239

Evaluation Instrument Form of "Learn English Now" ................. 244

Evaluation Instrument Form of "Learn to Speak English" ............. 249

Evaluation Instrument Form of "Live Action" ......................... 254

Evaluation Instrument Form of "Longman Interactive English" ....... 259

Evaluation Instrument Form of "Making Connections" ................ 264 
Evaluation Instrument Form of "Rosetta Stone" .................... 269

Evaluation Instrument Form of "Side-by-Side" ...................... 274

Evaluation Instrument Form of "Talk Now!" ......................... 279

Evaluation Instrument Form of "Tell me More" ..................... 284

Evaluation Instrument Form of "Who's Oscar Lake?" ................ 289

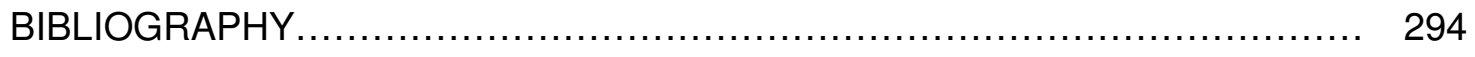




\section{LIST OF TABLES}

Table 1 Criteria and Questions for the Evaluation of the Incorporation of Technological Features into ESL/EFL Software

Table 2 Criteria and Questions for the Evaluation of the Incorporation of the Principles of Communicative Language Teaching into ESL/EFL Software

Table 3 Criteria and Questions for the Evaluation of the Incorporation of Individualized-Learning Features into ESL/EFL Software ..........

Table 4 Intra-Class Coefficients for Raters' Ratings for "New Dynamic English", "ELLIS", and "Side-by-Side"

Table $5 \quad$ Cronbach's Alpha Coefficients for the programs "Ellis", "New Dynamic English", and Side-by-Side

Table 6

Factor Loadings

85

Table $7 \quad$ Cronbach's Alpha Coefficients for Each Factor

87

Table 8 Ratings for the Items Related to How the Programs Helped Learners Move Through Content and Sequence.

Table 9 Ratings for the Items Related to How the Media Technology Differentiates Feedback.

Table 10 Ratings for the Item Related to How the Integration of Different Types of Media Facilitated Learning.

Table 11 Ratings for the Items Related to the Degree and Type of Individualization of Instruction.

Table 12 Total Ratings for the Items Related to the Programs' Degree and Type of Individualization of Instruction.

Table 13

Overall Ratings for the Category of Media Attributes of the Programs.

Table 14 Ratings for the Items Related to How the Use of the Program is Made Easy for Learners.

Table 15 Ratings for the Items Related to How Attractive the Media Technology Made the Programs. 
Table 16 Ratings for the Items Related to How the Programs Motivate Learning.......................................................... 106

Table 17 Overall Ratings for the Category of User-friendly Attributes...... 107

Table 18 Ratings for the Categories of Media Attributes and User-Friendly Attributes and Total Rating for these Categories Together ....... 108

Table 19 Ratings for the Items Related to the Theory of Language Learning and Teaching that Underlies the Programs.............. 110

Table 20 Ratings for the Items Related to How Content is Presented and Sequenced ....................................................... 114

Table $21 \quad$ Ratings for the Items Related to the Type and Quality of Language-Learning Activities.

Table 22 Ratings for the Items Related to the Type of Feedback Provided. 122

Table 23 Ratings for the Items Related to How the Programs Facilitate Learning.....

Table 24 Ratings of the Programs for the Category of Instructional Attributes...

Table 25 Total Ratings of the Programs....

Table 26 Total Ratings and Ratings for each Category of the Programs..... 


\title{
CHAPTER 1 - INTRODUCTION
}

\author{
Purpose of the Study
}

The purpose of this study was to evaluate software programs designed for teaching/learning English as a second/foreign language (ESL/EFL). Specifically, this

investigation aimed at: (a) developing and validating an evaluation instrument that can be used to analyze ESL/EFL software programs as to their potential for developing language skills according to the principles of Communicative Language Teaching and an interactive approach to computer use for language learning, and (b) assessing the extent to which commercially available software programs develop ESL/EFL skills according to the principles of Communicative Language Teaching, and an interactive approach to computer use for language learning. The study, therefore, addressed the evaluation of Computer Assisted Language Learning (CALL) by analyzing fifteen ESL/EFL software programs currently available on the market using the developed ESL/EFL software evaluation instrument.

Introduction

In recent years there has been a great deal of interest in using computers for language teaching and learning. Little more than a decade ago, the use of computers in the language classroom was of concern only to a small number of specialists. However, with the advent of multimedia computing and the Internet, the role of computers in language instruction has now become an important issue confronting large numbers of language teachers and researchers throughout the world. 
Computers have been used for language teaching since the 1960s. This $40-$ year history of Computer Assisted Language Learning (CALL) can be roughly divided into three main stages: behaviorist, communicative, and integrative CALL. Each stage corresponds to a certain level of technology as well as a certain pedagogical approach (Meskill, 2002).

Behaviorist CALL, conceived in the 1950s and implemented in the 1960s and 1970s, can be considered a sub-component of the broader field of computer-assisted instruction. Informed by the behaviorist learning model and the audio-lingual approach to language learning this mode of CALL featured repetitive language drills, referred to as drill-and-practice. In this paradigm, the computer was viewed as a mechanical tutor which never grew tired or judgmental and allowed students to work at an individual pace.

The next stage, communicative CALL, emerged in the late 1970 s and early 1980 s, at the time that behaviorist approaches to language teaching were being rejected at both the theoretical and pedagogical levels, and when new personal computers were creating greater possibilities for individual work. Proponents of communicative CALL stressed that computer-based activities should: (a) focus more on using forms than on the forms themselves, (b) teach grammar implicitly rather than explicitly, (c) allow and encourage students to generate original utterances rather than just manipulate prefabricated language, and (d) use the target language predominantly or even exclusively (Jones \& Fortescue, 1987; Phillips, 1987; Underwood, 1984).

Although communicative CALL was seen as an advance over behaviorist CALL, it too began to come under criticism. By the late 1980 s and early 1990 s, critics pointed out that the computer was still being used in an ad hoc and disconnected fashion and thus "finds itself making a greater contribution to marginal rather than central elements" of the language learning process (Kenning \& Kenning, 1990, p. 90). 
This critique corresponded to a broader reassessment of communicative language teaching theory and practice. Many teachers were moving away from a cognitive view of communicative teaching to a more social or socio-cognitive view, which placed greater emphasis on language use in authentic social contexts. Task-based, projectbased, and content-based approaches were all used to involve learners in authentic environments along with the various skills of language learning and use.

This movement led to a new perspective on technology and language learning, which has been termed integrative CALL (Warschauer, 1996c), a perspective which seeks both to integrate skills (e.g., listening, speaking, reading, and writing) and technology more fully into the language learning process. Integrative CALL incorporates socio-constructivist theories of learning and interactional approaches of language learning into the elaboration of educational computer programs for teaching and learning English as a Second and/or Foreign Language (ESL/EFL). Socio constructivist theory suggests that learning is a process by which learners construct new concepts by making use of their own knowledge and experience. Consequently, it is a problem-oriented learning approach in which the learner is expected to construct his or her own reality based on a personalized understanding of the learning materials, often through analysis and synthesis of ideas (Richard-Amato, 1996). The interactional approach to language learning sees language as a vehicle for the realization of interpersonal relations and for the performance of social transactions between individuals. Language is viewed as a tool for the creation and maintenance of social relations (Richards \& Rodgers, 1986).

The three stages mentioned above do not fall neatly into the above-mentioned timelines. As each new stage has emerged, previous stages continue. Current uses of computers in the language classroom correspond to all three of the paradigms mentioned above. 
Currently, advocators of CALL argue that software programs can: (a) provide realistic, native-speaker models of the language in a variety of media, (b) offer a language learning curriculum, (c) do a needs assessment, (d) determine the best next step for the learner and provide practice with that skill area, (e) record what the student has done, along with an evaluation, and (f) be available at any hour and require no additional pay or benefits.

A number of high-end packages have attempted to come as close as possible to meeting those needs in terms of English language teaching. What distinguishes these high-end packages from many other multimedia programs is that they include a curriculum, not just distinct elements for practice. However, the quality of the curriculum and its relevance to the target learners is not yet clearly established.

Another similarity in these high-cost products is their relative immutability. There is little or no provision for teacher-customized content, because it would be difficult to incorporate teacher-generated lessons into a fixed curriculum. Some of the programs have teacher's guides and suggest ways to incorporate lessons into a regular classroom, but the assumption is that students will tend to work through the computer-based curriculum independently of what goes on in the classroom. The most stand-alone of these programs also tend to be the least open-ended in the activities they provide; a human teacher is needed to evaluate free responses, where they occur.

Software programs offer practice in a variety of skills, but without extensive management systems or prescriptive curricula. Most expect the learner, often with the help of a teacher, to decide what skills to work on and what media to use. These can range from comprehensive to limited, very expensive to quite affordable. 
Where the computer is not seen as a substitute for a teacher, schools may purchase smaller, more limited, but more flexible software that individual teachers will use as an add-on to instruction or that will be placed in libraries as language references and resources. Language teachers have been especially blessed in this category of software, with hundreds of programs available. The benefits of adding a computer component to language instruction are many, and include: (a) multimodal practice with feedback, (b) individualization in a large class, (c) pair and small group work on projects, either collaboratively or competitively, (d) the fun factor, (e) variety in the resources available and learning styles used, (f) exploratory learning with large amounts of language data, and (g) real-life skill-building in computer use.

One of the great benefits of the growth of multimedia is that software vendors (and language teachers) no longer feel bound to grammar practice as the main goal of computer use in the language classroom. While the process has taken longer in the foreign language arena than in English language teaching, the movement toward communicative teaching with computers is clearly taking place. There are still a great many grammar and vocabulary drill programs available, but at least the vocabulary programs have started to be contextualized and to incorporate graphics, audio recording and playback, and video. Drills do have a place in language learning, particularly in the first stages of vocabulary acquisition where giving the same information in multiple modes, such as visual plus aural plus textual, enhances recognition and recall. More sophisticated error-checking can provide students real help in the feedback they receive, directing them to further practice or moving them to the next stage. Those who do need extra help with those aspects of language that improve with practice can use small, focused programs to give them additional time and assistance outside of regular class time. 
The changes or lack thereof over time in what teachers and students do with and think about technology provide a perspective in viewing the role of computers in education, and maybe even some ideas about activities that motivate students and encourage learning. Proof is elusive, but as more research is performed, the role technology plays in language learning becomes clearer.

\section{Statement of the Problem}

During the four decades of CALL development, materials have gone from an emphasis on basic textual gap-filling tasks and simple programming exercises to interactive multimedia presentations with sound, animation and full-motion video. But this progress has not been purely linear and, "in terms of pedagogy, the "new and improved' have not always replaced the 'old and tired'. Instead, many programs being produced today feature "little more than visually stimulating variations on the same gap-filling exercises used 40 years ago" (Beatty, 2003, p. 11).

There appears to be a substantial gap between what computer technology can do to support language learning and the way actual software programs provide for language learning. Therefore, there might be programs on the market which claim to be interactive but their design may lag behind current ESL pedagogy - The Communicative Approach to Language Teaching. Although a review of the literature on ESL/EFL computer programs supports a pedagogical use of computer tools, the incorporation of modern theories of learning in the elaboration of ESL computer programs seems to be rather complex and difficult to achieve.

The problem is that the commercial software industry is the major creator of the most commonly used CALL learning materials. Although it can be argued that the 
same is true for traditional publishing, the relationship between educators and print publishers is of a more symbiotic nature, particularly as governments, schools and universities tend to have syllabi to which publishers' materials must conform. The same is seldom true for CALL materials for the simple reason that there are not enough CALL materials to choose from and the market is not yet as competitive or adaptable to local needs, especially considering the high costs of producing a CD-

ROM, a process more akin to producing a movie than publishing a textbook. Also, since most software programs are designed for individual use, little attention is given to teachers' needs. Overall, changes in CALL tend to be governed more by advances in technology than by pedagogical insights (Beatty, 2003).

Consequently, it seems useful to identify meaningful ways of analyzing Computer Assisted Language Learning (CALL) material so that the characteristics associated with high quality interactive CALL material can be identified, articulated, and refined. Although there are many ways to evaluate and critique CALL programs, for in one sense their evaluation is analogous to the evaluation of a new textbook or other instructional resources, little attention has been given to whether particular programs effectively promote second language learning according to the principles of Communicative Language Teaching.

\section{Research Questions}

If CALL software packages are to be properly evaluated and matched with learning needs, there must be a set of criteria to be taken into consideration in their evaluation. Because this research is concerned with criteria for the evaluation of CALL software programs designed for ESL/EFL learning, it was necessary to design an 
evaluation instrument that encompassed the principles of Communicative Language

Teaching and an interactive approach to computer use for language learning.

Therefore, this study first examined the following questions:

1. To what extent does the ESL/EFL software evaluation instrument produce consistent results when administered under similar conditions? In other words, is the designed ESL/EFL software evaluation instrument reliable?

2. To what extent is the ESL/EFL software evaluation instrument valid to evaluate the potential of CALL programs to develop language skills according to the principles of Communicative Language Teaching principles and an interactive approach to computer use for language learning?

Using the ESL/EFL software evaluation instrument this study investigated these other questions:

3. Do ESL/EFL software programs incorporate the technological features associated with interactive CALL?

4. Do CALL programs present technological features that allow for individualized instruction?

5. Do ESL/EFL software programs incorporate the teaching principles of the principles of Communicative Language Teaching?

6. In sum, to what extent do CALL programs create environments that develop language skills according to the Communicative Approach to Language Teaching and an interactive approach to computer use for language learning?

Significance of the Study

Traditionally, much research on CALL has focused on whether or not students learn better with a computer, and whether or not second/foreign language skills can be 
developed by a software program. The question now is no longer whether or not computers should be used to teach and learn language. Questions now include how computers should be used and how well software programs incorporate into their design what is known as best practices for language learning.

This study attempts to go beyond previous research which has investigated the advantages and disadvantages of using computers to develop specific language skills and to influence students' attitude toward language learning. Because Computer Assisted Language Learning (CALL) is an important aspect of many languagelearning programs, it makes sense to be able to evaluate the types of programs which promote language development in second/foreign language learners.

Data gathered in this study will validate an instrument which is expected to help teachers select ESL/EFL software whose features fit the needs of their curriculum and students, and will inform researchers about the features in software programs that effectively develop language learning according to Communicative Language Teaching principles and to an interactive approach to computer use in language learning. 


\section{CHAPTER 2: LITERATURE REVIEW}

The principles of Communicative Language Teaching (CLT) and an interactive approach to computer use for language learning served as theoretical background for the elaboration of the ESL/EFL software evaluation instrument, which is used in this study to evaluate ESL/EFL software programs. Thus, section one of this review of the literature characterizes the main principles of CLT, and briefly describes the theories of language and language learning which provide the theoretical background for this teaching approach. The second section presents research and theories that support an interactive approach for CALL. Section three reviews literature on the uses of

multimedia for language learning. The final section reviews literature concerning different methods for analyzing software programs for language learning.

\section{Communicative Language Teaching}

Communicative language teaching (CLT) has been an influential approach for more than two decades. The very term 'communicative' carries an obvious ring of truth: we 'learn to communicate by communicating' (Larsen-Freeman 1986, p. 131).

The Communicative Approach to Language Teaching is based on a theory of language as communication. The goal of language teaching is to develop what Hymes (1972) referred to as 'communicative competence'. Hymes's theory of communicative competence was a definition of what a speaker needs to know in order to be communicatively competent in a speech community.

Another linguistic theory favored in Communicative Language Teaching (CLT) is Halliday's functional account of language use. "Linguistics ... is concerned ... with 
the description of speech acts or texts, since only through the study of language in use are all the functions of language, and therefore all components of meaning, brought into focus" (Halliday 1970, p. 145). Halliday described seven basic functions that language performs for children learning their first language:

1. Instrumental - using language to get things.

2. Regulatory - using language to control the behavior of others.

3. Interactional - using language to create interaction with others.

4. Personal - using language to express personal feelings and meanings.

5. Heuristic - using language to learn to discover.

6. Imaginative - using language to create a world of the imagination.

7. Representational - using language to communicate information.

Learning a second language was similarly viewed by proponents of Communicative Language Teaching, for example, Brumfit and Johnson, 1979; Savignon, 1983, as acquiring the linguistic means to perform different kinds of functions. Henry Widdowson is another theorist frequently cited for his views on the communicative nature of language. Widdowson (1978) presented a view of the relationship between linguistic systems and their communicative values in text and discourse. He focused on the communicative acts underlying the ability to use language for different purposes.

Expanding on the premise that language should be learned for communicative purposes, Canale and Swain (1980) identified four dimensions of communicative competence:

1. Grammatical competence - the domain of grammatical and lexical capacity.

2. Sociolinguistic competence - understanding of the social context in which communication takes place, including role relationships, the shared information of the participants, and the communicative purpose for their interaction. 
3. Discourse competence - the interpretation of individual message elements in terms of their interconnectedness and of how meaning is represented in relationship to the entire discourse or text.

4. Strategic competence - the coping strategies that communicators employ to initiate, terminate, maintain, repair, and redirect communication.

In sum, Communicative Language Teaching has a rich and eclectic theoretical base, whose characteristics can be summarized (Richards \& Rodgers, 1986) as:

1. Language is a system for the expression of meaning.

2. The primary function of language is for interaction and communication.

3. The structure of language reflects its functional and communicative uses.

4. The primary units of language are not merely its grammatical and structural features, but categories of functional and communicative meaning as exemplified in discourse.

Three key pedagogical principles that developed around CLT were: the presentation of language forms in context, the importance of genuine communication, and the need for learner-centered teaching. These were widely acknowledged but nevertheless open to interpretation, resulting in what Howatt (1984) described as weak and strong versions of CLT. The former includes pre-communicative tasks (such as drills, cloze exercises, and controlled dialogue practice) along with communicative activities. Littlewood (1981), for example, described pre-communicative activities as a necessary stage between controlled and uncontrolled language use.

One example of such an approach to CLT is what is known as the PPP lesson (for presentation, practice, and production). Language forms are first presented under the guidance of the teacher, then practiced in a series of exercises, again under the teacher's supervision. The chosen forms are finally produced by the learners 
themselves in the context of communicative activities that can be more or less related to the learners' real lives and interests (Beagle, 2002).

Regardless of how learner-centered and genuinely communicative the teacher makes it, the PPP structure clearly treats language as a product constructed from teachable parts; these parts being the linguistic forms and structures behind the pragmatic functional use of language. But, as Grenfell (1994, p. 58) has put it: "...language is not something that we access like a baggage of information, taking out the bits and pieces to suit our needs at a particular instant. It is rather the means by which we create sense: of our world, of and for ourselves."

In strong versions of CLT the teacher is required to take a 'less dominant role' and the learners are encouraged to be 'more responsible managers of their own learning' (Larsen-Freeman 1986, p. 131). Rather than a presentation and practice approach to language forms, the teacher begins with communicative classroom activities that allow learners to actively learn for themselves how the language works as a formal system.

In order to encourage meaningful language use, many popular communicative activities involve 'elements of puzzle-solving, role play, or simulation' (Hadfield 1990). They encourage learners to do things with information such as: guessing, searching, matching, exchanging, collecting, sharing, combining, and arranging.

Although communicative games are intended to have 'a non-linguistic goal or aim' (Hadfield 1990) this is usually only from the learners' perspective. Most often they are designed around a key language structure (for example, comparatives, present perfect tense, question forms) or a family of vocabulary items. If we consider the communicative principle of genuinely meaningful language use, then such activities are not always rich in unpredictability or risk-taking for the learner. Other criticisms leveled 
at nominally communicative activities have concerned lack of 'relevance and interest' (Swain, 1985), and restrictions on the range of learner response (Savignon, 1991). Content-based programs involve the teaching of subject matter content in the target language. This approach has been used with some degree of success in many parts of the world, most notably in Canada (Stern 1992). According to Stern (1992, p. $187)$, it is closer to "the communicative reality of the target language milieu" than classroom activities that are only "designed to have certain characteristics of natural discourse". It also has the potential to be more motivating for learners, given they have a degree of interest in the subject matter. Content-based teaching has obvious applications in the area of English for Specific Purposes, where learners are focusing on English relevant to a particular field of work or study.

Another alternative is provided by the task-based approach. As described by Willis and Willis (2001), task-based learning (TBL) is actually a more resolutely communicative application of CLT principles. It advocates the use of a syllabus based on communicatively-oriented tasks rather than linguistic forms. Mainstream English language textbooks are clearly not task-based, in that they provide only the forms that learners are expected to use. In TBL, "language forms are not prescribed in advance" and so learners are "free to use any language they can" in completing the required task (Willis and Willis 2001, p.174).

The alternative framework that Willis describes leads learners through a 'four stage task cycle' consisting of: 1) introduction to topic and task, 2) task, 3) planning, and 4) report. This allows learners to explore ideas and communicate informally about the task in the first two stages; then only in the last two stages is there an "emphasis on clarity, organization, accuracy as appropriate for a public presentation" (Willis 1994, p. 18). The addition of a language 'input phase' and a 'language focus task' at the end 
of the cycle gives some credence to the view that this is an upside down version of PPP.

Willis' task-based framework is an effective response to research that shows learners need "opportunities for negotiated interaction in order to accelerate their comprehension and production" (Kumaravadivelu 1994, p. 34). In contrast, the more traditional PPP structure has been called into question by second language acquisition studies that indicated that "structural practice of the skill getting variety (has) little influence on self expression, or skill using" (Savignon 1991, p. 267).

A central concern of a task-based framework is how elements of form- and message-focus may be combined. Various models have emerged in the literature. Willis (1996), for example, suggests sequences combining a task with pre- and posttask work. Others, like Johnson (1992), explore ways of injecting a degree of form focus into a message focused activity. Johnson (2002) presents a further possibility. In his framework, the teaching program has two components. The first component concerns language work, focusing on language structures in sequence, perhaps using a traditional structural syllabus. The second component contains nothing but messagefocused tasks, graded according to principles of task complexity. Johnson (2002) suggests using the first component as the traditional stages of 'presentation' and 'practice', and the second component as the production stage. He acknowledges that his framework is largely speculative, and longitudinal research would need to be done to explore its feasibility and cost effectiveness. Nevertheless, the notion of two linguistically unrelated components reflects the expectation that a more circuitous path exists linking what is taught and practiced with what becomes internalized and proceduralized. 


\section{Theories of Learning and of Language Learning supporting CLT}

In contrast to the amount that has been written in Communicative Language Teaching literature about communicative dimensions of language, little has been written about the learning theory underlying it. More recent accounts, however, have attempted to describe theories of language learning processes that are compatible with the communicative approach.

Krashen $(1981,1985,1987,2003)$, for instance, has developed theories considered compatible with the principles of Communicative Language Learning. In his language learning theory, Krashen (1981) draws a distinction between acquisition and learning, and states that acquisition refers to the unconscious development of the target language system as a result of using the language for real communication. Learning, on the other hand, is the conscious representation of grammatical knowledge that has resulted from instruction, and cannot lead to acquisition. Therefore, Krashen stresses that language learning comes about through using language communicatively, rather than through practicing language skills.

Krashen's Input Hypothesis $(1985,1987)$ claims that an important "condition for language acquisition to occur is that the acquirer understand language input that contains structures a bit beyond his or her current level of competence... If an acquirer is at stage or level $i$, the input he or she understands should contain $i+1$ " (p.100). In other words, the language that learners are exposed to should be just far enough beyond their current competence that they can understand most of it but still be challenged to make progress. The corollary to this is that input should neither be so far beyond their reach that they are overwhelmed, nor so close to their current stage that 
they are not challenged. The Input Hypothesis explicitly claims that "comprehensible input is the only causative variable in second language acquisition" (1981, p. 62).

Although Krasen's theory specifies both processes of and conditions for learning, some theories address primarily the conditions necessary for learning to take place without specifying what the learning processes themselves are presumed to be. Scholars such as Long (1980, 1989, 1991, 1996, 2005, 2006); Long and Sato (1984); Long \& Porter (1985); Pica (1983, 1993, 1994); Pica and Doughty (1985); Pica, Kanady, and Faladun (1993); and Gass and Varonis (1994) have directed their attention to examining what features of linguistic interaction and negotiation seem to make input more comprehensible and facilitate language learning.

Proponents of input-processing models make a number of claims about the relationship of interaction and negotiation to language learning. The first claim, related to Krashen's views as well as to research by Long (1980; 1985), is that "comprehension of message meaning is necessary if learners are to internalize L2 forms and structures" (Pica, 1994, p. 500).

A second claim is that interactional modifications due to negotiation of meaning facilitate language learning (Long, 1980; 1996; 2005; 2006). Negotiation is defined by Pica (1994: 495) as "modification and restructuring of interaction that occurs when learners and their interlocutors anticipate, perceive, or experience difficulties in message comprehensibility." Input modification devices deemed beneficial include repetitions, confirmations, reformulations, comprehension checks, recasts, confirmation checks, and clarification requests (Long, 1996). Research has indicated that these input modifications "are significantly more abundant during negotiation than during the rest of learners' interaction" (Pica, 1994, p. 506); they also occur to a greater degree in NS (native speaker)-NNS (non-native speaker) speech than in NS-NS speech (Pica, 1994). 
Michael Long (1985, 1996, 2005, 2006), taking up where Krashen left off, and supported by the interactional view of language, posits in what has come to be called the Interaction Hypothesis that comprehensible input is the result of modified interaction, which is defined as the various modifications that native speakers and other interlocutors create in order to render their input comprehensible to learners. In Long's view, interaction and input are two major players in the process of acquisition. In a radical departure from an old paradigm in which second language classrooms might have been seen as contexts for practicing grammatical structures and other language forms, conversation and interactive communication are the basis for the development of linguistic rules.

Long's theory of language learning is related to Vygotsky's (1978) learning theory, which stresses the importance of social interaction in the learning process. Vygotsky saw language as a tool for thought and believed that children use language to solve problems, first in interaction with others, and then, when speech is internalized, by thinking through problems themselves.

Vygotsky hypothesized that children would be able to solve problems with assistance from an adult or more capable peer before they could solve them alone. This observation was then used to reach several original conclusions. One conclusion was that the zone of proximal development - the distance between what a learner can do alone and what he/she can do in collaboration with a more capable peer or adults could be used to identify those skills most amenable to instruction. Another was that learning consists of internalization of social interactive processes. According to Vygotsky (1978), learning itself is a dynamic social process through which the teacher in a dialogue with a student can focus on emerging skills and abilities. This cooperative relationship is particularly important for second-language learning/teaching, for it leads to meaningful interaction about some content of interest. Through such interaction the 
teacher is naturally attuned to the students' emerging skills and abilities. Otherwise, meaningful communication could not take place.

Evidence of the importance of meaningful interaction in second-language learning/teaching is found in a study by Seliger (1977). He concluded that high inputgenerator students were able to test more hypotheses about the shape and use of the second langauge thus accounting for increased success by receiving more focused input through interaction. Low input generators, on the other hand, were particularly dependent upon the classroom environment to force interaction because they did not tend to initiate or allow themselves to become involved in it on their own.

More evidence comes from the Heidelberg Project (cited in Schumann, 1978) to support the notion that social interaction is important to second-language acquisition. In the study of Italian and Spanish guest workers acquiring German in Germany, the correlations were extremely high between German proficiency and leisure social contact (.64), and between German proficiency and social contact at work (.53). Carroll (1967) comes to a similar conclusion based on his study of university students majoring in French, German, Italian, Russian, and Spanish. Even a brief time spent abroad, where the students had social interaction, had a substantial effect on proficiency.

Once it is agreed that social interaction allows meaningful communication, and that meaningful communication is paramount to language learning, one is left with the question of what kind of input would be most conducive to forming generalizations about the language, thereby making acquisition possible. Krashen (1981) suggests that in addition to being relevant and/or interesting, the input must approximate the student's $i+1$. It must be comprehensible in that it is near the student's actual level of 
development $(I)$, but then it must stretch beyond that to include concepts and structures that the student has not yet acquired $(i+1)$.

According to Brown (1973), meaningful communication on one level always serves as the 'launching platform' for attempts at a higher level. It is not so much a mechanism to teach language as it is a way to continue or extend the rapport within a conversation for as long as possible. Also, the student ideally must be in a situation in which all the interlocutors desire to understand and be understood. It is often through gestures, the context itself, and linguistic modifications that the new concepts become internalized.

It is important to keep in mind, though, that findings of a wide range of immersion and naturalistic acquisition studies suggest that when second language learning is solely experiential and focused on communicative success, some linguistic features like accuracy do not develop to target language levels (e.g., Harley, 1992; Spada \& Lightbown, 1993). This occurs in spite of years of meaningful, comprehensible input and opportunities for interaction. Recent studies point to the inclusion of some degree of focus on form (Long, 1991; and Long \& Robinson, 1998), in classes that are primarily focused on meaning and communication, as particularly helpful in promoting accuracy in second language acquisition (Doughty \& Williams, 1998; and Spada, 1997).

At the same time, alongside a growing concern for formal accuracy, emphasis has also recently been on increasing learner autonomy in the learning process and on learner-centered approaches to both learning and teaching. The terms cooperative and collaborative learning are variously used and understood (Adams \& Hamm, 1996; Johnson \& Johnson, 1991; and McGroarty, 1993), but the primary features on which most will agree is that such approaches entail learners' taking responsibility for their own learning by working together to achieve both individual and common goals. This 
moves classroom interaction beyond mere group work in which learners work in physical proximity but may not consistently derive the greater benefit of working together. By involving learners actively in their own learning in a supportive environment, proponents of collaborative learning believe that educational outcomes can be improved.

These theories that underlie Communicative Language Teaching alter the way that language-teaching environments, in-class and out-of-class activities, are constructed. As frequently discussed (Brown, 1987; Li, 1998; Kern \& Warschauer, 2000; Carter \& Nunan, 2000), there are many characteristics of successful language learning environments using a communicative approach. First, there is the focus on meaningful tasks and efforts to make the language learning tasks relevant to a particular group of learners. Second, there is a premium placed on authentic (from real-life) materials. Third, group activities are important for promoting communication and interaction. Students are expected to interact with other people. Language learning environments must be a place where the learner feels secure and comfortable in order to make progress. Teachers, in turn, help learners in any way that motivates them to work with the language. Finally, language learners should develop strategies to become successful, independent language learners (autonomous, self-monitoring, etc.) to be able to transfer the skills they learn in one setting to another.

The characteristics of the Communicative Language Teaching and the above mentioned characteristics of successful language learning environments using a communicative approach were used as criteria in the elaboration of the software evaluation instrument for this study. Since these characteristics can only be implemented in software if programs are supported by an interactive approach to computer use for language learning, it is important to understand how computers can be interactively used for pedagogical purposes. 
An Interactive Approach to Computer Use for Language Learning

Social interaction is essential to language learning, according to the arguments presented by studies based in the communicative approach to language teaching (e.g., Hall \& Verplaetse, 2000; Lantolf, 2000; Long, 1983, 1996, 2005, 2006; Pica, 1994). Empirical evidence suggests that social interaction is a wellspring for negotiation of meaning, a communicative exchange that sustains and repairs conversations (Long 1983, 1996; Pica, 1994). Negotiation of meaning is a cognitive process that speakers use to better understand one another, that is, to increase the comprehensibility of language input. Furthermore, negotiation of meaning may result in modified interaction (Ellis, Tanaka, \& Yamazaki, 1994; Pica, 1994; Smith, 2004), which ostensibly optimizes second language acquisition (Ellis et al., 1994; Gass, 1997). Modified interaction, as defined by Long (1983), is partly accomplished through the conversational repair moves of negotiation of meaning, including utterances such as clarification requests, comprehension checks, and incorporations in learners' speech.

Therefore, Communicative Language Teaching principles and an interactive approach to computer use in language learning are supported by Vygotsky's theories. Within Vygotskyan theory (1978), instruction is more than just didactic teaching, with a teacher explaining and demonstrating through language. Effective forms of teaching require learners to take an active role in the learning process. Scaffolded instruction does not mean teacher-initiated discourse and learner dependency. Higher order learning (problem-solving, evaluation, synthesis) requires the learner to be selfregulated, and to demonstrate initiative and independent thought. Studies by Barnes (1992), Forman and Cazden (1985), and Donaldson (1978) suggest that students working together enjoy peer support and increased verbal exchange leading to higher levels of task involvement and problem solving behaviors. Social interaction and peer 
presence thus seem to be predictors of task related interaction and higher order thinking. If we accept that this is the case, how can verbal interaction be related to learning with computers?

The answer can be found in a sociocultural theory of learning in technology supported learning environments, because such a theory: endorses the fact that learning takes place in a social context; recognizes that language use is fundamental to learning; and acknowledges that learners need support and assistance to learn. All of these elements can be integrated in an interactive approach, which provides the basis for maximizing learning in technology-supported environments.

There is growing awareness that if we are to realize the full potential of computers in education, consideration must be given to their role as catalysts in the learning process, rather than simply technological tools. It is necessary then to recognize the social role of the computer in order to support the view that computers can be used to facilitate learning through language interaction. Research demonstrates the possibility of using a socio-constructivist theory in computer-based learning environments, and supports an interactive approach in the use of computers for language learning (Bonk \& Cunningham, 1998; Cobb, 1994; Jonassen, 1994; O’Malley, 1995; Schank \& Cleary, 1995, Chong, 1998; Muller-Hartmann, 2000). Technology can provide a socio-constructivist environment for relevant learning by creating whole, authentic, inherently interesting activities and setting up multiple representations of reality and actual experience for learners, thus enabling them to construct their own knowledge.

Research on computer based learning environments indicates that group work around computers offers opportunities for language use and enhanced learning outcomes. For example, group work with computers has been found to provide support for: relatively autonomous learning on the part of students (Laurillard, 1995; Collins \& 
Berge, 1996, Jonassen, 1994; Ocker \& Yaverbaum, 1999); increased collaboration and negotiation (Beauvois, 1992; Blake 2000; Fernandez-Garcia \& Martinez-Arbelaiz, 2002; Kelm, 1992; Kern, 1995; Kim, 1998; Light \& Mevarech, 1992; Pellettieri, 1996, 2000; Repman, 1993; Smith, 2001, 2003, and Warschauer, 1996b); a higher quality of exploratory talk and cognitive discourse (Davis \& Thiede, 2000; Irvine, 2000; Mercer, 1994, and Sengupta, 2001); greater problem solving competencies and higher order thinking (DeLoach \& Greenlaw, 2002; Kamhi-Stein, 2000b; MacKinley, 1999; and Nastasi \& Clements, 1992); development of writing skills and literary uses of language (Warschauer, 2004; Schultz, 1996; and Sullivan \& Pratt, 1996).

In addition to increasing the comprehensibility of input, negotiation of meaning may also raise speakers' awareness of target language forms. Speakers may be alerted that their speech is inaccurate when interlocutors make the repair moves of negative feedback, such as the recasts and explicit corrections interlocutors make to inform speakers of grammatical inaccuracies (Ellis, 1995; Gass, 1997; Long, 1996; Mackey, 1999; Spada, 1997). As a result, if the speaker recognizes the various types of negative feedback provided by interlocutors, the speaker may attempt to self-correct (Long, 1996).

Although it is widely agreed that computers can be used to facilitate interaction and negotiation of meaning, researchers still diverge as to the quality of interaction among second language learners facilitated by the use of the technology. Some recent studies (Bohlke, 2003; Fitze, 2006; Lee, 2004; Simpson, 2005; Smith, 2003) attempted to investigate the differences in the quality of interaction between face-to-face and written electronic conferences. These studies suggest that in the written electronic setting, tasks involving negotiation of meaning tend to lead to incidental interactions in which students are asked to clarify and rearticulate what they have written in the target 
language. Also, as compared to face-to-face interaction, computer-mediated communication has an equalizing effect on the quantity and quality of participation across gender, socioeconomic status, and age, because participants feel less anxious or shy. Other studies (Iwasaki \& Oliver, 2003; Jepson, 2005; Muniandy, 2002; Sauro, 2004; Warner, 2004) have compared learners' negotiated interactions in text and voice chat rooms. The studies suggest that although text chat is the more widely available and most studied form of chat, voice chat offers an environment in which learners are more apt to negotiate for meaning. Voice chats generated a number of repair moves, specifically negotiation of meaning-type repair moves. Because of the inherent absence of non-verbal communication and the focus that current voice chat technology places on pronunciation, voice chat may be an optimal environment for pronunciation work.

Besides facilitating language use, communicative, dialogic processes around computers can contribute to the development of higher order cognition. The potential benefits of discourse and learning are well documented in the literature. Many studies regard talk as a window to children's thought processes (Chi, Bassok, Lewis, Reimann \& Glaser, 1989). Learners' acquisition of new knowledge structures and cognitive strategies is facilitated by peer interaction where verbalization and dialogue are mediating forces. In groups, for example, students can learn from each other by giving and receiving help. By recognizing inconsistencies between their own and other people's perspectives, they can create mental models of problems. By observing and participating in problem solving approaches that have been the product of joint effort, students increase their own repertoire of skills (Webb, Troper \& Fall, 1995). In addition, exchanging ideas through verbal interaction promotes higher levels of thinking, such as question generation, explanation and elaboration (Webb \& Farivar, 1994; Chi et al., 
1989). Interpersonal discussion of ideas to resolve conflict and reach agreement is a further benefit of collaborative work with peers and computers (Pea, 1992). Overall, there is compelling evidence of the benefits of verbal interaction and communicative task-related talk in producing higher order learning within computer mediated environments.

Research conducted in classrooms indicates that judicious use of the computer has the potential to create conditions conducive to collaborative learning, and to sustain interactions leading to higher order learning (Light, 1993). Through talk, the process of representing one's thoughts for others, normally covert processes are made overt through language and dialogue. In classrooms where computers are used to support group work, articulation of thought processes enables metacognitive processes to become conscious, thereby developing awareness in students of their own thinking approaches. A further example of the potential of collaborative work around computers in supporting cognition and communication is provided by Mercer (1994) who has identified three categories of talk emerging from children's interactions in these settings:

1. Disputational talk - this kind of talk is usually characterized by disagreement and individualized decision making.

2. Cumulative talk - speakers build on each others' utterances and there are instances of elaboration and clarification.

3. Exploratory talk - partners engage with each other, and reciprocal exchanges and challenges are common.

Of these categories, exploratory talk is most likely to lead to cognitive change, as it is distinguished by reasoning processes and exchanges where learners explain, defend and argue for a case or point of view. Building on this research Wegerif (1996) suggests that it is possible to plan for, and build exploratory talk within a teaching 
program using directive software. Exploratory talk can be achieved by changing the normally asymmetric patterns of interaction which characterize the classroom, resulting in predominantly teacher initiated discourse. The typical pattern of classroom discourse has been described in the literature (Sinclair \& Coulthard, 1975; Mehan, 1979) as an "IR-F" pattern (Initiation - Response - Feedback), or three part exchange where the teacher initiates an exchange, a student responds, and the teacher gives feedback on this response.

The IRF communicative pattern allows little scope for student feedback or commentary on the discourse event or matter under discussion, and may well shortcircuit higher order thinking processes and critical thinking. This asymmetry needs to be balanced by student discussion, which can be achieved by encouraging students to engage with the software, and to discuss and evaluate their perceptions of working with a particular software package. Equally, the discussion element could be introduced into other classroom interactions, transforming the "I-R-F" structure into an "I-R-F-D" exchange, where "D" represents learner discussion of the event (Wegerif, 1996).

In summary, constructivists have found that communication technologies can realize constructivist ideals of learning (Bonk \& Cunningham, 1998): active, collaborative construction of knowledge instead of knowledge transfer from one person to another (Cobb, 1994; Jonassen, 1994; O'Malley, 1995; Schank \& Cleary, 1995), engagement in contextualized authentic tasks as opposed to abstract instruction, and less-controlled environments versus predetermined sequences of instruction where "conditions for shared understanding" are created and "alternative solutions and hypothesis building" (O'Malley, 1995, p. 289) are promoted through student interaction. Such learning environments encourage thoughtful reflection and "empower ... learners 
... to assume ownership of their knowledge, rather than reproducing the teacher's" (Jonassen, 1994, p. 6).

However, various technologies differ in the way and extent to which they facilitate the realization of constructivist principles (Tella \& Mononen-Aaltonen, 1998). Instructors need to identify the technologies and the implementations of those technologies, which best fulfill curricular goals (Bonk \& King, 1998; Chapelle, 1997; Tella \& Mononen-Aaltonen, 1998). Therefore, promoting constructivist learning through exploratory talk in technology supported environments also involves recognizing the role of the teacher in creating an appropriate context for learning through language. Empirical research on computer-supported learning environments points to the necessity of social and interactive frameworks to support discourse and higher order learning processes (Light, 1993). Collaboration involves discussion, mutual engagement and joint decision making.

Tasks should therefore be set to provide conditions for social collaboration. However, collaboration is a term used rather loosely to mean situations where more than one person is involved. It is often confused with the term cooperation, meaning that participants share the task by allocating responsibility for parts to each individual within a group. This division of labor does not necessarily lead to exchange of ideas, as each party is independent of the others once the task has been divided up. In true collaboration, all participants are engaged in a joint effort to solve the problem together, and they have to negotiate problem-solving actions and evaluate solutions (Rochelle \& Teasley, 1995).

Pedagogical tasks using computer-based telecommunications should be carefully designed. For example, without skillful preparation the interaction can be poor and the students can remain passive: real discussion is unlikely to occur without careful planning and preparation (Bates, 1995 p. 206). Salaberry (1996) believes that 
the implementation of pedagogical tasks in computer mediated communication environments should be attentive to two important features of the design process: the nature of interaction among humans (communication paradigm) and the roles of the learner in such interaction (language learning goals). He proposes that a distinction be made between the concepts of interaction and communication to the effects of providing a better theoretical foundation for the pedagogical uses of internet environments. According to Salaberry (1996), the technical distinction between interaction (mutual or reciprocal action or influence) and communication (a process by which meanings are exchanged between individuals through a common system of symbols) can help us keep in perspective the pedagogical value of computer mediated interaction for second language learning.

Higgins (1988) proposed a classification of CALL lessons into four types: instructional, revelatory, conjectural, and emancipatory. The Instructional lesson — typical of programmed learning — is based on the metaphor of the learner's mind as an empty vessel that is to be filled with knowledge. The revelatory lesson presents a structured experience (e.g., a simulation) that will presumably guide the learner towards discovery. The conjectural lesson sets a series of tasks that the learner must complete (task-based). Finally, the emancipatory lesson provides tools (e.g., online resources such as dictionaries, etc.) to facilitate learning. The first two types of lessons are the least effective towards learning because the computer takes over the instructional process: the learner is not in charge of learning, but $\mathrm{s} /$ he is the subject of teaching. The third and fourth types of instruction are more conducive to learning according to the above discussion. More specifically, the third type of lesson is based on the notion of a pedagogy that guides the learner towards acquisition of knowledge. 
On the other hand, the fourth type (emancipatory) does not specify the goals of instruction for the students.

The actual design of pedagogical activities based on computer-mediated interactions is tied to the particular goals of the teacher and the students. Learning with computers can be planned to ensure true collaboration and negotiation of information between participants, and as a medium where teachers and students can share thoughts and ideas. Teacher roles in the process need to be reconsidered. As peer collaboration is conducive to learning, social feedback from peers may be more helpful than direct corrective feedback from a teacher.

While many researchers agree that peer collaboration is conductive to learning, many debate the form that feedback needs to take (whether positive or negative) in order for second language learning acquisition to occur. Some researchers have maintained that positive evidence alone is sufficient for adult second language acquisition (e.g., Krashen, 1977, 1994). Others consider positive evidence as insufficient for second language learning to occur, and propose a role for both positive and negative evidence (e.g., Hatch, 1978; Long, 1983, 1996; White, 1987). Positive evidence tells the learner that linguistic features in the input are possible in the target language. In contrast to positive evidence, negative evidence provides information to learners about what is not possible in the target language (e.g., Lightbown \& White, 1987; Long, 1996; White, 1990). Other researchers claim that recasts - reformulation of a learner's ill-formed utterance - can provide implicit negative feedback, positive evidence, and enhanced salience through the juxtaposition of the original ill-formed utterance and the target language recast form (Leeman, 2000; Saxton, 1997; Saxton, Kulcsar, Marshall, \& Rupra, 1998). In contrast to explicit correction and recasts, negotiation of form does not provide learners with the correct target language form. 
Instead, it indicates to learners that they have produced an error and that the error requires repair (Lyster, 1998).

Recent second-language acquisition research has developed a noticeable interest in the role that implicit negative feedback, such as recasts and negotiation, plays in second language development (Ayoun, 2001; Han, 2002; Leeman, 2003; Long, Inagaki, \& Ortega, 1998; Mackey \& Philp, 1998; Morris, 2002; Muranoi, 2000). Findings suggest that implicit negative feedback facilitates learners' L2 development. Because of the potential benefits of implicit negative feedback, research has attempted to examine whether it is available to learners in different interactional contexts (e.g., Braidi, 2002; Buckwalter, 2001; Chaudron, 1988; Doughty, 1994; Ellis, Basturkmen, \& Loewen, 2001; Fanselow, 1977; Hamayan \& Tucker, 1980; Lin \& Hedgcock, 1996; Lyster, 1998, 1998b; Lyster \& Ranta, 1997; Mackey, Oliver, \& Leeman, 2003; Moroishi, 2001; Morris, 2002b; Nystrom, 1983; Ohta, 2000; Oliver, 1995, 1998, 2000, 2002;

Oscoz \& Liskin-Gasparro, 2001; Panova \& Lyster, 2002).

These studies demonstrate that implicit negative feedback is frequently available and used by second language learners. However, the majority of these studies have been carried out in adult contexts. Only a limited number have been carried out in the context of child-to-child conversations (e.g., Mackey, Oliver, \& Leeman, 2003; Oliver, 1995, 2000, 2002; and Morris, 2005). Research (Morris, 2005) on child-to-child interactions, either non-native-speaker/non-native-speaker interaction or native-speaker/non-native-speaker interaction, reveals that while children provide implicit negative feedback in the form of recasts and negotiations, negotiations are the most common form of feedback. With regard to repair, children in child-to-child conversations frequently incorporate the feedback in their subsequent second 
language production, while the rate of repair is higher when the interlocutor is a nonnative speaker.

McLaughlin \& Oliver (1998) present several strategies that might help teachers foster meaningful learning through language, assuming that the teacher's role will be supportive and discursive rather than didactic and managerial. The teacher can create a context for learning around the computer by: (a) modeling and teaching appropriate communication habits, (b) clarifying expectations about language use and communication, (c) providing opportunities for students to explain their decision making processes, (d) encouraging groups to evaluate alternative solutions, (e) promoting verbal expression of different perspectives, $(f)$ creating activities where meaning negotiations is combined with spatial and diagrammatic representation, $(\mathrm{g})$ establishing collaborative problem solving tasks, (h) encouraging competing solutions and approaches, (i) requiring learners to repair and self-correct their explanations and elaborations, (j) supporting students in posing questions and offering criticism to each other, $(k)$ structuring activities through which students can challenge each other's productions, (I) enabling students to account for, and justify their approaches and solutions to problems, and $(\mathrm{m})$ facilitating diverse interpretations of problems (McLaughlin \& Oliver,1998).

These strategies involve using language to find, resolve and agree on problem solving procedures, and to justify approaches adopted. Learning around computers, therefore, may entail a new discourse role for teachers and students, as they engage in discussion, interaction, reflection and adaptation of ideas. It is clear that the quality of learning around computers is not entirely dependent upon the interface between learners and the technology. Instead, it is related to the whole social climate of the 
classroom and the opportunities created for interaction and exploratory talk between participants in the learning process.

As indicated, research provides evidence that the computer, when adequately used, can be a social facilitator in the sense that it provides opportunities for collaboration, group work and interaction which fosters cognitive change. This study seeks to develop an instrument which can evaluate whether ESL/EFL software programs available on the market display characteristics of Communicative Language Teaching and an interactive approach to computer use in language learning, and can therefore foster collaboration and language learning.

The Uses of Multimedia for Second Language Learning

Some of the major areas of software-related research in CALL have been the amount and types of interaction at the computer; effects of skill-building software, particularly writing; responses to multimedia; and attitudes toward computers and CALL.

The question of how students interact at and with the computer has been addressed in a number of studies, with Piper's (1986) being one of the earliest. In her study, as in many others (cf. Abraham \& Liou, 1985; Levy \& Hinckfuss, 1990; Dziombak, 1991; Dudley, 1995; Pujol, 1995/96; Meskill, 1993), the type of software and the tasks teachers set for students had a large effect on the type and quality of student interaction with each other when working in pairs or small groups. Overall, software that requires a minimum of verbal interaction generates very little student participation, while having students write a joint report or produce something collaboratively results in a substantial amount of interaction. 
Huang (1997) and Huang and Liu (2000) explored not only how students interact with computers, but also how they adjust themselves in learning English with the aid of multimedia computers. The studies presented two types of communication in the multimedia lab from the perspective of Communicative Language Teaching. First, Communicative Language Teaching in the multimedia lab presented a large impact on student-teacher communication. The student-teacher communication seemed to be blocked to some extent by the layout of the multimedia lab. The physical distance enlarged the psychological distance. The two-way communication between the teacher and the students turned into the one-way teacher to student communication. Second, student-computer communication was relatively new to students. For most of the students, it was the first time for them to take so much time "talking" to a computer. Students had to learn how to communicate with the computer so that they knew what move they should make next. They also noted that, because a multimedia lab is far larger than a traditional classroom, the teacher needed to talk to students through the broadcasting system. The "intimacy" between the student and the teacher was consequently gone. Nevertheless, Huang and Liu (2000) pointed out that the multimedia lab offered the opportunity for students to visualize the situation. The computer software created a virtual world that was very similar to the real world.

A study by Brett (1997) also investigated students' reactions to the use of multimedia, their attitudes to its learning efficacy and their attitudes to multimedia as an independent study tool. Following the use of the CD-ROM English for Business 1 with a sample of 107 undergraduates, a questionnaire was administered. The questionnaire probed general reactions to the use of multimedia, attitudes to its learning efficacy and attitudes to multimedia as an independent study tool. Data on learner comparisons between multimedia and conventional learning tools were also collected and the statistical associations between types of learners and particular attitudes calculated. 
The results indicated: strongly favorable attitudes toward multimedia, that learners believed they could learn effectively from multimedia, and that it delivered a high quality independent learning experience. Implications are that multimedia has a beneficial role to play in the curriculum and may have potential to facilitate effective language learning; may motivate; may have special value for learners regarding themselves as less able; is useful for self access; may supersede other language learning technology and that further courseware development is warranted.

Questions regarding student attitudes toward computers seem to be part of most studies, including many of those cited here. Students tend to like using computers, even when they may not make much progress (Stenson, Downing, Smith, \& Smith, 1992) - and when they may feel that computers do not necessarily improve their language learning (Schcolnik, Abarbanel, Friedler, Heyman, \& Tsafir, 1995/96). Given the number of variables associated with language learning and the difficulty in controlling those variables, particularly in a second language learning setting, it is not surprising that those who design studies prefer to research the easier area of student attitude.

Another area with a great amount of research on multimedia uses for language learning has focused on the development of specific language skills. For example, research on writing has traditionally explored how students felt about and performed with word-processors. Daiute's (1985) Writing and Computers, set the stage for much of what teachers did with writing in the classroom, in the language arts as well as in foreign language teaching. Studies by Neu and Scarcella (1991) and Phinney (1991) found that students had positive attitudes toward writing with computers and less apprehension about writing. Thaipakdee (1992) found better attitudes toward writing with computers which led to the improvement of writing skills. More recent research on writing includes the study of email correspondence as a way of improving motivation 
and writing skills (Kelm,1995; Soh \& Soon,1991; Sotillo, 2000; Sullivan \& Pratt,1996; Tella, 1992a, 1992b; Warschauer, 1995).

Of the many studies examining second language writing using computers, some investigated specific aspects of writing skills such as grammar and grammatical accuracy (Gonzalez-Bueno \& Perez, 2000; Liou, Wang, \& Hung-Yeh, 1992), error feedback (Ogata, Feng, Hada, \& Yano, 2000; Van der Linden, 1993), the writing process (Thorson, 2000), or the writing environments (Sullivan \& Pratt, 1996).

Research on skills other than writing has tended to focus on student attitudes toward drills and effectiveness of drills (Schaeffer, 1981; Abraham, 1985; Kleinmann, 1987; Robinson, 1989; Dalgish, 1991; Al-Juhani, 1992, Botiono, 1992; Evans, 1993; Van der Linden, 1993; Wang, 1993). The results have been mixed, largely because the types of software, teacher roles, and student tasks have been quite diverse. An exception to the focus on drills is Hsu, Chapelle, and Thompson (1993), who looked at what students did in an exploratory environment.

One skill area where research has more recently begun is listening, probably because sound-capable computers were not in widespread use until fairly recently. However, there have been a number of studies focusing on the use of multimedia for developing listening comprehension. Grezel and Sciarone (1994) investigated the effects of computer testing of listening comprehension on 352 students learning Dutch as a second language. Learners were then measured for the effects of two instructional modes: computer-delivered cloze test, and a daily listening test, both for a period of three weeks. Significant effects on general language proficiency were found for the computer-based group.

Brett (1996) carried out investigations into the affective domain of multimedia for listening skills and also into the quantitative gains afforded to listening comprehension by the use of multimedia. He studied the initial attitudes and reactions 
to the use of video based CD-ROMs for listening comprehension by 107 undergraduates. He found overwhelming support for the technology. Results showed favorable attitudes: learners believed they could learn effectively from multimedia and believed that it delivered a high quality independent learning experience.

Brett (1997) has also investigated listening performance in a computer-based multimedia environment. He compared the learner success rates on comprehension tasks and follow up cloze tests while using (1) media of audio and video with pen and paper to and (2) multimedia. Results of learners' performance on the tasks in the different situations showed more effective comprehension and recall while using multimedia than either audio or video plus pen and paper. The reasons proposed for the greater success rates were: efficiency of delivery with all the media for input and learning tasks in one place, the effect of the on-line feedback in guiding learners to correct interpretations of the message, and students' constant monitoring of their interpretations of the message.

Jakobsdottir and Hooper(1995) studied listening with a unique focus. They used a modified total physical response method to gauge elementary students' listening skills. Students selected buttons and graphics on a computer screen in response to commands given in Norwegian. They concluded that providing congruent text with spoken words facilitated acquisition of listening skills, at least for these elementary students.

Some research on the uses of multimedia for the development of specific language skills has focused on the uses of CALL to develop reading comprehension skills. Two aspects of reading received the most attention in research: the use of glossing formats and the acquisition of vocabulary.

Glossing formats are aids used to help the reader understand the meaning of words and phrases, and the effects of various forms of glosses were studied (Adair- 
Hauck, Willingham-Mclain, \& Youngs, 1999; Davis \& Lyman-Haget; 1997; Lomicka, 1998; Nagata, 1999). The second aspect that received major attention was the acquisition of vocabulary for supporting reading comprehension (Chun \& Plass, 1996; Grace 1998a, 1998b, 2000; Kang \& Dennis, 1995; Liu, 1995; Liu \& Reed, 1995; Van Bussel, 1994). These studies showed that computer-supported glossing formats proved to be helpful in developing reading proficiency and that vocabulary learning could be greatly enhanced by incorporating a variety of annotations for words through visual media in multimedia technology.

In studying the use of multimedia for the acquisition of vocabulary as a way to enhance reading skills, Chun and Plass (1996) found positive effects for the learning of German vocabulary through a multimedia program with annotations combining pictures and text more effective than those with video and text. On the other hand, Greifnieder (1995) found that the aural input did not add anything extra to the learning which was not supplied by just seeing the word in a study of computer delivered audio to support learning of vocabulary in a CALL environment with 70 children.

A study by Liu and Reed (1995) investigated the effect of the use of multimedia courseware on the learning and retention of eighty items of vocabulary. Their study used four, ten-minute clips of the movie "Citizen Kane", designed for language learning. The new design made available to learners the text of the clips with twenty target vocabulary items highlighted. These items were linked hypertextually to a definition, a part of speech, example sentences, video context and relationships of each word. There was also the option to do exercises using the vocabulary. Results showed a positive effect of the multimedia materials on post-test scores and on a retention test for all ability levels. They found no significant main effect for learning styles and that attitudes to computers became more positive and anxiety was reduced. The study also showed that those with more positive attitudes generally had better 
vocabulary test scores. In conclusion they say "... that the learners' different needs were accommodated by the hypermedia environment to some extent" (p.173).

Other research has examined combined skills like reading and writing (Nagata 1998), writing and culture (Lee, 1997), and global/holistic language development (Kubota, 1999; Osuna, 2000). One study focused on culture learning (Osuma \& Meskill, 1998), one examined students' evaluation of the computer tools (Oliva \& Pollastrini, 1995), one surveyed students' opinions of the technology (Lee, 1998), one looked at how educators across the state of New York used the technology (Meskill \& Mossop, 2000), and one focused on a software designer as he moved through stages of task design (Wolach, 1994).

Some studies have investigated how technology could be used to promote speaking skills (Borras, 1993; Coniam,1998; Derwing, Munro, Carbonaro, 2000; Gonzalez-Edfelt, 1990; Johnston \& Milne 1995; and Liaw, 1997).

Liaw's (1997) research described a group of students using computer books and the conversations that took place as they read them. The study found that, as the students became more prolific readers, their discussions shifted from dealing with technological difficulties to the content of the books. Furthermore, the study suggested, for meaningful discussions to take place, learners must have something to talk about. Computer books could provide the content on which discussions could center.

Borras (1993) and Johnston and Milne (1995) found that the multimedia software allowed for an increase in meaningful communicative exchanges. Coniam (1998) and Derwing, Munro, and Carbonaro (2000) addressed the use of speech recognition software to draw attention to production errors for foreign language learners. Results thus far seem to indicate that speech recognition software shows a great deal of promise; however, it is currently not feasible for use in foreign language 
learning because of its inability to provide reliable feedback on nonnative speaker utterances.

Borrás (1993) investigated the use of subtitled multimedia courseware on the spoken performance of students of French. They found significant effects on spoken performance. Learners viewing with subtitles spent less time watching the video sequence than those without, and had more positive reactions to the application. Johnstone and Milne (1995) in a year-long study showed that the use of a teacher-controlled multimedia tool increased the use of communicative discourse in the classroom by both teachers and pupils.

Wachowicz and Scott (1999) reviewed three levels of speech-interactive learning activities in selected commercial products: activities for vocabulary development, conversational practice, and pronunciation. Their review suggests that the effectiveness of speech-interactive CALL is determined less by the capabilities of the speech recognizer than by (a) the design of the language learning activity and feedback, and (b) the inclusion of repair strategies to safeguard against recognizer error.

Wachowicz and Scott (1999) concluded that the approach seen in many pronunciation activities - "Repeat, imitate, get corrected by your teacher"-reflected dated pedagogical practices. At times, the computer is visualized as a high-quality tape recorder. One clear advantage computers can offer is to show the multimodal aspect of pronunciation. However, in most of the CALL packages the researchers reviewed neither video nor photographs of native speakers articulating target sounds accompanied Automatic Speech Recognition (ASR)-based pronunciation activities. Wachowicz and Scott (1999) argued that CALL needs the kind of careful internal development and tuning of ASR, together with structuring of exercises, that is found in the experimental systems but not in the commercial products. Among commercial 
offerings, minimal pair exercises and acoustic wave-form comparisons appear the most promising kinds of activities to help pronunciation.

Wachowicz and Scott (1999) proposed, then, a checklist of desirable features in speech-interactive CALL. The best products from their review have the following characteristics: task-based instruction with an emphasis on communicative authenticity; implicit as opposed to corrective feedback in those tasks; multimodal formats (video, drawings, photos) to enhance authenticity; focus on schematized, relatively predictable conversations; verification procedures and repair strategies to counter speech recognition errors. In these characteristics, the role of the computer in the interaction is not the traditional role of tutor but rather of partner in the conversation or agent in the game. Other desirable features include: giving learners a chance to correct their own errors; providing visual support for pronunciation activities (e.g., native speakers articulating target phonemic distinctions). Desirable features that Wachowicz and Scott (1999) have not seen in commercial products but have seen in some experimental systems include: adaptive sequencing of items in an exercise to accommodate individual learners' performance; use of authentic texts; focus on listening activities as a complement to speaking; and attention to the sociolinguistic variability of speech.

A number of studies on the uses of multimedia for language learning have dealt with various learning strategies that could be enhanced using technology. These studies focused on: computer instruction in grammar over teacher instruction (Nutta, 1998); students working in pairs or alone (Chang \& Smith, 1991); autonomy (Sciarone \& Meijer, 1993); student interactions (Meskill, 1993); comparisons between using and not using multimedia or intelligent computer instruction (Nagata, 1996, 1997; Soo \& Ngeow, 1998); strategies for using voice hints (Ikeda, 1999); different modes of 
instruction to encourage linguistic, metacognitive, socioaffective, and academic skills (Kasper, 2000, and Plass, Chun, Mayer, Leutner, 1998).

Chang and Smith (1991) compared students working in pairs in front of the computer and students working alone and found no difference in language gains between the two groups.

Meskill (1993) looked at interactions between native and nonnative English speakers, and found a tendency for conversation to be dominated by the native speakers.

In their study on learner autonomy, Sciarone and Meijer (1993) found that full autonomy to use the technology did not ensure completion of tasks, because the students needed feedback and structure to complete the assignments.

Other studies compared classroom performances with or without the use of multimedia (Nagata, 1997; Soo \& Ngeow, 1998), and found that different learning situations required different pedagogical approaches. The teacher in a multimedia environment needed to assume the role of a facilitator or resource advisor and may have had to dedicate more time to one-on-one-teacher-student interactions.

More recently, interactive video research has provided some of the first results about multimedia effectiveness in language teaching.

Verano's (1989) study of interactive video for Spanish teaching, for example, found that the more interactive the video worked, the more students retained.

De Felix, Johnson, and Schick (1990) also had favorable results, showing that ESL students in a fourth grade class were motivated by the use of interactive videodisc.

Liu (1992) found that computer-based hypermedia enhanced vocabulary learning, while Engelsberg (1997) had mixed results from a multimedia program. In Englesberg's study, students enjoyed the multimedia courseware a great deal for the 
first five weeks of the term but became increasingly dissatisfied and did not perform as well as time went on. As in other areas of effectiveness research, the variables here were complex.

A study by Brett (2000) investigated the effects of three learning support elements in a multimedia application: video, subtitles, and comprehension tasks to accompany the video text. Subjects were asked to watch a video clip accompanied by different combinations of media elements. These were: (a) video only; (b) video and subtitles; (c) video and tasks; and (d) video, subtitles and tasks. Following their use of the combinations of media, subjects wrote a written summary of the video clip having been asked to reuse as much of the original language of the clip as they could. Subjects' transcripts were scored for cross matches with the idea units in the original text and for matches of strings of words (3 or more long) from the original text. In both categories subjects using the media combinations of video and subtitles scored highest, followed by the true multimedia experience group of video, subtitles and tasks. The video only group scored lowest on both counts. He concluded that although the addition of the multi elements improved comprehension and language reuse, full blown multimedia (video, tasks and subtitles) did not lead to highest comprehension and language reuse scores, maybe indicating that too many media in multimedia are distracting.

Nevertheless, the majority of investigations of learning success through use of multimedia or Interactive Video Disc (IVD) reports learning gains.

Watts (1989) used IVD with French beginners and found positive effects for the translation of words and short sentences into and out of French and for the understanding of short spoken sentences. A second study compared learners using IVD with those using identical material delivered by video tapes and worksheets. Both 
groups showed increases in understanding but the IVD group made more significant gains. She noted particular gains in pronunciation for the IVD users.

In summary, a review of the literature on the uses of multimedia for language learning shows the potential strength of CD-ROM materials. Exploitation of real world CD-ROMs leads learners to engage with such authentic language materials. Another potential strength of CD-ROM materials is their ability to create a situation in which learners can interact with the learning materials and reference materials. The materials on CD-ROMs can be linked into courses, syllabuses or assigned to learners for homework or as follow up activities to work undertaken in classroom sessions. Reference CD-ROMs can also be used by teachers, as a help in preparing lessons, and by students, as research materials. Learners working together around a multimedia PC can use the tasks, input, or information as a basis for group work, discussions and joint decision-making.

At the micro level of motivation, multimedia may motivate learners to attend to the input through its use of combined media. This amalgamated use of video, supported by subtitles with instantly accessible definitions of language items and through on-line tasks with synchronous feedback, may all collectively or individually motivate learners to attend. Video may add interest and increase comprehension; online tasks may provide motivational goals for attention. Such an environment and the learning support features, more than other learning tools, may motivate learners to attend to the input, because such learning supports may make the input more comprehensible and accessible. These learning supports may also motivate learners to "notice" and consequently understand features of the input. The features of the multimedia-delivered may well provide the forum for supporting, encouraging or 
motivating the use of meta-cognitive strategies such as "monitoring" and being able to evaluate their own performance.

Another area which underpins multimedia is that of autonomous and selfinstructed language learning. Multimedia-delivered language learning environments are primarily designed to be used by learners studying alone. They can deliver authentic input, provide meaningful language learning tasks, deliver feedback on those tasks and can be manipulated according to the learning agenda of the user. Therefore they may have great potential in facilitating autonomous language learning.

However, as argued by Huang and Liu (2000), the choice of appropriate computer software that fits into the setting of a multimedia lab is one of the keys to success. Consequently, choosing software programs appropriate for the goals, needs, and interests of the students is essential, and in order to be able to choose the right software it is necessary to be able to effectively evaluate software programs.

\section{Evaluating ESL/EFL Software}

Although there are different ways to evaluate and critique CALL software programs, there is an important point that cannot be forgotten: "the basic tenet of software evaluation is that "pedagogy must drive technology" (Burston, 2003, p. 35). This principle means identifying curricular needs first, then looking for software that meets these needs.

However, little attention has been given as to whether particular software programs effectively promote second language learning (Beatty, 2003). The model of learning featured in a particular CALL software package is seldom stated, and software packages sold as so-called learning games are often highly behaviorist. 
Because CALL is an important aspect of many language-learning programs, more consideration needs to be given to the types of programs that promote language development in second/foreign language learners.

The growing number of instructional software applications for second language learning, and the large variety of features and components of these applications generate a need for ways of systematically evaluating these materials.

Scholfield (2000) presents three points to be considered when evaluating software materials: (a) the nature of the software, (b) the nature of the teacher/learner situation - the learners and their needs, uses etc, and (c) a rating system to judge the suitability of the software to one or both of the previously mentioned points, with due attention to relevant universal principles of good teaching/learning.

Plass (1998) suggests examining software based on the particular approach it uses or skill mastery it targets. He proposes steps to be followed when evaluating particular aspects of software:

1. Identify relevant skills, competencies, and domain knowledge.

2. Identify activities that cultivate and develop these skills, competencies, and knowledge.

3. Identify the cognitive processes involved in these activities.

4. Assess the level of support for the cognitive processes.

Using Plass's suggestions, a taxonomy of ESL/EFL software features would be based on the underlying pedagogy or principles of education, and would address how well the individual components of software programs are able to facilitate them.

Thorn (1995) has also outlined points to consider when evaluating interactive multimedia. He focused on six components of software that need to be addressed: (a) ease of navigation, (b) cognitive load, (c) information presentation, (d) media integration, (e) aesthetics, and (f) overall functionality. These components are a good 
starting point for evaluation, but do not address the questions presented by Chapelle (1997), Krashen (1982), or Laurillard (as cited in McLoughlin \& Oliver, 1998): how the software being evaluated addresses the students' linguistic needs.

With exceptional insight into the aspects of software selection, Healey and Johnson (1997) proposed a tool to assist educators with software selection. Healey and Johnson narrowed the focus of their tool to include six basic categories: (a) educational level, (b) academic goals/focus, (c) educational setting, (d) teacher interaction level, (e) computer hardware, and (f) money.

Scholfield (2000) went beyond the presentation of points to be considered when evaluating software material. He addressed the types of evaluation that could be executed: empirical evaluation, and introspective judgmental evaluation.

For Scholfield (2000), empirical evaluation generally requires a great deal of work, and for the materials to have been used for some time by learners in actual classes, so they are often firmly fixed in a specific teaching/learning situation. However, they do move away from the purely introspective approach.

In addition to noting the lack of evaluative criteria which measure not only learning outcomes but also learning processes, Reeder, Heift, Roche, Tabyaninann, Schlickau, and Golz (2004) identified a number of shortcomings in current evaluative practices:

1. Problems of validity and generalizability in experimental evaluation designs, which includes difficulty in attributing outcomes validity to the treatment, and invalid reduction of complex learning processes.

2. Failure to take educational goals into account.

3. Inability to deal with new and multiple literacies.

4. No reflection of the issues of intercultural communication and sociocultural variation among user groups. 
5. Lack of flexibility to include the interaction between emerging possibilities offered by new technologies and their effects on instructional paradigms. Chapelle (1998, pp. 29-31) suggested the following research questions to illustrate how empirical evaluation procedures could be developed to parallel principles of design in CALL: 1)

1. Is there evidence that learners attended to salient linguistic characteristics of the target language input?

2. Do learners choose to see the modifications of linguistic input?

3. Do learners produce "comprehensible output"?

4. Is there evidence that learners notice errors in their output?

5. Do learners correct their linguistic output?

6. To what extent do the learners interact with the computer to engage in modified interaction focusing on form and meaning?

7. Do learners work toward communication-oriented goals?

The other way of executing evaluation studies suggested by Scholfield (2000) is introspective judgmental evaluation. This can be done purely individually, subjectively, globally and introspectively. The teacher simply looks through the material, or tries out the program (or just reads the blurb about it in a catalogue), and comes to an overall intuitive judgment about whether it would suit his/her class. This could be described as the global 'expert judgment' method of evaluation. The evaluator introspects and assesses an unanalysed notion of some users of the software, an unanalysed impression of the software, and matches the two often using inexplicit criteria.

However, to regard evaluation in systematic way it is necessary at the very least to 'unpack' this approach. The teacher (or anyone else) acting alone as evaluator 
should break down the 'overall' or global judgment into parts. Scholfield (2000) suggests then:

1. Look carefully at different aspects of the materials separately.

2. Think of all the relevant different aspects of the learning situation, learners, potential use etc.

3. Judge aspects of the nature of the software with respect to the nature of the learner situation.

This is where checklists come in, according to Scholfield (2000). Checklists are a type of introspective judgmental evaluation. They may be made by the teacher/ evaluator, or adopted from someone else. They at least provide a way of ensuring that important aspects do not get forgotten and that there is some consistency if the same person evaluates several things. However, the evaluation still remains individual, introspective and maybe subjective. Checklists generally take the form of sets of headings to be considered or sets of questions to ask oneself. They may or may not include a system for weighting different elements, or adding up a total score in some way.

As pointed out by Burston (2003, p. 36), there is a problem with the existing checklists; they are extremely simplistic. A program can get good marks in many categories and still, intuitively, users may not be very impressed with it. One of the reasons for this situation may be that checklist items typically have the same relative weighting, whereas in any particular situation some feature of the software may be more important than others. Likewise, there is enormous variety in available software (stand alone usage, exploitation over the web; tutorial, collaborative, facilitative, etc.), so it can be very difficult to know how predetermined checklist categories should be applied. 
In investigating the main elements found in introspective and empirical evaluations, Reeder et al. (2004) research revealed two main components: productrelated, and learning/instructional design. They found that assessments of both sorts of components appeared in some cases to lack coherent connections to best practices in language teaching or current understandings of language learning.

Product-related components (Reeder et al., 2004, p. 258) in software evaluation is concerned with the general characteristics of the software itself and the ease with which it can be used. Product-related components include:

1. Technical aspects - implementation considerations, documentation, packaging, hardware specifications, cost effectiveness, instructional and operational manual, suggested classroom activities, and the description of the links and branching techniques between data.

2. Content considerations - the accuracy and presentation of the material, consistency regarding the level and nature of the content presented, and the general appropriateness of the material for the typical users.

3. General use considerations: the quality of the user interface, including menu types, items covered and terminology used in the interface, and support material availability, including adaptability to the Internet. In investigating the learning/instructional design components, Reeder et al. (2004, p. 59) found no examples of formative evaluation of software in which the learning outcomes and the learning processes leading to those outcomes were systematically examined. Lack of a match between course objectives and instructional features included in the design of software seems to be the main reason for the unreliability of most student-gain based evaluations. 
In fact, an examination of most software evaluation systems reveals the experimental nature of the evaluation approaches. "The prevailing methodology in the evaluation of software in the classroom is based on an experimental paradigm - control group, test, post-test control, etc" (Gros \& Spector, 1994, p. 38).

Perhaps a solution for the problems found in both experimental and introspective studies on software evaluations can be drawn from Chapelle's (1998) argument that some design features and evaluation criteria for multimedia CALL should be developed on the basis of hypotheses about ideal conditions for second language acquisition. For each of the hypotheses about SLA drawn from the interactionist perspective, Chapelle $(1998,2003)$ makes a corresponding suggestion for developing multimedia CALL. Each of the hypotheses comes primarily from the study of face-to-face oral communication between learners or between learners and proficient L2 speakers. As such, they attempt to describe multimedia characteristics with respect to the psycholinguistic responses that they might evoke from learners rather than exact replicas of conversations among learners. Chapelle (1998) suggests the following for multimedia CALL:

1. Make key linguistic characteristics salient.

2. Offer modifications of linguistic input.

3. Provide opportunities for 'comprehensible output'.

4. Provide opportunities for learners to notice their errors.

5. Provide opportunities for learners to correct their linguistic output.

6. Support modified interaction between the learner and the computer.

7. Act as a participant in second language tasks.

While the majority of software developers as well as the evaluation systems agree on the significance of instructional considerations in the development and 
evaluation of educational courseware, there is no agreement among researchers and evaluators as to what criteria to use to assess this aspect of language software (Reeder at al., 2004).

Part of this difficulty, as noted by Hubbard (1992), could be caused by the absence of instructors on software design teams, creating a gap between design, development, and classroom implementation.

A possible solution to bridge the gap between what teachers of English as a second language know of and expect from software programs and what educational multimedia experts know of the requirements for multimedia products can be found in a research project (Sinclair and Smith, 2002) that investigated the interactions of language teaching experts and multimedia experts engaged in the design of a CDROM targeting ESL students preparing for the IELTS English Language Speaking Test. The data Sinclair and Smith (2002) presented suggest that the theoretical key to developing design collaborations is the boundary between language-teaching and multimedia knowledge and expertise. Specifically, design collaborations between language-teaching experts and multimedia experts are likely to be facilitated by encouraging the demystification of disciplinary knowledge and expertise and an engagement with one's counterpart's knowledge and expertise. The analysis of data indicates that when considering collaborative flexible learning materials design involving language-learning experts and multimedia experts, it is imperative that:

1. Multimedia platforms, methods, techniques and terminology be explained and demonstrated via the use of concrete, visual examples coupled with lay and educational language. 
2. Student profiles along with content concepts and their sets, be explained, demonstrated and tied to design by language-teaching experts (thinking aloud is helpful in relation to making ties to design).

3. Multimedia knowledge should be understood as a pedagogic tool kit for developing and enhancing content and skills, with multimedia methods as the vehicle for pedagogy, including assessment and feedback (Sinclair and Smith, 2002, p.303).

Since the instructional needs of any given classroom are context-dependent, building accurate evaluative criteria into software evaluation systems presents a serious technical challenge to most software evaluation systems. As Leu, Hillinger, Loseby, Balcom, and Dinkin (1998, p. 204) put it, "Although new technologies are becoming more widely available they are not always appropriated by teachers and systematically integrated into the curriculum".

These considerations bring us back to the critical part of this research: to what extent does this modern pedagogical tool - the computer - help develop language skills according to the principles of Communicative Language Teaching and an interactive approach to computer use for language learning. In order to answer this question it was necessary to establish criteria to look for in evaluating foreign or second language software. And the simplest approach to evaluate software was then to work from a checklist, since several already existed. However, none of them seemed to fit the goal of this research, because the available checklists did not integrate the systematic properties presented by Burston (2003) or the parameters suggested by Hubbard (1988) into their elaboration. These parameters and systematic properties were considered crucial by this researcher.

Burston (2003, p. 37) suggested a look at critical systematic properties as a viable alternative to software evaluation checklists. According to him, software 
programs must meet the first two of the following requirements and some combination of the last three: (a) pedagogical validity (software must conform to sound instructional methodology); (b) curriculum adaptability (it must fit, or be adaptable to, curricular needs); (d) efficiency (it must make something teachers are already doing easier to accomplish); (e) effectiveness (it must produce better results); (f) pedagogical innovation (it must allow teachers to do something new and different).

Still, the fundamental question here is not only whether a software program meets these conditions, but the extent to which and how it meets them. Determining the answer to this question involves a close analysis of key program parameters. Hubbard (1988, pp. 60-63) established the following key parameters in CALL program analysis which were used as criteria in the development of the evaluation instrument designed for this study:

1. The software's methodology (objectives, easy-to use-format, feedback to learners' responses).

2. The software's approach to language instruction (linguistic assumptions, approach to language, support for a particular method of language teaching, and the platforms it is available for).

3. The software's design (exercises geared toward or adjustable for learner variables, arrangement of exercises - according to the notional/functional approach, for example, integration to cultural and every-day life aspects, linguistic levels of exercises - discourse syntax, lexis, morphology).

4. The software's procedures (types of activities the software offers, how the software presents these activities, and how much control it allows learners and/or instructors over the content of the lessons).

It is worth noting, however, that the parameters used by Hubbard (1992), and which are also used as framework for software reviews in the CALICO Journal, are not 
geared toward any particular language learning approach. They are useful parameters for choosing software or for evaluating software appropriateness for different teaching/learning contexts.

In summary, a review of major publications on how to evaluate the use of software material for ESL/FL instruction/learning and the analysis of many evaluation checklists indicated that what was still needed was a comprehensive instrument based on what is known not only about the second language learning process but also about the best practices for language learning in order to assess the potential of CALL programs to develop language skills. Consequently, the characteristics of the Communicative Approach to Language Teaching that promote language learning according to what is known about second language acquisition and the technological features that allow for an interactive pedagogical use of computers were taken into consideration in the elaboration of the ESL/EFL software evaluation instrument for this study.

In meeting the need for a concerted effort to extend the reach of CALL software evaluation to take into account the distinct nature of multimedia language learning software and the teaching and learning that can ensue from its uses, the following systematic agenda of research in this field, as suggested by Reeder at al. (2004, pp. 62-63), was carefully followed in the pursuit of this goal:

1. Description: constructing and pilot testing a research instrument to describe multimedia language-learning materials in a systematic and consistent manner.

2. Theory building: developing a theoretical framework for evaluation of new media in language learning. 
3. Instrumentation: deriving from the theoretical framework a suite of new instruments and guidelines for evaluation of multimedia language learning materials of different types in different development and application contexts.

4. Empirical studies: testing the suite of instruments and guidelines on current multimedia language learning materials in a representative range of instructional settings with a representative range of users. 


\section{CHAPTER 3: METHODOLOGY}

This chapter describes the overall design for the investigation of the potential of ESL/EFL software programs to develop language skills according to the principles of Communicative Language Teaching and an interactive approach to computer use for language learning. In addition, this section details the elaboration of the ESL/EFL software program evaluation instrument, describes the types of reliability tests performed to test the inter-rater reliability and the internal consistency of this instrument, and the method of data collection and analysis of the ESL/EFL software programs available on the market. This section also specifies the criteria for the selection of software programs, describes the administration of this instrument and the characteristics of the study participants.

\section{Overview of the Study}

The purpose of this study was to evaluate ESL/EFL software programs. The main goals of this research were:

1. To construct and validate an evaluation instrument that can be used to analyze ESL/EFL software programs as to their potential for developing language skills according to the Communicative Language Teaching principles and an interactive approach to computer use in language learning.

2. To assess the extent to which Computer Assisted Language Learning software programs available on the market develop ESL/EFL skills according to: a) the Communicative Language Teaching principles, and b) an interactive approach to computer use for language learning. 
Two approaches were used to achieve these goals. First, an ESL/EFL evaluation instrument was designed and tested for its reliability and validity. Second, this instrument was utilized to analyze ESL/EFL software programs available on the market.

\section{Research Design}

Evaluation is a key aspect of CALL that needs consideration. "Evaluation is a matter of judging the fitness of something for a particular purpose" (Hutchinson and Waters 1987, p. 96). Evaluation therefore implies an activity where something is declared suitable or not and consequent decisions are to be made or action taken. There are two broad ways of actually executing evaluation studies: introspective (checklists, reviews) and empirical evaluations.

Introspection means relying on one's own judgment/experience, a theory, or published consensus on what should be there and what is good or bad. In this case, evaluation can be done purely individually, subjectively, globally and introspectively. However, in order to regard evaluation in a systematic way, it is necessary at the very least to look carefully at different aspects of the materials separately and to think of all the relevant aspects of the learning situation, learners, potential use etc., and to judge aspects of language learning with respect to what the syllabus or program covers.

This is where checklists come in. They at least provide a way of ensuring that important aspects do not get forgotten and that there is some consistency if the same person evaluates several materials. However, the evaluation still remains individual, introspective and subjective. In fact, many published checklists appear as a rather miscellaneous collection of points or questions. 
In contrast, empirical evaluations require that the materials have to be used for some time by actual learners in a learning situation. However, a survey of recent evaluation projects of an empirical type suggests a lack of methodological rigor or at very least a lack of agreed-upon methodological protocols (Chapelle and Jamieson, 1986,1989, 1991, and Chapelle, 1990, 1995, 1997).

Therefore, in order to meet the need for CALL software evaluation to take into account the distinct nature of multimedia language learning software and the teaching and learning that can ensue from its use, this study proposed a systematic approach consisting of the following steps:

1. Develop a theoretical framework for evaluation of software in language learning.

2. Derive from the theoretical framework an instrument for evaluation of ESL/EFL software programs for language learning.

3. Construct and validate this ESL/EFL software evaluation instrument.

4. Use this ESL/EFL evaluation instrument to evaluate commercial ESL/EFL software programs.

In order to achieve the goals of this study, the research design took two approaches:1) elaboration and validation of the ESL/EFL software evaluation instrument; and 2) analysis of ESL/EFL software programs. The selection of materials and participants and the description of the procedures and of the method of data collection and analysis are reported with respect to each of these approaches.

Approach 1: Elaboration and Validation of the ESL/EFL Software Evaluation Instrument 


\section{Elaboration of the ESL/EFL Software Evaluation Instrument}

The first step taken in the elaboration of the ESL/EFL software evaluation instrument consisted of a review of available software evaluation instruments designed by the following researchers: Al-Kahtani \& Abalhassan (1999), Chapelle (1998), Cunningham (1995), Dudley-Marling \& Owston (1988), Garrett et al. (1995), Healey \& Johnson (1997a), Hubbard (1987, 1988), Janelle (1984), Kerr (2001), Mitra (2002), Murray and Barnes (1998), Odell (1986), Plass (1998), Poulsen (1990), Reeder (2004), Reeves (1994 and 1997), Shueckler \& Shuell (1989), Stieglitz (1997), Thorn (1995), and Warschauer (1996c). The results of the review provided an understanding of the factors that should be considered in designing an effective ESL evaluation instrument.

The instrument was divided into two parts:

1. The "Descriptive Analysis", which describes the technical and pedagogical orientation of the software programs based on the documentation.

2. The "Critical Analysis", which assesses the extent to which software programs available on the market develop ESL/EFL skills according to the principles of the Communicative Approach and an interactive model of computer use for language learning.

The criteria used for the EL/EFL software evaluation instrument were based on:

(a) technological features associated with interactive CALL; (b) features of the Communicative Language Approach; and (c) technological features that allow for individualized instruction. The gathered criteria were grouped into three clusters encompassing desirable features of software programs for ESL/EFL learning: (a) Technological features; (b) Pedagogical features; and (c) Individualized-learning 
features. The following criteria were used in the elaboration of the questions in the "Critical Analysis" part of the ESL/EFL software evaluation instrument.

\section{Technological Criteria}

Although the quality of learning around computers is related to the social climate of the classroom and the opportunities created for interaction and exploratory talk between participants in the learning process, the interface between learners and the technology is highly correlated with how well users enjoy using a specific program. No matter how pedagogically appropriate a program might be, if students do not feel

motivated to use it, it has very little chance to facilitate learning. Therefore, the analysis of software should start with an evaluation of the user interface. It is important to assess the incorporation of technological features associated with high quality interactive CALL into ESL/EFL software. Criteria for the evaluation of specific technological features include: ease of use, navigation, screen design, and media integration. Table1, below, presents criteria for the analysis of the user interface technological features and the questions that were elaborated to verify the existence of these features. The answers to these questions provide the information necessary to answer Research Question 3: Do ESL/EFL software programs incorporate the technological features associated with interactive CALL? 
Table 1

Criteria and Questions for the Evaluation of the Incorporation of Technological Features into ESL/EFL Software

Criteria for the evaluation of technological Questions in the instrument

features in ESL/EFL software

Ease of use:

The perceived facility with which a user interacts with a multimedia program. The meaning of icons and symbols should be easy to understand and remember. Options, choices, and menus have to be easily found. Instructions should be helpful.

Media integration:

How well an interactive program combines different media to produce an effective whole. It also deals with whether or not the various media components are necessary to the function of the program.

Screen design:

The quality and design of: text, icons, graphics, color, and other visual aspects of interactive programs.

\section{Navigation:}

Ability to move through the contents of an interactive program in an intentional manner. An important aspect of navigation is orientation, i.e., the degree to which a user feels that he/she knows where he/she is in the program and how to go to another part of it. A good approach to navigation is the WIMP (window-icons -mouse-pointing) interface.
1.1 Are menu items understandable and descriptive?

1.2 Are the commands and instructions for the activities clear and objective?

1.3 Does the program give the learners effective clues to clarify their doubts about its use?

1.4 Do graphics and sound enhance learning?

1.5 Does each screen use text and graphic/animation to make a particular teaching point clear?

1.6 Does the sound add to the understanding of the teaching point?

1.7 Is the animation effective in minimizing boredom by motivating learners?

1.8 Is the program effectively integrated with other technological resources (such as dictionaries on the web, grammar on line, etc) as the learner uses it?

1.9 Are screen displays uncluttered?

1.10 Do graphics make information attractive?

1.11 Do graphics aid understanding?

1.12 Do graphics organize information into a coherent structure?

1.13 Do graphics help memorization of key information?

1.14 Do icons, buttons and menus allow learners to readily search for additional information while doing an activity?

1.15 Do buttons, icons or menu items make Help or Hint-type options easily accessible?

1.16 Does the program allow random selection of lessons/activities? 


\section{Pedagogical Criteria}

An analysis of the approach adopted by the programs is the most critical parameter of software evaluation, for it determines the pedagogical soundness and appropriateness of the program. This analysis primarily involves looking at the theoretical underpinnings of activities, judging how well they conform to the principles of Communicative Language Teaching, and determining how closely they are aligned with the program's objectives. The criteria used for this type of analysis are based on the principles of Communicative Language Teaching and are grouped in the "Pedagogical Features"”' section of the instrument. Table 2 shows the criteria used for the evaluation of the features of Communicative Language Teaching in ESL/EFL software programs and the questions that indicate the incorporation of these features into the programs. The data collected from this section of the instrument provide an answer to Research Question 5: Do CALL programs incorporate the teaching principles of the Communicative Language Approach into the elaboration of ESL/EFL software?

Table 2

Criteria and Questions for the Evaluation of the Incorporation of the Principles of Communicative Language Teaching into ESL/EFL Software

Criteria for evaluation of the incorporation

of the teaching principles of the

Questions in the instrument

Communicative Language Approach in ESL/EFL software

Theory of Language and of Learning:

- Language is a system for the expression of meaning; its primary function is interaction and communication, and it is learned through tasks that are meaningful to the learner.

- The target linguistic system is learned best through the process of struggling to communicate.

- Linguistic variation is a central concept in
2.17 Does the program make use of authentic texts and other realia?

2.18 Does the program integrate information about culture/literature/daily situations into the presentations and activities?

2.19 Does the program present and practice language structures in meaningful communicative contexts?

2.20 Does the program present and practice vocabulary in meaningful communicative 
materials and methodology.

Objectives:

- include functional skills (such as instrumental, interactional, and personal) as well as linguistic objectives (grammar and vocabulary for example);

- reflect the interest and needs of the learner;

- are made very clear to teachers and students.

Syllabus

- includes structures, functions, notions, themes, and tasks.

- ordering is guided by learner's needs and interests.

- sequencing is determined by consideration of content, function, or meaning.

Activities:

- engage learners in communication, and involve processes such as information sharing, negotiation of meaning and interaction;

- allow unplanned and unpredictable responses;

- involve real communication;

- develop communicative competence (i.e. the ability to use the linguistic system effectively). contexts?

2.21 Does the program develop the functional skills it aims to develop?

2.22 Does the program develop the level of linguistic competency it aims to develop?

2.23 Does the program arouse sensory and cognitive curiosity?

2.24 Does the program maintain attention throughout the lesson?

2.25 Does the use of animation invite learners' reaction or input?

2.26Does the program give learners a clear explanation of its purposes and methodological orientation?

2.27 Does the program give learners a clear orientation of how to use its different sections components?

2.28 Is the course syllabus in accordance with the linguistic assumptions and with the methodological approach the program claims to have?

2.29 Is content selection determined by communicative skills and/or themes?

2.30 Is content sequencing determined by functional complexity?

2.31 Is content presented communicatively?

2.32 Does the program develop the content at appropriate levels of communicative complexity?

2.33 Is the program content educationally relevant and interesting for the learner?

2.34 Is the program content appropriate for intended learners?

2.35 Is the program content applicable to real life contexts?

2.36 Does the program allow learners to work together in communicative activities?

2.37 Does the program provide challenging activities?

2.38 Do the activities allow unplanned and/or unpredictable responses?

2.39 Do the activities lend themselves to group discussions?

2.40 Do the activities aim at developing competencies other than syntactical and lexical? 


\section{Individualized Learning Criteria}

Individualized instruction is a very strong premise of Communicative Language Teaching. Therefore, in order to evaluate the incorporation of Communicative Teaching principles into CALL, it is also important to analyze how technological features enable ESL/EFL software to adapt itself to fit different learning styles, needs and interests. Individualization of instruction has long been a major pursuit of CALL because it justifies having students practice ESL on the computer (Chapelle and Jamieson, 1986). Individualization refers to the fact that the computer enables students to work alone and at their own pace. To provide an individualized learning environment, many developers have used a systems approach to design: a learning hierarchy is formulated, and a diagnostic mechanism is used so that either the computer program or the student can decide when the student needs to review (Dick \& Carey, 1978; Tennyson, 1981). The difficulty, however, is in designing a diagnostic mechanism that will enable each student to proceed along a tailor-made path. Although its potential has been demonstrated, individualization has not been achieved at a sophisticated level (Hart, 1981; Kearsley, Hunter, \& Seidel, 1983). This traditional view of individualization in CALL is now seen in a new light. Some educators have proposed that students use the computer as a means of exploring and playing with material (such as the target language) through group work tasks and student-initiated exchanges. Individualization is directly related to the type of social environment students create for their own learning experiences.

The capability of collecting data and keeping records is a second aspect of individualized CALL. Data on any interaction that occurs between the student and the computer can be collected and subsequently analyzed. A good software program should be capable of keeping a permanent record of learner performance for the instructor, and of allowing the learner to carry on from where he/she has left off. This 
dimension also deals with immediate information on accuracy of response and /or a summary of total right and/or wrong answers.

Some software materials have incorporated research findings that indicate students learn better when they have to answer questions (rather than simply read material) and receive 'knowledge' of the correct response - clues of what is wrong and right (Anderson, Kulhavey, \& Andre, 1971; Sassenrath, 1975). Thus, the third aspect of individualized CALL instruction is embodied in answer judging. Answer judging occurs after students answer a question posed by the computer. The computer informs them whether it is right or wrong. Moreover, if the answer is wrong, the program should provide students with a meaningful explanation as to why the answer is wrong. So, this third distinguishable dimension of software programs refers to the type of feedback given to the students. Software programs should provide feedback that helps students judge when, and mainly why, their answer is wrong.

Table 3, below, presents individualized-learning features and the questions elaborated to verify the presence of these features. Data from the answers to these questions answer Research Question 4: Do CALL programs present technological features that allow for individualized instruction?

Table 3

Criteria and Questions for the Evaluation of the Incorporation of Individualized-Learning Features into ESL/EFL Software

Criteria for the evaluation of

Technological Features that allow for Individualized Learning

Adaptation to students' needs, interests, and styles:

- satisfy or complement the instructional needs of the learners;
3.41 Does the program allow for different routes and choices for learning?

3.42 Does the program allow for review of old information?

3.43 Does the program allow branching to new 
- give the learner some degree of freedom to choose among different tasks the ones which will more effectively lead him/her to learning the necessary language skills;

- adapt to the responses given by the learner, branching to more or less complicated tasks as appropriate.

\section{Record-keeping}

- give immediate information on accuracy of response and on summary of total right and/or answers;

- collect and analyze wrong responses;

- use this type of data for error diagnosis and remediation.

\section{Answer judging}

- reinforce the correct answer with positive feedback;

- supply the correct response and evaluate the students' answer;

- be able to explain why the students' answer was incorrect, and encourage students to obtain the correct answer;

- be able to recommend special remediation to students. information?

3.44 Does the program allow students to select activities according to their ages?

3.45 Does the program allow students to select activities according to their learning styles?

3.46 Does the program allow students to select activities according to their interests?

3.47 Does the program adapt to the responses given by the learners, branching to more or less complicated questions as appropriate?

3.48 Does the program allow learners to go through its content at their own pace and rhythm?

3.49 Does the program allow the teacher to interact with students while they are doing an activity?

3.50 Does the program prevent learners from repeating exercises, therefore, minimizing guessing?

3.51 Does the program keep records of learners' performance to allow them to continue activities from where they left off?

3.52 Does the program keep track of students' scores?

3.53 Does the program provide non-threatening feedback?

3.54 Does the program allow learners to repeat an activity after feedback is provided?

3.55 Does the program offer a selection of possible correct responses?

3.56 Does the program provide feedback for both correct and incorrect answers?

3.57 Does the program give learners the chance to correct their errors?

3.58 Does the program effectively signal the mistakes before providing the right answers?

3.59 Does the program effectively specify different types of errors, such as differences between a syntactic error and an incorrect word choice?

3.60 Does the program provide the students with feedback (in hypertext form, for example) that would allow them to correct their mistakes? 
It is also important to add that most of the evaluation forms and software reviews analyzed for this study included an overall rating, although there was a great deal of variability as to the form and ratings used. For example, evaluation forms assigned the overall rating on the basis of: (a) a simple "yes/no/not applicable" response, (b) a rating scale (e.g. ranging from 5 for "highly recommended" to 1 for "not recommended"), (c) a checklist, in which specific features of the software were pointed out, (d) a one to ten scale dimension, or (e) a weighted total. It was also observed that in most instances the overall rating was not derived explicitly from the preceding criteria used in the elaboration of the instrument, and ended up being little more than the subjective impression of the evaluator.

Since the purpose of the present study was not only to provide a better understanding of the way language was being taught by means of a computer, but also to assess the extent to which Computer Assisted Language Learning software material was suitable for developing ESL/EFL skills according to Communicative Language Teaching principles, it seemed obvious that the elaborated ESL/EFL software evaluation instrument should also include a rating scale, and that the rating should be based on the criteria being used.

The rating scale designed to answer all questions in the "Critical Analysis" part ranged from 1 (for low) to 4 (for high). Zero would be chosen when the feature was not present in the program. The higher the rating of a program, the more the program would be evaluated as having the potential to develop ESL/EFL skills according to the principles of Communicative Language Teaching and to an interactive approach to computer use for language learning.

A draft of the ESL/EFL software evaluation instrument was tested for its internal consistency in a Pilot Study, reported in Appendix A. The Cronbach Alpha Coefficients for the ratings of the three programs analyzed in the pilot study indicated that the 
elaborated ESL/EFL software evaluation instrument had high levels of internal consistency. The data from the pilot study were used to construct a revised draft of the ESL/EFL software evaluation instrument with minor alterations - some items were reworded and the rating scale was modified. In the first draft, the rating scale ranged from 0 to 5 ( 0 = "not present;" 1 = "very low;" 2 = "low;" 3 = for "adequate;" 4 = "high;" and 5 = "very high"). As described previously, in the revised draft, the rating scale ranged from 0 to 4 ( 0 = "not present;" 1 = "low;" and 4 = "high") in order to avoid participants from choosing a mean point from 1 to 5 (Rule of Central Tendency), which would not be very indicative whether they thought the feature to be either present to a low degree (from $1-2$ ) or to a high degree (from 4-5).

The revised ESL/EFL software evaluation instrument used in this study is in Appendix B.

\section{Study Participants}

In order to test the internal consistency and the inter-rater reliability of the ESL/EFL software evaluation instrument, this instrument was used by ESL/EFL teachers in the evaluation of ESL/EFL software programs. The selection of participants for this study was based on the following criteria:

1. Status of ESL and EFL teachers, since most software programs are designed for both ESL and EFL learners.

2. Teaching experiences that encompassed most contexts in which ESL/EFL is taught (middle, and high schools, university, and adult education).

3. ESL/EFL certified teachers. 
Invitational letters were sent to fifteen American ESL teachers and to twenty Brazilian EFL teachers, known to this researcher, who met the above-specified criteria. Thirty teachers agreed to voluntarily participate in the study. (The Informed Participant Consent Form is presented in Appendix C). Twenty-six teachers returned their evaluation results - 15 Brazilian EFL teachers and 11 American ESL teachers.

\section{Materials}

For the reliability tests, three ESL/EFL software programs were selected ELLIS, New Dynamic English, and Side-by-Side. The criteria for the selection of these three programs were based on: 1) programs designed for ESL/EFL young adult or adult learners; 2) multi-leveled programs (designed to take learners from one to another level of language development; 3 ) multi-skills programs (designed to teach listening, speaking, reading and writing skills in English as a second/foreign language; and 4) availability of enough demonstration CD-Roms that could be distributed to all participants in the study.

\section{Procedures}

The ESL/EFL software evaluation instrument was used by the ESL/EFL teachers to evaluate the selected ESL/EFL software programs. Each teacher received a sample CD-Rom of each of the three programs which included sample lessons of different levels of the program, and an overview of the whole program. Since this study was also investigating how clearly and objectively the instrument could be used by teachers with different backgrounds and experiences to identify criteria of the Communicative Approach of Language Teaching and an interactive model of computer use for language learning used in the design of the programs, teachers were not given 
any training on how to use the instrument, nor were they assigned any specific time or amount of time to analyze the programs. However, all teachers were asked to go through at least one complete lesson in each level of the software program. All teachers were also encouraged to ask about and/or take notes on doubts or questions while using the instrument to analyze the programs.

\section{Method of Data Collection and Analysis}

The data used to test the reliability of the ESL/EFL software evaluation instrument came from the 26 participant-teachers' ratings for the items in the ESL/EFL software evaluation instrument for each of the three selected programs.

In order to test the inter-rater reliability of the ESL/EFL software evaluation instrument, the 26 teachers' ratings for the items in the instrument for each program's evaluation were entered into the Statistical Package for the Social Sciences program (SPSSP, Version 12.0). The following statistical tests were performed to test the interrater reliability:

1. The Pearson Coefficients were calculated to establish the degree of agreement among the raters for each program.

2. The Intra-Class Coefficients were calculated to determine the degree of correlation among the ratings of the raters for each program. In the computation of the Intra-Class Coefficients (ICC), a two-way mixed model was used because the raters were seen as a fixed effect (not a random sample of all possible raters) and the items as a random effect. The ICC in this case is interpreted as not being generalizable beyond the given raters. The Consistency type was used because the interest was to measure raters' relative ratings; that is, if raters' ratings were consistent as long as their relative ratings 
were similar. The Average Measure Reliability gives the reliability of the mean of the ratings of all raters because the research design involved averaging multiple ratings for each item. The Average Measure Reliability is a Cronbach's Alpha Coefficient.

In order to evaluate the internal consistency of the ESL/EFL software evaluation instrument, the following statistical tests were run in the SPSS program, version 12.0, in this order:

1. Descriptive statistics were used to explore the dependent variables - the ratings for each item in the evaluation instrument for each program. The mean and the standard deviation for each item's ratings for each program were calculated.

2. The Cronbach Alpha Coefficients were calculated for the ratings for all the items of the ESL/EFL software evaluation instrument for each program.

3. Factor analysis was done with the ratings for the items of the ESL/EFL software evaluation instrument for the program with the highest Cronbach Alpha Coefficient.

4. The Cronbach Alpha Coefficients were calculated for the items loaded in each factor.

5. The Cronbach Alpha Coefficients were calculated for the items all together. The ESL/EFL software evaluation instrument was also submitted to two experts' analysis for face and content validity. The criteria used for the elaboration of the ESL/EFL software evaluation instrument were also presented to these experts.

The results of the analysis of the data in the first approach - elaboration and validation of the ESL/EFL software evaluation instrument - are presented in Chapter 4. 
Approach 2: Analysis of ESL/EFL Software Programs

\section{Materials}

Since the purposes of this research were to develop and validate an instrument which assessed the extent to which Computer Assisted Language Learning software programs available on the market were suitable to develop ESL/EFL skills according to Communicative Language Teaching principles and an interactive approach to computer use for language learning, and to assess the extent to which Computer Assisted Language Learning software programs on the market could develop ESL/EFL skills because they incorporated the principles of Communicative Language Teaching and an interactive approach to computer use, a software search in a database was conducted in order to select software programs to be analyzed. The selection of software followed these criteria:

1. Software programs designed for teaching/learning all four language skills (listening, speaking, reading, and writing), because the principles of the Communicative Approach apply to the teaching and learning of all four skills).

2. Multi-level software programs, so that the development of language skills could be observed from one level to another.

3. Software programs designed for teaching/learning ESL or EFL to adolescents and adults. Children/elementary grade learners were not included because ESL teaching/learning for this age/grade level also involves teaching/learning content area subjects.

Several databases were searched for the keywords $E S L / E F L+$ software, and 76 different titles were identified. Eliminating dictionaries and grammar and pronunciation tutors, the list was reduced to 63 titles. Of these 63 titles, 40 were discarded because they referred to software for either specific purposes, e.g., Business 
English, English for Traveling, or elementary education, and/or were designed to teach just one level of language proficiency (either beginner, intermediate or advanced students), or developed only one language skill (either listening, speaking, reading or writing). The resulting list of 23 programs was compared to the listing of software programs posted by TESOL (Teachers of English to Speakers of Other Languages Organization), and five other programs not previously included were added. The following CALL software programs for ESL/EFL instruction seemed to meet the criteria described above:

1. A+ Advanced Learning System (American Education Corporation)

2. Asterix (EuroTalk Interactive)

3. BBC New English Course (Ladder Multimedia)

4. Classworks Gold (Knowledge Adventure)

5. Ellis (Intro, Middle, Senior Mastery) (CALI)

6. $\quad$ English Discoveries (Edusoft Ltd.)

7. English Express Deluxe (Knowledge Adventure)

8. English Mastery (ALA)

9. English Tutor (Queue Inc.)

10. English Your Way (Syracuse Language Systems)

11. I Speak English (Intechnica International)

12. Instant Immersion (English Deluxe)

13. Issues in English (Protea Textware)

14. 101 Languages of the World (Transparent Language)

15. Learn English (Transparent Language)

16. Learn to Speak English (The Learning Company)

17. Live Action English Interactive (Command Performance Language Institute) 
18. Longman English Interactive (Pearson Education)

19. Making Connections (Heinle \& Heinle)

20. New Dynamic English (Dyned International)

21. Side By Side Interactive (Pearson Education)

22. Smart Start Language Software (Syracuse Language)

23. Talk Now! (Topics Entertainment)

24. Talk More (Topics Entertainment)

25. Tell Me More Comprehensive (Auralog)

26. The Rosetta Stone (Fairfield Language Technology)

27. Who Is Oscar Lake? (Topics Entertainment)

28. World Talk (Topics Entertainment)

Procedures

Letters were sent to the publishers of the above listed programs requesting demonstration CD-Roms of the programs. Ten program publishers sent demonstration CDs of the programs and the documentation for them. The other eighteen programs had to be purchased. However, six programs - "BBC New English Course" (Ladder Multimedia), "Classworks Gold" (Knowledge Adventure), "English Mastery" (ALA), "English Your Way” (Syracuse Language Systems), "I Speak English” (Intechnica International), and "Smart Start Language Software" (Syracuse Language) - were not found in the market.

Once the twelve programs were acquired, a quick analysis revealed that some of the program titles were in fact either different language proficiency levels of the same program, or program packages containing some of the programs that were listed separately. For example, "Talk Now", "Talk More", and "World Talk" (all by Topics 
Entertainment) are three different language proficiency levels of the same program. "English Express Deluxe" and "Instant Immersion" (both by Knowledge Adventure) are just software program packages. The Instant Immersion package includes the programs “Talk Now”, “Talk More”, “World Talk”, and "Who's Oscar Lake?”, and an English Dictionary. The "English Express Deluxe" package includes the same five programs included in the "Instant Immersion" package and three audio CDs. "English Tutor" (Queue Inc.), although advertised as a multi-skill software program, is in fact a pronunciation-tutor software program which also includes printable workbooks on grammar, reading, listening, and writing. "The program 101 Languages of the World" was also a package, which included the program "Learn English." The program "A+ Advanced Learning System" was also discarded because it was a program for teaching/learning content areas which offered extra support for ESL learners; in other words, it did not meet the assigned criteria for software program selection. In sum, the number of analyzed software programs was reduced from the 22 programs currently available on the market to 15 software programs that truly met the specified criteria for the selection of software programs for this study:

The following fifteen programs were analyzed by this researcher using the ESL/EFL software evaluation instrument: "Asterix", "ELLIS", "English Discoveries", "Issues in English", "Learn English", "Learn to Speak English", "Live Action Interactive”, "Longman English Interactive", "Making Connections", "New Dynamic English", "Rosetta Stone", "Side-by-Side", "Talk Now", "Tell me More”, and "Who's Oscar Lake?".

Method of Data Collection and Analysis

Data were collected from the evaluation of the above-mentioned fifteen programs using the ESL/EFL software evaluation instrument. In order to evaluate the 
programs, this researcher went through the process of installing, running and analyzing each program. Several lessons at different language proficiency levels for each program were completely finished. In each of the analyzed lessons for each program, the researcher also took the role of a learner, going through presentations, doing the activities, quizzes, games, recording readings and pronunciation of words in each program's syllabus. Mistakes were purposefully made in different activities of each program in order to analyze how programs treated errors and provided feedback.

Notes were also taken during the evaluation of each program, and a form of the ESL/EFL software evaluation instrument was completed for each program at the conclusion of the process described above. (The completed forms of the ESL/EFL software evaluation instrument for each program are presented in Appendix D.) When the fifteen programs were evaluated, data were organized and analyzed in the following way:

1. Ratings for the items in the categories of Media Attributes and User-Friendly Attributes of the ESL/EFL software evaluation instrument were analyzed in order to determine the degree of incorporation of technological features by the ESL/EFL software programs. The ratings for the category of Media Attributes and the ratings for the category of User-Friendly Attributes were added together and the percentage of the total maximum rating for these two categories together was calculated.

2. Ratings for the items related to the programs' degree and type of individualized instruction were analyzed to determine the degree of incorporation of individualized-learning features by the ESL/EFL programs. The ratings for these items were added and the percentage of the possible maximum rating for these items was calculated for each program. 
3. Each program's ratings for all the items in the Media Attributes category were analyzed, and the percentage of the possible maximum rating for this category was calculated for each program.

4. Each program's ratings for all the items in the User-Friendly Attributes category were analyzed, and the percentage of the maximum possible rating for this category was calculated for each program.

5. Ratings for the items in the Instructional Attributes category were analyzed in order to determine the programs' degree of incorporation of the Communicative Language Learning Principles by the ESL/EFL software programs. Ratings for the items in this category were added and the percentage of the possible maximum rating for the category was calculated for each program.

6. Ratings for each program for all the items in all categories of the evaluation instrument were added, and the percentage of the possible total ratings was calculated in order to determine the extent to which the ESL/EFL software programs created environments that developed language skills according to the Communicative Language Teaching approach and the socio-interactive CALL model.

7. Ratings for each program in the three different categories of the ESL/EFL software evaluation instrument - Media, User-friendly, and Instructional Attributes -were used to identify the type of features which each program, and/or most programs, met best and/or failed to meet.

8. Ratings for all the items in the ESL/EFL software evaluation instrument for each program were also compared across each category.

The results of the analysis of the data in the second approach - analysis of ESL/EFL software - are presented in Chapter 5. 


\section{CHAPTER 4: RESULTS OF THE RELIABILITY AND VALIDATION ANALYSES OF}

THE ESL/EFL SOFTWARE EVALUATION INSTRUMENT

\section{Research Questions Restated}

The purpose of this study was to evaluate ESL/EFL software programs. The main goals of this research were: (a) to develop and validate an evaluation instrument that can be used to analyze ESL/EFL software programs as to their potential for developing language skills according to the Communicative Language Teaching principles and an interactive approach to computer use in language learning, and (b) to assess the extent to which Computer Assisted Language Learning software programs available on the market develop ESL/EFL skills according to the principles of Communicative Language Teaching, and an interactive approach to computer use for language learning. Two approaches were used to achieve these goals. First, an ESL/EFL evaluation instrument was designed and tested for its reliability and validity. The second approach utilized this instrument to analyze ESL/EFL software programs available on the market. The first approach examined the following questions:

1. To what extent does the ESL/EFL software evaluation instrument produce consistent results when administered under similar conditions? In other words, is the designed ESL/EFL software evaluation instrument reliable?

2. To what extent is the ESL/EFL software evaluation instrument valid to evaluate the potential of CALL programs to develop language skills according to the Communicative Language Teaching principles and an interactive approach to computer use in language learning?

The investigation of these questions started with the development of an ESL/EFL software evaluation instrument (described in Chapter 3: Methodology) and 
the use of this instrument in a pilot study to test its reliability (Appendix A). The Cronbach's Alpha Coefficients for the ratings of the three programs analyzed in the pilot study indicated that the elaborated ESL/EFL software evaluation instrument had high levels of internal consistency. The data from the pilot study were used to construct a revised draft of the ESL/EFL software evaluation instrument with minor alterations some items were reworded and the rating scale was modified. In the first draft, the rating scale ranged from 0 to $5(0=$ "not present;" 1 = "very low;" 2 = "low;" $3=$ for "adequate;" 4 = "high;" and 5 = "very high"). In the revised draft, the rating scale ranged from 0 to 4 ( 0 = "not present;" 1 = "low;" and 4 = "high").

This chapter deals with the results of the reliability and validation analyses of the ESL/EFL software evaluation instrument. Results are presented in four sections: the first section describes the results for face validity and content validity; section two presents the results of inter-rater reliability measures; the third section describes the results of internal consistency measures; and the last section summarizes the results of the reliability and validity analysis.

\section{Results for Face Validity and Content Validity}

The ESL/EFL software evaluation instrument was submitted for the analysis to two experts in ESL/EFL pedagogy ${ }^{1}$. These experts determined that 'on the face of it', the ESL/EFL software evaluation instrument seemed appropriate and valid.

Then, these experts were given the criteria that guided the elaboration of the ESL/EFL software evaluation instrument. They examined the evaluation instrument

\footnotetext{
${ }^{1}$ The experts were Dr. Willis Poole and Dr. Christine Meloin. Dr. Poole is the director of the Master's and Endorsement ESL Programs at Rhode Island College. Dr. Christine Meloni is an Associate Professor Emeritus of English as a Foreign Language at The George Washington University. Dr. Meloni is currently an ESL teacher at Northern Virginia Community College in Alexandria, Virginia, and a Senior Research Associate at the National Capital Language Resource Center at GWU.
} 
using these criteria, and both agreed that the items in the evaluation instrument comprised the set of criteria associated with the principles of the Communicative Approach to language teaching and an interactive model of computer use for language learning.

Results of Inter-Rater Reliability Measures

The ESL/EFL evaluation instrument was tested for its inter-rater reliability. Two statistical procedures - Pearson Coefficient and Intra-Class Coefficient (ICC) - were used to measure the inter-rater reliability among the 26 raters' ratings for the 60 items of the ESL/EFL software evaluation instrument in the evaluation of the software programs - "ELLIS”, “New Dynamic English”, and "Side-by-Side. Although both procedures assess the homogeneity of the ratings among raters, the Pearson Coefficient establishes the degree of agreement on the ordering of the ratings among the raters only, while the Intra-Class Coefficient determines the degree of agreement not only of the ordering of the ratings but also of the range of the ratings among the raters. Therefore, the Pearson Coefficient is an index of the degree of correlation among raters, while the Intra-Class Coefficient is an index of the degree of correlation among the ratings of the raters.

\section{Pearson-Coefficients}

The degree of agreement among the 26 raters for the program "New Dynamic English" ranged from $r=.729$ to $r=.995$. For the program "ELLIS", the degree of agreement ranged from $r=.749$ to $r=.938$. The Pearson Coefficients for the program 
"Side-by-Side" ranged from $r=.769$ to $r=.981$. These results indicate a significant linear correlation among the raters.

\section{Intra-Class Coefficients}

In the computation of the Intra-Class Coefficients (ICC), a two-way mixed model was used because the raters were seen as a fixed effect (not a random sample of all possible raters) and the items as a random effect. The ICC is interpreted as not being generalizable beyond the given raters. The Consistency type was used because the interest was to measure raters' relative ratings; that is, if raters' ratings were consistent as long as their relative ratings were similar. The Average Measure Reliability gives the reliability of the mean of the ratings of all raters because the research design involved averaging multiple ratings for each item. The Average Measure Reliability is a Cronbach's Alpha Coefficient. The Intra-Class Coefficients for the raters' ratings for the 60 items in the ESL/EFL software evaluation instrument are shown in Table 4.

\section{Table 4}

Intra-Class Coefficients for Raters' Ratings for "New Dynamic English", "ELLIS", and "Side-by-Side

\begin{tabular}{lccc}
\hline Programs & $\begin{array}{c}\text { Intraclass } \\
\text { Correlation/ } \\
\text { Cronbach's } \\
\text { Alpha }\end{array}$ & $\begin{array}{r}\text { L5\% Confidence Interval } \\
\text { Lownd }\end{array}$ & $\begin{array}{r}\text { Upper } \\
\text { Bound }\end{array}$ \\
\hline English & .990 & .986 & .994 \\
ELLIS & .994 & .991 & .996 \\
Side-by-Side & .994 & .992 & .996 \\
\hline
\end{tabular}


For the program "Dynamic English," the ICC correlation was .990, at 95\% of confidence level, lower bound $=.986$, upper bound $=.994$. For the program "ELLIS", the ICC correlation was .994 , lower bound $=.991$, upper bound $=.996$. For the program "Side-by-Side", the ICC was .994 , lower bound $=.992$, upper bound $=.996$. These results indicate a strong correlation among the 26 raters' ratings for the three programs.

The results of the Pearson Coefficient and the ICC Coefficient measures indicate a high degree of inter-rater reliability. These results suggest that the study participants were an appropriate sample, and that despite their different backgrounds (American and Brazilian, ESL and EFL) there was a high level of agreement among the participants.

Results of Internal Consistency Measures

Internal consistency focuses on the degree to which the individual items are correlated with each other. The statistical measures used in this study to measure the level of internal consistency for the ESL/EFL software evaluation instrument were the Cronbach's Alpha Coefficients for inter item reliability and Factor Analysis followed by re-calculation of the Cronbach's Alpha Coefficients.

\section{Cronbach- Alpha Coefficients for Inter-Item Reliability}

The following table shows the Cronbach's Alphas for three programs used to test the internal consistency of the instrument: "ELLIS", "New Dynamic English", and "Side-by-Side". The data used to compute the Cronbach's Alpha coefficients came from the results of the analysis of the three programs by $26 \mathrm{ESL} / \mathrm{EFL}$ teachers who 
used the instrument to evaluate the programs.

The Cronbach's alpha reliability tests applied to the analysis of the three specified programs indicated the following Cronbach's Alphas: .721 for ELLIS; .916 for New Dynamic English, and .866 for Side-by-Side. The results indicate adequate levels of inter item reliability among the items of the ESL/EFL software evaluation instrument (see Table 5).

Table 5:

Cronbach's Alpha Coefficients for the programs "Ellis", "New Dynamic English", and Side-by-Side.

\begin{tabular}{ll}
\hline Programs & Cronbach's Alpha Coefficients \\
\hline Ellis & .721 \\
New Dynamic English & .916 \\
& .866 \\
Side-by-Side & \\
\hline
\end{tabular}

Factor Analysis

A Principal Component Analysis was conducted to determine what, if any, underlying structure existed for measures on the 60 items of the ESL/EFL software evaluation instrument. The data used for the factor analysis were derived from the results of the evaluations of the 26 ESL/EFL participant teachers who used the instrument to evaluate the program "New Dynamic English". The decision to use the data gathered from the evaluations of this program was based on the fact that "New Dynamic English" had the highest Cronbach's Alpha Coefficient (.916) when compared 
to the other two programs' Cronbach's coefficients (.721 for "ELLIS", and .866 for "Side-by-Side").

The 60 items were analyzed using a principal components analysis extraction method and varimax rotation with Kaizer normalization resulting in 15 components. The first three components accounted for $62.65 \%$ of the total variance in the original items. The first component - Factor 1 - accounted for $36.95 \%$ of the total variance, and consisted of 28 of the 60 items. The second component - Factor 2 - accounted for $14.93 \%$, and consisted of 16 items. The third component - Factor 3 - accounted for $10.76 \%$ of the total variance, and included 11 items. The other factors were not kept because, besides having few items loaded in them, the items loaded in these other factors were also loaded in one of the first three factors with higher path coefficients.

The 5 remaining items (out of the original 60 ones) had path coefficients $<.4$, and were eliminated:

1. Item 1.6 - "The sound adds to the understanding of the teaching point," loaded in Factor 8 (-399), was eliminated based on the analysis of that item being either too obvious (anyone could presuppose that the sound should add to the understanding of the teaching point), or not clearly understood (what was really meant by adding to the understanding of the teaching point? what would that look like?).

2. Item 1.12 - "Graphics organize information into a coherent structure," loaded in Factor 5 at .-393, was considered redundant; items 1.11 - "Graphics aid understanding" - and 1.10 - "Graphics make information attractive" - covered the same criteria. If 'graphics aid understanding' and if they 'make information attractive', it is very likely that they do so because they 'organize the information into a coherent structure'. 
3. Item 1.16 - "The program allows learners to move through its contents on they own will" - loaded in Factor 2 at .-314, was eliminated since its content was considered to be repeated in Item 3.48, also loaded in Factor 2 - "The program allows learner to go through its content at their own pace and rhythm." 'On their own will' can be understood as 'at their own pace and rhythm'. Besides, item 3.48 had a higher path coefficient (.643) than item $1.16(.-314)$.

4. Item 2.27 - "The program gives teachers a clear orientation of how to use its different components" - loaded low in Factor 1 at .346 - was eliminated because in the 'Descriptive Analysis' part of the ESL/EFL software evaluation instrument, one of the items asks for the same type of information (cf. item 2.14 in the Descriptive Analysis, Appendix B).

5. Item 2.37 - "The program provides challenging activities" - loaded in Factor 1 at .388 - was eliminated because it was considered very subjective (different people have different concepts of challenge).

The path coefficients of the 55 items loaded in the first three components are reported in Table 6.

Table 6

Factor Loadings

\begin{tabular}{lr}
\hline Factors & $\begin{array}{c}\text { Path } \\
\text { Coefficie }\end{array}$ \\
\hline Factor 1 & $(.457)$ \\
1.4 Graphics and sound enhance learning. & $(.822)$ \\
1.7 The animation is effective in minimizing boredom by motivating learners. & $(.638)$ \\
1.9 Screen displays are uncluttered. & $(.612)$ \\
1.10 Graphics make information attractive. & $(.782)$ \\
1.13 Graphics help memorization of key information & $(.543)$ \\
2.17 The program makes use of authentic texts and other realia. & $(.628)$ \\
2.18 The program integrates information about culture/daily situations into the & $(.636)$ \\
presentations and activities. & $(.636)$ \\
2.19 Lessons present and practice language structures in meaningful & \\
communicative contexts. & $(.471)$ \\
2.20 Lessons present and practice vocabulary in meaningful communicative & \\
contexts. & \\
2.21 Lessons develop the communicative skills the program aims to develop. &
\end{tabular}


2.22 Lessons develop the level of language proficiency the program aims to develop.

2.28 The course syllabus reflects a communicative approach to language teaching/learning.

2.29 Content selection is determined by communicative skills and/or themes.

2.30 Content is sequenced from simple communicative functions, such as introducing oneself, greeting, etc, to complex ones, such as stating an opinion, disagreeing, etc.

2.31 Content is presented communicatively.

2.32 The program develops the content at appropriate levels of language proficiency.

2.33 The program content is educationally relevant and interesting for the learner.

2.34 The program content is appropriate for intended learners.

2.35 The program content is applicable to real life contexts.

2.36 The program allows learners to work together in communicative activities.

2.38 The activities allow unplanned and/or unpredictable responses.

2.39 The activities lend themselves to group discussions.

2.40 The activities aim at developing other competencies in addition to

syntactical and lexical.

2.49 The program allows the teacher to interact with students while they are

doing an activity.

3.53 The program provides non-threatening feedback.

3.54 The program allows learners to repeat an activity after feedback is provided.

3.55 Activities allow for more than one correct response.

3.60 The program provides the students with feedback that would allow them

to correct their mistakes.

Factor 2

1.11 Graphics aid understanding.

3.41The program allows for different routes and choices for learning.

3.42 The program allows for review of old information.

3.43 The program allows branching to new information.

3.44 The program allows students to select activities according to their ages.

3.45 The program allows students to select activities according to their learning styles.

3.46 The program allows students to select activities according to their interests.

3.47 The program adapts to the responses given by the learners, branching to more or less complicated questions as appropriate.

3.48 The program allows learners to go through its content at their own pace and rhythm.

3.50 The program prevents learners from repeating exercises, therefore, minimizing guessing.

3.51 The program keeps records of learners' performance to allow them to continue activities from where they left off.

3.52 The program keeps track of students' scores.

3.56 The program provides feedback for both correct and incorrect answers.

3.57 The program gives learners the chance to correct their errors.

$(.-604)$

3.58 The program effectively signals the mistakes before providing the right answers.

3.59 The program effectively specifies different types of errors, such as

\section{Factor 3}


1.2 The commands and instructions for the activities are clear and objective.

1.3 The program gives the learners effective clues to clarify their doubts about its use.

1.5 Each screen uses text and graphic/animation to make a particular teaching

point clear.

1.8 The program is effectively integrated with other technological resources (such as dictionaries on the web, grammar on line, etc) as the learner uses it. 1.14 Icons, buttons and menus allow learners to readily search for additional information while doing an activity.

1.15 Buttons, icons or menu items make Help or Hint-type options easily accessible.

2.23 The program arouses sensory and cognitive curiosity.

2.24 The program maintains attention throughout the lesson.

2.25 The use of animation invites learners' reaction or input.

2.26 The program gives teachers a clear explanation of its purposes and methodological orientation.

After the 5 items were dropped from the ESL/EFL software evaluation instrument, and the remaining items were grouped into the three factors, the Cronbach Alpha Coefficients were calculated for the items kept within each of the three major factors, and for all the 55 items together. The correlation was high, with the Cronbach's Alpha Coefficients for the items in the three factors and for all the items together reported in Table 7 .

\section{Table 7}

Cronbach's Alpha Coefficients for Each Factor

Factor number Cronbach's Alpha

\begin{tabular}{cc}
$\mathbf{1}(\mathrm{n}=28)$ & .96 \\
$\mathbf{2}(\mathrm{n}=16)$ & .93 \\
$\mathbf{3}(\mathrm{n}=11)$ & .92 \\
Total $(\mathrm{n}=55)$ & .94 \\
\hline
\end{tabular}


The inter-item reliability tests for each factor resulted in higher alpha values and thus a more robust set of items - .96 for Factor 1, .93 for Factor 2, and .92. The Cronbach's Alpha coefficient for the 55 items in the analysis of "New Dynamic English" was .94. This indicates that the inter-item reliability of the original 60 items, obtained from the data of the analysis of the program "New Dynamic English", which was already significant (Cronbach's Alpha $=.916)$, turned out to be even higher after the five items were eliminated (Items 1.6, 1.12, 1,16, 2.27, and 2.37).

After deciding which components (factors) to retain and where to place items that were either not heavily loaded $(<.4)$ in any component or loaded in more than one component, it was necessary to examine the items that comprised each component and try to interpret these factors in terms of their underlying parameters in order to be able to name the factors. The data from this study suggested that there were three key parameters that could be measured as represented in the three factors identified in the factor analysis.

The first parameter - Factor 1 - that needed to be measured when evaluating ESL/EFL programs was thus called "instructional attributes." Clearly, when evaluating any educational material the first concern should be the potential effectiveness of its instructional attributes. These instructional attributes include: the theory of language learning and teaching that underlies the program (Items 2.17, 2.18, 2.19, 2.20, 2.21, 2.22 and 2.28), how content is presented and sequenced (Items 2.29, 2.30, 2.31, 2.32, 2.33, 2.34 and 2.35), the type and quality of language-learning activities (Items 2.36, $2.38,2.39,2.40$ and 2.49 ), the type of feedback provided (Items 3.53, 3.54, 3.55 and 3.60), and how the program facilitates learning (Items 1.4, 1.7, 1.9, 1.10 and 1.13). The second parameter - Factor 2 - to be measured in the evaluation of 
ESL/EFL software programs was called "media attributes" since the items in this component were directly related to the technological features of software programs. These media attributes include: the degree and type of individualization of instruction the program provides (Items 3.41, 3.42, 3.43, 3.44. 3.45, 3.46, 3.47 and 3.48), how the program helps learners move through its content and sequence (Items 3.51, 3.52), how the media technology differentiates feedback (Items 3.50, 3.56, 3.57, 3.58 and 3.59), and how the integration of different types of media facilitates learning (Item 1.11).

The third parameter to be used in the evaluation of software programs was named "user-friendly attributes" - the items in Factor 3 relate to how the program is perceived as attractive, easy to follow, and/or motivating to learners and teachers. Although this is a more subjective parameter, it is also important because learning heavily depends on how motivated students and teachers feel about a specific course or program. The user-friendly attributes include: how the use of the program is made easy to learners (Items $1.1,1.2,1.3,1.14,1.15$ and 2.26$)$, how attractive the media technology makes the program to be (Items 1.5, 1.8 and 2.23) and how the program motivates learning (Items 2.24 and 2.25).

In summary, after dropping the 5 items with factor weight below .4 from the set of 60 original items and re-grouping the remaining 55 items into three factors, the alpha coefficients had higher values. This indicates that the revised draft of the ESL/EFL software evaluation instrument has a more robust set of items and higher levels of internal consistency.

\section{Summary of Results}

Analysis of data from the face and the content validity measures, the inter-rater coefficient measures, and the internal consistency measures suggest these answers to the questions addressed in this study: 
1. To what extent does the ESL/EFL software evaluation instrument produce consistent results when administered under similar conditions? In other words, is the designed ESL/EFL software evaluation instrument reliable? The results of the Pearson Coefficient and the ICC Coefficient measures indicate high levels of inter-rater reliability for this group of 26 teachers. The Cronbach's Alpha Coefficients for the three programs indicated that the ESL/EFL software evaluation instrument had adequate levels of inter-item reliability. The factor analysis resulted in a set of 55 items with even higher alpha values and thus a more robust set of items. The results suggest that the ESL/EFL software evaluation instrument has high levels of internal consistency, and they also suggest inter-rater reliability. All these results assure the evaluation instrument a high degree of reliability.

2. To what extent is the ESL/EFL software evaluation instrument valid to evaluate the potential of CALL programs to develop language skills according to the Communicative Language Teaching principles and an interactive approach to computer use in language learning? The positive indicators of reliability obtained from the procedures used to assess the inter-rater reliability and the internal consistency and the face and content validity attributed to this instrument suggest that the ESL/EFL software evaluation instrument is potentially a valid instrument to assess the degree to which ESL/EFL software programs develop language skills according to the Communicative Language Teaching principles and an interactive approach to computer use in language learning. 
CHAPTER 5: RESULTS OF THE ANALYSIS OF THE PROGRAMS USING THE ESL/EFL SOFTWARE EVALUATION INSTRUMENT

\section{Research Questions Restated}

This study addressed the analysis of ESL/EFL software programs available on the market. The main goals of this research were: (a) to develop and validate an evaluation instrument that could be used to analyze ESL/EFL software programs as to their potential for developing language skills according to Communicative Language Teaching principles and an interactive approach to computer use in language learning; and (b) to assess the extent to which Computer Assisted Language Learning software programs available on the market develop ESL/EFL skills according to the principles of Communicative Language Teaching principles and an interactive approach to computer use for language learning. In order to achieve these goals, an ESL/EFL software evaluation instrument was designed (as described in Chapter 3 ) and validated (as described in Chapter 4). Then, this instrument was utilized to analyze ESL/EFL software programs available on the market.

Chapter 5 reports the results of the evaluation of ESL/EFL software programs available on the market, and examines the following questions:

1. Do ESL/EFL software programs incorporate the technological features associated with interactive CALL?

2. Do CALL programs present technological features that allow for individualized instruction?

3. Do ESL/EFL software programs incorporate the teaching principles of Communicative Language Teaching? 
4. In sum, to what extent do CALL programs create environments that develop language skills according to the principles of Communicative Language Teaching and an interactive approach to computer use for language? Results are presented in four sections: Section one reports ratings for the programs with respect to the categories of Media and User-Friendly Attributes which are technological features associated with interactive CALL. In this section the ESL/EFL software programs were also evaluated as to how they provided for individualized instruction. Section two presents the ratings for the programs with respect to the category of Instructional Attributes, which are based on the teaching principles of the Communicative Language Approach. Section three presents the overall ratings for the programs and evaluates the extent to which the programs create environments that develop language skills according to the principles of Communicative Language Teaching and an interactive approach to computer use for language learning. Finally, in the last section, a summary of the results is presented with respect to the research questions addressed in this chapter.

\section{Analysis of the Incorporation of Technological Features by the ESL/EFL Software Programs}

Findings related to the incorporation of technological features of the ESL/EFL programs were based on the ratings obtained for these programs in the categories of Media Attributes and User-Friendly Attributes. Media Attributes include: how the program helps learners move through the content and sequence of activities (Items 2.39, and 2.40$)^{2}$, how the media technology differentiates feedback (Items 2.38, 2.41, $2.42,2.43$ and 2.43 ), how the integration of different types of media facilitates learning

\footnotetext{
${ }^{2}$ All the items referred to in this Chapter are from the validated ESL/EFL software evaluation instrument (Appendix B).
} 
(Item 2.29), and the degree and type of individualization of instruction the program provides (Items 2.30, 2.31, 2.32, 2.33. 2.34, 2.35, 2.36 and 2.37).

Table 8 shows the ratings for the items related to how the programs helped learners move through content and sequence.

\section{Table 8}

Ratings ${ }^{3}$ for the Items Related to How the Programs Helped Learners Move Through Content and Sequence

\begin{tabular}{|c|c|c|c|c|c|c|c|c|c|c|c|c|c|c|c|}
\hline Items & $\frac{\frac{x}{\bar{d}}}{\frac{\Phi}{0}}$ & 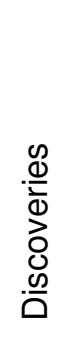 & 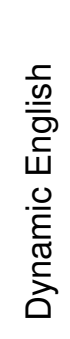 & $\frac{\varrho}{\vec{\Xi}}$ & 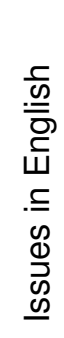 & 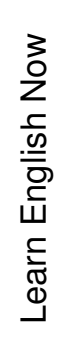 & 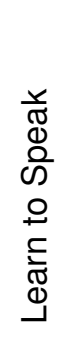 & 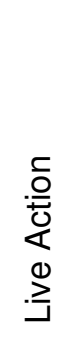 & 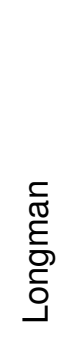 & 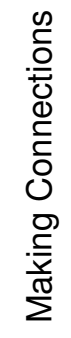 & 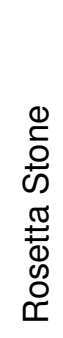 & $\begin{array}{l}\frac{0}{0} \\
\text { की } \\
\frac{1}{0} \\
\frac{\dot{d}}{\dot{0}} \\
\frac{0}{\omega}\end{array}$ & $\begin{array}{l}\bar{z} \\
0 \\
z \\
\underline{\underline{y}} \\
\stackrel{\sigma}{V}\end{array}$ & 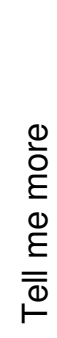 & 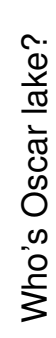 \\
\hline $\begin{array}{l}2.39 \text { The program keeps } \\
\text { records of learners' } \\
\text { performance to allow them } \\
\text { to continue activities from } \\
\text { where they left off. }\end{array}$ & 2 & 4 & 2 & 3 & 2 & 2 & 1 & 2 & 2 & 2 & 3 & 1 & 2 & 4 & 1 \\
\hline $\begin{array}{l}2.40 \text { The program keeps } \\
\text { track of students' scores. }\end{array}$ & 3 & 4 & 2 & 4 & 2 & 2 & 1 & 2 & 3 & 3 & 3 & 0 & 3 & 4 & 1 \\
\hline
\end{tabular}

The incorporation of features related to how the programs helped learners move through content and sequence varied from program to program, with ratings varying from 0 to 4 . With the exception of three programs - "Learn to Speak English" (rated 1), "Side-by-Side" (rated 1 and 0), and "Who's Oscar Lake?" (rated 1). The other programs were able to keep records of learners' performance (item 2.39) and to keep track of students' scores (item 2.40); ratings varied from 2 to 4 . In general, these software programs, except for "Learn to Speak English," "Side-by-Side," and "Who's

\footnotetext{
${ }^{3}$ In the validated ESL/EFL software evaluation instrument all items could be rated from 0 (not present), 1 (low degree) to 4 (high degree).
} 
Oscar Lake?," were able to a lesser or greater degree to keep records of learners' correct/incorrect answers, but were not very effective in keeping track of learners' performance beyond a pre-determined, and therefore limited list of possible answers.

The ratings for the items related to how the media technology differentiated feedback are presented in the Table 9.

Table 9

Ratings for the Items Related to How the Media Technology Differentiates Feedback

\begin{tabular}{|c|c|c|c|c|c|c|c|c|c|c|c|c|c|c|c|}
\hline Items & $\frac{\frac{x}{\frac{x}{d}}}{\frac{0}{4}}$ & 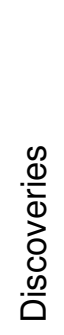 & 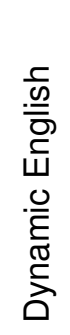 & $\frac{\stackrel{\varrho}{\lrcorner}}{\vec{W}}$ & 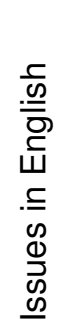 & 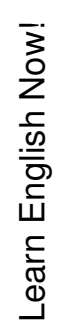 & 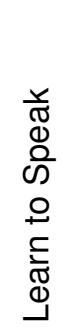 & 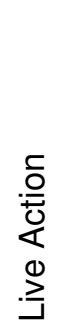 & 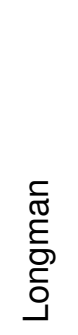 & 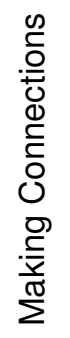 & 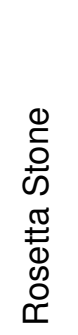 & $\begin{array}{l}\frac{0}{0} \\
\frac{0}{0} \\
\frac{1}{0} \\
\frac{0}{\dot{d}} \\
\frac{0}{\infty}\end{array}$ & $\begin{array}{l}\bar{z} \\
2 \\
\underline{z} \\
\stackrel{x}{\sigma}\end{array}$ & 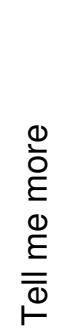 & 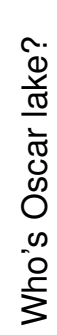 \\
\hline $\begin{array}{l}2.38 \text { The program } \\
\text { prevents learners from } \\
\text { repeating exercises, } \\
\text { therefore, minimizing } \\
\text { guessing. }\end{array}$ & 3 & 2 & 2 & 2 & 2 & 1 & 1 & 1 & 2 & 1 & 1 & 1 & 1 & 3 & 2 \\
\hline $\begin{array}{l}2.41 \text { The program } \\
\text { provides feedback for } \\
\text { both correct and } \\
\text { incorrect answers. }\end{array}$ & 2 & 1 & 2 & 3 & 2 & 1 & 1 & 1 & 1 & 1 & 1 & 1 & 2 & 4 & 1 \\
\hline $\begin{array}{l}2.42 \text { The program gives } \\
\text { learners the chance to } \\
\text { correct their errors. }\end{array}$ & 2 & 3 & 2 & 3 & 2 & 3 & 3 & 1 & 3 & 2 & 1 & 3 & 3 & 4 & 2 \\
\hline $\begin{array}{l}2.43 \text { The program } \\
\text { effectively signals the } \\
\text { mistakes before } \\
\text { providing the right } \\
\text { answers. }\end{array}$ & 2 & 3 & 1 & 1 & 2 & 1 & 2 & 2 & 2 & 2 & 1 & 2 & 1 & 3 & 1 \\
\hline $\begin{array}{l}2.44 \text { The program } \\
\text { effectively specifies } \\
\text { different types of errors, } \\
\text { such as differences } \\
\text { between a syntactic } \\
\text { error and an incorrect } \\
\text { word choice. }\end{array}$ & 1 & 0 & 0 & 0 & 2 & 0 & 0 & 1 & 0 & 1 & 0 & 0 & 0 & 1 & 0 \\
\hline
\end{tabular}


Ratings for the items related to how media technology differentiated feedback indicated that, although the programs were able to record and give feedback on the learners' writing, speech, and progress, they did not specify the different types of errors, for example, grammatical or usage (ratings for item 2.44 varied from 0 to 1 ). Also, with the exception of "Tell me More" and "ELLIS," the programs did not provide feedback for both correct and incorrect answers (item 2.41).

However, most programs provided learners the opportunity to correct their errors (item 2.42); with the exception of "Live Action" and "Rosetta Stone" (both rated 1), the programs provided learners with the chance to correct their errors (ratings varied from 2 to 4 ).

In items 2.38 (the program prevents learners from repeating exercises) and 2.43 (the program effectively signals the mistakes before providing the right answers), none of the programs obtained the highest rating (4). However, two programs, "Asterix" and "Tell me More" (both rated 3 in item 2.38), avoided having learners repeat an exercise over and over by prompting a help hyperlink after the learners' second trial. Also, the programs "Tell me More" and "Discoveries" (rated 3 in item 2.43) highlighted wrong answers before presenting the right ones, giving the learners an indication that there was something wrong with their answers. However, these programs did not specify the type of errors learners had made.

Table 10 shows the ratings for the item related to how the integration of different types of media facilitated learning. 
Table 10

Ratings for the Item Related to How the Integration of Different Types of Media Facilitated Learning

\begin{tabular}{|c|c|c|c|c|c|c|c|c|c|c|c|c|c|c|c|}
\hline Items & 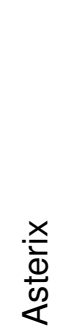 & 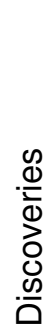 & 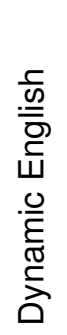 & $\stackrel{\varrho}{\vec{H}}$ & 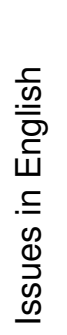 & 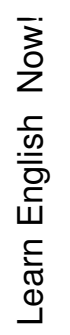 & 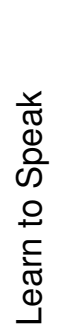 & 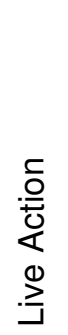 & 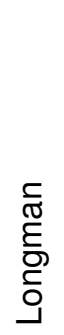 & 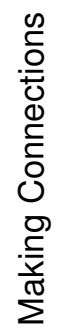 & 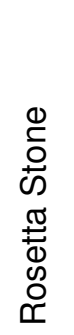 & $\begin{array}{l}\frac{0}{0} \\
\frac{0}{\infty} \\
\frac{1}{\alpha} \\
\frac{0}{\dot{d}} \\
\frac{0}{0} \\
\frac{0}{\infty}\end{array}$ & $\begin{array}{l}\bar{z} \\
0 \\
z \\
\bar{\Sigma} \\
\stackrel{\Xi}{-}\end{array}$ & 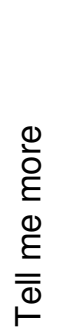 & 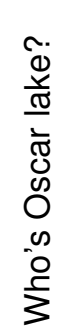 \\
\hline $\begin{array}{l}2.29 \text { Graphics aid } \\
\text { understanding. }\end{array}$ & 3 & 3 & 3 & 4 & 3 & 1 & 3 & 3 & 3 & 3 & 1 & 3 & 3 & 4 & 3 \\
\hline
\end{tabular}

The use of graphics to aid understanding (item 2.29) was rated high (ratings varied from 3 to 4) for all programs, except for "Learn English Now" and "Rosetta Stone," which were rated 1. In most programs, graphics were used to show word or sentence stress, the change of word order from statements to questions, subject-verb agreement, or meaning of words.

The results of the evaluation concerning how the ESL/EFL software programs incorporated technological features associated with individualization of instruction were based on the ratings obtained for the items related to the degree and type of individualization of instruction in the category of Media Attributes. These ratings are presented in Table 11. 
Table 11

Ratings for the Items Related to the Degree and Type of Individualization of Instruction

\begin{tabular}{|c|c|c|c|c|c|c|c|c|c|c|c|c|c|c|c|}
\hline Items & 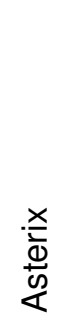 & 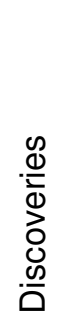 & 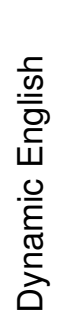 & $\frac{\mathscr{\omega}}{\vec{H}}$ & 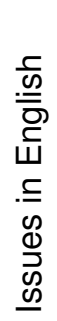 & 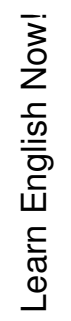 & 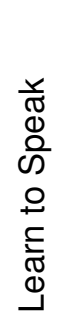 & 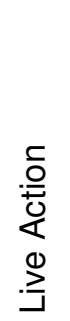 & 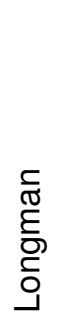 & 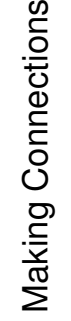 & 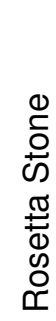 & 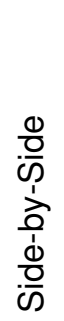 & 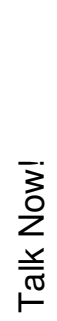 & 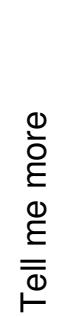 & 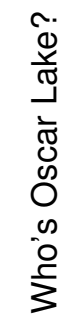 \\
\hline
\end{tabular}

2.30 The program allows for different routes and choices for learning.

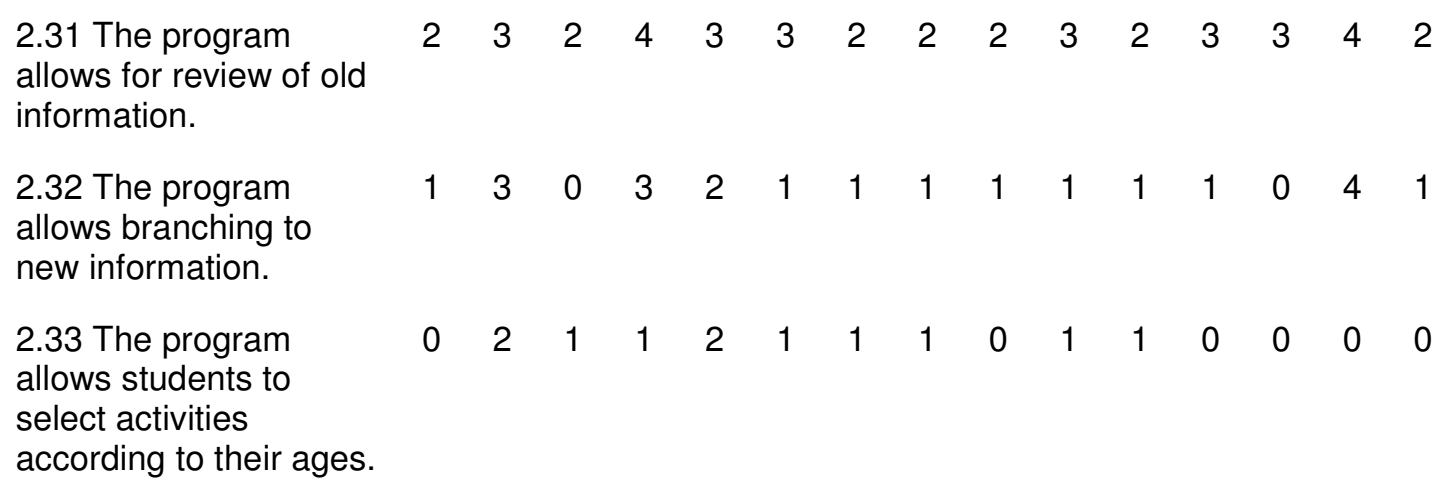

\subsection{The program} allows for review of old information.

2.36 The program adapts to the responses given by the learners, branching to more or less complicated questions as appropriate. allows learners to go through its content at their own pace and rhythm. 
The strongest feature related to individualization of instruction was the program's capability of allowing learners to go through the content at their own pace and rhythm; for item 2.37 eight out of the fifteen programs were rated 4 (maximum rating), six were rated 3 , and only one was rated 1 .

However, three other features associated with individualization of instruction were rated low for all the programs. The program's capability of adapting to the responses given by the learners (item 2.36) was not present at all in twelve programs (ratings $=0$ ), and was rated very low in three programs (ratings $=1$ ). The possibility of allowing learners to select activities according to their ages (item 2.33) and/or their learning styles (item 2.34) was also a feature not very well incorporated into the programs. These features were either not present at all in six programs (ratings $=0$ ), or rated 1 (very low) in seven programs. Only two programs - "Discoveries" and "Issues in English" - were rated 2 because they offered learners the choice to select the sequencing of the activities they were supposed to go through.

The ratings indicated two differentiating features of individualization of instruction among the programs. The first one was the program's capability of allowing branching to new information (item 2.32). One program - "Tell me More" - obtained the highest rating (4), two programs - "Discoveries" and "ELLIS" - were rated 3, and one program - "Issues in English" - was rated 2, while nine other programs were rated very low (1), and two programs - "Dynamic English" and "Talk Now!" - did not present this feature (0). The other differentiating feature was the program's capability of allowing students to select activities according to their interests (item 2.35). One program "Discoveries" - obtained the highest rating (4), two programs - "Learn English" and "Tell me More" - obtained a 3, five programs were rated 2, three programs were rated 1 , and four programs were rated 0.

The ratings for features such as allowing for different routes and choices for 
learning (item 2.30), and allowing for review of old information (item 2.31) had a wide range: from 1 to 4 (item 2.30), and from 2 to 4 (item 2.31). Two programs - "Tell me More" and "ELLIS" - were both rated 4 for the two items. "Discoveries" was rated 4 for item 2.30 and rated 3 for item 2.31. Three programs - "Issues in English," "Learn English," and "Talk Now!" - were rated 3 for both items. The ratings for the other programs varied from 1 to 2 .

Since one of the questions in this study addressed how the incorporation of technological features allowed for individualization of instruction, the ratings for the items related to the program's degree and type of individualized instruction were added and the percentage of the possible maximum rating was calculated. The results are presented in Table 12.

Table 12

Total Ratings for the Items Related to the Programs' Degree and Type of Individualization of Instruction (totals and percentages of possible maximum rating for these items)

\begin{tabular}{lc}
\hline \multicolumn{1}{c}{ Programs } & $\begin{array}{c}\text { Individualization of Instruction } \\
\text { Features }\end{array}$ \\
\hline Discoveries & $23(71.87 \%)$ \\
Tell me More & $19(59.37 \%)$ \\
Ellis & $18(56.25 \%)$ \\
Issues in English & $18(56.25 \%)$ \\
Learn English Now! & $16(50 \%)$ \\
Live Action & $13(40.62 \%)$ \\
Making Connections & $13(40.62 \%)$ \\
Learn to Speak English & $12(37.5 \%)$ \\
Longman English Interactive & $11(34.37 \%)$ \\
Rosetta Stone & $10(31.25 \%)$ \\
Talk Now! & $10(31.25 \%)$
\end{tabular}


Side-By-Side

Who's Oscar Lake?

Dynamic English

Asterix
$9(28.12 \%)$

$9(28.12 \%)$

$8(25 \%)$

$7(21.87 \%)$

The results indicated that most programs displayed less than half of the possible features associated with individualization of instruction. Only one program, "English Discoveries" (71.87\%), was rated above $70 \%$ for the items related to how the programs allowed for individualized instruction, while four other programs were rated above 50\% for these items - "ELLIS", rated 56.25\%," Issues in English", rated 56.25\%, "Learn English Now, rated 50\%, " and "Tell me More”, rated 59.37\%. All the other ten programs were rated below $50 \%$.

In order to make an overall analysis of the Media Attributes of the programs, each program's ratings for all the items in this category were added and the percentage of the possible maximum rating for the category was calculated. Table 13 shows the overall ratings of the programs for the category of Media Attributes.

\section{Table 13}

Overall Ratings for the Category of Media Attributes of the Programs (totals and percentages of possible maximum rating for the category)

\begin{tabular}{lc}
\hline \multicolumn{1}{c}{ Programs } & Media Attributes \\
\hline Tell me More & $46(71.87 \%)$ \\
Discoveries & $43(67.18 \%)$ \\
ELLIS & $39(60.93 \%)$ \\
Issues in English & $35(54.68 \%)$ \\
Learn English Now! & $28(43.75 \%)$ \\
Making Connections & $28(43.75 \%)$
\end{tabular}


Longman English Interactive

Live Action

Asterix

Talk Now!

Learn to Speak English

Dynamic English

Rosetta Stone

Side-By-Side

Who's Oscar Lake?
$27(42.18 \%)$

$26(40.62 \%)$

$25(39.68 \%)$

$25(39.68 \%)$

$24(37.5 \%)$

$22(34.37 \%)$

$21(32.81 \%)$

$20(31.25 \%)$

$20(31.25 \%)$

"Tell me More" was the program that obtained the highest overall rating for the category of Media Attributes (71.87\%). It was also the only program rated above $70 \%$. "English Discoveries" came next with $67.18 \%$, followed by "ELLIS" with $60.93 \%$, which was followed by "Issues in English" with $54.68 \%$. The other programs were rated below $50 \%$, which indicates that the media attributes of these programs need to be improved.

In summary, the analysis of the media attributes of the ESL/EFL software programs indicated that the evaluated ESL/EFL software programs simply carried out what computers do best. Computers, being binary machines, were programmed to cue human input and to respond given a limited set of rules or criteria. Few programs reflected attempts to incorporate the goals and procedures involved in the interactive approach to computer use for language learning.

The evaluation of the incorporation of the technological features by the ESL/EFL programs was also based on the ratings for these programs in the category of User-friendly Attributes. The items in the User-friendly Attributes relate to how the program is perceived as attractive, easy to follow, and/or motivating to learners and teachers. The user-friendly attributes include: how the use of the program is made easy for learners (Items 3.45, 3.46, 3.47, 3.50, 3.51 and 3.55), how attractive the 
media technology makes the program (Items 3.58, 3.49 and 3.52), and how the program motivates learning (Items 3.53 and 3.54).

Table 14 below shows the ratings for the items related to how the use of the programs was made easy for learners.

\section{Table 14}

Ratings for the Items Related to How the Use of the Program is Made Easy for Learners

\begin{tabular}{|c|c|c|c|c|c|c|c|c|c|c|c|c|c|c|c|}
\hline Items & $\frac{\stackrel{x}{\frac{x}{d}}}{\frac{10}{4}}$ & 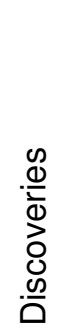 & 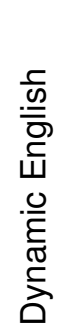 & $\begin{array}{l}\frac{\varrho}{J} \\
\vec{\Psi}\end{array}$ & 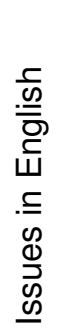 & 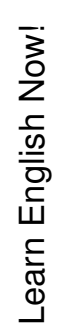 & 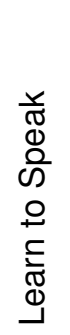 & 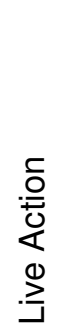 & 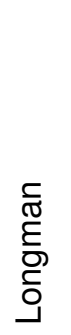 & 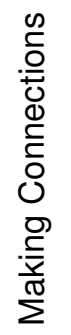 & 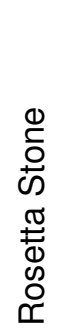 & $\begin{array}{l}\frac{0}{0} \\
\frac{0}{0} \\
\frac{1}{2} \\
\frac{0}{\dot{d}} \\
\frac{0}{0} \\
\text { की }\end{array}$ & $\begin{array}{l}\bar{z} \\
0 \\
z \\
\text { I } \\
\vdash\end{array}$ & 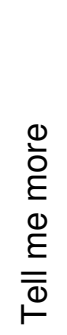 & 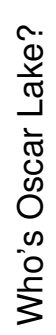 \\
\hline $\begin{array}{l}3.45 \text { Menu items are } \\
\text { understandable and } \\
\text { descriptive. }\end{array}$ & 2 & 1 & 3 & 4 & 3 & 3 & 2 & 1 & 4 & 3 & 2 & 4 & 3 & 2 & 2 \\
\hline $\begin{array}{l}3.46 \text { The commands } \\
\text { and instructions for } \\
\text { the activities are clear } \\
\text { and objective. }\end{array}$ & 2 & 2 & 3 & 3 & 3 & 3 & 2 & 1 & 4 & 3 & 2 & 4 & 3 & 2 & 2 \\
\hline $\begin{array}{l}3.47 \text { The program } \\
\text { gives the learners } \\
\text { effective clues to } \\
\text { clarify their doubts } \\
\text { about its use. }\end{array}$ & 2 & 1 & 3 & 4 & 3 & 2 & 2 & 2 & 3 & 2 & 2 & 3 & 2 & 2 & 1 \\
\hline $\begin{array}{l}3.50 \text { Icons, buttons } \\
\text { and menus allow } \\
\text { learners to readily } \\
\text { search for additional } \\
\text { information while } \\
\text { doing an activity. }\end{array}$ & 2 & 1 & 2 & 4 & 2 & 3 & 2 & 2 & 3 & 3 & 1 & 1 & 2 & 2 & 0 \\
\hline $\begin{array}{l}3.51 \text { Buttons, icons or } \\
\text { menu items make } \\
\text { Help or Hint-type } \\
\text { options } \\
\text { accessible. }\end{array}$ & 2 & 2 & 2 & 4 & 3 & 3 & 2 & 2 & 3 & 3 & 1 & 1 & 3 & 2 & 1 \\
\hline
\end{tabular}




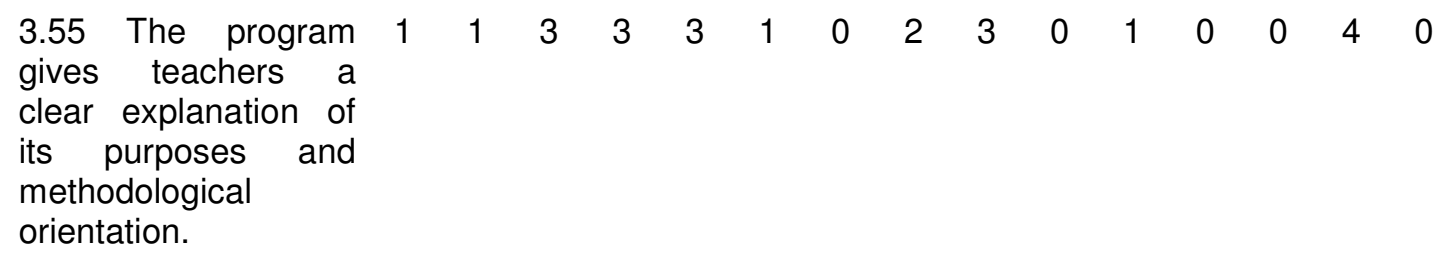

Interestingly, the two highest-rated programs in the category of Media Attributes - "Tell me More" and "Discoveries" - had low ratings for the items related to how the use of the program is made easy for learners. With the exception of item 3.55 , for all the other items related to how the use of the program is made easy for learners, these two programs were rated either 1 or 2 . Because the features in the Media Attributes were more sophisticated in the two programs, their use became more complicated and less clear to the user. Menu items were cluttered (item 3.45), commands and instructions were not clear (item 3.46), and users were not oriented as to how to go through the programs and their features (item 3.47). The use of text and graphic/animation (item 3.48), instead of making a particular point clear, was sometimes overwhelming and distracting. To counterbalance these poor user-friendly attributes, "Tell me More" came with documentation (in both hard copy and on the screen) which offered teachers a clear explanation of its purposes and gave them methodological orientation (item 3.55). Five programs - "Learn to Speak English," "Making Connections," "Side-by-Side," "Talk Now," and "Who's Oscar Lake?" (rated 0 in item 3.55) - came with no orientation to their use, while "Asterix," Discoveries," "Learn English," and "Rosetta Stone" (rated 1 in item 3.55) presented a very brief orientation on screen only.

Although "ELLIS" and "Longman Interactive" displayed the best ratings (rated either 3 or 4 ) in all the items related to how the use of the program is made easy for users, these two programs were neither rated very high nor very low in their Media 
Attributes. Results indicated that the programs were not able to manage being both rich in media attributes and user-friendly to the same degree.

Table 15 shows the ratings for the items related to how attractive the media technology made the programs.

\section{Table 15}

Ratings for the Items Related to How Attractive the Media Technology Made the Programs

\begin{tabular}{|c|c|c|c|c|c|c|c|c|c|c|c|c|c|c|c|}
\hline Items & $\frac{\frac{x}{\bar{d}}}{\frac{0}{20}}$ & 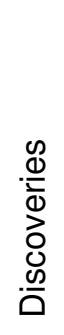 & 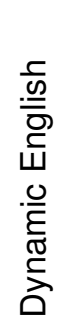 & 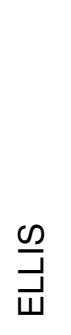 & 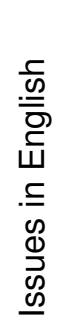 & 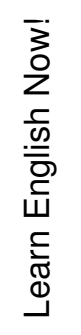 & 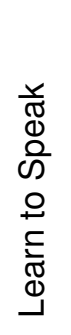 & 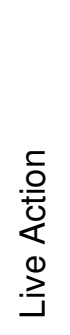 & 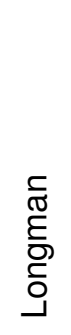 & 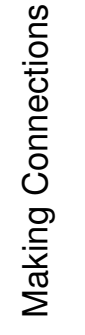 & 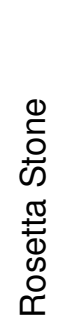 & $\begin{array}{l}\frac{0}{0} \\
\frac{0}{\infty} \\
\frac{1}{0} \\
\frac{1}{0} \\
\frac{0}{\infty} \\
\frac{0}{\infty}\end{array}$ & $\begin{array}{l}\bar{z} \\
0 \\
z \\
\frac{x}{\sigma}\end{array}$ & 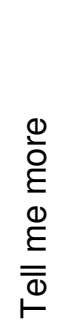 & 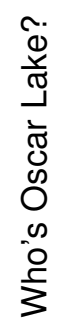 \\
\hline $\begin{array}{l}3.48 \text { Each screen } \\
\text { uses text and } \\
\text { graphic/animation to } \\
\text { make a particular } \\
\text { teaching point clear. }\end{array}$ & 2 & 2 & 3 & 4 & 3 & 1 & 2 & 3 & 3 & 2 & 2 & 3 & 3 & 3 & 2 \\
\hline $\begin{array}{l}3.49 \text { The program is } \\
\text { effectively integrated } \\
\text { with other technological } \\
\text { resources (such as } \\
\text { dictionaries on the web, } \\
\text { grammar on line, etc) } \\
\text { as the learner uses it. }\end{array}$ & 1 & 3 & 0 & 2 & 2 & 0 & 2 & 1 & 1 & 0 & 0 & 0 & 0 & 3 & 1 \\
\hline $\begin{array}{l}3.52 \text { The program } \\
\text { arouses sensory and } \\
\text { cognitive curiosity. }\end{array}$ & 3 & 3 & 3 & 4 & 3 & 2 & 2 & 2 & 3 & 2 & 1 & 2 & 2 & 4 & 3 \\
\hline
\end{tabular}

Ratings for item 3.48 indicated that the programs were quite effective in using text and graphic/animation to make a particular teaching point clear. Most programs were able to use both their graphical environment to cue the user to make a choice or to do something, and to respond according to what the user did. "ELLIS" was the program that displayed the most sophisticated visuals and possibilities for screen 
manipulations (rated 4 in item 3.48). In most programs, for example, highlights or camera focusing (in videos) were used to signal the learner's turn to respond. Ratings also indicated a relationship between the programs' ability to use text and graphics to make a particular point clear (item 3.48) and their ability to arouse sensory and cognitive curiosity (item 3.52). There was a close similarity between the ratings for these two items in most programs.

Although hypermedia (links to various media such as text, sound, image, animation and/or video) and multimedia (use of a variety of media as a mode of presentation) can be considered the special features of software programs that give them the potential to offer something different (if not better) than traditional teaching and learning materials, ratings for item 3.49, when contrasted to the ratings for item 3.48 , indicated some disparity between the way programs made use of multimedia (item 3.48) and the way programs made use of hypermedia (item 3.49). Whereas most programs were rated relatively high in item 3.48, they were rated relatively low in item 3.49. Except for two programs, "Tell me More" and "Discoveries" (rated 3 in item 3.49), all others were rated between 0 and 2 in the way they effectively integrated with other technological resources.

The last two features within the User-friendly Attributes are related to how the programs motivated learning. Ratings for these features are presented in Table 16. 
Table 16

Ratings for the Items Related to How the Programs Motivate Learning

\begin{tabular}{|c|c|c|c|c|c|c|c|c|c|c|c|c|c|c|c|}
\hline Items & 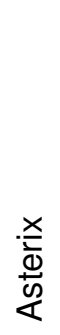 & 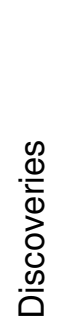 & 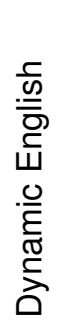 & $\frac{\varrho}{\vec{H}}$ & 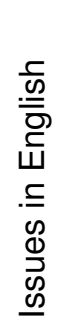 & 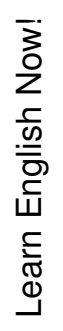 & 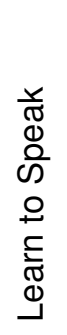 & 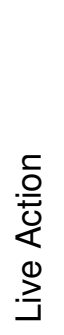 & 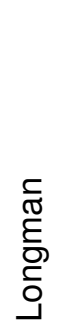 & 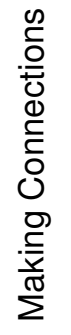 & 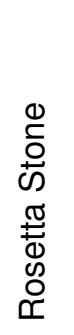 & 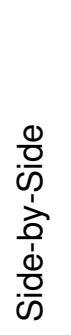 & 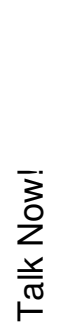 & 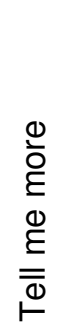 & 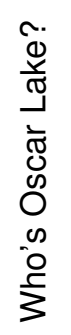 \\
\hline $\begin{array}{l}3.53 \text { The program } \\
\text { maintains attention } \\
\text { throughout the lesson. }\end{array}$ & 2 & 3 & 2 & 4 & 3 & 2 & 2 & 2 & 3 & 2 & 1 & 2 & 2 & 4 & 1 \\
\hline $\begin{array}{l}3.54 \text { The use of } \\
\text { animation invites } \\
\text { learners' reaction or } \\
\text { input. }\end{array}$ & 2 & 2 & 2 & 3 & 3 & 1 & 2 & 2 & 3 & 2 & 1 & 2 & 2 & 4 & 2 \\
\hline
\end{tabular}

As the ratings for item 3.53 indicated, only five programs (rated between 3 and 4) were capable of maintaining good levels of attention throughout the lesson. In eight other programs (rated 2) attention seemed to fade away as the activities became repetitive. Two programs (rated 1) were not able to maintain attention right from the beginning of the lesson either because of its poor use of multimedia integration, drill type of activities, and repetition ("Rosetta Stone"), or due to the lack of hints or clues to help learners move through its content (“Who's Oscar Lake?").

The similarity between the ratings for item 3.54 (Table 16) and for item 3.52 (Table 15) indicated a relationship between the programs' ability to arouse sensory and cognitive curiosity (item 3.52) and their ability to invite learners' reaction or input (item 3.54). Nine programs obtained the same ratings for these two items, while the others were rated a little lower for item 3.54 .

In order to make an overall analysis of the User-friendly Attributes of the programs, each program's ratings for all the items in this category were added, and the 
percentage of the maximum possible rating for the category was calculated. Table 17 shows the overall ratings for each program for the category of User-friendly Attributes.

Table 17

Overall Ratings for the Category of User-friendly Attributes (totals and percentages of possible maximum rating for each category)

\begin{tabular}{lc}
\hline Programs & User-friendly Attributes \\
\hline ELLIS & $39(88.63 \%)$ \\
Tell me More & $33(75 \%)$ \\
Longman English Interactive & $31(70.45 \%)$ \\
Issues in English & $26(59.09 \%)$ \\
Dynamic English & $22(50 \%)$ \\
Making Connections & $22(50 \%)$ \\
Side-By-Side & $22(50 \%)$ \\
Talk Now & $21(47.72 \%)$ \\
Asterix & $21(47.72 \%)$ \\
Discoveries & $21(47.72 \%)$ \\
Learn English Now! & $20(45.45 \%)$ \\
Learn to Speak English & $20(45.45 \%)$ \\
Live Action & $15(34.1 \%)$ \\
Who's Oscar Lake? & $141.81 \%)$ \\
Rosetta Stone & \\
\hline
\end{tabular}

"ELLIS" obtained the highest overall rating for the category of User-friendly Attributes $-88.63 \%$. "Tell me More" was rated $77.27 \%$ for this category, "Longman English Interactive" was rated 75\%, and "Issues in English" was rated 70.45\%. All the 
other programs were rated below 60\%. "Dynamic English" was rated 59.09\%, and "Side-by-Side," "Making Connections," and "Talk Now" were all rated 50\%. The other programs' overall rating - below $50 \%$ of the possible total - indicated that these programs need to be changed if their interface is be more user-friendly.

In order to analyze how the ESL/EFL software programs incorporated the technological features associated with an interactive CALL model, the ratings for the category of Media Attributes and the ratings for the category of User-Friendly Attributes were added together and the percentage of the total maximum rating for these two categories together was calculated. The results are presented in Table 18.

\section{Table 18}

Ratings for the Categories of Media Attributes and User-Friendly Attributes and Total Rating for these Categories Together (totals and percentages of possible maximum rating for the categories together)

\begin{tabular}{lccc}
\hline Programs & $\begin{array}{c}\text { Ratings for } \\
\text { Media } \\
\text { Attributes }\end{array}$ & $\begin{array}{c}\text { Ratings for } \\
\text { User-friendly } \\
\text { Attributes }\end{array}$ & Total Rating \\
\hline Tell me More & 46 & 34 & $80(74.07 \%)$ \\
Ellis & 39 & 39 & $78(72.22 \%)$ \\
Issues in English & 35 & 31 & $76(70.37 \%)$ \\
Discoveries & 43 & 21 & $64(59.25 \%)$ \\
Longman English Interactive & 27 & 33 & $60(55.55 \%)$ \\
Making Connections & 28 & 22 & $50(46.29 \%)$ \\
Learn English Now! & 28 & 21 & $49(45.37 \%)$ \\
Dynamic English & 22 & 26 & $48(44.44 \%)$ \\
Talk Now! & 25 & 22 & $47(43.52 \%)$ \\
Asterix & 25 & 21 & $46(42.59 \%)$ \\
Live Action & 26 & 20 & $46(42.59 \%)$ \\
Learn to Speak English & 24 & 20 & $44(40.74 \%)$ \\
Side-By-Side & 20 & 22 & $42(38.88 \%)$ \\
\hline
\end{tabular}




\begin{tabular}{llcc}
\hline Rosetta Stone & 21 & 14 & $35(32.40 \%)$ \\
Who's Oscar Lake? & 20 & 15 & $35(32.40)$
\end{tabular}

The overall rating for the categories of Media Attributes and User-Friendly Attributes together indicated that only three programs were rated higher than $70 \%$ "Tell me More," rated $74.07 \%$ for the two categories together, "ELLIS," rated 72.22 for the two categories together, and "Issues in English", rated 70.32\% for the two categories together. Two other programs were rated above $50 \%$ for the categories together - "Discoveries" (59.25\%) and "Longman English Interactive" (55.55\%). All other programs were rated below $50 \%$ for the categories together. The results indicated that most analyzed ESL/EFL software programs did not incorporate many of the technological features associated with an interactive CALL model.

Analysis of the Incorporation of the Principles of Communicative Language Learning by the ESL/EFL Software Programs

In the evaluation of the incorporation of the principles of Communicative Language Teaching by the ESL/EFL software programs, the ratings obtained by the programs in the category of Instructional Attributes were analyzed. These Instructional Attributes include: the theory of language learning and teaching that underlies the program (Items 1.6, 1.7, 1.8, 1.9, 1.10,1.11, and 1.12), how content is presented and sequenced (Items $1.13,1.14,1.15,1.16,1.17,1.18$, and 1.19), the type and quality of language-learning activities (Items 1.20, 1.21, 1.22, 1.23, and 1.24), the type of feedback provided (Items 1.25, 1.26, 1.27 and 1.28), and how the program facilitates learning (Items 1.1, 1.2, 1.3, 1.4and 1.5).

The ratings for the items related to the theory of language learning and teaching that underlies the programs are reported in Table 19. 
Ratings for the Items Related to the Theory of Language Learning and Teaching that Underlies the Programs

\begin{tabular}{|c|c|c|c|c|c|c|c|c|c|c|c|c|c|c|c|}
\hline Items & 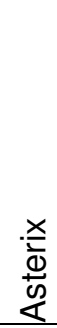 & 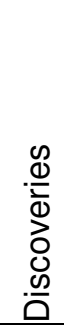 & 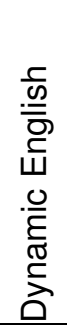 & $\frac{\mathscr{\omega}}{\vec{H}}$ & 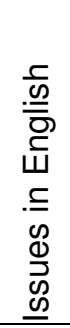 & 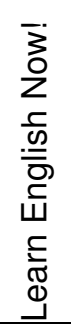 & 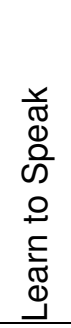 & 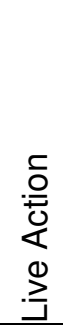 & 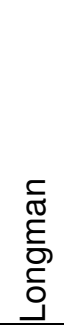 & 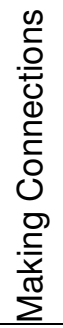 & 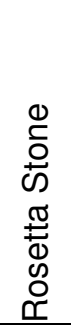 & $\begin{array}{l}\frac{0}{0} \\
\frac{0}{0} \\
\frac{1}{2} \\
\frac{1}{0} \\
\frac{0}{0} \\
\frac{0}{\infty}\end{array}$ & 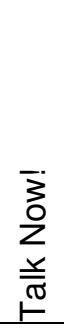 & 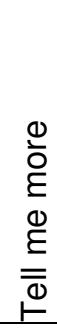 & 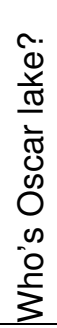 \\
\hline $\begin{array}{l}\text { 1.6 The program makes } \\
\text { use of authentic texts and } \\
\text { other realia. }\end{array}$ & 2 & 3 & 2 & 4 & 3 & 2 & 2 & 2 & 4 & 1 & 1 & 3 & 1 & 4 & 4 \\
\hline $\begin{array}{l}1.7 \text { The program integrates } \\
\text { information about } \\
\text { culture/daily situations into } \\
\text { the presentations and } \\
\text { activities. }\end{array}$ & 2 & 3 & 1 & 4 & 4 & 4 & 3 & 1 & 4 & 1 & 1 & 3 & 1 & 4 & 4 \\
\hline $\begin{array}{l}1.8 \text { Lessons present and } \\
\text { practice language } \\
\text { structures in meaningful } \\
\text { communicative contexts. }\end{array}$ & 2 & 3 & 1 & 4 & 4 & 2 & 3 & 2 & 4 & 1 & 1 & 3 & 1 & 4 & 4 \\
\hline $\begin{array}{l}1.9 \text { Lessons present and } \\
\text { practice vocabulary in } \\
\text { meaningful communicative } \\
\text { contexts. }\end{array}$ & 2 & 3 & 1 & 4 & 4 & 2 & 3 & 2 & 4 & 1 & 1 & 3 & 1 & 4 & 4 \\
\hline $\begin{array}{l}\text { 1.10 Lessons develop the } \\
\text { communicative skills the } \\
\text { program aims to develop. }\end{array}$ & 2 & 3 & 2 & 3 & 3 & 2 & 2 & 2 & 3 & 2 & 1 & 2 & 1 & 4 & 3 \\
\hline $\begin{array}{l}1.11 \text { Lessons develop the } \\
\text { level of language } \\
\text { proficiency the program } \\
\text { aims to develop. }\end{array}$ & 2 & 3 & 2 & 3 & 3 & 3 & 2 & 2 & 3 & 2 & 1 & 2 & 2 & 4 & 2 \\
\hline $\begin{array}{l}1.12 \text { The course syllabus } \\
\text { reflects a communicative } \\
\text { approach to language } \\
\text { teaching/learning. }\end{array}$ & 2 & 3 & 2 & 4 & 3 & 2 & 3 & 2 & 3 & 1 & 1 & 3 & 1 & 3 & 3 \\
\hline
\end{tabular}

"Tell me More" obtained the highest ratings for the items related to the theory of language learning and teaching underlying the program, while "Rosetta Stone" obtained the lowest. 
The programs "Tell me More," "ELLIS," “Longman," and "Who's Oscar Lake?" were rated as the ones making the best use of authentic texts and other realia (all rated 4 in item 1.6). "Rosetta Stone," "Making Connections," and "Talk Now" were rated 1 for this item, because their presentations and activities did not reflect authentic contexts of language interactions. "Dynamic English" was rated 2 in item 1.6, since in the video interactions the close-up facial recordings of people having a conversation did not portray authentic interactions between real people. "Live Action," based on the Total Physical Response Approach, was also rated 2 for the same item, because all the activities involved commands and physical responses, which limited other types of real life language input for learners; consequently the material could not be considered very authentic. "Asterix" was also rated 2 in item 1.6 since a whole program based on a cartoon story does not reflect the variety of everyday contexts. "Learn English" was also rated 2 in this item because of its limited scope of contents - all based on traveling situations.

The programs "Tell me More”, “ELLIS”, "Longman,” "Learn English”, "Issues in English," and "Who's Oscar Lake?" integrated relevant information about culture and daily situations in hyperlink notes into the presentations and activities (all rated 4 in item 1.7). There was very little integration of cultural information in "Dynamic English," "Live Action," "Making Connections," "Talk Now," and "Rosetta Stone" (the five programs were rated 1 in item 1.7). "Discoveries," "Learn to Speak English," and "Sideby-Side" integrated cultural information into some of their presentations and activities (these three programs were rated 3).

In all programs, ratings for items 1.8 were the same as for item 1.9 - the quality of the presentations and practices of language structures (item 1.8) was the same as the quality of the presentations and practices of vocabulary (item 1.9). The lessons in "Tell me More," "ELLIS," "Issues in English”, "Who's Oscar Lake," and "Longman" 
presented and practiced vocabulary (item 1.9) and language structures (item 1.8) in very meaningful communicative contexts, e.g., showing interactions among people in daily situations, and that is why the three programs were rated 4 in items 1.8 and 1.9. However, the contexts of presentations and practices of the structures and vocabulary in "Rosetta Stone," "Making Connections," "Talk Now," and "Dynamic English" were either not very meaningful or not very communicative, and therefore these programs were rated 1 in items 1.8 and 1.9. In these programs, vocabulary and language structures were presented detached from any context. "Live Action" was rated 2 for items 1.8 and 1.9 because its approach to presenting and practicing vocabulary and language structures always in contexts that allowed for a Total Physical Response was not very meaningful and communicative. Rather, it was restricted to contexts which would allow for a physical response only. "Asterix" was also rated 2 since its approach to present and practice vocabulary and structures was limited to those contexts of the cartoon story on which the program was based. In "Learn English Now" the contexts for vocabulary and structure presentations and practice were only those found in traveling situations; this program was therefore also rated two.

Again, the ratings obtained for item 1.10 were the same as the ratings for item 1.11 in almost all programs (except for "Who's Oscar Lake," "Talk Now," and "Learn English Now"), and these ratings were also very close to the ratings for items 1.8 and 1.9. According to the principles of Communicative Language Teaching, communicative skills need to be developed (item 1.10) in order to achieve language competence (item 1.11), and for this to happen language structures (item 1.8) and vocabulary (item 1.9) have to be presented and practiced in meaningful communicative contexts. Therefore, the more the programs presented and practiced language structures and vocabulary in meaningful communicative contexts the more the programs could develop communicative skills and language competence. "Tell me More," rated for 4 for items 
1.8 and 1.9, was also rated 4 for items 1.10 and 1.11, "ELLIS" and "Longman," although rated 4 for items 1.8 and 1.9 , were rated 3 for items 1.10 and 1.11 , because they failed to allow for improvisation and unpredictability. They did not provide for open response (without following a script), yet true communicative competence is very rarely fully achieved without one being submitted to interact in unpredictable and unexpected contexts. On the other hand, "Dynamic English," rated 1 for items 1.8 and 1.9, was rated 2 (still not high) for items 1.10 and 1.11. In this program the context of the presentations and practices were not very communicative and meaningful, but the sequencing and structuring of the program was organized well enough to allow for the development of llinguistic proficiency (though not true communicative competence). For items 1.10 and 1.11, "Discoveries" was rated 3, "Learn to Speak English," "Live Action," "Making Connections" and "Side by Side" were rated 2, and "Rosetta Stone" was rated 1. "Who's Oscar Lake" was rated 3 for item 1.10 and 2 for item 1.11, "Talk Now" was rated 1 for item 1.10 and 2 for item 1.11, and "Learn English" was rated 2 for item 1.10 and 3 for item 1.11. Although not exactly the same, the ratings for items 1.10 and 1.11 in these three programs were very close.

For item 1.12, "ELLIS" was the only program rated 4 . The overall organization of this program was evaluated as the one that best reflected a communicative approach to language teaching and learning. Although the course syllabi of programs such as "Tell me More," "Discoveries," "Longman," "Learn to Speak English," "Issues in English," "Who's Oscar Lake," and "Side-by-Side" reflected a communicative approach to language learning in most of their sections, they failed in others. "Dynamic English," "Asterix," "Learn English" and "Live Action", rated 2 for item 1.12, need to undergo considerable changes in their syllabi so that they can be more in accordance with Communicative Language Teaching . "Making Connections," "Rosetta Stone," and 
"Talk Now" were rated 1 on this item for failing to comply with the principles of the Communicative Language Teaching.

Table 20 shows the ratings for the items related to how content was presented and sequenced.

Table 20

Ratings for the Items Related to How Content is Presented and Sequenced

\begin{tabular}{|c|c|c|c|c|c|c|c|c|c|c|c|c|c|c|c|}
\hline Items & $\frac{\frac{x}{d}}{\frac{1}{4}}$ & 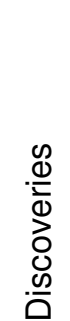 & 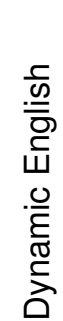 & $\frac{\mathscr{\omega}}{\vec{H}}$ & 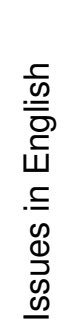 & 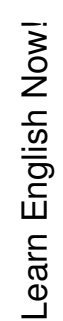 & 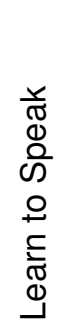 & 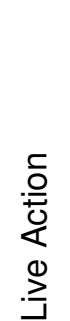 & 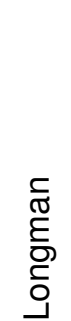 & 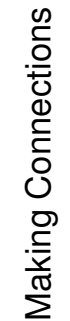 & 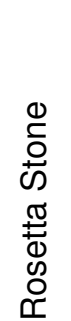 & 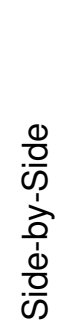 & 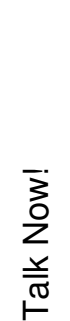 & 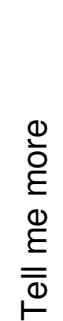 & 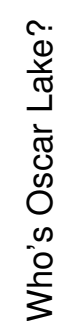 \\
\hline $\begin{array}{l}1.13 \text { Content selection is } \\
\text { determined by communicative } \\
\text { skills and/or themes. }\end{array}$ & 3 & 4 & 2 & 4 & 3 & 3 & 3 & 2 & 4 & 2 & 1 & 3 & 1 & 4 & 4 \\
\hline $\begin{array}{l}\text { 1.14 Content is sequenced } \\
\text { from simple communicative } \\
\text { functions, such as introducing } \\
\text { oneself, greeting, etc, to } \\
\text { complex ones, such as stating } \\
\text { an opinion, disagreeing, etc. }\end{array}$ & 2 & 2 & 2 & 4 & 2 & 3 & 3 & 2 & 4 & 2 & 1 & 3 & 2 & 4 & 1 \\
\hline $\begin{array}{l}1.15 \text { Content is presented } \\
\text { communicatively. }\end{array}$ & 2 & 3 & 2 & 4 & 3 & 2 & 3 & 3 & 4 & 1 & 1 & 2 & 1 & 4 & 4 \\
\hline $\begin{array}{l}1.16 \text { The program develops } \\
\text { the content at appropriate } \\
\text { levels of linguistic proficiency. }\end{array}$ & 2 & 3 & 4 & 4 & 2 & 3 & 3 & 2 & 3 & 2 & 1 & 3 & 2 & 4 & 2 \\
\hline $\begin{array}{l}1.17 \text { The program content is } \\
\text { educationally relevant and } \\
\text { interesting for the learner. }\end{array}$ & 3 & 3 & 2 & 4 & 3 & 3 & 3 & 3 & 4 & 2 & 1 & 2 & 2 & 4 & 3 \\
\hline $\begin{array}{l}1.18 \text { The program content is } \\
\text { appropriate for intended } \\
\text { learners. }\end{array}$ & 3 & 3 & 2 & 4 & 3 & 3 & 3 & 3 & 4 & 2 & 1 & 3 & 3 & 4 & 4 \\
\hline $\begin{array}{l}1.19 \text { The program content is } \\
\text { applicable to real life contexts. }\end{array}$ & 2 & 3 & 2 & 4 & 3 & 3 & 3 & 3 & 4 & 2 & 1 & 3 & 2 & 4 & 4 \\
\hline
\end{tabular}

For the programs "Tell me More," "Discoveries," "ELLIS," "Longman," and "Who's Oscar Lake," content selection was determined by communicative skills and/or themes (these four programs were rated 4 in item 1.13). In "Asterix, "Learn English,” 
"Learn to Speak English" and "Side-by-Side" (rated 3 for item 1.13), although the content sequence was based on the structures of the language, it was still guided by communicative skills. "Dynamic English," "Live Action," and "Making Connections" (rated 2 for item 1.13) attempted to select content based on communicative skills, but these communicative skills followed a very structured sequence and organization unlike authentic communication. "Rosetta Stone," and "Talk Now" were rated 1 for item 1.13 since their content was selected to present and practice the structures, and not the skills of the language.

Sequencing content from simple communicative functions to complex ones (item 1.14), e.g., from greetings and introductions to agreeing or disagreeing with a point of view, was evident in "Tell me More," "ELLIS," and "Longman" (rated 4 for item 1.14). In "Dynamic English," "Issues in English,“"Live Action," "Making Connections," and "Talk Now" sequencing was more strongly guided by levels of language structure complexity (these programs were rated 2 for item 1.14). In these programs, word and language structure choices were clearly based on linguistic complexity since many of the communicative contexts in which vocabulary and grammar were introduced and practiced deliberately did not include other ways of performing the same communicative functions. These other ways would use more complex language structures or less common words. "Asterix" and "Discoveries" were also rated 2 for item 1.14, because "Asterix's" cartoon-like approach and "Discoveries" open approach mode did not provide any kind of complexity sequencing, leaving it for the learners to choose their own learning paths. "Learn English," "Learn to Speak English," and "Sideby-Side" were rated 3 for item 1.14, since their content sequencing did not lead learners to develop higher levels of communicative functions, even though the more basic communicative functions were sequenced according to communicative complexity. Content sequencing in "Rosetta Stone" (rated 1) was clearly determined by 
grammatical complexity only. "Who's Oscar Lake" was also rated 1 in item 1.14 because the program did not follow any content sequencing, but that of game playing.

Ratings for item 1.15 (content is presented communicatively) were closely related to the ratings for items 1.8 and 1.9 (lessons present and practice language structures [1.8] and vocabulary [1.9] in meaningful communicative contexts). "Tell me More," "ELLIS," "Who's Oscar Lake," and "Longman,” rated 4 for items 1.8 and 1.9, were also rated 4 for item 1.15. "Discoveries" and "Learn to Speak English," rated 3 for items 1.8 and 1.9, were also rated 3 for item 1.15. "Making Connections," "Side-bySide," and "Talk Now," rated 1 for items 1.8 and 1.9, were also rated 1 for item 1.15. "Asterix" was rated 2 for items 1.8, 1.9, and 1.15 because all contexts in the program (for content, vocabulary and structure presentations and practices) were restricted to those of the cartoon stories. However, "Dynamic English," rated 1 for items 1.8 and 1.9, was rated a little higher for item 1.15 (rated = 2). "Live Action," rated 2 for items 1.8 and 1.9, was also rated a little higher for item 1.15 (rated = 3). In "Dynamic English" the contexts of presentations and practices (video interactions between the static close-up facial recordings of people) were not considered communicative or very meaningful. Nevertheless, there was an attempt to present the content in communicative situations ('people' interacting with one another). In "Live Action," although the contexts of presentations and practices of the structures and vocabulary were neither very meaningful nor very communicative, the presentation of the content was not completely decontextualized. On the other hand, in "Side-by-Side" (rated 3 for items 1.8 and 1.9, and 2 for item 1.15), while the videos of interaction among real people provided communicative and meaningful contexts, the strong structural organization of the content avoided its presentation in a true communicative approach. Also, in "Issues in English" (rated 4 in items 1.8 and 1.9 and three in item 1.15), the content is presented 
communicatively (item 1.15), but there is very little specific vocabulary and structure presentation and practice (items 1.8 and 1.9).

In analyzing how the programs developed content at appropriate levels of language proficiency (item 1.16), it is necessary to point out that language proficiency is usually related to the domains of the vocabulary and structure of a language, defined by Canale and Swain (1980) as grammatical competence, as opposed to language competence, defined by Canale and Swain (1980) as communicative competence. Therefore, it is possible to develop grammatical competence (language proficiency) without necessarily developing communicative competence. For example, one can learn some basic vocabulary and structures of a language and still not be able to communicate in that language. Similarly, it is possible to develop some basic interpersonal communicative competence without necessarily developing a similar level of grammatical competence. For example, in immersion situations, a person can 'pick up' some words and expressions from hearing other people speak the language. These words and expressions allow the person to communicate in some situations, but do not guarantee that the person will be able to communicate in unpredictable situations, and or in more cognitively demanding contexts. Only "Tell me More" and "ELLIS" were able to develop content communicatively while developing linguistic proficiency (the two programs were rated 4 for item 1.16). Although "Discoveries," "Longman," and "Who's Oscar Lake" developed content in a communicative way (all rated 4 for item 1.13), the development of linguistic proficiency was not as successful either because in these programs there was little practice of more complex structures, as in "Discoveries" and "Longman," both were rated 3 for item 1.16, or because there was almost no practice of any language structures, as in “Who's Oscar Lake”, rated 2 in item 1.16. "Dynamic English" (rated 2 for item 1.13), however, failed to develop content in a truly communicative way, but was better able to develop linguistic 
proficiency (rated 4 for item 1.16), since it provided language structure practice. The other programs, "Learn English," "Learn to Speak English," "Live Action," "Making Connections," "Side-by-Side," and "Rosetta Stone" (rated 3, 3, 2, 2, 3, and 1 respectively for item 1.13) developed communicative and linguistic proficiency at the same levels (rated $3,3,2,2,3$, and 1 respectively for item 1.16).

For all programs, except for "Asterix," "Talk Now", and "Who's Oscar Lake", the ratings for items $1.17,1.18$, and 1.19 were the same, even though content could be educationally relevant and interesting for the learner (item 1.17), without being necessarily appropriate for that learner (item 1.18). At the same time, content could be educationally relevant, interesting and appropriate for the learner (items 1.17 and 1.18) without being necessarily applicable to real life contexts (item 1.19) - such as in "Asterix," rated 3 for items 1.17 and 1.18 and 2 for item 1.19 - although there might be a close relation between being applicable to real life and being interesting and relevant to the learner. For example, in one of the first lessons in the beginning level of "Rosetta Stone," the purpose of a presentation was to introduce the prepositions 'over', 'under', 'above', and 'below' - educationally relevant. These prepositions were presented through a series of pictures of a 'ball' and a 'boy' - appropriate for the learner. The pictures were humorous - interesting to the learner. However, showing a 'boy' under a huge 'ball' did not seem very applicable to real life context. "Tell me More," "ELLIS," and "Longman" were all rated 4 for items 1.17, 1.18, and 1.19. "Discoveries," "Learn to Speak English," "Issues in English," and "Live Action" were rated 3 for these items. "Dynamic English," "Making Connections," and "Talk Now" were rated 2 for items 1.17, 1.18,and 1.19, while "Rosetta Stone" was rated only 1 for these items.

Ratings for the items related to the type and quality of language-learning activities are presented in Table 21. 
Table 21

Ratings for the Items Related to the Type and Quality of Language-Learning Activities

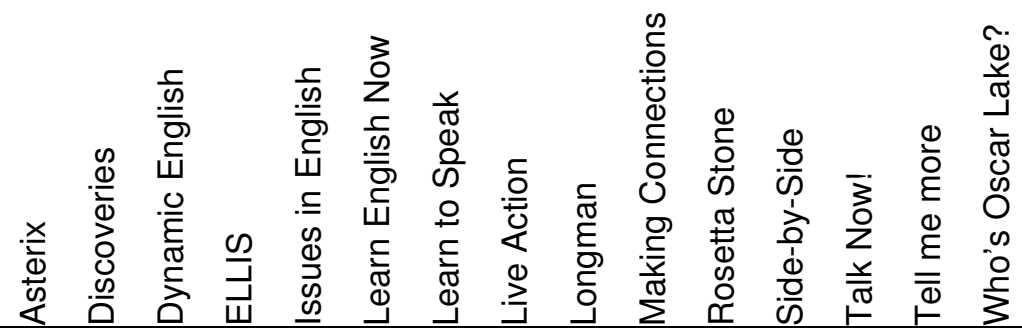

1.20 The program allows learners to work together in communicative activities.

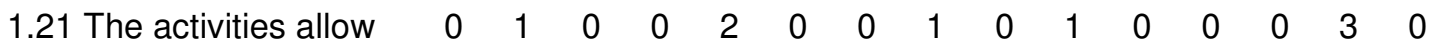
unplanned and/or

unpredictable responses.

1.22 The activities lend $\quad \begin{array}{llllllllllllllll} & 0 & 0 & 0 & 0 & 2 & 0 & 0 & 1 & 1 & 0 & 0 & 0 & 0 & 0 & 1\end{array}$ themselves to group discussions.

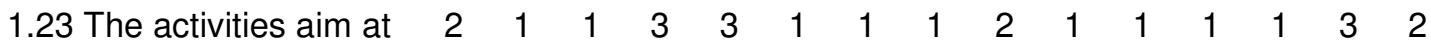
developing other competencies in addition to syntactical and lexical.

1.24 The program allows the teacher to interact with students while they are doing an activity.

The ratings for the items related to the type and quality of language-learning activities indicated that, in general, the programs need to provide more communicative activities if they are to follow the principles of Communicative Language Teaching.

Allowing learners to work together in communicative activities (item 1.20) was absent in ten of the programs - "Asterix," "Learn English," "Talk Now," "Who's Oscar Lake," Tell me More," "ELLIS," "Learn to Speak English," "Making Connections," "Sideby-Side" and "Rosetta Stone" were all rated 0 for this item. "Discoveries," "Longman," "Dynamic English," and "Live Action" were rated 1 for item 1.20 because in their supplementary materials - 'companions,' 'workbooks,' etc - they provided activities that 
could allow for some kind of cooperative work. In these supplementary materials there were projects to be developed in groups and/or links to chatrooms where students could interact with a tutor and/or with other learners to clarify doubts. "Issues in English" was rated 3 because some activities elicited pair or group work.

Only "Tell me More" had some activities that allowed unplanned and/or unpredictable responses (rated 3 for item 1.21). In this program, some activities asked for open-ended responses while others allowed for interactions which had to be performed without a script. In "Issues in English," a few activities allowed for openended responses - this program was rated 2 in item 1.21. In "Discoveries," "Live Action," and "Making Connections" (all rated 1 for item 1.21), unplanned or unpredictable activity was only provided in their supplementary material. The activities in the other programs did not allow for unplanned and/or unpredictable responses (all rated 0 for item 1.21).

"Issues in English" provided very few activities that would lend themselves to group discussions (rated 2 in item 1.22). "Longman" and "Live Action” presented some activities that could lend themselves to group discussions in their supplementary material only - both were rated 1 for item 1.22. None of the other programs provided activities that could lend themselves to group discussion - all were rated 0 for item 1.22.

In only three programs - "Tell me More," "Issues in English," and "ELLIS" were there activities aimed at developing competencies beyond syntactic and lexical. For example, in these programs, reading comprehension activities also aimed at developing high order thinking and comprehension skills. Also, some of their writing activities aimed at developing discourse skills since they required learners to write different text genres. These three programs were rated 3 for items 1.23. "Asterix," "Longman," and "Who's Oscar Lake" had very few activities which could develop other 
competencies in addition to syntactic and lexical, and were rated 2 for item 1.23 . In all other programs, the activities developed very little beyond syntactic and lexical competencies - these programs were all rated 1 for item 1.23.

Although all the analyzed programs also have computer lab versions, only one - "Tell me More" (rated 3 for item 1.24) - allowed teachers to interact with students during an activity. In "Issues in English" and "Live Action" (rated 1 for item 1.24) interaction between teacher and students was only possible at the end of a session or a lesson.

Feedback was also analyzed in the previous section (Analysis of the Incorporation of Technological Features Associated with Interactive CALL). However, in that section the focus was on how the media attributes of the programs differentiated feedback. In this section the analysis focused on the type of feedback provided by the program, and it is therefore related to the instructional attributes associated with the Incorporation of pedagogical features associated with the principles of Communicative Language Teaching.

In Table 22 the ratings for the items related to the type of feedback provided by the programs are reported.

Table 22

Ratings for the Items Related to the Type of Feedback Provided

\begin{tabular}{|c|c|c|c|c|c|c|c|c|c|c|c|c|c|c|c|}
\hline Items & $\frac{\sqrt[x]{\frac{D}{0}}}{\frac{\omega}{4}}$ & 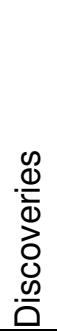 & 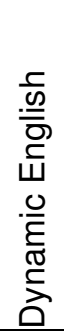 & $\frac{\mathscr{\omega}}{\vec{J}}$ & 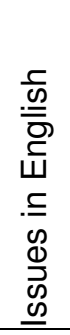 & 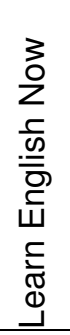 & 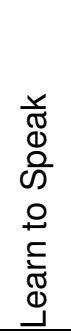 & 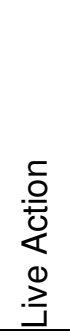 & 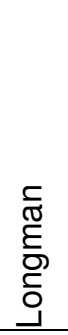 & 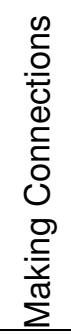 & 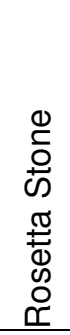 & 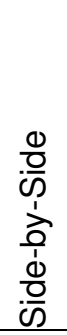 & 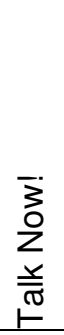 & 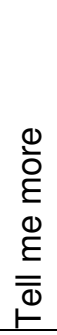 & 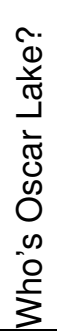 \\
\hline $\begin{array}{l}1.25 \text { The program } \\
\text { provides non- } \\
\text { threatening feedback. }\end{array}$ & 3 & 4 & 4 & 4 & $\overline{3}$ & 3 & 3 & 3 & $\overrightarrow{4}$ & 3 & 2 & 4 & 4 & 3 & 4 \\
\hline
\end{tabular}




\begin{tabular}{|c|c|c|c|c|c|c|c|c|c|c|c|c|c|c|c|}
\hline $\begin{array}{l}1.26 \text { The program } \\
\text { allows learners to } \\
\text { repeat an activity after } \\
\text { feedback is provided. }\end{array}$ & 3 & 3 & 0 & 2 & 3 & 2 & 3 & 1 & 2 & 3 & 2 & 4 & 4 & 4 & 2 \\
\hline $\begin{array}{l}1.27 \text { Activities allow for } \\
\text { more than one correct } \\
\text { response. }\end{array}$ & 0 & 1 & 0 & 3 & 3 & 0 & 1 & 0 & 1 & 0 & 1 & 1 & 0 & 4 & 3 \\
\hline $\begin{array}{l}1.28 \text { The program } \\
\text { provides the students } \\
\text { with feedback that } \\
\text { would allow them to }\end{array}$ & 1 & 1 & 2 & 2 & 2 & 2 & 1 & 1 & 2 & 1 & 1 & 0 & 1 & 3 & 1 \\
\hline
\end{tabular}

The programs were, in general, able to provide non-threatening feedback (item 1.25); seven programs were rated 4 for item 1.25 , seven were rated 3 for the same item, and one was rated 2 for item 1.25, because of the rather annoying sound played when a mistake was made.

Most programs allowed learners to repeat an activity after providing feedback (item 2.26), "Dynamic English" (rated 0 for item 2.26) being the only exception. However, in "ELLIS," "Learn English," "Longman," "Rosetta Stone," and "Who's Oscar Lake" (all rated 2 for item 2.26), learners could only repeat an activity after completing all the items in that activity. "Tell me More," "Talk Now," and "Side-by-Side" were rated 4 for item 1.26 because in these programs repeating an activity after feedback was very simple and easy. Although repetition of an activity after feedback being provided was also simple and straightforward in "Asterix," "Discoveries," Issues in English," "Learn to Speak English," and "Making Connections," this repetition could be done until the learner got the right answer by guessing the right answer. These programs were rated 3 for item 1.26.

In four programs, "Tell me More," "Issues in English," "Who's Oscar Lake," and "ELLIS" (rated 4, 3, 3, and 3 respectively), many activities allowed for more than one correct response (item 1.27). In "Discoveries," "Longman," "Learn to Speak English," "Side-by-Side," and "Rosetta Stone" (all rated 1 for item 1.27), the activities almost 
always had only one right answer. In "Dynamic English" and "Making Connections" (rated 0 for this item), all activities had only one correct response.

For many of the activities in "Tell me More", feedback first signaled the mistake before correcting it (item 1.28). This program was rated 3 for item 1.28. In "ELLIS," "Longman," "Issues in Englihs," "Learn English," and "Dynamic English" some activities (usually writing activities) provided some kind of feedback (such as underlying what was grammatically wrong) before correcting learners' responses. These programs were rated 2. In all the other programs, except for "Side by Side," responses were sometimes highlighted before correction, but without giving any clue as to what was wrong with the response. These programs were rated 1 for item 1.28. In "Side-by-Side" (rated 0 for this item), activities were checked as right or wrong without any feedback as to what was wrong or why it was wrong.

Although graphics and sounds are related to the Media Attributes of the programs associated with the incorporation of the technological features associated with CALL, the combination of graphics and sounds can be used to facilitate learning, and is therefore also related to the Instructional Attributes of the programs associated with how they incorporate the principles of Communicative Language learning.

Table 23 shows the ratings for the items related to how the programs facilitated learning. 
Table 23

Ratings for the Items Related to How the Programs Facilitate Learning

\begin{tabular}{|c|c|c|c|c|c|c|c|c|c|c|c|c|c|c|c|}
\hline Items & $\frac{\sqrt[x]{\frac{1}{d}}}{\frac{\Phi}{\infty}}$ & 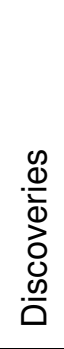 & 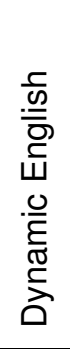 & $\frac{\varrho}{\vec{\omega}}$ & 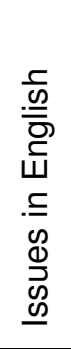 & 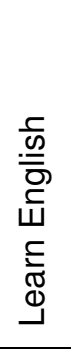 & 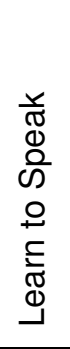 & $\begin{array}{l}.0 \\
\stackrel{0}{0} \\
\frac{0}{0} \\
0 \\
\stackrel{0}{3}\end{array}$ & 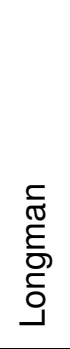 & 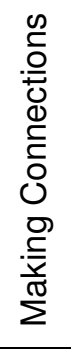 & 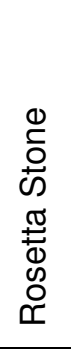 & $\begin{array}{l}\frac{0}{0} \\
\text { की } \\
\text { do } \\
\frac{0}{\dot{d}} \\
\frac{0}{0}\end{array}$ & 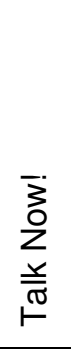 & 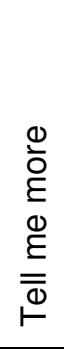 & 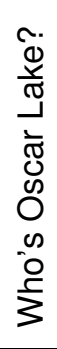 \\
\hline $\begin{array}{l}1.1 \text { Graphics and sound } \\
\text { enhance learning. }\end{array}$ & 3 & 3 & 3 & 4 & 2 & 2 & 2 & 3 & 3 & 2 & 2 & 3 & 2 & 3 & 3 \\
\hline $\begin{array}{l}1.2 \text { The animation is } \\
\text { effective in minimizing } \\
\text { boredom by motivating } \\
\text { learners. }\end{array}$ & 3 & 2 & 1 & 4 & 2 & 2 & 2 & 3 & 3 & 2 & 1 & 2 & 2 & 4 & 3 \\
\hline $\begin{array}{l}1.3 \text { Screen displays are } \\
\text { uncluttered. }\end{array}$ & 3 & 3 & 3 & 4 & 4 & 2 & 2 & 3 & 4 & 3 & 2 & 3 & 3 & 3 & 3 \\
\hline $\begin{array}{l}1.4 \text { Graphics make } \\
\text { information attractive. }\end{array}$ & 3 & 2 & 2 & 4 & 3 & 2 & 3 & 3 & 3 & 2 & 1 & 3 & 2 & 4 & 3 \\
\hline $\begin{array}{l}1.5 \text { Graphics help } \\
\text { memorization of key } \\
\text { information. }\end{array}$ & 2 & 3 & 3 & 4 & 3 & 2 & 3 & 3 & 3 & 2 & 1 & 2 & 2 & 4 & 3 \\
\hline
\end{tabular}

The ratings for the items related to how the programs facilitated learning indicate that most programs used technology to make themselves attractive and motivating to the learners. "ELLIS" was the program that obtained the highest ratings for all items (ratings $=4$ ). In "Tell me More" (rated 3 for items 1.1 and 1.3), the graphics were in a few places overwhelming, making screen displays a little cluttered. Consequently, in these places graphics and sound distracted learning instead of enhancing it, because their combination took learners' focus away from the teaching point. For item 1.1, the other programs that were also rated 3 were: "Asterix," "Discoveries," “Longman," "Dynamic English," "Live Action,” "Who's Oscar Lake," and "Side-by-Side". In these programs the combination of sounds and graphics enhanced 
learning most of the time. In "Issues in English," "Learn English," "Learn to Speak English," "Making Connections," "Rosetta Stone," and "Talk Now," the combination of graphics and sounds sometimes enhanced learning and sometimes distracted learners. These programs were rated 2 for item 1.1.

For item 1.3, "ELLIS," "Issues in English," and "Longman" were rated 4 because graphics and sound were combined nicely and neatly and screen displays were never cluttered. Still for item 1.3, other programs - "Asterix," "Discoveries," "Dynamic English," "Live Action," "Making Connections," "Talk Now," "Tell me More," and "Sideby-Side" were rated 3, while "Rosetta Stone," "Learn English," and "Learn to Speak English," were rated 2.

Animation was always effective in minimizing boredom (item 1.2) in "Tell me More" and "ELLIS" (both rated 4 for this item). In "Asterix," "Longman," "Live Action," and "Who's Oscar Lake," animation was effective in minimizing boredom (item 1.2) most of the time. These programs were rated 3 for item 1.2. However, in "Discoveries," "Issues in English," Learn English," "Learn to Speak English," "Making Connections," "Side-by-Side," and "Talk Now," animation was sometimes motivating and sometimes boring, since it was repetitive at times. These programs were rated 2 for item 1.2. In "Dynamic English" and "Rosetta Stone" the use of animation bored learners more than motivated them. These programs were rated 1 for item 1.2.

Ratings for item 1.4 were very similar to the ratings for item 1.5. In "Tell me More" and "ELLIS", animation was very effective in making information attractive (item 1.4) and in helping memorization of information (item 1.5). In these two programs items 1.4 and 1.5 were rated 4. In "Issues in English," "Longman," "Learn to Speak English," "Live Action," and "Who's Oscar Lake," animation was most of the time effective in making information attractive and easier to memorize. These programs were rated 3 for items 1.4 and 1.5. In "Discoveries" and "Dynamic English" animation was more 
effective in helping memorization of information than in making the information attractive. Both programs were rated 2 for item 1.4 and 3 for item 1.5. In "Asterix" and "Side-by-Side" animation was effective in making information attractive but not really in facilitating memorization. "Side-by-Side" was rated 3 for item 1.4 and 2 for item 1.5. The use of graphics had very little effect in making information either attractive or easier to memorize in "Side-by-Side" (rated 1 for items 1.4 and 1.5).

In order to make an overall analysis of how the programs incorporated the teaching principles of Communicative Language Teaching into their elaboration, each program's ratings for all the items in the category of Instructional Attributes were added and the percentage of the possible maximum rating for the category was calculated. In Table 24 the overall ratings of each program for the category of Instructional Attributes are shown.

\section{Table 24}

Ratings of the Programs for the Category of Instructional Attributes (totals and percentages of possible maximum rating for the category)

\begin{tabular}{lc}
\hline Programs & Instructional Attributes \\
\hline Tell me More & $96(85.71 \%)$ \\
ELLIS & $88(78.57 \%)$ \\
Longman English Interactive & $82(73.21 \%)$ \\
Issues in English & $79(70.53 \%)$ \\
Discoveries & $67(59.82 \%)$ \\
Who's Oscar Lake? & $63(56.25 \%)$ \\
Side-By-Side & $61(54.46 \%)$ \\
Learn to Speak English & $60(53.57 \%)$ \\
Live Action & $56(50 \%)$ \\
Asterix & $54(48.21 \%)$ \\
\hline
\end{tabular}




\begin{tabular}{lc}
\hline Learn English Now & $53(47.32 \%)$ \\
Dynamic English & $47(41.96 \%)$ \\
Making Connections & $42(37.5 \%)$ \\
Talk Now! & $42(37.5 \%)$ \\
Rosetta Stone & $28(25 \%)$ \\
\hline
\end{tabular}

"Tell me More" was the program that obtained the highest overall rating for the category of Instructional Attributes $-85.71 \%$. The other three programs with high overall ratings for this category were "ELLIS" (78.57\%), "Issues in English" (70.53\%), and "Longman English Interactive" (73.21\%). "Discoveries," "Learn to Speak," "Live Action," "Side by Side," and "Who's Oscar Lake" were rated above 50\%. All the other programs were rated lower than $50 \%$. "Rosetta Stone" was the program with the lowest rating (25\%).

Analysis of the Extent to which the ESL/EFL Software Programs Created Environments that Developed Language Skills according to the Communicative Approach to Language and an Interactive CALL Model

In order to analyze the extent to which the ESL/EFL software programs created environments that developed language skills according to the principles of Communicative Language Teaching and an interactive approach to computer use for language learning, the ratings obtained by each program for all the items in all categories of the evaluation instrument were added, and the percentage of the possible total ratings was calculated. Results are shown below. 
Table 25

Total Ratings of the Programs

\begin{tabular}{lcc}
\hline Programs & Total Rating & $\begin{array}{c}\text { Percentage of possible } \\
\text { maximum rating }\end{array}$ \\
\hline Tell me More & 176 & $80 \%$ \\
ELLIS & 166 & $75.45 \%$ \\
Issues in English & 145 & $66.09 \%$ \\
Longman English Interactive & 142 & $64.54 \%$ \\
Discoveries & 131 & $59.54 \%$ \\
Learn English & 112 & $50.99 \%$ \\
Learn to Speak English & 104 & $47.27 \%$ \\
Side-By-Side & 103 & $46.81 \%$ \\
Live Action & 102 & $46.36 \%$ \\
Asterix & 100 & $45.45 \%$ \\
Who's Oscar Lake? & 98 & $44.54 \%$ \\
Dynamic English & 95 & $43.18 \%$ \\
Making Connections & 92 & $41.81 \%$ \\
Talk Now! & 89 & $40.45 \%$ \\
Roseta Stone & 63 & $28.63 \%$ \\
\hline
\end{tabular}

The "Tell Me More" program had the highest overall rating ( $80 \%)$, followed by "ELLIS", with an overall rating of $75.45 \%$. In fact these were the only programs rated above $75 \%$; all the other programs failed to meet at least three quarters of the features associated with Communicative Language Teaching and interactive CALL. Four other programs - "Issues in English“ (66.09\%), Longman English Interactive” (64.54\%), "English Discoveries" (59.54\%), and "Learn English" (50.99\%) - met more than half of the features associated with Communicative Language Teaching and interactive CALL, while all other programs were rated below $50 \%$. 
The comparison of the ratings for each program in the three different categories of the ESL/EFL software evaluation instrument - Media, User-friendly, and Instructional Attributes - helped to better identify the type of features which each program, and/or most programs, met best and/or failed to meet. The results of this comparison are shown in Table 26.

Table 26

Total Ratings and Ratings for each Category of the Programs (totals and percentages of possible maximum rating for each category)

\begin{tabular}{|c|c|c|c|c|}
\hline Programs & Media Attributes & $\begin{array}{l}\text { User-friendly } \\
\text { Attributes }\end{array}$ & $\begin{array}{l}\text { Instructional } \\
\text { Attributes }\end{array}$ & Total Rating \\
\hline Tell me More & $46(71.87 \%)$ & $34(77.27 \%)$ & $96(85.71 \%)$ & $176(80 \%)$ \\
\hline Ellis & $39(60.93 \%)$ & $39(88.63 \%)$ & $88(78.57 \%)$ & $166(75.45 \%)$ \\
\hline Issues in English & 35 (54.68\%) & $31(70.45 \%)$ & $79(70.53 \%)$ & $145(60.09 \%)$ \\
\hline $\begin{array}{l}\text { Longman English } \\
\text { Interactive }\end{array}$ & $27(42.18 \%)$ & $33(75 \%)$ & $82(73.21 \%)$ & $142(64.54 \%)$ \\
\hline Discoveries & $43(67.18 \%)$ & $21(47.72 \%)$ & $67(59.82 \%)$ & $131(59.54 \%)$ \\
\hline Learn English Now & $28(43.75 \%)$ & $21(47.72 \%)$ & $53(47.32 \%)$ & $112(50.99 \%)$ \\
\hline $\begin{array}{l}\text { Learn to Speak } \\
\text { English }\end{array}$ & $24(37.5 \%)$ & $20(45.45 \%)$ & $60(53.57 \%)$ & $104(47.27 \%)$ \\
\hline Side-By-Side & $20(31.25 \%)$ & $22(50 \%)$ & $61(54.46 \%)$ & $103(46.81 \%)$ \\
\hline Live Action & $26(40.62 \%)$ & $20(45.45 \%)$ & $56(50 \%)$ & $102(46.36 \%)$ \\
\hline Asterix & $25(39.68 \%)$ & $21(47.22 \%)$ & $54(48.21 \%)$ & $100(45.45 \%)$ \\
\hline Who's Oscar Lake? & $20(31.25 \%)$ & $15(34.1 \%)$ & $63(56.25 \%)$ & $98(44.54 \%)$ \\
\hline Dynamic English & $22(34.37 \%)$ & $26(59.09 \%)$ & $47(41.96 \%)$ & $95(43.18 \%)$ \\
\hline $\begin{array}{l}\text { Making } \\
\text { Connections }\end{array}$ & $28(43.75 \%)$ & $22(50 \%)$ & $42(37.5 \%)$ & $92(41.81 \%)$ \\
\hline Talk Now! & $25(39.68 \%)$ & $22(50 \%)$ & $42(37.5 \%)$ & $89(40.45 \%)$ \\
\hline Rosetta Stone & $21(32.81 \%)$ & $14(31.81 \%)$ & $28(25 \%)$ & $63(28.63 \%)$ \\
\hline
\end{tabular}


The analysis of the ratings across all categories for each program showed the weakest and the strongest set of features of each program. Media Attributes were the weakest features for most programs: "Asterix (39.69\%) "Dynamic English” (34.37\%), "ELLIS” (60.93\%), "Issues in English” (54.68\%), "Learn English“ (37.5\%), Learn to Speak English" (37.5\%), "Live Action” (40.62\%), "Longman” (42.18\%), "Side-by-Side" (31.25\%), "Tell me More" (71.87\%), and "Who's Oscar Lake" (31.25\%). Among these programs, "Tell me More" was rated highest, while "Side-by-Side" was rated lowest. Media Attributes were, however, the strongest features for "Discoveries" (67.18\%) and "Rosetta Stone" (32.81\%). User-friendly Attributes were the weakest features only for "Discoveries" (47.72\%). These attributes were the strongest features for "Dynamic English" (59.09\%), "ELLIS” (88.63\%), “Longman” (75\%), and "Making Connections” (50\%). Among these programs "ELLIS" was rated the highest for User-friendly Attributes. Instructional Attributes were the weakest features for "Rosetta Stone" (25\%), "Talk Now" (37.5\%), and "Making Connections" (37.5\%), while these attributes were the strongest features for "Learn to Speak English" (53.57\%), "Live Action" (50\%), "Side-by-Side" (54.46\%), and "Tell me More" (85.71\%). Among these programs, "Tell me More" was rated the highest for Instructional Attributes.

However, this type of analysis did not yield much information about the potential of each program to teach the language according to the principles of Communicative Language Teaching and to an interactive CALL model, since for some programs even the strongest features were still rated very low overall. Therefore, ratings for each program were compared across each category.

In the category of Media Attributes, only "Tell me More" was rated above $70 \%$ (total ratings $=71.87 \%$ ). Three other programs - "ELLIS," "English Discoveries," and "Issues in English" - were rated above 50\% in this category ("ELLIS" = 60.93\%, 
"English Discoveries" = 67.18\%, and "Issues in English" = 54.68\%). All the other programs were rated below $50 \%$ in the category of Media Attributes.

In the category of User-friendly Attributes, four programs were rated above $70 \%$ ("ELLIS" = 88.63\%; "Tell me More" = 77.27\%; "Longman" = 75\%; and "Issues in English" $=70.45 \%$ ). Four programs were rated above 50\% ("Dynamic English" = 59.09\%, "Making Connections" = 50\%, "Side-by-Side" = 50\%, and "Talk Now" =50\%). The other programs were rated below $50 \%$ of the possible total ratings for the category of User-friendly Attributes.

In the category of Instructional Attributes, "ELLIS," "Longman," "Issues in English," and "Tell me More" were rated above 70\% ("ELLIS" = 78.57\%, "Longman" = 73.21\%, "Issues in English" = 70.53\%, and "Tell me More" = 85.71\%). In this category, "Discoveries," "Learn to Speak English," "Live Action," "Side-by-Side," and "Who's Oscar Lake" were rated above 50\% ("Discoveries" = 59.82\%, "Learn to Speak English" = 53.57\%, "Live Action" = 50\%, "Side-by-Side" = 54.46\%, and "Who's Oscar Lake" = $56.25 \%$ ), while the others were rated below $50 \%$.

The ratings for the category of Media Attributes indicated that there is still a lot to be improved in these features - only one program was rated above $70 \%$, three above $50 \%$, and all the other ones below $50 \%$. The analysis of the results for the categories of User-friendly Attributes and Instructional Attributes indicated that while some programs still need to make improvements in their User-friendly Attributes (three programs were rated below $50 \%$ in this category), others have to make a great effort to make their Instructional Attributes better (three programs were rated below $50 \%$ in this category).

The analysis of the total ratings of each program and of the ratings for the categories of each program also indicated that "Tell Me More" was the program rated highest (80\%). However, this program was surpassed by "ELLIS" in the ratings for the 
features in the User-friendly Attributes - "ELLIS" was rated 88.63\%, and "Tell me More" was rated $77.37 \%$ for the same category. In fact, "ELLIS" had the highest rating for the category of User-friendly Attributes. For both programs - "Tell me More" and "ELLIS" the weakest feature was the Media Attributes (71.87\% for "Tell me More," and $60.93 \%$ for "ELLIS"). However, while for "ELLIS" the strongest feature was the User-friendly Attributes (88.63\%), for "Tell me More" the strongest feature was the Instructional Attributes (85.71\%). Nevertheless, these were the only programs which were rated above $75 \%$. The ratings for the other programs $(<70 \%)$ indicated that the programs did not meet at least a quarter of the criteria to be considered good examples of programs which have incorporated the principles of the Communicative age teaching Language Teaching and an interactive CALL model.

\section{Summary of Results}

Analysis of data from the ratings for the Media Attributes, User-friendly Attributes, and Instructional Attributes, and programs' total ratings suggest the following answers to the major questions of this part of the study:

1. Do ESL/EFL software programs incorporate the technological features associated with interactive CALL? The results presented in Table 18 indicate that only three programs incorporated more than three quarters of the features associated with interactive CALL, and two others incorporated more than half of these features. The other ten programs incorporated less than $50 \%$ of these features.

2. Do CALL programs present technological features that allow for individualized instruction? Results in Table 12 indicate that only one program contained over 
$70 \%$ of the technological features that allowed for individualization of instruction. Four other programs were rated between $50 \%$ and $60 \%$. The other ten programs contained less than half of the technological features that could allow for individualized instruction.

3. Do CALL programs incorporate the teaching principles of the Communicative Language approach into the elaboration of ESL/EFL software? Four programs incorporated more than $70 \%$ of the principles of the Communicative Language approach into their elaboration. Five programs incorporated more than half of these principles, while the other six programs incorporated less than $50 \%$ of the principles of the Communicative Language approach into their elaboration (Table 24).

4. In sum, to what extent do CALL programs create environments that develop language according to the principles of Communicative Language Teaching and interactive approach to computer use for language learning? Results shown in Table 25 indicate that only two programs created environments that developed language skills according to more than $70 \%$ of the features of Communicative Language Teaching and of an interactive approach to computer use for language learning. Two other programs created environments that developed language according to more than half of these features. All other programs were not able to attend to even half of the features that create environments that develop language according to the principles of Communicative Language Teaching and an interactive approach to computers for language learning. 


\section{CHAPTER 6: DISCUSSION AND IMPLICATIONS}

This chapter discusses the overall results of this study, connects the findings to the research literature, and addresses the original questions of the investigation. Specifically, to what extent does the ESL/EFL software evaluation instrument produce consistent results when administered under similar conditions? In other words, is the designed ESL/EFL software evaluation instrument reliable? To what extent is the ESL/EFL software evaluation instrument valid to evaluate the potential of CALL programs to develop language skills according to the Communicative Language Teaching principles and an interactive approach to computer use in language learning? Do ESL/EFL software programs incorporate the technological features associated with interactive CALL? Do CALL programs present technological features that allow for individualized instruction? Do CALL programs incorporate the teaching principles of Communicative Language Teaching into the elaboration of ESL/EFL software? In sum, to what extent do CALL programs create environments that develop language according to the principles of Communicative Language Teaching and an interactive approach to computer use for language learning? Additionally, this discussion cites the major limitations of the validation measures of the ESL/EFL software evaluation instrument and of the analysis of the programs. Finally, this discussion suggests potential avenues for future investigations and connects research to practice by identifying implications for the development of ESL/EFL software programs.

Major Findings and Discussion

Reliability

To what extent does the ESL/EFL software evaluation instrument produce consistent 
results when administered under similar conditions? In other words, is the designed ESL/EFL software evaluation instrument reliable?

Inter-rater reliability is the extent to which two or more individuals (in this case the twenty six teacher raters who participated in the study) agree. In order to measure inter-rater reliability, two procedures were used: The Pearson Coefficients and ICC Coefficients were calculated for the raters' ratings of three software programs "ELLIS," "New Dynamic English," and "Side-by-Side."

A significant correlation indicates a reliable relationship. Generally, correlations greater than 0.7 are considered strong. Correlations less than 0.3 are considered weak. Correlations between 0.3 and 0.7 are considered moderate. The Pearson Coefficients, ranging from $r=.729$ to $r=.995$ for the program "New Dynamic English," from $r=.749$ to $r=.938$ for the program "ELLIS," and from $r=.769$ to $r=.981$ for the program Side-by-Side, indicate a significant linear correlation among the raters when rating the three above mentioned programs using the ESL/EFL software evaluation instrument.

Since inter-rater reliability addresses the consistency of the implementation of a rating system, an internal consistency approach for assessing the reliability of the total score on a test can be applied to assessing inter-rater reliability. Therefore, the ICC Coefficients were calculated for the raters' ratings for the three above-mentioned programs as another measure of inter-rater reliability. The ICC Coefficients are Cronbach's Alpha Coefficients. A high Cronbach's Alpha Coefficient (above .9) indicates consistency among raters. The Cronbach's Alpha Coefficients were .990 for “New Dynamic English,” .994 for "ELLIS," and .994 for "Side-by-Side," showing a high degree of consistency among the raters for the three programs. 
Internal consistency is the extent to which tests or procedures assess the same characteristic, skill or quality. It is a measure of the precision between the observers or the measuring instruments used in a study. This type of reliability often helps researchers interpret data and predict the value of scores and the limits of the relationship among variables. In this study, an analysis of the internal consistency of the items in the ESL/EFL software evaluation instrument revealed the extent to which the items in the instrument focused on the features of Communicative Language Teaching and an interactive approach to computer use for language learning.

There are several statistical indices that may be used to measure the amount of internal consistency for a test. The most popular index (and the one used in this study) is referred to as Cronbach's Alpha. Cronbach's Alpha is often considered a measure of item homogeneity; i.e., large alpha values (> .9) indicate that the items are tapping a common domain.

The first set of inter-item reliability tests yield the following Cronbach's Alpha Coefficients: .721 for "ELLIS," .916 for "New Dynamic English," and .866 for "Side-bySide."

Factor analytic techniques were applied to the data from the program with the highest Cronbach's Alpha - "Dynamic English." The main applications of factor analytic techniques are: (a) to reduce the number of variables, (b) to detect structure in the relationships between variables, that is to classify variables, and (c) to see whether different measures are tapping aspects of a common dimension. Factor analysis was consequently used to uncover the latent structure (dimensions) of the set of variables (the items in the ESL/EFL software evaluation instrument), and to identify clusters of cases and/or outliers. It was understood that if several variables correlated highly, they 
would measure aspects of a common underlying dimension. These dimensions are called factors.

This in turn leads nicely into a discussion of the connection between the reliability of a multi-item test and the (exploratory) factor analysis of the data obtained by administering such a test to a large group of subjects. Since this researcher has been talking about the internal consistency of the ESL/EFL software evaluation instrument, it would seem that if all of the items inter-correlated highly with one another, say .7 and above, one big factor and several little ones would be obtained.

Therefore, the 60 items of the original ESL/EFL software evaluation instrument were analyzed using a principal components analysis extraction method and varimax rotation with Kaizer normalization resulting in 15 components. The first three components accounted for $62.65 \%$ of the total variance in the original items. The first component - Factor 1 - accounted for $36.95 \%$ of the total variance, and consisted of 28 of the 60 items. The second component - Factor 2 - accounted for $14.93 \%$, and consisted of 16 items. The third component - Factor 3 - accounted for $10.76 \%$ of the total variance, and included 11 items. The other factors were not kept because, besides having few items loaded in them, the items loaded in these other factors were also loaded in one of the first three factors with higher path coefficients. The 5 remaining items (out of the original 60 ones) had path coefficients $<.4$, and were eliminated.

After the 5 items were dropped from the ESL/EFL software evaluation instrument, and the remaining items were grouped into the three major factors, the Cronbach Alpha Coefficients were calculated for the items kept within each of the three factors, and for all the 55 items together. The correlation was high, with the following Cronbach's Alpha Coefficients: .96 for the items in factor 1, .93 for the items in factor 2 , 
.92 for the items in factor 3 , and .94 for all the items together. The data suggested that there were three key parameters that could be measured as represented in the three factors identified in the factor analysis.

All these results suggest high levels of inter-rater reliability and of internal consistency, which assures theESL/EFL software evaluation instrument a high degree of reliability.

In sum, the results of the reliability measures suggest that it is possible to use the ESL/EFL software evaluation instrument to measure the degree to which ESL/EFL software programs incorporate the features of Communicative Language Teaching and an interactive approach to computer use for language learning into their design. The 55 items in the ESL/EFL software evaluation instrument, clustered around three components, represent specific and distinguishing attributes of software programs that can be used as yardsticks for measuring the incorporation of the Media, User-Friendly, and Instructional Attributes into the elaboration and design of software programs. The incorporation of these attributes can, in turn, account for the integration of the features of Communicative Language Teaching and an interactive approach to computer use for language learning into software programs.

\section{Validity}

To what extent is the ESL/EFL software evaluation instrument valid to evaluate the potential of CALL programs to develop language skills according to the Communicative Language Teaching principles and an interactive approach to computer use in language learning?

Validity is the strength of a study's conclusions, inferences or propositions. 
More formally, Cook and Campbell (1979) define it as the best available approximation to the truth or falsity of a given inference, proposition or conclusion.

When a test measures what it is intended to measure and nothing else, it is valid. Most important kinds of validity are content and face validity. Content Validity evaluates if the test accurately reflects the syllabus on which it is based. The purpose of a content specification list is to ensure that the test reflects all areas to be assessed in suitable proportion. Face Validity evaluates if the test looks like a good one: what teachers and students think of the test. Other types of validity measures are: (a) predictive validity, which evaluates if the test accurately predicts performance in some subsequent situation; (b) concurrent validity, which measures if the test gives similar results to existing tests that have already been validated; and (c) construct validity, which measures if the test reflects accurately the principles of a valid theory of foreign language learning.

Reliability is required to make statements about validity. However, reliable measures could be biased and hence "untrue" measures of a phenomenon, or confounded with other factors such as acquiescence response set. However, reliability is a prerequisite for measuring validity.

In this study, the positive indicators of reliability obtained from the procedures used to assess the inter-rater reliability and the internal consistency of the instrument, and the face and content validity attributed to the instrument, suggest that the ESL/EFL software evaluation instrument is potentially a valid instrument to assess the degree to which ESL/EFL software programs develop language skills according to the principles of Communicative Language Teaching and an interactive approach to computer use for language learning. 


\section{Technological Features}

Do ESL/EFL software programs incorporate the technological features associated with interactive CALL?

Findings related to the incorporation of technological features of the ESL/EFL programs were based on ratings obtained for these programs in the categories of Media Attributes and User-Friendly Attributes. These attributes include: (a) programs' simplicity of installation and navigation, (b) how the media technology differentiates feedback, (c) how the integration of different types of media facilitates learning, (d) how the program helps learners move through the content and sequence of activities, and (e) the degree and type of individualization of instruction the program provides.

The results presented in Table 18 indicate that only three programs incorporated more than three quarters of the features associated with interactive CALL, and two others incorporated more than half of these features. The other 10 programs incorporated less than $50 \%$ of these features.

\section{Simplicity of Installation and Navigation}

The analysis of how the ESL/EFL software programs incorporated technological features associated with interactive CALL indicated that the more interactive the programs are the better they are for lab use than for individual use. One example of such a case is the program "Tell me More". It requires an expert to organize and install data for use. Besides, students need some time for experimentation or a brief introduction by an instructor to learn their way around the program. Novice computer users will probably need the instructor to direct them for a couple of sessions before they are comfortable with the learning environment that the program offers. Without an instructor's guidance, the use of technology might hinder students' progress in 
language acquisition. Overall the program is, however, straightforward and easy to use, especially the 'Dynamic Mode' that customizes learning according to each individual and builds on previously introduced vocabulary and/or linguistic items.

Another example of a program which is a better fit for lab use is "English Discoveries". Like "Tell me More", it requires computer expertise to install the program, and an instructor to introduce learners to its content and features and to guide them in navigating through the program. Nevertheless, navigation through "English Discoveries" is fairly easy, since each learning section and working mode is presented by an icon. To get to a specific learning section users have to click on the respective icon. To exit the program from any screen users click on the Quit icon. However, because the program offers two different learning approaches - an open approach where users choose their own learning path, and three different kinds of prefabricated lessons, within which users have to follow the sequence of each lesson - navigation through its content and sequence might take a while to be mastered.

An exception to this trend is the program "ELLIS", that, although also coming with good interactive features, is quite easy to be installed and runs well in individual computers.

Less interactive programs, like the "Longman English Interactive", are easier to install and perform well in individual computers. In fact, the installation of the program “Longman English Interactive" was completed easily without any problems, following the onscreen instructions. The instructions can be read in any of nine different languages (English, Chinese, French, German, Italian, Japanese, Korean, Portuguese, and Spanish), which can be very helpful for ESL/EFL learners. The software is easily uninstalled from the Windows Start Menu.

"Longman English Interactive" is a good example of a program which helps learners move through its content and sequence with confidence and ease. The 
interface is clean, well organized, and consistent throughout the program. Navigation, help, and resources are placed at the top right of each screen and forward/back arrows are placed at the bottom of the screen. Navigation is consistent and easy to use, and works properly. Learners can jump anywhere within a unit via a drop-down menu. They can also go to any specific part within a course from the Course Outline, which lists a detailed table of contents. Learners can also go to the previous and next pages by clicking the forward/back arrow buttons.

"Live Action" is another example of a program that, although not very interactive, can be easily installed and run. This program does not require special installation or make great hardware demands. It does, however, need the QuickTime player to be installed in order for the program to work properly. QuickTime 5.0 is included on the CD as a stand-alone installation in case it is not already installed on the computer. The program runs directly from the CD but can also be transferred to hard disk. The programs "Asterix," "Learn English," and "Talk Now" also require the installation of Quick Time 5.0.

The interface of "Live Action," "Asterix," "Learn English," and "Talk Now" are easy to use. Users do not need to spend time learning to navigate through lessons and activities.

"Dynamic English" is also an easy to install and navigate program, although even less interactive than the above mentioned ones. The program is very easy to load and performs well. The screens are clear and uncluttered and navigational tools and menus are consistently placed. In "Dynamic English", the screens are clear and uncluttered and navigational tools and menus are consistently placed. The icons that represent buttons are fairly internationally intuitive (play, rewind, etc.). However, it was impossible to find a way to skip forward within a unit, which could make it frustrating for learners and teachers. It is assumed this was built into the program to force students to 
complete an activity before moving onto the next. It would be nice if there were a SAVE feature, so that users could exit and later continue where they had left off. The exit button is multi-functional, used to exit lesson, unit and program. Users who have not read all the instructions would be unlikely to click the exit button unless they wished to leave the program altogether.

"Side-by-Side" is also easy to install and navigate. The screens are uncluttered and directions to use the program are very helpful.

"Who's Oscar Lake?" is an example of highly sophisticated software with simple installation features. This mystery game played in a virtual environment is fairly easy to open and navigate, although not user-friendly. However, the instruction manual and the on-line help are very useful for installation and starting the program.

\section{Feedback}

Another feature associated with interactive CALL relates to how the media technology differentiates feedback. Computer-generated feedback can be done in the forms of: (a) positive evidence, which tells the learner that linguistic features in the input are possible in the target language (Hatch, 1978; Krashen, 1977, 1994; Long, 1983, 1996; White, 1987); (b) negative evidence, which provides information to learners about what is not possible in the target language (Lightbown \& White, 1987; Long, 1996); and (c) implicit negative feedback, which can take the form of recasts reformulation of a learner's ill-formed utterance - or negotiation of meaning. It is argued that recasts can provide implicit negative feedback, positive evidence, and enhanced salience through the juxtaposition of the original ill-formed utterance and the TL recast form (Leeman, 2000; Saxton, 1997; Saxton, Kulcsar, Marshall, \& Rupra, 1998). In negotiation of form (see Lyster, 1998; Lyster \& Ranta, 1997), instead of 
providing learners with the correct target language form, the software indicates to learners that they have produced an error and that the error requires repair. It is claimed that interactional modifications due to negotiation of meaning facilitate language learning (Long, 1980; 1996, 2005). Implicit feedback is, therefore, more closely associated with an interactive approach to computer use in language learning.

Unfortunately, in the fifteen analyzed programs most feedback took the form of positive evidence only. Generally speaking, the type of feedback provided by the analyzed programs needed to be improved in many aspects. Although not threatening, feedback given by the programs did not specify different types of errors, and very few programs offered feedback for both correct and incorrect answers.

Among all the analyzed programs, "Telll me More" offered the best feedback features. In "Tell me More", by default, there is no time limit for students to complete an activity; they simply click the $<\mathrm{OK}>$ icon whenever they complete a given task. This time flexibility allows challenging activities without producing student frustration and anxiety. It is, however, possible for instructors to add a time limit on responses should it be required. As for feedback, the program provides visual feedback by highlighting mistakes in red and correct responses in green.

Also, the automatic voice recognition feature of "Tell me More" is particularly useful in enabling students to improve their pronunciation and intonation skills. It includes waveform and pitch curve graphs that record the rising and falling intonation of students' voice and indicates the areas that need improvement. Moreover, it evaluates students' accuracy on a scale of 1 to 7 ( 7 being the highest) and allows them to repeat phonemes, words or sentences as many times as they wish by emulating male/female native speakers of English who have slight variations in accents and tones. This combination of audio-visual input and output quickly provides an efficient and effective model of error correction that improves pronunciation accuracy. 
However, there are instances when the recording function does not immediately recognize the sentence output and includes an "I did not understand you" or "speak faster" prompt. This slight shortcoming requires speakers to pause slightly after the "speak" prompt appears at the top left side of the screen. Yet "Tell me More" does well in recognizing and evaluating sentences, words and phonemes. Still, with complete sentence structure, there are times when automatic speech recognition does not accurately detect errors and highlights mistakes in red even though they are pronounced correctly. Such a shortcoming is both frustrating for those with an excellent pronunciation and misleading for those with particularly poor pronunciation skills who may think that their speaking skills have improved.

In "Live Action", response feedback, which is essentially limited to right/wrong answer processing, is complemented by program actions. For instance, in 9 of the 12 Interacts, the user hears a command and then drags an object to the proper place in the middle of the screen, where (if it is the correct object) a video is activated and the object is used as the command is carried out. In the Write activity, the dictation gives hints for errors until all have been corrected.

In "Longman English Interactive", learners can record their voice and listen to their conversation with the virtual partner - one of the characters from the video who speaks directly to the learner in a "Point of View" style. Learners can also view the transcript when listening to the conversation. The test sections have features that allow students to save their test scores, but it must be set up to do that at the beginning. For the network version, all student results are retained on a server via the teacher reporting tool.

"Issues in English," like most other analyzed programs, does not have a flexible anticipated response handling. Predetermined feedback is limited to an indication of 
correctness or incorrectness - there are no contextualized explanations linked to correct and incorrect answers. Explanatory information on teaching points is available in a separate information section, but is decontextualized and could easily be overlooked.

"Who's Oscar Lake?" provides the learner with two responses or questions from which to choose. The meanings are the same, but stated differently. In the activities, which are separate form the game, the learner is sometimes given a choice of answers. If answered incorrectly, the learner is informed and then just has to choose the other answer. Some activities require that learners move objects to certain places. The directions are written as well as spoken. If the learner moves the object incorrectly, a voice encourages the learner to try again. Feedback on activities is immediate and a score is displayed upon completion. The activities and the game itself are not timed.

\section{Integration of Media}

Perhaps the strongest feature associated with the level of interactivity afforded by the analyzed computer programs is integration of media, although there are several limitations to how media is effectively integrated. Current ESL/EFL software programs classified by their vendors as multimedia generally fall into the broad definition of multimedia as the integration of text, images, sound, video and/or animations (a mode of presentation), and leave out the integration of hypermedia (a pedagogical perspective). Whereas multimedia refers to the use of a variety of media, hypermedia can be defined from the two words that make up the term (hyper means non-linear or random and media refers to information represented in many formats (Thompson, Simonson \& Hargrave, 1992). Hypermedia can be defined as an external associational memory where the technology provides assistance in organizing and accessing information (Dede, 1997). The advantage of hypermedia is the possibility for easy 
access to various links within a program; selected referents would be only a keystroke away. Although most analyzed programs used several types of media (multimedia), they unfortunately allowed for only a fixed linear path (leaving out the possibilities of hypermedia).

The computer's potential to provide an interactive multimedia learning program is well-demonstrated in "Issues in English". Audio and text alternatives are provided for transcripts, help and some of the exercises and feedback. Graphics are used to convey language meaning in some of the transcripts and exercises at the lower levels. Hypertext is used to great advantage in video transcripts and in the writing and grammar sections, with hot-words linking to explanations of meaning or examples of language use.

Although multimedia is used effectively in many ways to facilitate learning, the computer's capability for presenting audio/visual material has not been fully exploited in this program. Each lesson/theme is presented in a video clip, with a person speaking directly into the camera, as if addressing an imaginary listener (i.e., the learner). While this use of video does not exploit the media's full potential for delivering complementary visual and auditory cues in authentic contexts, the author of the program has intentionally used improvised contexts so that the "users feel that the speaker is speaking to them". This simple approach is quite effective, but would perhaps seem more convincing with a less awkward and stilted delivery of the 'talking heads'.

"English Discoveries" is a colorful program supported by good graphics, sound and video sequences offering learning material for vocabulary and grammar as well as a variety of authentic material in order to explore and practice language for communicative use, e.g. reading postcards, listening to radio shows, watching a soap opera on TV, listening to an answering machine, role-play, reading short stories etc. In addition, a game called "The Adventure" provides learners with an opportunity to use 
their language as if they were in a 'real life' situation. However, although the program offers choices of learning approaches, it offers little integration of hypermedia.

"ELLIS" is another program that provides learners with as much visual, oral and auditory practice as possible. The program also effectively introduces students to the United States culture. The strategy of the program is to create a "real world" learning environment for each lesson that is relevant to the student's life through the presentation of a short video segment. The dialogue from the video segment is transferred to the computer screen where the student is guided through a series of learning activities that include listening vocabulary, phrases, grammar, culture and pronunciation. Lesson concepts and context are introduced via brief, high-quality video dialogues posing situations that students and their families are likely to face. From the video segment (which can be played as many times as the student likes), the English language learner can ask the computer to slow down the audio portion. Clicking on a turtle icon slows the pace. The ability to record and immediately compare one's intonation and phrasing to a native English speaker is a particularly popular and useful way to practice the language (and recording to get closer to the model is just fine by the software).

Although "ELLIS" presents itself as a complete integrated multimedia system boasting student placement, record keeping, interactivity, integrated video, pronunciation practice, grammar instruction and practice, student voice recording and playback capability, vocabulary practice, and cultural instruction, it lacks significant hypermedia integration.

"Longman English Interactive" is a good example of perfect integration of multimedia with little use of hypermedia. Materials are presented through video, audio, animated texts, and regular text. The video has high resolution and its sound is clear 
and in sync with the images. Students can view a video clip as often as they want and they can easily play a segment that they want to view by clicking a bar underneath the video. Animated texts keep learners' attention and are appealing to visual learners because they highlight grammar and pronunciation points visually.

In "Longman English Interactive", each grammar explanation is accompanied by an audio-recording and animated text. If users are happy with the textual information alone and choose not to play the accompanying audio, they don't see the attendant animation. Text animations often demonstrate grammatical points, such as transformations and insertions. In order to take full advantage of animation effects, users need to both listen to audio and watch the animation, which is the recommended use of the grammar and pronunciation sections.

Finally, "Dynamic English" is a perfect example of the level of multimedia integration into most programs. The screen design is easy to manage because of its simplicity. The lessons use simple illustrated graphics to convey meaning and to support the spoken text through schematic inference. Students are encouraged to concentrate on the main information being conveyed before testing their understanding through a variety of activity types. The $A B C$ button in the bottom right-hand corner allows the student to listen with or without the text. Certain words are highlighted and are hyperlinked to the glossary, which provides detailed grammatical explanations and examples of the word or structure in a sentence. Unfortunately there is no print facility for students to use this information for reference at a later date.

The simple, synthetic design of the pictures belies the true potential of today's technology. Authentic interactions between real people (video) would have affected the whole tone of the program. It is unfortunate that software developers do not always attempt to contextualize the learning situations. 


\section{User-Friendly}

Other technological features associated with interactive CALL relate to userfriendly attributes of the programs, which includes how the use of the program is made easy for learners, how attractive the media technology makes the program, how the program motivates learning, and how well the program helps learners move through its content and sequence.

With regard to the user-friendly attributes, the design of "Tell me More" provides an excellent layout for visual and auditory presentation. There are appealing musical tunes and rich colorful graphics in both the foreground and background. The quality of graphics in the video clips is excellent. They flow smoothly and easily without any interruptions. The quality of sound is also excellent due to the clarity of speech and authentic speech rate and accent. Having a speech rate that corresponds to that of native speakers is particularly suitable for advanced language learners who have already developed control over the language and need to learn to recognize speech at a faster and less controlled pace.

In "Live Action", the video screen provides quite intuitive icons for controlling the video, and the speaking activity screen also has easy to understand icons for controlling listening and recording functions. One constraint is that the rewind button for the video will always return the learner to the start of the video. Only with text displayed can the learner move to different sections of the text.

In "Longman English Interactive", the user-friendly highlights are the integration of an English-English dictionary, a glossary, culture notes, and a grammar reference book, which can be accessible throughout the program. The translated versions of the cultural notes are available in Levels 1 and 2. 
"New Dynamic English" includes a very comprehensive study guide and user's guide. The study guide provides detailed instruction on all aspects of the program. The user guide explains, in equal detail, how to set up and use the program. Additionally, the program is accompanied by an Instructor's Manual that includes the key vocabulary and grammar focus for each lesson and a selection of follow-up exercises.

"Issues in English" gives learners choice of content, level, task type, sequence, learning approach and pace, and thus gives learners greater control over their own learning to accommodate individual needs. Learners are also given the option to read video transcripts while listening, if this is their preferred learning strategy. While learners may find this a useful feature, it is possible that they are not always the best judges of the most effective strategies to use when such options are given.

To encourage learners to listen first, before reading the text in the video activities, the author has built into the design of the program a 'no text' option as the default. However, for learners who are inclined to substitute reading comprehension for listening comprehension, more explicit guidance in appropriate strategies is likely to be required.

Learners will benefit most from this program working in 'Learn Mode' rather than 'Test Mode'. In the 'Learn Mode', feedback after each response rather than at the end of an exercise enables further attempts at a correct answer. The program attempts to compensate for the lack of interpersonal feedback by responding to answers with encouraging expressions such as 'Excellent', or 'No' with a rising intonation to encourage another try. Also, it is possible to browse questions before attempting to answer them, and to skip questions or exit the activity at any time.

What is not provided is a 'give up' feature to enable quick reference to a correct answer for learners who do not know and do not want to guess the correct answer. In the Vocabulary 'opposite meaning' activity, for example, a student is required to make 
three attempts before a clue (the next letter in the word) is provided. This requirement removes control from the learners, locking them into a tedious path of negative feedback as they work their way closer and closer toward the correct answer.

Some programs have very positive user-friendly attributes. For example, "Longman English Interactive" has a bookmark function to allow users to automatically continue working from where they leave off. With the network version, each user is given a user name and password, which allows bookmarks to be kept within users' folders.

Just like in the program "Longman English Interactive", one of "ELLIS's" best features is the ability of the software to provide assistance to the learner in the student's own native language. At the click of a mouse, learners can get help in their native language.

In "Tell me More", the menu bar at the top and bottom of the screen makes the program user-friendly and invites students to explore the available program features. Navigating each lesson is simple as learners can flip through each lesson by clicking on different lesson activities that appear at the bottom of the screen, including a visual prompt (i.e., a flashing green human icon) that allows learners to move to the next stage when they are ready.

The Help and Information feature that is included at the top of each screen is particularly useful because it offers step-by-step visual and textual cues for each of the screens. There is also on-screen help that appears whenever users click on a new activity. This screen asks users to choose whether they want to learn about the current screen or begin the activity. Users who do not want this option to appear every time they change screens also have the option of choosing the "don't show me this window again." Adult learners who want to spend more time on language tasks and activities 
rather than learning to operate the software will find this feature particularly useful because they activate the help feature and learn about the program only when they feel it is necessary.

The user interface of "Issues in English" is user-friendly in its simplicity of design, although it is not entirely intuitive. While an on-line help function is provided, it is limited to providing information about the use of icons in the interface, and is a little awkward to use at first. It is easy to forget that the help feature is turned on, and to get trapped in a 'help maze'. Whereas adequate information about icon functions, possible learning paths and learning strategies are provided in the printed manual, this information is not provided on-line.

In the program "Who's Oscar Lake?," a mystery game designed specifically for ESL/EFL learners, the learner must use problem-solving skills to solve the mystery. The student is supposedly led through a series of encounters with different characters that have information needed to solve the mystery. The virtual environment displayed by "Who's Oscar Lake?" makes it an attractive program. The characters in the game are fairly lifelike in movement and appearance. They speak with human voice at a reasonable speed. The other sounds, such as telephone ringing and cars whizzing by, are very realistic. However, the lack of user-friendly attributes in this program makes maneuvering around the game complicated. There are no clues on screen as to what steps to take to get the information necessary for the completion of the tasks. Besides being impossible to exit the activities once started, the successive trial and error approach makes activities take too long to be completed, what lowers levels of motivation.

In summary, the use of the ESL/EFL software evaluation instrument made it possible to analyze the user-technological interface in the programs. Results indicated that most of the software programs did not truly integrate the features of interactive 
CALL associated with the learner's interface. It seems that most program designers and publishers relied on the fact that the interface between learners and technology is highly correlated with how well users enjoy using a specific program, and put forth their best efforts in developing attractive software.

The overall analysis of how the ESL/EFL software programs incorporated technological features associated with interactive CALL should revisit the concept of interactive, since in the documentation of CALL programs this concept has become vague from overuse. In its simplest sense, interactive refers to a software program in which the learner has some small degree of choice, perhaps only in selecting answers to multiple-choice questions. Many of the analyzed software programs allowed for choices of question types, such as true/false, select an image or part of an image and move parts of picture or a sentence to correct positions. However, in more elaborate interactive programs, the learner should be able to enter into a simulated world, and make choices which would affect the direction of learning.

How the media technology differentiated feedback is another factor related to the level of interactivity between the learner and the computer. Besides allowing learners a second chance to correct their mistakes, the programs should provide some kind of explanation as to why the response was correct or incorrect and make it possible for the learners to access information (in hyperlinks, for example) that would clarify their doubts. Unfortunately, as the ratings for the Media Attributes and for the User-friendly Attributes indicated most of the analyzed programs still incorporated the simplest sense of the concept of interactivity.

Individualization of Instruction 
Do CALL programs present technological features that allow for individualized instruction?

Individualization refers to the fact that the computer enables students to work alone and at their own pace. To provide an individualized learning environment, software developers have to use a systems approach to design: a learning hierarchy is formulated, and a diagnostic mechanism is used so that either the computer program or the student can decide when the student needs to review (Dick \& Carey, 1978; Tennyson, 1981). This traditional view of individualization in CALL is now seen in a new light. Some educators have proposed that students use the computer as a means of exploring and playing with material (such as the target language) through group work tasks and student-initiated exchanges. Individualization is directly related to the type of social environment students create for their own learning experiences (Braidi, 2002; Mackey, Oliver \& Leeman, 2003; and Morris, 2005).

Results in Table 12 indicate that only one program contained over $70 \%$ of the technological features that allowed for individualization of instruction. Four other programs were rated between $50 \%$ and $60 \%$. The other ten programs contained less than half of the technological features that could allow for individualized instruction.

Technological features makes it possible for instruction to be individualized by: (a) allowing for different routes and choices of learning; (b) adapting to students' needs, interests, styles, and ages; and (c) helping learners move through content at their own pace and rhythm.

Allowing for different Routes and Choices of Learning 
Only three programs - "Discoveries", "ELLIS", and "Tell me More" - allow for different routes and choices for learning.

"Tell me More" offers three menus for navigating through the activities and lessons: 'Free-to-Roam' Mode, ‘Guided Mode' and 'Dynamic Mode'. The ‘Free-toRoam' Mode gives learners access to all the linguistic and pedagogical contents of the program. It offers a range of resources that are organized into six workshops: 'Lesson Workshops', 'Cultural Workshops', 'Vocabulary Workshops', 'Grammar Workshops', Oral Workshops', and 'Written Workshops'. The lessons in the 'Lesson Workshops' are based on communicative situations and descriptive themes. Using the same resources, the 'Guided Mode' suggests a learning path that corresponds to the learner's priorities (but is not based on any diagnostic evaluation). There are fifteen lessons included in this mode and 297 activities. The lessons are the same ones included in the 'Free-toRoam Mode'. Yet the activities that go with each lesson allow learners to follow an automated learning path. The 'Dynamic Mode' adapts the learning program according to the learner's goals and objectives. The screen includes a panel that offers learners the possibility to choose from three objectives: 'Predefined Objective', which asks learners to choose one of the possibilities - complete, compression, expression, vocabulary, grammar, complete beginner; 'Objective according to Ability', which asks learners to choose between oral comprehension or oral expression, and allow a choice of level - very easy, easy, medium, difficult, specialized; and 'Objective according to Knowledge', which targets grammar and vocabulary skills, which are also categorized according to levels of difficulty.

"Discoveries" offers two different 'learning approaches': an 'open approach' where users choose their own learning path, and three different kinds of "prefabricated lessons', within which users have to follow the sequence of each lesson. However, 
there is no orientation, or diagnostic evaluation, to guide the student in the choice of what path to choose or how to navigate through the 'open approach'.

"ELLIS" offers a placement test that suggests where the learner should begin. The placement test is correlated to the lessons in the three instructional levels and has reading, vocabulary, grammar, and listening sections with individual scores for each category. The "adaptive" nature of the placement test is worth noting. Starting at a midpoint of difficulty, subsequent questions will be easier or more difficult based on the number of correct answers in the preceding group. This makes the test more efficient since advanced students do not have to go through questions that are too easy and lower level students do not get overly frustrated attempting questions that are too difficult for them. However, after having the language proficiency level diagnosed, the learner has to follow a determined path.

Although, the programs "Issues in English," "Learn English Now," "Live Action," and "Talk Now" do not really allow for different routes for learning, they allow for choices of learning. These four programs give learners the option to choose from: (a) viewing and listening to the video; (b) listening to the video only; or (c) viewing, listening and reading the transcript of the video segment. They also offer the choice between listening to audio material in a 'normal' speech mode, or in a 'slower' mode. In "Learn English Now" learners can also choose if they want to listen and read about a certain theme (e.g., 'dining out') before listening to dialogs in the context of the theme, or if they want to begin from the dialogs and then move on to read about the themes. "Live Action" gives the learners the freedom to choose the order in which they want to cover the twelve units. However, all units follow the same path and format.

The way the other programs allow for different routes and choices for learning consists only of choosing whether or not to see the translation of the segment of the 
unit being presented and/or practiced.

Allowing Learners to Move Through Content at their Own Rhythm

All programs, except for one, allowed students to go through content at their own pace. In fact, this was the strongest feature of individualization of instruction displayed by the programs. For example, learners can view a video presentation as often as they want, and can repeat activities as many times as needed.

Features such as 'allowing for branching to new information', and 'allowing students to select activities according to their ages, learning styles, and interests' are the most problematic ones to be made available by the programs. Only three programs, "Discoveries," "ELLIS," and "Tell me More" allow for branching to new information. In these programs, learners can access cultural notes, grammar and vocabulary helpers at any time during presentations and activities. These programs are also the only ones that allow students to select activities according to their interests, since they are also the only ones that allow for different routes and choices for learning.

Adapting to Learners' Needs, Interests, and Styles

None of the fifteen programs adapts to the responses given by the learners, branching to more or less complicated questions as appropriate. As mentioned previously, "ELLIS" displays this feature in the 'placement test', but not within the units and lessons. An "adaptive" feature would allow for more motivating and relevant practice as advanced students would not have to go through activities that were too 
easy, and lower level students would not get overly frustrated attempting activities that were too difficult for them.

In summary, the use of the ESL/EFL software evaluation instrument to analyze the fifteen programs indicated that the weakest features in all programs were related to individualization of instruction, even though this is a very strong premise of Communicative Language Teaching. In fact, only one program has a built-in diagnostic mechanism that enables each student to proceed along a tailor-made path. It was observed that, although its potential has been demonstrated in research studies, individualization was not achieved at a sophisticated level in the analyzed programs. Very few programs presented activities and tasks that allowed for group work tasks and student-initiated exchanges.

\section{Principles of CLT}

Do CALL programs incorporate the teaching principles of Communicative Language Teaching into the elaboration of ESL/EFL software?

In the evaluation of the incorporation of the principles of Communicative Language Teaching by the ESL/EFL software programs, the ratings obtained by the programs in the category of Instructional Attributes were analyzed. These Instructional Attributes include: (a) the theory of language learning and teaching that underlies the program, (b) how content is presented and sequenced, (c) the type and quality of language-learning activities, (d) the type of feedback provided, and (e) how the program facilitates learning.

Four programs incorporated more than $70 \%$ of the principles of the Communicative Language approach into their elaboration - "ELLIS," Issues in English," "Longman," and "Tell me More." Five programs incorporated more than half of these 
principles - "Discoveries," "Learn to Speak English," "Live Action," "Side-by-Side," and "Who's Oscar Lake?." The other six programs incorporated less than 50\% of the principles of the Communicative Language approach into their elaboration (Table 24).

\section{Theory of Language Learning and Teaching}

The communicative approach of "Tell me More", the program with the highest rating for this category, is most apparent in the broad set of audio, visual and video materials that draw a clear distinction between fluency and accuracy. The dialogue exercises have been designed to promote fluency. The purpose is for students to use language without the intervention of a voice recognition feature to correct pronunciation and grammatical errors. For instance, in Seeing the USA, there is a dialogue that begins with "You are thinking of visiting the United States, what place are you going to visit?" Students can respond by stating, California, the East Coast, or Florida. If the student recognizes the picture of San Francisco on the left of the screen and responds by stating "California," a woman's voice says, "Ah San Francisco! Los Angeles! They're beautiful cities!." If the student responds by stating, the East Coast or Florida, however, the screen proceeds to the next question. It may seem that the computer's lack of response when the student's answer does not match the given picture tends to make the conversation artificial and somewhat mechanical. The fact that there is no right or wrong response, however, is consistent with a communicative approach that engages learners and prepares them to cope with a variety of everyday real-life situations that they may encounter in a foreign country.

The strategy of "ELLIS," the program with the second highest rating for the category of Instructional Attributes, is to create a "real world" learning environment for each lesson that is relevant to the student's life through the presentation of a short 
video segment. The dialogue from the video segment is transferred to the computer screen where the student is guided through a series of learning activities that include listening vocabulary, phrases, grammar, culture and pronunciation. Writing activities are provided in a companion workbook. Students are encouraged to speak English through the use of role play activities in which they assume the role of one of the actors in the video segment and insert their voice into the segment for playback and review. There are multiple practice activities that prepare students for their performance evaluations.

As the total ratings for the category of Instructional Attributes" approaches $70 \%$, the level of integration of the principles of Communicative Language Teaching declines. The programs rated third and fourth in this category, although presenting many of the features of this approach to language teaching, also display some behaviorist features.

"Longman," the program with the third highest rating in the category of Instructional Attributes, is an integrated-skills program based on videos offering learners opportunities to learn and practice communicative skills and functional competencies that they need in the real world. It does in fact provide authentic contexts and plenty of information on American culture with the culture notes. Notwithstanding, it must be said that there is much greater focus on receptive than productive skills (a behaviorist feature).

"Issues in English," rated fourth in the category of Instructional Attributes, combines a variety of facilitative, interactive and instructional CALL methodologies which reflect elements of behaviorist second language acquisition theories. However, in using an interactive CALL methodology, the program is able to partially compensate for an absence of interpersonal interaction. The design of the program facilitates a communicative style of learner interaction with the computer, and negotiation of 
meaning through a variety of media including print, audio, visual and audio-visual. The inclusion of contextualized tutorial information for various teaching points, immediate feedback on most tasks, and learner control over learning paths and strategies set the scene for active participation in learning. However, the program would be more instructive if learners were more informed of the choices available to them in respect to learning paths and strategies.

In "Live Action," rated $50 \%$ in the category of Instructional Attributes, while all of the exercises are instructional, no collaborative activities are included in the program. Neither does it provide sociolinguistic information about the context of activities or detailed grammatical explanations. These need to be provided by an instructor. "Live Action" is an engaging program for the purpose of developing ESL/EFL learners' vocabulary, especially that of verbs in imperative constructions. Through a variety of activities in one lesson, learners are supposed to internalize all the verbs in addition to the basic vocabulary in the lesson. However, there is a potential weakness in this program deriving from an inherent limitation in the TPR approach. Although each lesson has different themes, repetitive activities involving commands and physical responses to the exclusion of other activities could become monotonous to learners. Use of imperatives provides very limited language input for learners. Moreover, the relevance of some of the vocabulary used in the program in relation to the needs of the target audience is uncertain.

"Learn to Speak English," rated $53.57 \%$ in the category of Instructional Attributes, is communicative, because rather than teaching grammar or vocabulary out of context, it proposes authentic-looking videos of typical situations, and expects the learner to listen carefully, understand and repeat what native speakers say in those situations. The communicative approach adopted, with authentic dialogues and a variety of activities based on them, can certainly improve receptive skills in the learner. 
However it is unfortunate that there are no creative possibilities for the student, no collaborative activities, no open-ended activities. For listening comprehension, overall understanding of English and passive vocabulary acquisition the program does an excellent job, and this in itself is a good achievement. However, the computer has to be (and can be) used in different ways to encourage and improve productive skills.

\section{Content Presentation and Sequencing}

To a greater or lesser degree of sophistication and with some minor variations, almost all units in the analyzed programs followed the same basic pattern: presentation, practice, and production (Beagle, 2002). The only exception to this pattern was "Who's Oscar Lake?.” Its game-like approach introduced the learner to the vocabulary and structures of the language as he/she played the game, trying to discover who is Oscar Lake.

\section{Activities}

In all programs, there was a variety of activity types such as drag and drop, multiple choice, fill in the blanks, dictation, cloze questions and speech recognition. However, most of them practiced the same type of grammar, vocabulary, listening, reading, speaking, and writing skills (usually much more in terms of decoding and lower level skills than in terms of higher-order thinking and problem-solving skills).

Among the analyzed programs, "Tell me More" had the widest range of activity types. For example, activities included: dialogue (in which the new vocabulary and language structure(s) are presented), sentence pronunciation, word pronunciation, phonetic exercises, picture association, word searches, word association, the right 
word, fill-in-the-blanks, words and topic, words and functions, grammar practice, mystery phrase, crossword puzzle, word order, sentence practice, dictation, glossary, video and questions, grammar explanation for the lesson, text transformation, and written expression.

The methodology underlying "Tell me More" subscribes to a communicative approach even though most of the activities were structure-based and involved simple picture/word association, contextual sentences and pure structure manipulation, etc. The activities were designed to foster language usage and resemble a series of everyday situations that might arise when learners attempt to communicate in English. In addition to video-clips, students interact with the computer and answer context specific questions that a friend, colleague, travel agent or flight attendant would ask them in real life.

Moreover, in the advanced level version of "Tell me More", the text transformation and written expression features have automated assessment technology that identifies students' writing mistakes. In the text transformation activities students are presented with a short paragraph based on the video clip and are asked to transform it from one grammatical structure into another. The program shades the sentences that contain errors and draws a red line under the misspelled or grammatically incorrect words. Once students correct the first error, the program underlines the next error until all are corrected. If students do not know what the right answer is, they can click on a light-bulb icon to see the solution at the bottom-right of the screen. The program presents students with the correct text and gives them a grade that is presented on a percentage assessment bar. As for the written expression exercise, it is an activity in which students view a video clip that may or may not include an oral narrative. They are either prompted to summarize the narrative or describe what they think the series of visuals is about. 
In "Longman," as in most of the analyzed programs, there is much greater focus on receptive than productive skills. Speaking practice is not really speaking but rather practicing the scripted dialogue. Grammar exercises are just simple multiple-choice, drag and drop, or filling the blanks. Nevertheless, the sequence and organization of the software are pedagogically sound. Its variety of exercises helps learners stay motivated while using this program. The methodology underlying the program is a combination of exposure to authentic language usage, i.e., comprehensible input (Krashen, 1982), simulated oral communication practice, deductive grammar, plus drill and practice exercises.

"Longman" provides learners plenty of listening comprehension activities and is designed so that listening and speaking exercises are practiced before a Grammar section. Activities include comprehension and discussion of video clips, performing scripted dialogues, grammar drills, practicing functional expressions as presented in the Speaking section, practicing vocabulary items in the presentation of researched information.

Also, as in most programs, in "Live Action" exercises focus mainly on listening comprehension of imperative phrases and new vocabulary without any direct reinforcement of grammatical structures except for verb tense. The intent is to allow learners to focus on their listening and pronunciation without any pressure to speak. However, because of its TPR approach, activities always follow the same sequence in all the units: 1) Listen and watch, 2) Listen and do the actions watching the video clips or photos, and 3) Listen and do the actions without watching.

In Watch, learners listen to a sequence of imperatives watching a video or animated photos, upon which the rest of the unit is based. Then Listen asks the user to listen to a sentence and select the right video clip. After learners become immersed in the topic with Watch and Listen activities, they are asked to do a drag-and-drop 
exercise in the Interact section, which is claimed to be dynamic and interactive. In this activity, the user listens to an imperative and interacts with the screen to make things happen. Some units have slightly different formats than others. The Watch \& Read mode is a repeat of the Watch section but with the written text on the right-hand portion of the screen. Watch \& Read is the first introduction of a full set of sentences in writing. It allows users to click on any sentence to hear it and see it enacted. In the Order section students are asked to drag sentences into the correct order. In the Verbs section, different tenses of the verbs that appear in the unit (such as the simple present, the present progressive, the simple past or the future with going to and will) are introduced and practiced through either fill-in-the-blank or multiple-choice exercises. Though the vocabulary is the same as used elsewhere in the lesson, here the verbs are integrated into a brief story, so that their forms are practiced in context, rather than in isolation or in single out-of-context sentences. The Verbs section also has a built-in capacity for varying the difficulty level of the exercises by turning the sound on or off, and by showing or hiding the selection of verbs or verb forms. . With the sound off and the selection hidden, the activity is a cloze exercise where the learners have neither visual cues nor audio cues; they must rely only on the context and their own memories and comprehension of the language and vocabulary.

As mentioned previously, with a greater or lesser variety of activities, the programs cover the same language aspects: vocabulary, grammar, pronunciation, listening, reading, speaking and writing. In all programs, there are a lot of listen and repeat activities. In fact emphasis is placed on the role of repetition in acquiring good listening skills.

Facilitation of Language Skills Development 


\section{Listening}

"New Dynamic English," for example, explicitly promotes itself as a listening based interactive multimedia course in spoken English for young adult/adult learners. The advertising claims that Dynamic English provides sophisticated, highly motivating speaking practice with engaging age-appropriate content. As the program proceeds the language structures are capable of becoming more complex depending on the learners' response, mainly due to the shuffler feature. There seemed however to be a mismatch in the variety of language structures presented at a certain level. For example, the elementary style of narration in "Dynamic English" Level 2 quickly developed through a broad language variety, requiring the listener to cope with more advanced sentences and structures. The Instructor's Manual states that: "As a listening based course, Dynamic English is best used with students who find the lessons somewhat challenging." (p.2). It goes on to say that "students working on a particular lesson should be able to understand the basic meaning of most sentences in one or two listenings, with the help of the graphics that accompany the narrative, but it would be quite difficult for them to produce the sentences orally." The emphasis is on reception rather than production.

Although the publishers of "Longman English Interactive" claim the program develops all language skills, there is an evident emphasis on listening, as the following description of the sequence of activities exemplifies. Learners are expected to view each clip three times. Before viewing the first time, students are asked one or more prediction questions. After viewing a second time, learners answer comprehension questions. Upon a third viewing, they are given exercises that focus on the vocabulary and grammatical structures use. In levels 3-4, feedback loops on incorrect answers allow users to access the exact part of the video that will help them answer correctly. 
The Listening Challenge section of Levels 1 and 2 of "Longman" extends the main dialogue through video practice with higher-level language. In the "More Listening" section, learners listen to an audio recording that is thematically related to the videos, often a telephone conversation, and answer comprehension questions about it. Transcripts and translations are available throughout Levels 1 and 2 . In the Task Listening section of Levels 3 and 4, students listen to an audio clip that is related to the video listening topic and complete a task interactively with Flash animation. Task types include sentence reconstruction, picture or vocabulary matching, and identifying the order of appearance in the audio clip. Interactive animation provides instant feedback. At all levels, the playback interface allows learners to go back to any section, and points to which they should be paying attention are noted.

\section{Speaking}

In all programs, the development of the speaking ability is most of the time limited to the development of pronunciation skills, and the development of pronunciation skills is restricted to the pattern of Listen, Repeat, Listen and Compare.

In the Speaking section of each topic and level in "Issues in English", for example, learners can record their own voice and compare their pronunciation of words from the spoken text with that of a native English speaker. The pronunciation activities provide meaningful language practice to the extent that the words and sentences included in the practice activities are extracted from or based on the language from the video clips. While this approach is a pedagogically appropriate use of context-based language, it is unfortunate that opportunities are not provided for learners to practice and compare their pronunciation of larger sections of the continuous speech from the video clips. Such interaction could enhance awareness of the prosodic features of natural and continuous speech - accent, intonation and rhythm. 
Nevertheless, some programs, like "Longman," try to add a more communicative approach to the development of pronunciation skills. For example, the Speaking section of levels 1-4 includes role-play. Students can record and replay as much as they wish while engaging in scripted conversation with a video character. Though called role-play, it is really the practice of a scripted dialogue. In levels 3-4 learners hear expressions spoken and then are asked multiple-choice questions to test their understanding. The difference between the Speaking and the Pronunciation sections is that in the Pronunciation section the focus is on intonation, rhythm and word stress as well as more traditional consonant/vowel comparison exercises. In both sections, learners first check their ability to hear the specific point, and then record their speech for comparison with the models provided and answer multiple-choice questions with extra practice when necessary.

In addition to the 'speaking' and 'pronunciation' sections included in the different levels of the program, "ELLIS" also includes a Master Pronunciation CD, which is a practice program for pronunciation skills and accent reduction, and an online computer-adaptive assessment called Placement that indicates which programs and where within that program the student should work.

The ability to record and immediately compare one's pronunciation and phrasing to a native English speaker is particularly popular among all programs. In most programs, it is fine if the recording gets closer to the model. After all, most programs do not have effective built-in speech recognition devices.

In most programs, the generic voice recognition can be very frustrating to a student who is simply trying to learn the language. The more fine-tuned, high-end voice-recognition software can be "educated" to recognize speech patterns and accents of specific individuals and its tolerance levels for variations from the "norm" can be regulated to allow a great deal of flexibility in accepting answers that may be 
correct but just not pronounced that perfectly. Some of the analyzed ESL/EFL software programs manage to have hit a fairly happy medium, but many of the lower-end natural-speech voice recognition engines used in the ESL software programs do not allow for much deviation from the "broadcast English" norm. Thus, even a native speaker of English (in some programs) may not pass the oral component of a placement test or even get very far along in an oral practice without receiving negative responses. Encouragement, positive responses and lots of opportunity to practice are some of the key elements in learning a language and a voice recognition component can sometimes work against a learner.

\section{Reading and writing}

As with speaking, the development of reading and writing abilities in most of the analyzed ESL/EFL programs is limited to the development of lower-level skills. In reading, practice is restricted to decoding and literal comprehension skills, and in writing to spelling, word order, and sentence formation.

For example, in "Longman," in the Reading section, a short article on the topic of video listening or task listening is presented. Learners preview the topic and vocabulary by answering multiple-choice questions or dragging and dropping the right phrase or word. Feedback contains no explanations of errors. In the reading passages, selected words are hyperlinked to the Glossary. Multiple-choice questions are provided for checking comprehension. For Levels 1 and 2, instructions are translated with transcripts and cultural notes.

"Live Action" offers a good example of how limited the scope of the writing sections in the programs are. The Write section is a dictation exercise to type complete sentences with word-by-word feedback routines to edit and guide learners' answers. 
As indicated in the manual, beginners may delay the last two activities, Verbs and Write, until a later time since these two are most difficult. The transition from listening to reading to writing follows a key tenet of TPR and other listening approaches to language learning—sufficient input should precede production. The program has a scorecard feature which allows users to print out their record (name, date, numbers of correct and incorrect answers), results however cannot be saved within the program itself.

"Issues in English" offers an example of the problems that arise when the writing activities attempt to go beyond the scope of handwriting, punctuation, word order and sentence formation. The Writing section of the program also includes activities and exercises on punctuation, comprehension and expressing opinion at each of the four levels. The writing activities are well structured and appropriately scaffolded from level to level, with tutorial support provided for Punctuation, What Do You Think? and Summary Writing activities. In addition, Levels 3 and 4 introduce the steps involved in summary writing. Apart from punctuation, which is a multiple-choice type of exercise at Levels 1 to 3 , all other Writing activities involve open written responses which require teacher feedback. However, there are a number of problems relating to response handling and feedback which could have been avoided, to some extent, by providing additional instructions and information at various points in the activities. Firstly, the open-ended written exercises require teacher feedback, but the program does not notify the learner of this. Thus students tend to become confused when the computer does not provide feedback. Secondly, the open-ended exercises often do not include clear instructions notifying the learner of the option to use pen and paper. Learners who find typing into text boxes slow and tedious may not be aware that the handwritten approach is an option - they may, after all, be expecting feedback from the computer. Thirdly, a more significant problem presents itself if learners wish to 
refer back to a video clip to complete a task, as the video clip is located on a different screen from the response box. This occurs with summary writing activities at Level 3, in which the task is to identify and record the main ideas. The learner who attempts to respond to the task on-screen, rather than on paper, is faced with the additional cognitive load of retaining information while moving between screens. The program is perhaps also overly ambitious in attempting to incorporate instruction about writing conventions, when the only models used are transcripts of spoken language.

Although "Tell me More" is unquestionably a program that incorporates many of the features associated with the principles of Communicative Language Teaching, the only pedagogical concern that the program raises is its approach to writing, in particular the use of its automated assessment feature. In the text transformation activities, the program only corrects students' punctuation and grammatical errors, focusing on surface level accuracy rather than fluency. The goal of most writing tasks at the advanced level is to improve the ability of learners to produce a text that is based upon their own interpretation of particular video clips or reading texts. The program, however, does not encourage students to write argumentative or persuasive essays. In fact, the sample paragraphs that the program supplies range from five to eight lines that do not adhere to the conventional structure (i.e., introduction, body and conclusion) that one would expect at the advanced level. While students may learn to detect their punctuation and grammatical mistakes, they learn very little about how well they express meaning or write an argumentative or expository essay with supporting paragraphs. Moreover, sample answers that are given at the bottom of the screen merely provide a short descriptive paragraph that focuses on the setting and people rather than the possible dialogue or project at hand. While, admittedly, it is beyond the limits of current technology to intelligently handle discourse analysis, model answers should at least incorporate an introduction, body and conclusion and provide argument 
and supporting evidence. Such features are critical to learning how to write essays at advanced academic levels.

It follows that the writing activities in "Tell me More" do not take into account the complexity of writing and writing assessment, including students'/teachers' backgrounds, expectations, experiences and perceptions of the world. In the light of the complexity of the writing process, it is no surprise that the automated assessment feature of "Tell me More" falls far short of the kind of evaluation provided by an instructor. Furthermore, it is even less useful than the automatic correction provided by a standard word processor spell/grammar checker.

In order to make better use of the software programs' writing tasks, it is important for instructors who use them to alter, change and adjust the writing tasks to accommodate their students' particular needs. It is equally important for instructors to make the appropriate corrections to the essays. Computer software assessment ignores the social dynamics of writer, reader, and text. By handing essays over to computers, educators not only abandon their professional roles, but also relegate writing to a space where no reader ever existed. Automated essay assessment, in turn, silences the very students that educators want to help.

\section{Grammar and vocabulary}

The approach to the teaching/learning of grammar adopted by most programs follows a 'structural' organization of grammatical structures across the levels, that is, it sequences them according to a particular view of levels of grammatical difficulty. Exercise types include multiple choice, fill-in-the-gap or complete the sentence. Mostly, these involve transformation of a given grammatical structure for which feedback is provided. In some programs, tutorial information is available to support the activities. 
For example, in "Longman," each unit contains three grammar presentations which consist of a short video with the Grammar Coach introducing the essential points. Presentations are done with a Flash animation using sound and animation with color, spelling and size changes to illustrate key points. Text animations often demonstrate grammatical points, such as transformations and insertions. In order to take full advantage of animation effects, users need to both listen to audio and watch the animation. From the presentation learners can access the Grammar Reference that provides definitions of grammar terms and additional information on form and usage. Two exercises with multiple-choice questions, fill-in-the blank or dragging exercises follow the presentations, giving instant feedback with an additional opportunity to answer. Clicking on a little $<\mathrm{e}>$ gives an explanation.

With the exception of "Rosetta Stone", vocabulary presentations are contextualized in all programs. In some programs, vocabulary items are presented after a reading text and/or listening (and sometimes viewing) passage. In others, like "Learn to Speak English," before listening to the dialogues in 'Story and Action', learners are shown most of the vocabulary they contain, and can hear individual words and expressions, or the words or phrases in context - as used in the dialogue - as well as get English translations. Each chapter practices around 30 "essential" words or phrases, for a total of 900 , and learners can also see "extra" vocabulary, which should almost double the number, though in some chapters ( 15 for example) many extra items turn out to be also on the "essential" list.

The programs, however, present no discussion of the differences between spoken and written modes of language (functions, forms and linguistic characteristics), or more specifically the differences linked to levels of formality that exist between social formal and informal interactions and personal and academic writing. Certain vocabulary and grammatical constructions, though normally avoided in formal contexts, are 
acceptable in informal speech and personal forms of writing. For example, in the program "Issues in English", even in the Gambling Level 4 transcript (the most formal level of spoken language in the program), informal language such as contractions (there's, can't) and other expressions (So I guess and guesstimate) are used. At Level 3, the language is less formal - Well; Anyway, to cut a long story short; Oh, it wasn't too bad. While the program does provide meanings for some of the informal expressions, it would perhaps also have been useful to include comment on language use, that is, information about levels of formality and the appropriateness or otherwise of using informal expressions in written texts.

In general, the vocabulary and grammar sections of the analyzed ESL/EFL programs do not go beyond the development of syntactical and lexical competencies.

In summary, the analysis of the Instructional Attributes of the programs indicated that the pedagogical shortcomings of these programs are chiefly related to their limited capacity for dealing with language in a meaningful way. Many programs were not able to simulate the complexities of human language as it is used for communication between individuals. To do so, the programs should have allowed for communication to take place within complex webs of social, physical, cognitive, and experiential factors that constitute communication. While a few programs could provide opportunities for some types of language learning activity, most of them fell short when it came to realistic, communicative practice. This was particularly problematic as Communicative Language Teaching places special emphasis on productive, meaningful use of language in all its complexity.

Principles of CLT and an Interactive Approach to Computer Use for Language Learning 
In sum, to what extent do CALL programs create environments that develop language according to the principles of Communicative Language Teaching and interactive approach to computer use for language learning?

Results shown in Table 26 indicate that only two programs created environments that developed language skills according to more than $70 \%$ of the features of Communicative Language Teaching and of an interactive approach to computer use for language learning. Two other programs created environments that developed language according to more than half of these features. All other programs were not able to attend to even half of the features that create environments that develop language according to Communicative Language Teaching and an interactive approach to computers for language learning.

The use of the ESL/EFL software evaluation instrument to analyze the programs provided evidence that the key differentiating factor in ESL software programs lies not only in their pedagogical orientation, but mainly in how they incorporate this orientation into their design. As previously stated, the criteria used in the elaboration of the ESL/EFL software evaluation instrument were based on the principles of the Communicative Language Teaching approach. Although all programs claim to incorporate communicative theories of language learning into their elaboration, they seem to have, to a greater of lesser degree, difficulty in elaborating activities that would develop language skills according to this approach. Communicative Language Teaching principles were incorporated in theory but not in practice in the programs. The syllabi of most programs presented characteristics of Communicative Language Teaching. However, the activities they presented were different from the type of activities that would aim to develop language skills for communicative purposes.

In effect, underneath some fancy graphics, sound effects, and an input device, 
the human-machine dialogue provided by these programs was essentially the same as the bare bones exchanges in the first stages of CALL. These programs, by virtue of more sophisticated visuals and possibilities for screen manipulations, were certainly more comfortable and empowering than the first commercial ESL/EFL software programs. However, the fact that the current programs have become more attractive as processing power increased has not changed the elemental format for machine-user interaction: same dialogue, new interface.

In order to have truly incorporated the principles of the Communicative Language learning, the programs should have encouraged student-to-student interaction, and thus would have overcome their shortcomings as a means of communicative practice. In other words, explicit cues for paired student-student conversation could have been built into these software programs. All programs failed in cueing interaction by stimulating student exchange through visual and accompanying text prompts. Unfortunately, all the analyzed programs were designed for the single user, even when they came in lab versions. In the programs that allowed for lab use, the onus for orchestrating and prompting purposeful communication around these software programs was on the teacher.

\section{Limitations of the Study}

Several limitations complicate the discussion of the results of the validation of the ESL/EFL software evaluation instrument and of the results of the analysis of the ESL/EFL software programs. 


\section{Participants}

The study participants were either Brazilian EFL teachers or American ESL teachers. These teachers do not represent all the EFL/ESL teacher population, since teachers from other countries where English is taught either as second or a foreign language were not represented in this study's sample. Thus, the sample represents a portion of the whole population of ESL/EFL teachers.

\section{Study design}

The study design consisted of the evaluation of three ESL/EFL software programs using the ESL/EFL software evaluation instrument. The method consisted, therefore, of an introspective judgmental evaluation, which can arguably be done purely individually, subjectively, globally and introspectively (Scholfield, 2000). No experimental studies were undertaken to test if the way learners responded to the programs matched the expectations raised by the evaluation of the programs using the ESL/EFL software evaluation instrument.

Also, because participation was voluntary, the teachers who agreed to participate may have knowingly or unwittingly biased the study results. Although the items in the ESL/EFL software evaluation instrument were objectively based on a set of criteria, every introspective evaluation involves a certain degree of subjectivity.

\section{Materials}

Limitations of the availability of enough demonstration CD-Roms to be distributed among the participating teachers did not allow random assignment of 
software programs to the 26 raters for the items in the ESL/EFL software evaluation instrument. Additionally, the 26 teacher-raters evaluated the three assigned programs by analyzing the sample lessons included in the demo CDs, and not the whole software program. Since the analyzed lessons were included in a demonstration CDRom (and the purpose of a demonstration CD is to advertise and sell a software program), it can be argued that the lessons might not be good representations of all the other lessons of a software program, and so, of the programs as a whole.

\section{Reliability and validity}

In order to measure the validity of the ESL/EFL software evaluation instrument, two reliability measures were pursued: inter-rater reliability and internal consistency, and content and face validity were verified. However, although the inter-rater and the internal consistency coefficients were high, and the two experts granted face and content validity to the instrument, other types of reliability and validity measures, such as predictive validity, were not undertaken. Also, since the data used for the reliability tests came from a sample of convenience, it is important to run the same tests with data from a larger and more diverse sample of the ESL/EFL teacher population.

\section{Limitations of the Evaluation of the ESL/EFL Software Programs}

\section{Study design}

The evaluation of the fifteen ESL/EFL software programs currently available on the market was an introspective study based on the results of the ratings for these programs using the ESL/EFL software evaluation instrument. The analyzed programs 
were not experimentally tested with ESL/EFL learners in an actual learning environment. Therefore, the discussion of the results of the analyses can only be interpreted in the light of the potential of the analyzed ESL/EFL software programs to develop language skills according to the principles of the Communicative Language Teaching and an interactive approach to computer use for language learning.

\section{Materials}

This study investigated the extent to which Computer Assisted Language Learning software material available on the market is suitable for developing ESL/EFL skills according to the Communicative Language Teaching principles and an interactive approach to computer use for language learning. It was limited to CALL software programs available on the market after 1990 since the interactive framework on pedagogical use of computers, adopted in this research, only began to be implemented in the nineties. Also, CALL programs available only online were not examined since these programs are usually kept online for a limited time. As the focus was to study how closely ESL/EFL software matches current theoretical understandings, no generalizations can be made about the extent to which online computer programs actually help develop language skills according to the principles of Communicative Language Teaching and an interactive approach to computer use for language learning.

\section{Implications for Further Research}

The results of this investigation suggest specific areas for further research. Additional studies using the ESL/EFL software evaluation instrument might further 
confirm the reliability and validity of this instrument. Additional studies should consider other types of reliability and validity measures.

Future studies should incorporate more diverse populations of ESL/EFL teachers, and include teachers from different countries. Besides, further studies should also use a larger sample of participants. Furthermore, the evaluation of ESL/EFL software programs should be done through the analysis of the whole programs, rather than just through the analysis of sample lessons in demonstration CD ROMs.

Also, other experts should be asked to evaluate the extent to which the items in the ESL/EFL software evaluation instrument comprise the set of criteria to be taken into account when assessing a software program's potential to develop language skills according to principles of Communicative Language Teaching and an interactive approach to computer use for language learning. These additional studies would grant the ESL/EFL software evaluation instrument more reliability and validity.

Further studies should also attempt to use the ESL/EFL software evaluation instrument to evaluate not only commercial software, but also software programs privately developed by universities and other language learning institutions. Also, future research should evaluate CALL programs available on the Internet

Finally, other methods of investigating ESL/EFL software programs should be pursued. It would be relevant to first analyze an ESL/EFL software program using the ESL/EFL software evaluation instrument, and then have a group of ESL/EFL learners use this software program in order to see if the way actual learners respond to the program corresponds to the expectations of the program to potentially develop language skills according to the principles of Communicative Language Teaching and an interactive approach of computer use for language learning.

All studies on CALL programs should continue to document information on the effectiveness and limitations of computer technology for language learning. Additional 
information would help the development of CALL programs both in terms of their potential use for language learning as well as in terms of the areas that need further improvement.

Implications for the Development of Software Programs

The results of this study encourage the development of alternative approaches for language learning through ESL/EFL software programs. The evaluation of the programs in this study indicated aspects of software programs that need refinement if they are to develop language skills according to the principles of Communicative Language Teaching and an interactive approach to computer use for language learning. Specifically, ESL/EFL software programs should be designed to:

1. Individualize instruction to match learners' needs, interests, and learning styles.

2. Allow for unexpected communicative situations, in which the learner would be able to interact without a script.

3. Develop competencies other than lexical and syntactical.

4. Provide feedback for expected and unexpected errors, and adapt the level of difficulty of the activities according to the responses given by the learners.

5. Specify the type of mistakes the learners make giving them the opportunity to self-correct their mistakes before providing the correct response.

6. Allow for collaborative work among learners and between learners and the instructor.

7. Provide accessible information (background knowledge: linguistic, cultural, factual) necessary for the accomplishment of the activities and tasks. In order to individualize instruction to match learners' needs, interests, and learning styles, software programs should be able to provide learners different 
instructional paths to achieve a common goal. This would mean that software programs shift from the traditional presentation - practice - production (PPP) approach to a task-based approach in the organization of their syllabus (Willis and Willis, 2001, p.174), in which "language forms are not prescribed in advance" and learners are free to use any linguistic form they can to complete a required task in the target language. Tasks are activities in which the target language is used by the learners for a communicative purpose in order to achieve an outcome. They are therefore goaloriented.

For example, instead of starting a lesson with a video clip of students meeting and greeting each other on the first day of school, and having them listen to people's social interactions (presentation), repeat the interactions (practice), and then role-play the interactions with the pre-recorded voice of an 'imaginary' person (production), programs should begin a lesson by introducing the task learners are to perform to achieve their goal. Using the same example, learners could be given the task of having to get to know their classmates on the first day of school. In this case, learners would have to use the target language in order to meet their classmates.

One question could be raised then: How could this be done if the learner is sitting by him/herself in front of a computer screen? A possible solution would be then to create a virtual classroom in which the learner would log on as one of the students in the classroom as an avatar ${ }^{4}$. The other students in the virtual classroom could be other learners also doing the same lesson and logged onto the same virtual environment, or virtual classmates role played by recorded voices that would respond accordingly to the language interactions initiated by the learner.

\footnotetext{
${ }^{4}$ Avatar is an icon or representation of a user in a shared virtual reality; avatars are used in MOOs to represent a person and can be manipulated to move around an environment and interact with other participants' avatars. MOO - MUD object oriented - is a derivative of MUD and is a text-based online virtual reality system to which multiple users are connected at the same time.
} 
However, if the learners did not know how to introduce themselves and meet other people in the target language, they would not be able to accomplish the given task. That could be solved if the program also provided a series of closed tasks to be performed before learners attempted to do the open task ${ }^{5}$. In the example being used to illustrate this approach, the closed tasks could be: (a) ask if that is Professor X's class, walk into the room and sit at an empty desk; (b) turn to someone next to you, say "good morning "and your name; and (c.) say "nice to meet you" to the person you introduced yourself to.

However, if the learners did not know, for example, how to ask if that was Professor X's class, they would have the option to ask for 'help'. A drop-down menu, for example, could show a video-clip of someone performing the same closed task. In case that is not enough for the learners to feel confident that they could perform the task, they should be given the opportunity to practice this type of interaction before having to perform it. From that moment on, the learning mode would switch to a PPP approach. Once the stages of presentation and practice were covered, the learners could go back to the virtual environment and perform the task (production). Learners would be given different paths to achieve the same goal based on their language needs and interests. Not all learners would have to go through the stages of presentation and practice of a specific closed task, nor would all learners have to go through all presentation and practice stages of an open task.

Programs should also be able to individualize instruction by allowing learners to choose their learning route. In this case, a set of different tasks could be provided for

\footnotetext{
${ }^{5}$ According to Willis (1999, p. 28), closed tasks are highly structured and have very specific goals. They are presented with very precise instructions, the information is restricted and they allow for only one possible outcome. Open tasks, on the other hand, are loosely structured and have a less specific goal.
} 
the achievement of the same language learning goals. For instance, learners should be able to choose if they wanted to do: task 1 - get to know your classmates on the first day of school; task 2 - get to know your colleagues on the first day of work in a new job; or task 3 - get to know the people who live around the house you have just moved into.

If, on the other hand, the learners do not feel confident to perform the assigned task because they lack some factual or cultural information on the topic, programs could make use of hypermedia to provide learners with assistance in accessing and organizing necessary information. As Dede (1997) states, learners should be able to quickly access various links that could supply the information they needed. Specific tasks, and/or lessons, should be hyperlinked to specific cultural and/or informative sites where the necessary information could be found.

Besides allowing for instruction to be individualized to match learners' needs, interests, and learning styles, a task-based approach would also allow for unexpected communicative situations, especially when learners perform their tasks logged onto a virtual environment in which the other people in the environment would also be actual learners logged on as different avatars. Although given the opportunity to practice the language in more controlled situations (through a scripted role play, for example), the learners would not have to follow the same scripted interactions in the virtual environment. Additionally, this type of approach would also allow for implicit negative feedback, such as recasts and negotiations of meaning (Ayoun, 2001; Han, 2002; Leeman, 2003; Long, Inagaki, \& Ortega, 1998; Mackey \& Philp, 1998; Morris, 2002; Muranoi, 2000; Nabei \& Swain, 2002).

In order to make this approach instructionally relevant to the learners, software programs would need to provide for feedback that is adaptive, and goes beyond the scope of correcting grammatical and lexical mistakes. 
Software programs would first signal the mistakes before correcting them. For example, if a learner responds to the question, "What's your name?," made by another learner while both are performing the task of getting to know their classmates on the first day of school (using the same example given above), with "is John," the software should signal to the learner that there is a problem with the language he/she has used. If the task is being done in the virtual environment, the software could either provide a transcript of the learner's language interactions, or record these interactions to be played back, once the task is achieved. If the language exchanges are presented as written transcriptions, the mistake can be underlined or bolded. If the language exchanges are recorded and played back, there can be some kind of pause after the mistake. Additionally, software programs could specify the type of mistakes made by the learners. Further, if learners were presented with the transcript of their language interactions, mistakes would be underlined or bolded, and the type of mistake would be specified; e.g., "subject-verb agreement," "word order," "sentence stress," "word choice," "usage," "run-on-sentences," "lack of topic sentence" (in a writing task, for example), etc.

Learners could then be given the choice of either going back and performing the same task again, if they can recognize the type of mistake they made and know how to correct it, or to ask for 'help' to clarify the mistake. Help could also be presented as a drop-down menu, in which the specific language structure, vocabulary item (in case the learner made a lexical mistake), or phoneme, word/sentence stress, or intonation (in case of pronunciation mistakes) would be presented and explained.

Furthermore, software programs should also be able to adapt the level of difficulty of the activities and tasks according to the responses given by the learners. For example, if the learners while performing a certain task repeatedly made the same type of mistake, e.g., "is John," "am from Brazil," or "is Professor X'S class?," the 
software could recommend that the learners focus on that grammatical structure. In this case, the learners would be taken to a 'grammar lesson' (which could also be presented by a drop-down menu). Also, instead of presenting the grammatical aspect as a piece of prescriptive grammar, the 'grammar lesson' could be presented through an inductive-deductive approach. In addition, the 'grammar lesson' could provide specific grammar activities concerning the grammatical aspect being learned. If learners succeed in the first set of activities in the 'grammar lesson', they should be informed that they are ready to go back and try doing the task again. If they made many mistakes, reinforcement of the language pattern could be provided, and learners could attempt another set of activities, and so forth. This approach could be used for repetitive grammar, lexical or pronunciation mistakes.

Finally, a task-based approach would also allow for collaborative work among learners and between learners and the instructor depending on the type of the task assigned for the learners.

For example, at an early language developmental stage, learners could be given the following task: You and a friend are traveling by car. You are both tired and decide to stop at a motel to spend the night. You take an exit and get into a small town. Find the motel you have marked on your traveling map. One of you is the driver and the other is passenger holding the map and guiding the driver. In this case, the two learners would first have to decide which role to take. Then, one learner would log on as the driver while the other would be the passenger with map. A virtual environment would allow the task to sound and look real and authentic. Since the passenger was the only one who could see the map, he/she would have to give directions to the driver. The driver, in turn, would need to be able to correctly follow the passenger's directions while driving. Both the driver and the passenger would have to collaborate in order to accomplish their goal - to arrive at the specified motel. This is an example of a task 
that could be used at a beginning level and that would aim at practicing listening and speaking skills, and giving and following directions.

Tasks could also develop several language skills. For example an open task could be: You and your classmates are not happy about the principal's decision of having students wear uniforms for the next school year. Write a persuasive letter to the principal presenting the reasons why uniforms should not be made compulsory in the school. Remember that to be persuasive you and your friends must provide strong and concrete arguments to the principal. In groups, decide what you should all include and write the letter.

In this example, the task would be for a more advanced proficiency level. In groups students should decide how they would make their arguments convincing. Suggestions of how to approach the task could be made by the program. For instance, the program might suggest (as closed tasks): do a survey around the school to find out how other students and teachers feel about wearing uniforms; research the internet to find how many and which schools in your town require the use of uniforms, etc... In this case, although the skill being practiced in the open task is writing, the closed tasks could aim at developing listening and speaking skills, besides note-taking; researching skills, etc...

In summary, computer programs can provide specific opportunities for collaborative work among learners to accomplish communicative tasks. These collaborative tasks can in turn provide the authentic context for meaningful language interactions. Authentic context for meaningful interactions can in turn be facilitated by a combination of virtual reality with multimedia integration of sound, animation, and fullmotion video. The concept of interactivity should be expanded beyond the scope of learner-computer interactions. In a more elaborate interactive learning program, 
learners could enter into a simulated world and make choices which affect the direction of learning.

This view of CALL is based on a socio-cognitive view of language learning, and involves apprenticing into new discourse communities. The purpose of interaction is to help students learn to enter new communities and familiarize themselves with new genres and discourses. From this point of view, the content of the interaction and the nature of the community are extremely important. It is not enough to engage in communication for communication's sake.

Further, in this view of CALL, English communication is incidental to the main task. However, as learners carry out tasks, they are learning important new genres and engaging in new discourses. This is related to the objective of CALL and, indeed, of language learning, which evolved originally from accuracy to, later, accuracy plus fluency. Now a new objective has been added to the previous two: agency (Warschaurer, 2005).

A key concept that should motivate the understanding of English teaching in the 21 st century is that of agency. Due to changes in globalization, employment, and technology, begun in the past 30 years and intensified in the present century, second language speakers of English will use the language less as an object of foreign study and more as an additional language of their own to impact and change the world. They will use English, together with technology, to express their identity and make their voices heard. There is no need to choose between an integrative discourse, which views English as a door to international commerce, tourism, technology, and science, and an empowering discourse, which views English as an ideological instrument of unequal power relations (Cox \& Assis-Peterson, 1999). English is both and more.

English, together with technology, can be a carrier of inequality, even more so than today, which is precisely why increasing numbers of people will use English to 
challenge that inequality, either by breaking down doors or by rewriting rules. As a group of Brazilian scholars said, "The learning of English, considering its hegemonic role in international exchanges, can contribute to the formulation of counter-discourses in relation to inequalities between countries and social groups" (Secretaria de Educação Fundamental, cited in Cox \& Assis-Peterson, 1999, p. 434). English teachers can promote students' ability to formulate such counter discourses, by assisting learners' development of critical literacies in multiple media and genres.

The point is that technology has made it possible for the video game industry to integrate virtual reality to simulate worlds where the players feel engaged and motivated to play. Therefore the ESL/EFL software industry could also integrate technology to motivate learners and engage them in the process of learning according to the principles of Communicative Language Teaching and an interactive approach to computer use for language learning.

The expansion of CALL undoubtedly provides new opportunities for learners of English to study from the convenience of their home (Warschauer, Shetzer, \& Meloni, 2000). However, the commercialization of CALL programs poses significant dangers. The types of CALL programs that are most effective for language learning involve a good deal of personal interaction, and are thus expensive to set up and teach (Warschauer et al. 2000; Feenberg, 1999a; 1999b). Thus quality educational programs involving extensive personal interaction face mounting economic competition from inexpensive but pedagogically unsound programs (Blumenstyk, 1999). Thus, ESL/EFL software program evaluation based on the principles of Communicative Language Teaching and an interactive approach to computer use for language learning plays an important role in ensuring that educationally relevant CALL programs can be chosen among the ones available on the market. 


\section{APPENDIX A}

\section{PILOT STUDY - ESL/EFL SOFTWARE EVALUATION INSTRUMENT}

A pilot study was conducted in order to test the validity and the reliability of the ESL/EFL software evaluation instrument, which was elaborated to assess the extent to which Computer Assisted Language Learning software programs available on the market develop ESL/EFL skills according to the Communicative Language Teaching principles and an interactive model of computer use in language learning.

\section{Method}

\section{Procedures}

The elaborated ESL/EFL software evaluation instrument was used by ten ESL/EFL teachers to analyze three ESL/EFL software programs. Each teacher received a sample CD-Rom of the programs. The CD-Rom contained sample lessons of different levels of the program, besides an overview of the whole program. Because it was important to evaluate how clearly and objectively the instrument could identify well-known criteria of the Communicative Approach of Language Teaching and an interactive model of computer use for language learning used in the design of the programs, teachers were not given any instructions or training on how to use the instrument, nor were they assigned any specific time or amount of time to analyze the programs. However, all teachers were asked to go through at least one complete lesson in each level of the software program. All teachers were also encouraged to ask 
about and/or take notes of doubts or questions that could arise while using the instrument to analyze the programs. No doubts or questions were reported.

\section{Material selection}

The programs "Longman English Interactive," "New Dynamic English," and "Rosetta Stone" were selected from the list of CALL software programs for ESL/EFL instruction (cf. pp. 24/25) to be analyzed in this study. The choice was based on the wide availability of these software programs and on the publishers' claims that these programs followed the Communicative Approach to Language Teaching.

\section{Participant selection}

The selection of participants for this study was based on the following criteria:

1. Equal number of ESL and EFL teachers, since most software programs are designed for both ESL and EFL learners.

2. Teaching experiences that would encompass most contexts in which ESL/EFL is taught (elementary, middle, and high schools, university, and adult education).

3. ESL/EFL certified teachers, with Masters' Degree in TESL (Teaching English as a Second Language) or in Applied Linguistics.

4. At least 5 years of experience in teaching ESL and/or EFL.

Teachers who met these criteria were invited to voluntarily participate in the pilot study. Ten teachers returned their analysis and signed the Participant Consent Form (cf. Appendix B). The group of ten teachers whose analyses are presented consists of five teachers of English as a foreign language, and five teachers of English as a second language. These teachers have been teaching English for at least eight 
years in the following contexts: one teaches ESL in elementary school, one teaches ESL in middle school, one teaches EFL in high school, two teach ESL in adult education programs, four teach EFL in a university, and one teaches ESL in a university. The four EFL university teachers have also taught EFL at the high school level. (Appendix $\mathrm{C}$ provides an overview of the teaching background of each teacher.)

\section{Data analysis}

Data analysis focuses on: 1) the capability of the elaborated ESL/EFL software evaluation instrument to identify differences among CALL programs as to their potential for developing language skills, and 2) the reliability of the instrument.

Instrument's capability for identifying differences among CALL software programs

In order to evaluate the capability of the elaborated instrument to identify differences among CALL programs the following procedures were used:

1. The ratings of the ten teachers for each question item for each program were tabulated.

2. The mean ratings of the ten teachers for each question item for each program were calculated.

3. The overall rating of each teacher for each subcategory for each program was calculated.

4. The means for the overall ratings of the ten teachers for each subcategory for each program were calculated. 
5. The overall rating of each teacher for each category for each program was calculated.

6. The means for the overall ratings of the ten teachers for each category for each program were calculated.

7. The overall rating of each teacher for each program was calculated.

8. The means for the overall ratings of the ten teachers for each program were calculated.

\section{Reliability of the instrument}

The validity of the results of the proposed study depends on the appropriateness of the elaborated instrument to consistently measure the potential of CALL software programs to develop language skills according to the Communicative Approach to Language Teaching and an interactive approach to computer use in language learning. Therefore, the instrument needed to be tested for its reliability, that is, it was necessary to assess the extent to which it could produce consistent results when administered under similar conditions. Two statistical procedures were employed to test the reliability of the instrument: the split-half test, and the Cronbach's Alpha test.

In order to use the split-half method, the ESL/EFL software evaluation instrument was first split into two similar parts. Then, the ratings for the items on the two halves of the instrument were correlated as if they were two separate instruments. If the items proved homogeneous, all odd-numbered items would become one half and the even-numbered items would become the other half. The correlation between the two halves would give the reliability for half the instrument. Once the reliability of half of the instrument was obtained, the Spearman Brown's prophecy formula was used to determine the reliability of the full instrument. According to the Spearman Brown's 
prophecy formula, the reliability of the full instrument is equal to the reliability of half of the instrument multiplied by two and divided by one plus the reliability of the half instrument. Reported test reliability of .90 or more using the Spearman Brown prophecy formula indicates that the instrument is reliable.

\section{Results and Discussion}

Results of data analysis are presented according to the purposes that guided the analyses: 1) to identify programs' features and assess the capability of the elaborated ESL/EFL software evaluation instrument to identify differences among CALL programs as to their potential of developing language skills, and 2) to test the reliability of the instrument.

\section{Programs' Features and Differences among the programs "Longman English Interactive," "New Dynamic English," and "Rosetta Stone"}

The results of the teachers' evaluations of the three programs were categorized as follows: means for overall program ratings; means for overall ratings for each category of each program, means for overall ratings for each subcategory of each program.

Table 1 shows the means for the overall program ratings for "Longman English Interactive", "New Dynamic English", and "Rosetta Stone". 
Table 1

Means for Overall Program Ratings for "Longman English Interactive", "New Dynamic English", and "Rosetta Stone". 6

\begin{tabular}{ll}
\hline Programs & Overall Program Means \\
\hline Longman English Interactive & 137.7 \\
New Dynamic English & 116.9 \\
Rosetta Stone & 75.6 \\
\hline
\end{tabular}

Results indicated that the "Longman English Interactive" was the program that received the highest ratings ( $m=137.7,76.5 \%$ of the overall ratings), while the "Rosetta Stone" was the one that got the lowest ratings $(m=75.6,42 \%$ of the overall ratings). The means for the "New Dynamic English" was 116.9 or 64.94 or the overall ratings $\%$.

In order to better analyze the characteristics of each program, the mean ratings for each category ${ }^{7}$ of each program were calculated. Table 2 shows the mean ratings for each category of the program "Longman English Interactive".

Table 2:

Mean ratings for each category of the "Longman English Interactive".

\begin{tabular}{lll}
$\begin{array}{l}\text { Categories of the "Longman English } \\
\text { Interactive" }\end{array}$ & Mean Ratings & $\begin{array}{l}\text { Percentage of the } \\
\text { possible maximum rating } \\
\text { for the category }\end{array}$ \\
\hline Individualized Instruction Features & 38.8 & 64.66 \\
Pedagogical Features & 55.3 & 76.8 \\
Technological Features & 43.5 & 90.62 \\
\hline
\end{tabular}

\footnotetext{
${ }^{6}$ The instrument consisted of 60 items. Each item could be rated from 0 to 3. Each program could therefore be rated from 0 to 180 .

${ }^{7}$ For all programs, the category of Individualized Features could be rated from 0 to 60 , the category of Pedagogical Features could be rated from 0 to 72, and the category of Technological Features could be rated from 0 to 48 .
} 
Data indicate that the category of Individualized Instruction Features of the "Longman English Interactive" had the lowest ratings $(64.66 \%$ of the possible maximum rating for the category), whereas the category of Technological Features had the highest ratings $(90.62 \%$ of the possible maximum rating for the category. The category of Pedagogical Features had $76.8 \%$ of the possible maximum rating for the category.

The mean ratings for each category of the program "New Dynamic English" are presented in Table 3.

Table 3

Mean ratings for each category of the "New Dynamic English"

\begin{tabular}{lll}
\hline Categories of the "New Dynamic English” & Mean Ratings & $\begin{array}{l}\text { Percentage of the } \\
\text { possible maximum } \\
\text { rating for the } \\
\text { category }\end{array}$ \\
\hline Individualized Instruction Features & 33.7 & 56.16 \\
Pedagogical Features & 47.7 & 66.25 \\
Technological Features & 29.8 & 73.96 \\
& &
\end{tabular}

Data indicate that the category of Individualized Instruction Features of "New Dynamic English" also had the lowest ratings $(33.7,56.16 \%$ of the possible maximum rating for the category), while the category of Technological Features had the highest ratings $(29.8,73.96 \%$ of the possible maximum rating for the category. The category of Pedagogical Features had $66.25 \%$ of the possible maximum rating for the category.

Table 4 shows the mean ratings for each category of the program "Rosetta Stone". 
Table 4

Mean ratings for each category of the "Rosetta Stone".

\begin{tabular}{lll}
\hline Categories of the "Rosetta Stone" & Mean Ratings & $\begin{array}{l}\text { Percentage of the possible } \\
\text { maximum rating for the } \\
\text { category }\end{array}$ \\
\hline Individualized Instruction Features & 16.9 & 28.16 \\
Pedagogical Features & 29.8 & 41.38 \\
Technological Features & 27.9 & 58.12 \\
& & \\
\hline
\end{tabular}

Like "Longman English Interactive" and "New Dynamic English", the category of Individualized Instruction Features of "Rosetta Stone" also had the lowest ratings ( $28.16 \%$ of the possible maximum rating for the category), while the category of Technological Features had the highest ratings $(58.12 \%$ of the possible maximum rating for the category. The category of Pedagogical Features had $41.38 \%$ of the possible maximum rating for the category.

Data were also analyzed as to how the ratings for each category compared across the three programs. Table 5 shows the mean ratings for the category of 'Individualized Instruction Features' for the programs "Longman English Interactive”, "New Dynamic English", and "Rosetta Stone".

Table 5:

Mean Ratings for the category of Individualized Instruction Features for the programs "Longman English Interactive", "New Dynamic English", and "Rosetta Stone".

\begin{tabular}{lll}
\hline Programs & $\begin{array}{l}\text { Mean ratings for the } \\
\text { category of } \\
\text { Individualized Instruction }\end{array}$ & $\begin{array}{l}\text { Percentage of the possible } \\
\text { maximum rating for the } \\
\text { category }\end{array}$ \\
\hline Longman English Interactive & 38.8 & 64.66 \\
New Dynamic English & 33.7 & 56.16
\end{tabular}


In the category of individualized learning features, the "Longman English Interactive" program had the highest mean $(m=38.8,64.66 \%$ of the possible maximum rating for the category), while "Rosetta Stone" had the lowest mean in this category ( $m=16.9,28.16 \%$ of the possible maximum rating for the category). The "New Dynamic English" program had a mean rating of 33.7 (56.16\% of the possible maximum rating for the category) in the category of individualized learning.

Table 6 presents the mean ratings for the category of 'Pedagogical Features' for the programs "Longman English Interactive", "New Dynamic English", and "Rosetta Stone".

Table 6

Mean Ratings for the category of 'Pedagogical Features' for the programs "Longman English Interactive", "New Dynamic English", and "Rosetta Stone"

\begin{tabular}{lll}
\hline Programs & $\begin{array}{l}\text { Means for the category of } \\
\text { Pedagogical Features }\end{array}$ & $\begin{array}{l}\text { Percentage of the } \\
\text { possible maximum rating } \\
\text { for the category }\end{array}$ \\
\hline Longman English Interactive & 55.3 & 76.8 \\
New Dynamic English & 47.7 & 66.25 \\
Rosetta Stone & 29.8 & 41.38 \\
& & \\
\hline
\end{tabular}

In the category of pedagogical features, the "Longman English Interactive" program again had the highest mean $(m=55.3,76.8 \%$ of the possible maximum rating for the category), while "Rosetta Stone" had the lowest $((m=29.8,41.38 \%)$. The mean rating for "New Dynamic English" in this category was 47.7 , or $66.25 \%$ of the possible maximum rating for the category. 
Table 7 shows the means for the category of 'Technological Features' for the programs "Longman English Interactive", "New Dynamic English", and "Rosetta Stone".

Table 7

Mean Ratings for the category of 'Technological Features' for the programs "Longman English Interactive", "New Dynamic English", and "Rosetta Stone".

\begin{tabular}{lll}
\hline Programs & $\begin{array}{l}\text { Means for the category of } \\
\text { Technological Features }\end{array}$ & $\begin{array}{l}\text { Percentage of the } \\
\text { possible maximum rating } \\
\text { for the category }\end{array}$ \\
\hline Longman English Interactive & 43.5 & 90.62 \\
New Dynamic English & 35.5 & 73.96 \\
Rosetta Stone & 27.9 & 58.12 \\
\hline
\end{tabular}

In the category of technological features, "Longman English Interactive" once again had the highest mean $(\mathrm{m}=43.5,90.62 \%$ of the possible maximum rating for the category), while the "Rosetta Stone" program had the lowest ( $m=27.9,158.12 \%$ of the possible maximum rating for the category). The category of technological features of "New Dynamic English" had a mean of 35.5, 73.96\% of the possible maximum rating for the category.

In sum, results indicated that the "Longman English Interactive" program consistently had the highest means of the three programs, while the "Rosetta Stone" Program consistently had the lowest. Data also indicate that the category of 'Individualized Learning Features' was rated the lowest for all the three programs (38.8 in "Longman English Interactive," 33.7 in the "New Dynamic English," and 16.9 in the Rosetta Stone), while the category of 'Technological Features' was rated the highest 
for all three programs (43.5 in "Longman English Interactive", 35.5 in "New Dynamic English", and 27.9 in "Rosetta Stone").

In order to better analyze the characteristics of each category, the means for each item in each category of all the three programs were calculated. In each category, items were grouped into subcategories according to the criteria on which the elaboration of the items was based.

Table 8 shows the means for each item in the category of 'Individualized Learning Features' for each program.

\section{Table 8}

Means for the items in the category of 'Individualized Learning Features' and overall means for each sub-category ${ }^{8}$

\begin{tabular}{|c|c|c|c|c|}
\hline $\begin{array}{l}\text { Sub- } \\
\text { categories of } \\
\text { Individualize } \\
\text { d learning }\end{array}$ & Items & $\begin{array}{l}\text { Mean } \\
\text { Longman }\end{array}$ & $\begin{array}{l}\text { Mean } \\
\text { New } \\
\text { Dynamic } \\
\text { English }\end{array}$ & $\begin{array}{l}\text { Mean } \\
\text { Rosetta } \\
\text { Stone }\end{array}$ \\
\hline \multirow{8}{*}{$\begin{array}{l}\text { Adapting to } \\
\text { students' } \\
\text { needs, } \\
\text { interests, } \\
\text { styles }\end{array}$} & $\begin{array}{l}\text { 1. Does the program allow for different } \\
\text { routes and choices for learning? }\end{array}$ & 1.5 & 1.3 & 0.5 \\
\hline & $\begin{array}{l}\text { 2. Does the program allow for reviewing old } \\
\text { information? }\end{array}$ & 2.3 & 2.2 & 1.6 \\
\hline & $\begin{array}{l}\text { 3. Does it allow branching to new } \\
\text { information? }\end{array}$ & 2.3 & 1.5 & 0.9 \\
\hline & $\begin{array}{l}\text { 4. Does the program allow students to } \\
\text { select activities according to their ages? }\end{array}$ & 1.2 & 1.0 & 0.3 \\
\hline & $\begin{array}{l}\text { 5. Does it allow students to select activities } \\
\text { according to their learning styles? }\end{array}$ & 1.5 & 0.4 & 0.4 \\
\hline & $\begin{array}{l}\text { 6. Does it allow students to select activities } \\
\text { according to their interests? }\end{array}$ & 1.8 & 0.6 & 0.3 \\
\hline & $\begin{array}{l}\text { 7. Does the program adapt to the responses } \\
\text { given by the learners, branching to more or } \\
\text { less complicated questions as appropriate? }\end{array}$ & 1.4 & 1.3 & 0.6 \\
\hline & $\begin{array}{l}\text { 8. Does the program allow learners to go } \\
\text { through its content at their own pace and } \\
\text { rhythm? }\end{array}$ & 2.8 & 2.8 & 2.0 \\
\hline
\end{tabular}

\footnotetext{
${ }^{8}$ The category of 'Individualized Learning Features' could be rated from 0 to 60 since each item could be rated from 0 to 3 .
} 


\begin{tabular}{|c|c|c|c|c|}
\hline & $\begin{array}{l}\text { 9. Does it allow the teacher to interact with } \\
\text { students while they are doing an activity? }\end{array}$ & 1.4 & 0.8 & 0.8 \\
\hline & Overall means in the subcategory & 1.8 & 1.3 & 0.82 \\
\hline & $\begin{array}{l}10 . \text { Does the program prevent learners from } \\
\text { repeating exercises, therefore, minimizing } \\
\text { guessing? }\end{array}$ & 1.3 & 1.2 & 0.7 \\
\hline \multirow[t]{6}{*}{$\begin{array}{l}\text { Record- } \\
\text { keeping }\end{array}$} & $\begin{array}{l}\text { 11. Does the program keep records of } \\
\text { learners' performance to allow them to } \\
\text { continue activities from where they left off? }\end{array}$ & 2.4 & 2.7 & 1.4 \\
\hline & $\begin{array}{l}\text { 12. Does the program keep track of } \\
\text { students' scores? }\end{array}$ & 3.0 & 2.8 & 2.0 \\
\hline & Overall means in the subcategory & 2.23 & 2.23 & 1.36 \\
\hline & $\begin{array}{l}\text { 13. Does the program provide non- } \\
\text { threatening feedback? }\end{array}$ & 2.9 & 3.0 & 1.3 \\
\hline & $\begin{array}{l}\text { 14. Does the program allow learners to } \\
\text { repeat an activity after feedback is } \\
\text { provided? }\end{array}$ & 2.4 & 2.9 & 0.6 \\
\hline & $\begin{array}{l}\text { 15. Does the program offer a selection of } \\
\text { possible correct responses? }\end{array}$ & 1.4 & 1.3 & 0.3 \\
\hline \multirow[t]{6}{*}{$\begin{array}{l}\text { Answer } \\
\text { judging }\end{array}$} & $\begin{array}{l}\text { 16. Does it provide feedback for both } \\
\text { correct and incorrect answers? }\end{array}$ & 2.4 & 2.3 & 1.3 \\
\hline & $\begin{array}{l}\text { 17. Does it give learners the chance to } \\
\text { correct their errors? }\end{array}$ & 2.4 & 2.2 & 1.0 \\
\hline & $\begin{array}{l}\text { 18. Does it effectively signal the mistakes } \\
\text { before providing the right answers? }\end{array}$ & 1.7 & 2.1 & 0.5 \\
\hline & $\begin{array}{l}\text { 19. Does it effectively specify different types } \\
\text { of errors, such as differences between a } \\
\text { syntactic error and an incorrect word } \\
\text { choice? }\end{array}$ & 1.0 & 0.5 & 0.3 \\
\hline & $\begin{array}{l}\text { 20. Does the program provide the students } \\
\text { with feedback (in hypertext form, for } \\
\text { example) that would allow them to correct } \\
\text { their mistakes? }\end{array}$ & 1.5 & 1.1 & 0.3 \\
\hline & Overall means in the subcategory & 1.96 & 1.92 & 0.7 \\
\hline
\end{tabular}

As indicated previously, the category of 'Individualized Learning Features' had the lowest means of all the programs. For all programs, the sub-category of recordkeeping had the highest means. The strongest Individualized Learning Features in all the programs seemed to be their ability to allow learners to go through the program at their own pace and rhythm (item 8), and their capability of keeping track of students' scores (item 12). Except for "Rosetta Stone", the other two programs also seem to be strong in providing non-threatening feedback (item 13). For "Longman Interactive" and “New Dynamic English” the subcategory of 'answer judging' had the lowest ratings. 
The possibility of allowing students to select activities according to their ages (Item 4), and the capability of specifying different types of errors (item 19) were the features which had the lowest ratings in all the programs.

Table 9 presents the means for each item in the category of pedagogical features of each program.

\section{Table 9}

Means for the items in the category of 'Pedagogical Features' and overall means of each sub-category 9

\begin{tabular}{|c|c|c|c|c|}
\hline $\begin{array}{l}\text { Sub- } \\
\text { categories of } \\
\text { Pedagogical } \\
\text { Features }\end{array}$ & Items & $\begin{array}{l}\text { Mean } \\
\text { Longman }\end{array}$ & $\begin{array}{l}\text { Mean } \\
\text { New } \\
\text { Dynamic } \\
\text { English }\end{array}$ & $\begin{array}{l}\text { Mean } \\
\text { Rosetta } \\
\text { Stone }\end{array}$ \\
\hline \multirow{10}{*}{ Objectives } & $\begin{array}{l}\text { 1. Does the program develop the skills it } \\
\text { aims to develop? }\end{array}$ & 2.3 & 2.4 & 1.6 \\
\hline & $\begin{array}{l}\text { 2. Is the course structure/design in } \\
\text { accordance with the linguistic } \\
\text { assumptions and with the } \\
\text { methodological approach the program } \\
\text { claims to have? }\end{array}$ & 2.3 & 2.7 & 1.3 \\
\hline & $\begin{array}{l}\text { 3. Does the program develop the level } \\
\text { of competency it aims to develop? }\end{array}$ & 2.5 & 2.2 & 1.3 \\
\hline & $\begin{array}{l}\text { 4. Does the program arouse sensory } \\
\text { and cognitive curiosity? }\end{array}$ & 2.3 & 1.9 & 1.8 \\
\hline & $\begin{array}{l}\text { 5. Does the program maintain attention } \\
\text { throughout the lesson? }\end{array}$ & 2.3 & 2.1 & 1.6 \\
\hline & $\begin{array}{l}\text { 6. Does the use of animation invite } \\
\text { learners' reaction or input? }\end{array}$ & 2.4 & 2.0 & 1.4 \\
\hline & $\begin{array}{l}\text { 18. Does the program give teachers } \\
\text { clear explanation of its purposes and } \\
\text { methodological orientation? }\end{array}$ & 3.0 & 2.7 & 0.3 \\
\hline & $\begin{array}{l}\text { 19. Does the program give teachers } \\
\text { clear orientation of how to use its } \\
\text { different sections and components? }\end{array}$ & 3.0 & 2.9 & 0.4 \\
\hline & Overall means in the subcategory & 2.51 & 2.36 & 1.21 \\
\hline & $\begin{array}{l}7 \text { Does the program make use of } \\
\text { authentic texts and other realia? }\end{array}$ & 3.0 & 2.3 & 1.8 \\
\hline $\begin{array}{l}\text { Theory of } \\
\text { language } \\
\text { learning and }\end{array}$ & $\begin{array}{l}8 \text { Does the program integrate } \\
\text { information about culture/literature/daily } \\
\text { situations into the presentations and } \\
\text { activities? }\end{array}$ & 2.6 & 1.7 & 1.4 \\
\hline
\end{tabular}

\footnotetext{
${ }^{9}$ The category of Pedagogical Features could be rated from 0 to 72 since each item could be rated from 0 to 3 .
} 


\begin{tabular}{|c|c|c|c|c|}
\hline \multirow[t]{7}{*}{ teaching } & $\begin{array}{l}\text { 9. Does the program present and } \\
\text { practice language structures in }\end{array}$ & 2.3 & 2.1 & 1.4 \\
\hline & meaningful communicative contexts? & & & \\
\hline & $\begin{array}{l}\text { 10. Does the program present and } \\
\text { practice vocabulary in } \\
\text { meaningful communicative contexts? }\end{array}$ & 2.4 & 2.3 & 1.4 \\
\hline & Overall means in the subcategory & 2.57 & 2.1 & 1.5 \\
\hline & $\begin{array}{l}\text { 11. Is content selection determined by } \\
\text { communicative skills and/or themes? }\end{array}$ & 2.2 & 2.2 & 1.3 \\
\hline & $\begin{array}{l}\text { 12. Is content sequencing determined } \\
\text { by functional complexity? }\end{array}$ & 2.5 & 2.2 & 1.9 \\
\hline & $\begin{array}{l}\text { 13. Is content presented } \\
\text { communicatively? }\end{array}$ & 2.7 & 2.3 & \\
\hline \multirow[t]{7}{*}{ Syllabus } & $\begin{array}{l}\text { 14. Does the program develop the } \\
\text { content at appropriate levels of } \\
\text { communicative complexity? }\end{array}$ & 2.5 & 2.3 & 1.9 \\
\hline & $\begin{array}{l}\text { 15. Is the program content educationally } \\
\text { relevant and interesting? }\end{array}$ & 2.7 & 2.2 & 1.4 \\
\hline & $\begin{array}{l}\text { 16. Is the program content appropriate } \\
\text { for intended learners? }\end{array}$ & 2.8 & 2.3 & 1.4 \\
\hline & $\begin{array}{l}\text { 17. Is the program content applicable to } \\
\text { real life contexts? }\end{array}$ & 2.8 & 2.3 & 1.4 \\
\hline & Overall means in the subcategory & 2.6 & 2.26 & 1.33 \\
\hline & $\begin{array}{l}\text { 20. Does the program allow learners to } \\
\text { work together in communicative } \\
\text { activities? }\end{array}$ & 0.5 & 0.3 & 0.0 \\
\hline & $\begin{array}{l}21 . \text { Does the program provide } \\
\text { challenging activities? }\end{array}$ & 2.7 & 1.5 & 1.5 \\
\hline \multirow[t]{4}{*}{ Activities } & $\begin{array}{l}\text { 22. Do the activities allow unplanned } \\
\text { and/or unpredictable responses? }\end{array}$ & 1.0 & 1.0 & 0.9 \\
\hline & $\begin{array}{l}\text { 23. Do the activities lend themselves to } \\
\text { group discussions? }\end{array}$ & 1.3 & 0.4 & 0.5 \\
\hline & $\begin{array}{l}\text { 24. Do the activities aim at developing } \\
\text { competencies other than syntactical } \\
\text { and lexical? }\end{array}$ & 1.5 & 1.3 & 1.0 \\
\hline & Overall means in the subcategory & 1.4 & 0.9 & 0.78 \\
\hline
\end{tabular}

In the category of pedagogical features, differences among programs seem be even broader since the mean ratings for this category had a wide range from 29.8 ("Rosetta Stone") to 55.3 ("Longman English Interactive"). The sub-category of 'Activities' had the lowest means in the category of 'Pedagogical Features' for all three programs. The ability of allowing learners to work together in communicative activities (item 20) was the weakest feature of all the programs. Other weak features were the possibility of activities to allow unplanned and/or unpredictable responses (item 22), 
and the possibility of activities to lend themselves to group discussions (item 23).

However, in two programs, "Longman English Interactive" and "Dynamic English", the clear explanation of their purposes and methodological orientations (item 18), and the orientations of how to use different sections and components (item 19) were considered strong features by the teachers.

Table 10 shows the means for each item in the category of 'Technological Features' for each program.

Table 10

Means for the items in the category of 'Technological Features' and overall means for each sub-category ${ }^{10}$

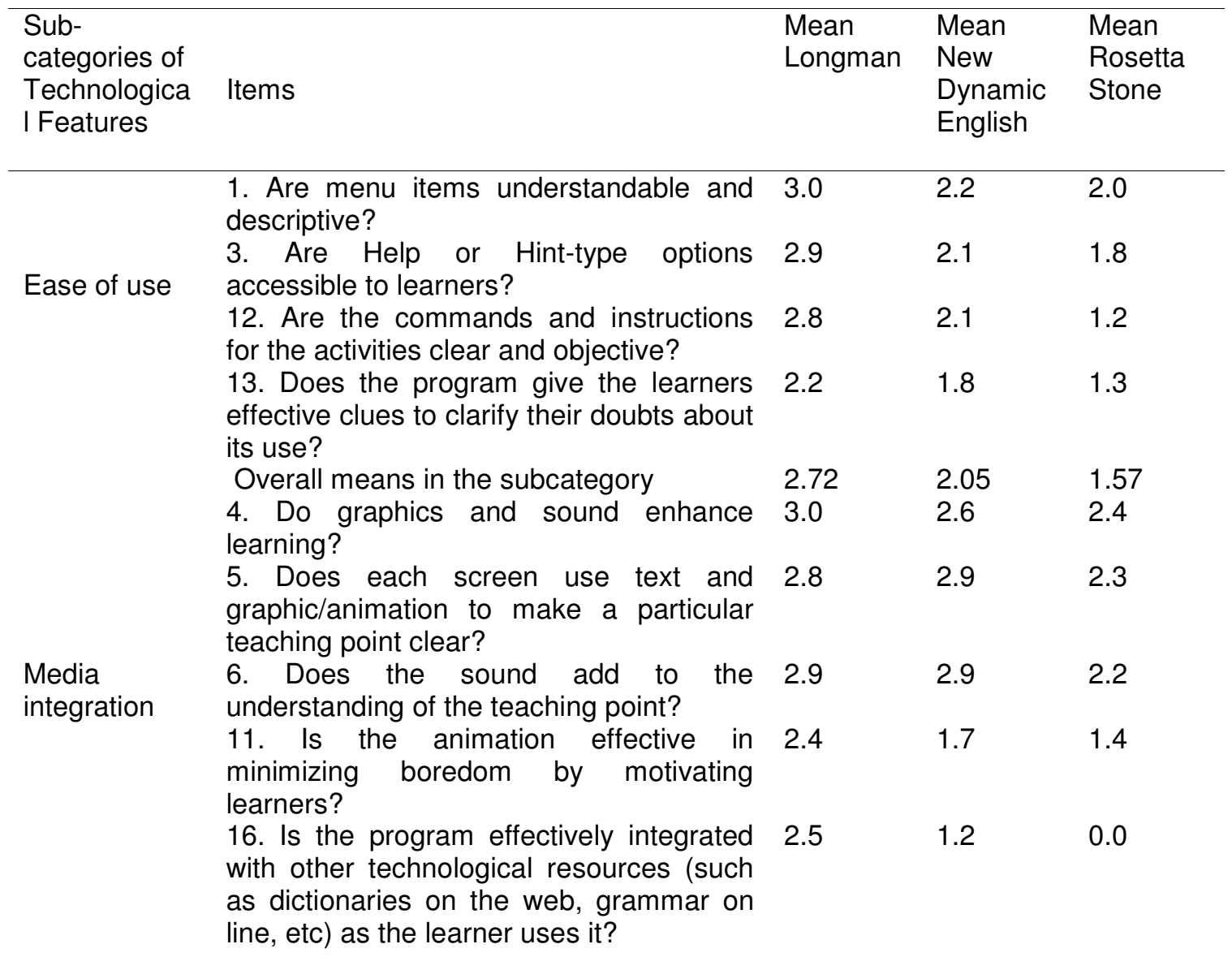

\footnotetext{
${ }^{10}$ The category of 'Technological features' could have the overall score ranging from 0 to 48 since each item could be scored from 0 to 3 .
} 


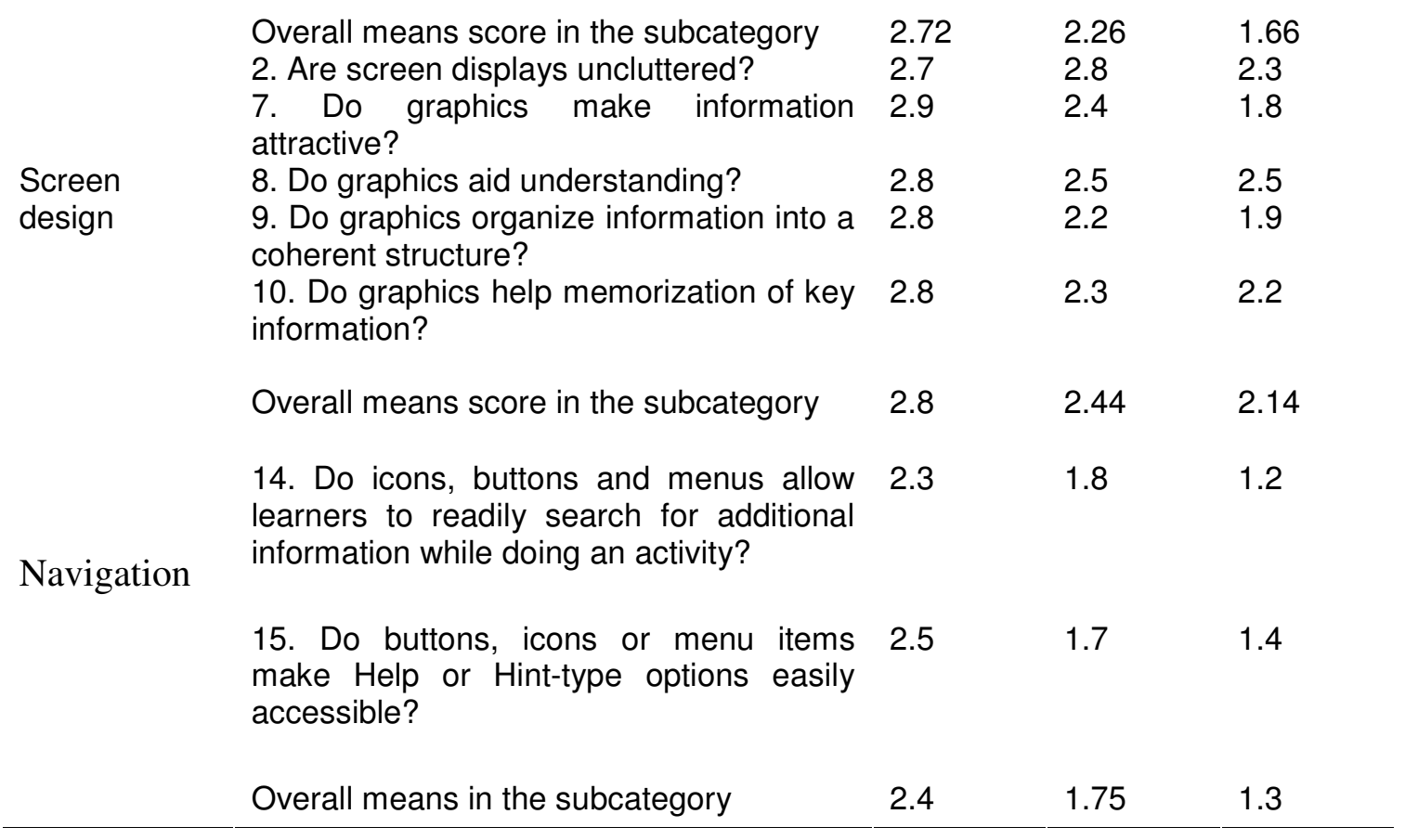

Very interestingly, although the category of 'Technological Features' had the highest means, it also presented the biggest differences among the programs as to their strong features. "Longman English Interactive" had high mean ratings in three of the four sub-categories of Technological Features. The sub-category of 'Screen Design' was rated the highest for all three programs. While for "Longman English Interactive" the strongest feature was the ability of the program's graphics and sound to enhance learning (item 4), for "Dynamic English" it was the program's ability of using graphics to make a particular teaching point clear (item 5) and of using sound to add to the understanding of the teaching point (item 6) that gave the program the highest ratings. The sub-category of 'Navigation' had the lowest ratings for all three programs. For two programs, "New Dynamic English" and "Rosetta Stone", the ability of the programs to effectively integrate with other technological resources (item 16) was the weakest technological feature. 
Table 11 shows the Spearman-Brown Coefficients for the programs "Longman English Interactive", "New Dynamic English”, and "Rosetta Stone”. Results indicate that the correlation was high for all the three programs: .916 for "Longman English Interactive," .941 for "New Dynamic English," and .922 for "Rosetta Stone."

\section{Table 11}

Spearman-Brown Coefficients for the programs "Longman English Interactive", "New Dynamic English", and "Rosetta Stone"

\begin{tabular}{ll}
\hline Programs & Spearman-Brown Coefficient \\
\hline Longman English Interactive & .916 \\
New Dynamic English & .941 \\
Rosetta Stone & .922
\end{tabular}

Still, another measure was used to test internal consistency and explore levels of reliability: Cronbach's Alpha. Cronbach's Alpha comprises a number of items that make up a scale designed to measure a single construct, and determines the degree to which all the items are measuring the same construct. Cronbach's Alpha assumes that all the items in the scale should be measured on an interval or ratio scale. In addition, each item should be normally distributed. Coefficient numbers close to 1.00 are very good, but numbers close to 0.00 represent poor internal consistency.

Table 12 shows the Cronbach's Alphas for the three programs: "Longman English Interactive," "New Dynamic English," and "Rosetta Stone." The Cronbach's alpha reliability tests applied to the analysis of the three above specified programs presented results close to 1.00 for all the three programs: .937 for "Longman English 
Interactive," .933 for the "New Dynamic English," and .960 for "Rosetta Stone." The results indicate that the instrument has good internal consistency.

Table 12:

Cronbach's Alpha for "Longman English Interactive," "New Dynamic English," and "Rosetta Stone".

\begin{tabular}{ll} 
Programs & Cronbach's Alpha \\
\hline Longman English Interactive & .937 \\
New Dynamic Englsih & .933 \\
Rosetta Stone & .960 \\
\hline
\end{tabular}

The same methods - split-half test and Cronbach's Alpha - were then used with the ratings for the all the items for all three programs together. Table 13 shows the results of the tests for all the items for all three programs - "Longman Interactive English," "New Dynamic English,” and "Rosetta Stone."

Table 13

Spli-halft test and Cronbach's Alpha for all the items for all the programs.

Split-half Test Cronbach's Alpha

The results of the split-half test and of the Cronbach's Alpha applied to the programs all together indicate very good levels of reliability. In summary, it is possible to say that the results of the two statistical procedures used in this study assure good internal consistency and reliability to the elaborated instrument. 


\section{DISCUSSION OF RESULTS}

The use of the elaborated ESL/EFL software evaluation instrument to analyze the programs "Longman English Interactive", "New Dynamic English", and "Rosetta Stone" indicated that the weakest features in all three programs were related to individualization of instruction (Tables 5, 6, and 7), even though this is a very strong premise of Communicative Language Teaching. Individualization refers to the fact that the computer enables students to work alone and at their own pace, and encompasses three aspects: keeping data record, judging answers, and adapting to students' needs, interests and styles. The three programs seem to be able to keep data records in a reasonable way (the subcategory of record-keeping received the highest number of points in this category). At least two of the programs (the Longman English Interactive and the New Dynamic English) were rated quite high in their capability of collecting data and keeping records and of allowing the learner to carry on from where he/she has left off. However, the three programs seem to have difficulty in having a diagnostic mechanism that would enable students to proceed along a tailor-made path.

The results also point out another aspect of individualization that needs refining: 'Answer Judging', which refers to the type of feedback given to the students. Data collected from the analysis of the three programs in this category indicate that individualization has not been achieved at a sophisticated level. The results in the subcategory of 'Adapting to Students' Needs, Interests, and Styles' point out that these programs do not allow students to use the computer as a means of exploring and playing with the target language through group work tasks and student-initiated exchanges. The programs do not relate individualization to the type of social environment students could create for their own language experiences. 
The use of the elaborated ESL/EFL software evaluation instrument to analyze the programs also provided evidence that the key differentiating factor in ESL software programs lies not only in their pedagogical orientation but mainly in how they incorporate this orientation into their design. As previously stated, the criteria used in the elaboration of the ESL/EFL software evaluation instrument are based on the principles of the Communicative Language Teaching. Although all three programs claim to incorporate Communicative theories of language learning into their elaboration, they seem to have, to a greater of lesser degree, difficulty in elaborating activities that would develop language skills according to this approach. Communicative Language Teaching principles are incorporated in theory but not in practice in the programs. The syllabi of two of the programs ("Longman Interactive English" and "New Dynamic English") present characteristics of Communicative Language Teaching. However, the activities they present are different from the type of activities that would aim at developing language communicatively.

The use of the elaborated ESL/EFL software evaluation instrument also made it possible to analyze the user technological interface in the three programs. Results indicate that the software programs integrate features of interactive CALL. In fact, this is the category which had the highest means in all three programs. It seems that program designers and publishers rely on the fact that the interface between learners and technology is highly correlated with how well users enjoy using a specific program, and put forth their best efforts in developing user-friendly software.

Analyzing the three programs in all three categories - individualized learning features, pedagogical features and technological feature - it appears that only one program approached the principles of Communicative Language Teaching. "Longman English Interactive" was the only program to obtain over $70 \%$ of the overall ratings. 
Attempts to use technology for language learning were not well integrated into these programs. The review of literature indicates that the application of technologies can be effective in almost all areas of language learning. Theoretically, modern technology can enhance the quality of input, authenticity of communication, and provide more relevant and useful feedback. However, "Longman English Interactive," "New Dynamic English," and "Rosetta Stone" were not capable of making effective use of what modern technology offers. The technology used in the programs was fragmented, and technological capabilities were not really translated into pedagogical applications. The programs do not create environments that develop language skills according to the socio-interactive CALL model and Communicative Approach to Language Learning; they lack student-centeredness and collaborative tasks.

The three programs follow a set scope and sequence that do not allow individual learners to pursue links which they could perceive as being both useful and interesting. Unfortunately none of the three programs has this ability. Effective CALL software needs to offer different interfaces or combinations of interfaces to accommodate different learning styles. The analysis of the results obtained with the use of the elaborated ESL/EFL software evaluation instrument points out the programs' lack of ability to establish collaborative situations at the computer. If the programs made use of questions and prompts that would allow for decision-making, a high degree of learner centeredness would have been possible, at the same time that they would have guided learners into collaborative learning practices. In order to allow learners to organize their own learning, software programs could post a schema or mental map of a learner's needs along with notes on the software packages which match each need. Such a chart could also include an overview of the curricular objectives to indicate how learners should progress through levels of language 
learning. This would involve learners in the process and make them much more responsible for their learning and, in doing so, also increase motivation.

An examination of the theoretical underpinnings of the programs' activities indicated that these activities did not really conform to the principles of Communicative Language Learning since most of them were basically of the instructional type (tutorials, drills, and text reconstruction). None of the programs exhibit collaborative tasks (games, simulations, and discussion forums) or facilitative resources (dictionary, database, spell/grammar checker, and authoring system).

In summary, the analysis of the programs "Longman English Interactive," "New Dynamic English," and "Rosetta Stone" indicates that the elaborated ESL/EFL software evaluation instrument is capable of measuring the potential of CALL software programs to develop language skills according to the principles of the Communicative Language Teaching and of an interactive model of computer use for language learning, and to detect relevant differences among these programs. Moreover, the statistical tests applied to the elaborated ESL/EFL software evaluation instrument indicate that it has high levels of internal consistency. Data show that the elaborated instrument is a reliable measurement of the criteria that serve as indicators of a software program's incorporation of the principles of the Communicative Approach to language teaching and of an interactive model of computer use for language learning. 


\section{APPENDIX B}

\section{ESL/EFL SOFTWARE EVALUATION INSTRUMENT}

Title of the program:

Publisher:

\section{DESCRIPTIVE ANALYSIS}

Please place a checkmark next to the item that best describes the program and/or its features.

\section{TECHNICAL FEATURES}

1.1 Components of the program:

\begin{tabular}{|l|l|l|}
\hline $\begin{array}{l}\text { Number of CD's: } \\
\begin{array}{l}\text { Per level } \\
\text { Total }\end{array}\end{array}$ & Teacher's guide __ Yes __ No & $\begin{array}{l}\text { Support materials __ Yes __ No } \\
\text { What type? }\end{array}$ \\
\hline
\end{tabular}

\subsection{Platform}

\begin{tabular}{|l|r|}
\hline Mac_ _ Mhz $\_$MB of RAM & $\begin{array}{r}\text { Windows } \\
\text { Mhz }\end{array} \quad$ MB of RAM \\
\hline
\end{tabular}

\subsection{Tools}

Word processing
Online forums
Online collaboration

Speech recognition
Web browsing
Encyclopedia or compendia

1.4 Other technological resources integrated into the program:

\begin{tabular}{|l|l|l|l|}
\hline _ dictionaries on the web & grammar on line & other web sites & _ none \\
\hline
\end{tabular}

1.5 Directions for use:

\begin{tabular}{|c|c|c|}
\hline are on the screen & are in the documentation & can be skipped at option of user \\
\hline
\end{tabular}

\section{PEDAGOGICAL ORIENTATION}

2.6 Program's theory of language

\begin{tabular}{|c|l|l|}
\hline structural & _ functional & interactional \\
\hline
\end{tabular}

2.7 Type of program

\begin{tabular}{|c|c|c|c|}
\hline $\begin{array}{l}\text { remediation } \\
\text { enrichment } \\
\text { tutoring }\end{array}$ & $\begin{array}{c}\text { demonstration } \\
\text { assessment }\end{array}$ & $\begin{array}{l}\text { education game } \\
\text { collaborative } \\
\text { projects }\end{array}$ & $\begin{array}{l}\text { problem solving } \\
\text { drill and practice } \\
\text { simulation }\end{array}$ \\
\hline
\end{tabular}


2.8 Curriculum capability

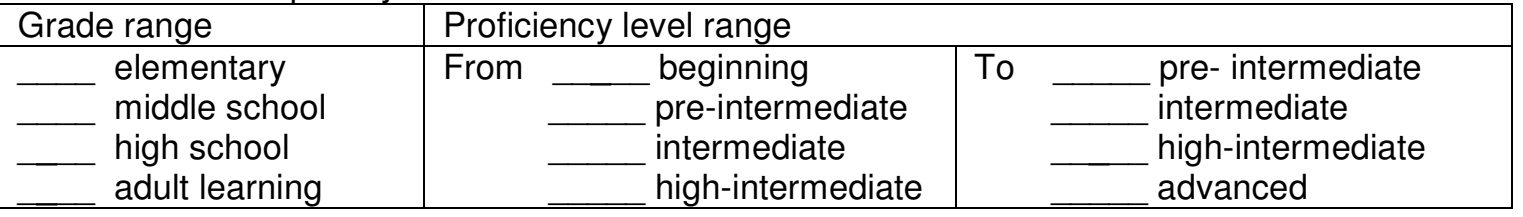

2.9 Method of language teaching claimed by the program

The Direct Method

The Natural Approach

Total Physical Response

The Audio-lingual Method

__ The Communicative Approach

2.10 Language skills developed in the program

\begin{tabular}{|l|l|l|l|}
\hline _ speaking & _ listening & _ reading & _ writing \\
\hline
\end{tabular}

2.11 Type of activities offered by the program

\begin{tabular}{|l|l|l|l|}
\hline $\begin{array}{l}\text { games } \\
\text { quizzes } \\
\text { others }\end{array}$ & simulation & tutorial & drill and practice \\
exploratory & text construction & problem solving \\
\hline
\end{tabular}

2.12 Orientation of how to use program and its feature

\begin{tabular}{|c|c|}
\hline for the teacher & on the screen \\
\hline for the student & on hard copy documentation \\
\hline for both & on both \\
\hline
\end{tabular}

2.13 Role of the teacher

\begin{tabular}{|l|l|l|l|}
\hline _ instructor & _ facilitator & _ lab manager & _ evaluator \\
\hline
\end{tabular}

2.14 Learners interact

\begin{tabular}{|c|l|l|}
\hline _ with one another & _ with the teacher & _ with neither \\
\hline
\end{tabular}

2.15 In case learners interact with one another, they can interact

\begin{tabular}{|l|l|}
\hline in all activities & in some activities \\
\hline
\end{tabular}

2.16 In case learners interact with the teacher, they can interact

at any time

at the end of the lesson at the end of the activities

there's no interaction

\section{CRITICAL ANALYSIS}

For each item, circle the numbers 1 (for low) to 4 (for high) to indicate your judgment of the degree to which the program possesses or demonstrates the feature identified in each item. Circle 0 if the feature is not present in the program. 


\begin{tabular}{|c|c|c|c|c|c|}
\hline \multicolumn{6}{|c|}{ Instructional Attributes } \\
\hline 1.1 Graphics and sound enhance learning. & 0 & $\begin{array}{c}\text { (low) } \\
1\end{array}$ & 2 & 3 & $\begin{array}{c}\text { (high) } \\
4\end{array}$ \\
\hline $\begin{array}{l}1.2 \text { The animation is effective in minimizing } \\
\text { boredom by motivating learners. }\end{array}$ & 0 & $\begin{array}{c}\text { (low) } \\
1\end{array}$ & 2 & 3 & $\begin{array}{c}\text { (high) } \\
4\end{array}$ \\
\hline 1.3 Screen displays are uncluttered. & 0 & $\begin{array}{c}\text { (low) } \\
1\end{array}$ & 2 & 3 & $\begin{array}{c}\text { (high) } \\
4\end{array}$ \\
\hline 1.4 Graphics make information attractive. & 0 & $\begin{array}{c}\text { (low) } \\
1\end{array}$ & 2 & 3 & $\begin{array}{c}\text { (high) } \\
4\end{array}$ \\
\hline $\begin{array}{l}1.5 \text { Graphics help memorization of key } \\
\text { information. }\end{array}$ & 0 & $\begin{array}{c}\text { (low) } \\
1\end{array}$ & 2 & 3 & $\begin{array}{c}\text { (high) } \\
4\end{array}$ \\
\hline $\begin{array}{l}\text { 1.6 The program makes use of authentic } \\
\text { texts and other realia. }\end{array}$ & 0 & $\begin{array}{c}\text { (low) } \\
1\end{array}$ & 2 & 3 & $\begin{array}{c}\text { (high) } \\
4\end{array}$ \\
\hline $\begin{array}{l}\text { 1.7 The program integrates information about } \\
\text { culture/daily situations into the presentations } \\
\text { and activities. }\end{array}$ & 0 & $\begin{array}{c}\text { (low) } \\
1\end{array}$ & 2 & 3 & $\begin{array}{c}\text { (high) } \\
4\end{array}$ \\
\hline $\begin{array}{l}1.8 \text { Lessons present and practice language } \\
\text { structures in meaningful communicative } \\
\text { contexts. }\end{array}$ & 0 & $\begin{array}{c}\text { (low) } \\
1\end{array}$ & 2 & 3 & $\begin{array}{c}\text { (high) } \\
4\end{array}$ \\
\hline $\begin{array}{l}\text { 1.9 Lessons present and practice vocabulary } \\
\text { in meaningful communicative contexts. }\end{array}$ & 0 & $\begin{array}{c}\text { (low) } \\
1\end{array}$ & 2 & 3 & $\begin{array}{c}\text { (high) } \\
4\end{array}$ \\
\hline $\begin{array}{l}1.10 \text { Lessons develop the communicative } \\
\text { skills the program aims to develop. }\end{array}$ & 0 & $\begin{array}{c}\text { (low) } \\
1\end{array}$ & 2 & 3 & $\begin{array}{c}\text { (high) } \\
4\end{array}$ \\
\hline $\begin{array}{l}1.11 \text { Lessons develop the level of language } \\
\text { proficiency the program aims to develop. }\end{array}$ & 0 & $\begin{array}{c}\text { (low) } \\
1\end{array}$ & 2 & 3 & $\begin{array}{c}\text { (high) } \\
4\end{array}$ \\
\hline $\begin{array}{l}1.12 \text { The course syllabus reflects a } \\
\text { communicative approach to language } \\
\text { teaching/learning. }\end{array}$ & 0 & $\begin{array}{c}\text { (low) } \\
1\end{array}$ & 2 & 3 & $\begin{array}{c}\text { (high) } \\
4\end{array}$ \\
\hline $\begin{array}{l}1.13 \text { Content selection is determined by } \\
\text { communicative skills and/or themes. }\end{array}$ & 0 & $\begin{array}{c}\text { (low) } \\
1\end{array}$ & 2 & 3 & $\begin{array}{c}\text { (high) } \\
4\end{array}$ \\
\hline $\begin{array}{l}\text { 1.14 Content is sequenced from simple } \\
\text { communicative functions, such as introducing } \\
\text { oneself, greeting, etc, to complex ones, such } \\
\text { as stating an opinion, disagreeing, etc. }\end{array}$ & 0 & $\begin{array}{c}\text { (low) } \\
1\end{array}$ & 2 & 3 & $\begin{array}{c}\text { (high) } \\
4\end{array}$ \\
\hline 1.15 Content is presented communicatively. & 0 & $\begin{array}{c}\text { (low) } \\
1\end{array}$ & 2 & 3 & $\begin{array}{c}\text { (high) } \\
4\end{array}$ \\
\hline $\begin{array}{l}1.16 \text { The program develops the content at } \\
\text { appropriate levels of language proficiency. }\end{array}$ & 0 & $\begin{array}{c}\text { (low) } \\
1\end{array}$ & 2 & 3 & $\begin{array}{c}\text { (high) } \\
4\end{array}$ \\
\hline $\begin{array}{l}1.17 \text { The program content is educationally } \\
\text { relevant and interesting for the learner. }\end{array}$ & 0 & $\begin{array}{c}\text { (low) } \\
1\end{array}$ & 2 & 3 & $\begin{array}{c}\text { (high) } \\
4\end{array}$ \\
\hline $\begin{array}{l}\text { 1.18 The program content is appropriate for } \\
\text { intended learners. }\end{array}$ & 0 & $\begin{array}{c}\text { (low) } \\
1\end{array}$ & 2 & 3 & $\begin{array}{c}\text { (high) } \\
4\end{array}$ \\
\hline $\begin{array}{l}1.19 \text { The program content is applicable to } \\
\text { real life contexts. }\end{array}$ & 0 & $\begin{array}{c}\text { (low) } \\
1\end{array}$ & 2 & 3 & $\begin{array}{c}\text { (high) } \\
4\end{array}$ \\
\hline $\begin{array}{l}1.20 \text { The program allows learners to work } \\
\text { together in communicative activities. }\end{array}$ & 0 & $\begin{array}{c}\text { (low) } \\
1\end{array}$ & 2 & 3 & $\begin{array}{c}\text { (high) } \\
4\end{array}$ \\
\hline $\begin{array}{l}\text { 1.21 The activities allow unplanned } \\
\text { and/or unpredictable responses. }\end{array}$ & 0 & $\begin{array}{c}\text { (low) } \\
1\end{array}$ & 2 & 3 & $\begin{array}{c}\text { (high) } \\
4\end{array}$ \\
\hline $\begin{array}{l}\text { 1.22 The activities lend themselves to group } \\
\text { discussions. }\end{array}$ & 0 & $\begin{array}{c}\text { (low) } \\
1\end{array}$ & 2 & 3 & $\begin{array}{c}\text { (high) } \\
4\end{array}$ \\
\hline
\end{tabular}




\begin{tabular}{|l|c|c|c|c|c|}
\hline $\begin{array}{l}1.23 \text { The activities aim at developing other } \\
\text { competencies in addition to syntactical and } \\
\text { lexical }\end{array}$ & 0 & $\begin{array}{c}\text { (low) } \\
1\end{array}$ & 2 & 3 & $\begin{array}{c}\text { (high) } \\
4\end{array}$ \\
\hline $\begin{array}{l}1.24 \text { The program allows the teacher to } \\
\text { interact with students while they are doing an } \\
\text { activity. }\end{array}$ & 0 & $\begin{array}{c}\text { (low) } \\
1\end{array}$ & 2 & 3 & $\begin{array}{c}\text { (high) } \\
4\end{array}$ \\
\hline $\begin{array}{l}1.25 \text { The program provides non-threatening } \\
\text { feedback. }\end{array}$ & 0 & $\begin{array}{c}\text { (low) } \\
1\end{array}$ & 2 & 3 & $\begin{array}{c}\text { (high) } \\
4\end{array}$ \\
\hline $\begin{array}{l}1.26 \text { The program allows learners to repeat } \\
\text { an activity after feedback is provided. }\end{array}$ & 0 & $\begin{array}{c}\text { (low) } \\
1\end{array}$ & 2 & 3 & $\begin{array}{c}\text { (high) } \\
4\end{array}$ \\
\hline $\begin{array}{l}1.27 \text { Activities allow for more than one } \\
\text { correct response. }\end{array}$ & 0 & $\begin{array}{c}\text { (low) } \\
1\end{array}$ & 2 & 3 & $\begin{array}{c}\text { (high) } \\
4\end{array}$ \\
\hline $\begin{array}{l}1.28 \text { The program provides the students with } \\
\text { feedback that would allow them to correct } \\
\text { their mistakes. }\end{array}$ & 0 & $\begin{array}{c}\text { (low) } \\
1\end{array}$ & 2 & 3 & $\begin{array}{c}\text { (high) } \\
4\end{array}$ \\
\hline \multicolumn{2}{|l|}{ Sub-total = } \\
\hline
\end{tabular}

\begin{tabular}{|c|c|c|c|c|c|}
\hline \multicolumn{6}{|c|}{ Media Attributes } \\
\hline 2.29 Graphics aid understanding. & 0 & $\begin{array}{c}\text { (low) } \\
1\end{array}$ & 2 & 3 & $\begin{array}{c}\text { (high) } \\
4\end{array}$ \\
\hline $\begin{array}{l}2.30 \text { The program allows for different routes } \\
\text { and choices for learning. }\end{array}$ & 0 & $\begin{array}{c}\text { (low) } \\
1\end{array}$ & 2 & 3 & $\begin{array}{c}\text { (high) } \\
4\end{array}$ \\
\hline $\begin{array}{l}\text { 2.31 The program allows for review of old } \\
\text { information. }\end{array}$ & 0 & $\begin{array}{c}\text { (low) } \\
1\end{array}$ & 2 & 3 & $\begin{array}{c}\text { (high) } \\
4\end{array}$ \\
\hline $\begin{array}{l}2.32 \text { The program allows branching to new } \\
\text { information. }\end{array}$ & 0 & $\begin{array}{c}\text { (low) } \\
1\end{array}$ & 2 & 3 & $\begin{array}{c}\text { (high) } \\
4\end{array}$ \\
\hline $\begin{array}{l}2.33 \text { The program allows students to select } \\
\text { activities according to their ages. }\end{array}$ & 0 & $\begin{array}{c}\text { (low) } \\
1\end{array}$ & 2 & 3 & $\begin{array}{c}\text { (high) } \\
4\end{array}$ \\
\hline $\begin{array}{l}\text { 2.34 The program allows students to select } \\
\text { activities according to their learning styles. }\end{array}$ & 0 & $\begin{array}{c}\text { (low) } \\
1\end{array}$ & 2 & 3 & $\begin{array}{c}\text { (high) } \\
4\end{array}$ \\
\hline $\begin{array}{l}2.35 \text { The program allows students to select } \\
\text { activities according to their interests. }\end{array}$ & 0 & $\begin{array}{c}\text { (low) } \\
1\end{array}$ & 2 & 3 & $\begin{array}{c}\text { (high) } \\
4\end{array}$ \\
\hline $\begin{array}{l}2.36 \text { The program adapts to the responses } \\
\text { given by the learners, branching to more or } \\
\text { less complicated questions as appropriate. }\end{array}$ & 0 & $\begin{array}{c}\text { (low) } \\
1\end{array}$ & 2 & 3 & $\begin{array}{c}\text { (high) } \\
4\end{array}$ \\
\hline $\begin{array}{l}2.37 \text { The program allows learners to go } \\
\text { through its content at their own pace and } \\
\text { rhythm. }\end{array}$ & 0 & $\begin{array}{c}\text { (low) } \\
1\end{array}$ & 2 & 3 & $\begin{array}{c}\text { (high) } \\
4\end{array}$ \\
\hline $\begin{array}{l}2.38 \text { The program prevents learners from } \\
\text { repeating exercises, therefore, minimizing } \\
\text { guessing. }\end{array}$ & 0 & $\begin{array}{c}\text { (low) } \\
1\end{array}$ & 2 & 3 & $\begin{array}{c}\text { (high) } \\
4\end{array}$ \\
\hline $\begin{array}{l}\text { 2.39 The program keeps records of learners' } \\
\text { performance to allow them to continue } \\
\text { activities from where they left off. }\end{array}$ & 0 & $\begin{array}{c}\text { (low) } \\
1\end{array}$ & 2 & 3 & $\begin{array}{c}\text { (high) } \\
4\end{array}$ \\
\hline $\begin{array}{l}\text { 2.40 The program keeps track of students' } \\
\text { scores. }\end{array}$ & 0 & $\begin{array}{c}\text { (low) } \\
1\end{array}$ & 2 & 3 & $\begin{array}{c}\text { (high) } \\
4\end{array}$ \\
\hline $\begin{array}{l}2.41 \text { The program provides feedback for both } \\
\text { correct and incorrect answers. The program } \\
\text { provides feedback for both correct and } \\
\text { incorrect answers. }\end{array}$ & 0 & $\begin{array}{c}\text { (low) } \\
1\end{array}$ & 2 & 3 & $\begin{array}{c}\text { (high) } \\
4\end{array}$ \\
\hline $\begin{array}{l}2.42 \text { The program gives learners the chance } \\
\text { to correct their errors. }\end{array}$ & 0 & $\begin{array}{c}\text { (low) } \\
1\end{array}$ & 2 & 3 & $\begin{array}{c}\text { (high) } \\
4\end{array}$ \\
\hline
\end{tabular}




\begin{tabular}{|c|c|c|c|c|c|}
\hline $\begin{array}{l}2.43 \text { The program effectively signals the } \\
\text { mistakes before providing the right answers. }\end{array}$ & 0 & $\begin{array}{c}\text { (low) } \\
1\end{array}$ & 2 & 3 & $\begin{array}{c}\text { (high) } \\
4\end{array}$ \\
\hline $\begin{array}{l}\text { 2.44 The program effectively specifies } \\
\text { different types of errors, such as differences } \\
\text { between a syntactic error and an incorrect } \\
\text { word choice. }\end{array}$ & 0 & $\begin{array}{c}\text { (low) } \\
1\end{array}$ & 2 & 3 & $\begin{array}{l}\text { (high) } \\
4\end{array}$ \\
\hline \multicolumn{6}{|c|}{ Sub-total $=$} \\
\hline \multicolumn{6}{|c|}{ User-Friendly Attributes } \\
\hline $\begin{array}{l}\text { 3.45 Menu items are understandable and } \\
\text { descriptive. }\end{array}$ & 0 & $\begin{array}{c}\text { (low) } \\
1\end{array}$ & 2 & 3 & $\begin{array}{c}\text { (high) } \\
4\end{array}$ \\
\hline $\begin{array}{l}\text { 3.46 The commands and instructions for the } \\
\text { activities are clear and objective. }\end{array}$ & 0 & $\begin{array}{c}\text { (low) } \\
1\end{array}$ & 2 & 3 & $\begin{array}{c}\text { (high) } \\
4\end{array}$ \\
\hline $\begin{array}{l}\text { 3.47 The program gives the learners effective } \\
\text { clues to clarify their doubts about its use. }\end{array}$ & 0 & $\begin{array}{c}\text { (low) } \\
1\end{array}$ & 2 & 3 & $\begin{array}{c}\text { (high) } \\
4\end{array}$ \\
\hline $\begin{array}{l}3.48 \text { Each screen uses text and } \\
\text { graphic/animation to make a particular } \\
\text { teaching point clear. }\end{array}$ & 0 & $\begin{array}{c}\text { (low) } \\
1\end{array}$ & 2 & 3 & $\begin{array}{c}\text { (high) } \\
4\end{array}$ \\
\hline $\begin{array}{l}\text { 3.49 The program is effectively integrated with } \\
\text { other technological resources (such as } \\
\text { dictionaries on the web, grammar on line, etc) } \\
\text { as the learner uses it. }\end{array}$ & 0 & $\begin{array}{c}\text { (low) } \\
1\end{array}$ & 2 & 3 & $\begin{array}{c}\text { (high) } \\
4\end{array}$ \\
\hline $\begin{array}{l}3.50 \text { Icons, buttons and menus allow learners } \\
\text { to readily search for additional information } \\
\text { while doing an activity. }\end{array}$ & 0 & $\begin{array}{c}\text { (low) } \\
1\end{array}$ & 2 & 3 & $\begin{array}{c}\text { (high) } \\
4\end{array}$ \\
\hline $\begin{array}{l}3.51 \text { Buttons, icons or menu items make Help } \\
\text { or Hint-type options easily accessible. }\end{array}$ & 0 & $\begin{array}{c}\text { (low) } \\
1\end{array}$ & 2 & 3 & $\begin{array}{c}\text { (high) } \\
4\end{array}$ \\
\hline $\begin{array}{l}\text { 3.52 The program arouses sensory and } \\
\text { cognitive curiosity }\end{array}$ & 0 & $\begin{array}{c}\text { (low) } \\
1\end{array}$ & 2 & 3 & $\begin{array}{c}\text { (high) } \\
4\end{array}$ \\
\hline $\begin{array}{l}3.53 \text { The program maintains attention } \\
\text { throughout the lesson. }\end{array}$ & 0 & $\begin{array}{c}\text { (low) } \\
1\end{array}$ & 2 & 3 & $\begin{array}{c}\text { (high) } \\
4\end{array}$ \\
\hline $\begin{array}{l}\text { 3.54 The use of animation invites learners' } \\
\text { reaction or input. }\end{array}$ & 0 & $\begin{array}{c}\text { (low) } \\
1\end{array}$ & 2 & 3 & $\begin{array}{c}\text { (high) } \\
4\end{array}$ \\
\hline $\begin{array}{l}\text { 3.55 The program gives teachers a clear } \\
\text { explanation of its purposes and } \\
\text { methodological orientation. }\end{array}$ & 0 & $\begin{array}{c}\text { (low) } \\
1\end{array}$ & 2 & 3 & $\begin{array}{c}\text { (high) } \\
4\end{array}$ \\
\hline \multicolumn{6}{|c|}{ Sub-total $=$} \\
\hline \multicolumn{6}{|c|}{ Total } \\
\hline
\end{tabular}

Sub-total of ratings for Instructional Attributes

Sub-total of ratings for Media Attributes

Sub-total of ratings for User-Friendly Attributes

Total rating 


\section{APPENDIX C}

\section{INFORMED PARTICIPANT CONSENT FORM}

I understand that I have been invited to participate in a study of "The incorporation of Communicative Language Teaching into the elaboration of interactive software for ESL/EFL learning". This study will involve using an ESL/EFL software evaluation instrument to analyze three ESL/EFL software programs whose CD-Roms will be given to me. I will have to go through the content of each program and then will answer the questions in the evaluation instrument using the provided rating scale. I am also encouraged to write down any other observations about the programs or about the evaluation instrument itself.

The information I give about the programs and the evaluation instrument will be used in a report which will be written about this study and presented in about a year from now. Information about my qualification background and my teaching experience will also be reported in the study. However, my personal information will be kept in strictest confidence. Neither my name nor my social security number will be used in reporting the results of this study.

I also understand that I may request an interpretation of my results once the study is completed. If I have an questions about the study or if I experience any discomfort or have any concerns that I would like to express I may contact the researcher (at vladiaborges2001@yahoo.com ) or her Major Professor, Dr. Julie Wollman-Bonilla, at Rhode Island College (at jwollman@ric.edu) .

My participation in this study is entirely voluntary and I may discontinue my participation at any point without penalty to myself. I acknowledge that the contents of this form have been explained to me and that I have been given an opportunity to ask questions. I have been given a copy of this form.

I DO CONSENT TO PARTICIPATE IN THIS RESEARCH PROJECT.

Signature of Participant: Date:

Signature of Investigator: Date: 


\section{APPENDIX D}

\section{ESL/EFL SOFTWARE EVALUATION INSTRUMENT}

\section{Title of the program ASTERIX - LEARN ENGLISH \\ Publisher/date EUROTALK INTERACTIVE}

\section{DESCRIPTIVE ANALYSIS}

Please place a checkmark next to the item that best describes the program and/or its features.

\section{TECHNICAL FEATURES}

1.1 Components of the program:

\begin{tabular}{|c|l|l|}
\hline $\begin{array}{c}\text { Number of CD's: } \\
\text { Per level 1 } \\
\text { Total } \mathbf{2}\end{array}$ & Teacher's guide __Yes_X_No & $\begin{array}{l}\text { Support materials__ Yes_X_No } \\
\text { What type? }\end{array}$ \\
\hline
\end{tabular}

1.2 Platform

\begin{tabular}{|c|c|}
\hline $\begin{array}{c}\text { Mac } 059 \text { or X } \\
\text { Mhz }\end{array}$ & $\begin{array}{l}\text { Windows 98/2000/XP } \\
\text { MBz of RAM }\end{array}$ \\
\hline
\end{tabular}

\subsection{Tools}

\begin{tabular}{|c|c|}
\hline $\begin{array}{l}\text { Word processing } \\
\text { Online forums } \\
\text { Online collaboration }\end{array}$ & $\begin{array}{l}\text { Speech recognition } \\
\text { Web browsing } \\
\text { Encyclopedia or compendia }\end{array}$ \\
\hline
\end{tabular}

1.4 The program integrates other technological resources such as

\begin{tabular}{|l|l|l|l|}
\hline$\frac{\text { web }}{\text { dictionaries on the }}$ & grammar on line & other web sites & X_ none \\
\hline
\end{tabular}

1.5 Directions for use:

\begin{tabular}{|l|l|l|}
\hline X_are on the screen & _ are in the documentation & $\underset{-}{\text { user }}$ \\
\hline
\end{tabular}

\section{PEDAGOGICAL ORIENTATION}

2.6 Program's theory of language

\begin{tabular}{|c|l|l|}
\hline structural & _ & functional \\
\hline
\end{tabular}

2.7 Type of program

\begin{tabular}{|c|c|c|c|}
\hline $\begin{array}{c}\text { remediation } \\
\mathbf{X} \text { enrichment } \\
\text { tutoring }\end{array}$ & $\begin{array}{l}\text { demonstration } \\
\text { assessment }\end{array}$ & $\begin{array}{l}\overline{\text { game }}^{\text {education }} \\
\text { collaborative } \\
\text { proiects }\end{array}$ & $\begin{array}{l}\text { problem solving } \\
\text { drill and practice } \\
\text { simulation }\end{array}$ \\
\hline
\end{tabular}


2.8 Curriculum capability

\begin{tabular}{|c|c|c|c|}
\hline Grade range & Proficie & ency level range & \\
\hline $\begin{array}{l}\text { elementary } \\
\text { middle school } \\
\mathbf{X} \text { high school } \\
\text { ___ adult learning }\end{array}$ & From & $\begin{array}{ll} & \text { beginning } \\
\text { pre- } \\
\text { intermediate } \\
\mathbf{X} \quad \text { intermediate } \\
\text { high-intermediate }\end{array}$ & 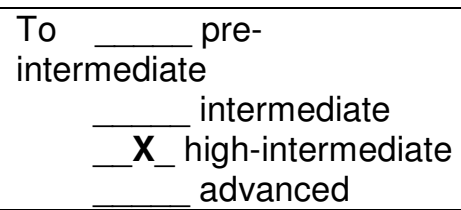 \\
\hline
\end{tabular}

2.9 Method of language teaching claimed by the program

\begin{tabular}{|l|l|}
\hline $\begin{array}{l}\text { The Direct Method } \\
\text { The Natural Approach } \\
\text { Total Physical Response }\end{array}$ & The Audio-lingual Method \\
\hline
\end{tabular}

2.10 Language skills developed in the program

\begin{tabular}{|l|l|l|l|}
\hline _ speaking & _ $\mathbf{X}$ _ listening & $\mathbf{X}$ _ reading & _ writing \\
\hline
\end{tabular}

2.11 Type of activities offered by the program

\begin{tabular}{|c|c|c|c|}
\hline $\begin{array}{c}\text { games } \\
\mathbf{X} \text { _ quizzes } \\
\text { others }\end{array}$ & $\begin{array}{r}\text { simulation } \\
\mathbf{X} \_ \text {exploratory }\end{array}$ & $\begin{array}{l}\text { tutorial } \\
\text { text } \\
\text { construction }\end{array}$ & $\begin{array}{r}\mathbf{X} \text { _ drill and practice } \\
\text { problem solving }\end{array}$ \\
\hline
\end{tabular}

2.12 Orientation of how to use program and its feature

\begin{tabular}{|c|c|}
\hline for the teacher & on the screen \\
\hline for the student & on hard copy documentation \\
\hline for both & on both \\
\hline
\end{tabular}

2.13 Role of the teacher

\begin{tabular}{|c|c|c|c|}
\hline instructor & facilitator & _._lab manager & __ evaluator \\
\hline
\end{tabular}

2.14 Learners interact

\begin{tabular}{|c|l|l|}
\hline _ with one another & _ with the teacher & $\mathbf{X}$ _ with neither \\
\hline
\end{tabular}

2.15 In case learners interact with one another, they can interact in all activities in some activities

2.16 In case learners interact with the teacher, they can interact

at any time

at the end of the lesson at the end of the activities

$\mathbf{X}$ _there's no interaction

\section{CRITICAL ANALYSIS}

For each item, circle the numbers 1 (for low) to 4 (for high) to indicate your judgment of the degree to which the program possesses or demonstrates the feature identified in each item. Circle 0 if the feature is not present in the program. 


\begin{tabular}{|c|c|c|c|c|c|}
\hline \multicolumn{6}{|c|}{ Instructional Attributes } \\
\hline 1.2 Graphics and sound enhance learning. & 0 & $\begin{array}{c}\text { (low) } \\
1\end{array}$ & 2 & 3 & $\begin{array}{c}\text { (high) } \\
4\end{array}$ \\
\hline $\begin{array}{l}1.2 \text { The animation is effective in minimizing } \\
\text { boredom by motivating learners. }\end{array}$ & 0 & $\begin{array}{c}\text { (low) } \\
1\end{array}$ & 2 & 3 & $\begin{array}{c}\text { (high) } \\
4\end{array}$ \\
\hline 1.4 Screen displays are uncluttered. & 0 & $\begin{array}{c}\text { (low) } \\
1\end{array}$ & 2 & 3 & $\begin{array}{c}(\text { high }) \\
4\end{array}$ \\
\hline 1.4 Graphics make information attractive. & 0 & $\begin{array}{c}\text { (low) } \\
1\end{array}$ & 2 & 3 & $\begin{array}{c}\text { (high) } \\
4\end{array}$ \\
\hline $\begin{array}{l}1.5 \text { Graphics help memorization of key } \\
\text { information. }\end{array}$ & 0 & $\begin{array}{c}\text { (low) } \\
1\end{array}$ & 2 & 3 & $\begin{array}{c}\text { (high) } \\
4\end{array}$ \\
\hline $\begin{array}{l}1.6 \text { The program makes use of authentic texts } \\
\text { and other realia. }\end{array}$ & 0 & $\begin{array}{c}\text { (low) } \\
1\end{array}$ & 2 & 3 & $\begin{array}{c}\text { (high) } \\
4\end{array}$ \\
\hline $\begin{array}{l}\text { 1.7 The program integrates information about } \\
\text { culture/daily situations into the presentations } \\
\text { and activities. }\end{array}$ & 0 & $\begin{array}{c}\text { (low) } \\
1\end{array}$ & 2 & 3 & $\begin{array}{c}\text { (high) } \\
4\end{array}$ \\
\hline $\begin{array}{l}1.8 \text { Lessons present and practice language } \\
\text { structures in meaningful communicative } \\
\text { contexts. }\end{array}$ & 0 & $\begin{array}{c}\text { (low) } \\
1\end{array}$ & 2 & 3 & $\begin{array}{c}\text { (high) } \\
4\end{array}$ \\
\hline $\begin{array}{l}1.9 \text { Lessons present and practice vocabulary in } \\
\text { meaningful communicative contexts. }\end{array}$ & 0 & $\begin{array}{c}\text { (low) } \\
1\end{array}$ & 2 & 3 & $\begin{array}{c}\text { (high) } \\
4\end{array}$ \\
\hline $\begin{array}{l}1.10 \text { Lessons develop the communicative skills } \\
\text { the program aims to develop. }\end{array}$ & 0 & $\begin{array}{c}\text { (low) } \\
1\end{array}$ & 2 & 3 & $\begin{array}{c}\text { (high) } \\
4\end{array}$ \\
\hline $\begin{array}{l}1.11 \text { Lessons develop the level of language } \\
\text { proficiency the program aims to develop. }\end{array}$ & 0 & $\begin{array}{c}\text { (low) } \\
1\end{array}$ & 2 & 3 & $\begin{array}{c}\text { (high) } \\
4\end{array}$ \\
\hline $\begin{array}{l}1.12 \text { The course syllabus reflects a } \\
\text { communicative approach to language } \\
\text { teaching/learning. }\end{array}$ & 0 & $\begin{array}{c}\text { (low) } \\
1\end{array}$ & 2 & 3 & $\begin{array}{c}\text { (high) } \\
4\end{array}$ \\
\hline $\begin{array}{l}1.13 \text { Content selection is determined by } \\
\text { communicative skills and/or themes. }\end{array}$ & 0 & $\begin{array}{c}\text { (low) } \\
1\end{array}$ & 2 & 3 & $\begin{array}{c}\text { (high) } \\
4\end{array}$ \\
\hline $\begin{array}{l}\text { 1.14 Content is sequenced from simple } \\
\text { communicative functions, such as introducing } \\
\text { oneself, greeting, etc, to complex ones, such } \\
\text { as stating an opinion, disagreeing, etc. }\end{array}$ & 0 & $\begin{array}{c}\text { (low) } \\
1\end{array}$ & 2 & 3 & $\begin{array}{c}\text { (high) } \\
4\end{array}$ \\
\hline 1.15 Content is presented communicatively. & 0 & $\begin{array}{c}\text { (low) } \\
1\end{array}$ & 2 & 3 & $\begin{array}{c}\text { (high) } \\
4\end{array}$ \\
\hline $\begin{array}{l}1.16 \text { The program develops the content at } \\
\text { appropriate levels of language proficiency. }\end{array}$ & 0 & $\begin{array}{c}\text { (low) } \\
1\end{array}$ & 2 & 3 & $\begin{array}{c}\text { (high) } \\
4\end{array}$ \\
\hline $\begin{array}{l}1.17 \text { The program content is educationally } \\
\text { relevant and interesting for the learner. }\end{array}$ & 0 & $\begin{array}{c}\text { (low) } \\
1\end{array}$ & 2 & 3 & $\begin{array}{c}\text { (high) } \\
4\end{array}$ \\
\hline $\begin{array}{l}\text { 1.18 The program content is appropriate for } \\
\text { intended learners. }\end{array}$ & 0 & $\begin{array}{c}\text { (low) } \\
1\end{array}$ & 2 & 3 & $\begin{array}{c}\text { (high) } \\
4\end{array}$ \\
\hline $\begin{array}{l}\text { 1.19 The program content is applicable to real } \\
\text { life contexts. }\end{array}$ & 0 & $\begin{array}{c}\text { (low) } \\
1\end{array}$ & 2 & 3 & $\begin{array}{c}\text { (high) } \\
4\end{array}$ \\
\hline $\begin{array}{l}1.20 \text { The program allows learners to work } \\
\text { together in communicative activities. }\end{array}$ & 0 & $\begin{array}{c}\text { (low) } \\
1\end{array}$ & 2 & 3 & $\begin{array}{c}\text { (high) } \\
4\end{array}$ \\
\hline $\begin{array}{l}1.21 \text { The activities allow unplanned and/or } \\
\text { unpredictable responses. }\end{array}$ & 0 & $\begin{array}{c}\text { (low) } \\
1\end{array}$ & 2 & 3 & $\begin{array}{c}\text { (high) } \\
4\end{array}$ \\
\hline $\begin{array}{l}1.22 \text { The activities lend themselves to group } \\
\text { discussions. }\end{array}$ & 0 & $\begin{array}{c}\text { (low) } \\
1\end{array}$ & 2 & 3 & $\begin{array}{c}\text { (high) } \\
4\end{array}$ \\
\hline
\end{tabular}




\begin{tabular}{|c|c|c|c|c|c|}
\hline $\begin{array}{l}\text { 1.23 The activities aim at developing other } \\
\text { competencies in addition to syntactical and } \\
\text { lexical }\end{array}$ & 0 & $\begin{array}{c}\text { (low) } \\
1\end{array}$ & 2 & 3 & $\begin{array}{c}\text { (high) } \\
4\end{array}$ \\
\hline $\begin{array}{l}1.24 \text { The program allows the teacher to interact } \\
\text { with students while they are doing an activity. }\end{array}$ & 0 & $\begin{array}{c}\text { (low) } \\
1\end{array}$ & 2 & 3 & $\begin{array}{c}\text { (high) } \\
4\end{array}$ \\
\hline $\begin{array}{l}\text { 1.25 The program provides non-threatening } \\
\text { feedback. }\end{array}$ & 0 & $\begin{array}{c}\text { (low) } \\
1\end{array}$ & 2 & 3 & $\begin{array}{c}\text { (high) } \\
4\end{array}$ \\
\hline $\begin{array}{l}1.26 \text { The program allows learners to repeat an } \\
\text { activity after feedback is provided. }\end{array}$ & 0 & $\begin{array}{c}\text { (low) } \\
1\end{array}$ & 2 & 3 & $\begin{array}{c}\text { (high) } \\
4\end{array}$ \\
\hline $\begin{array}{l}1.27 \text { Activities allow for more than one correct } \\
\text { response. }\end{array}$ & 0 & $\begin{array}{c}\text { (low) } \\
1\end{array}$ & 2 & 3 & $\begin{array}{c}\text { (high) } \\
4\end{array}$ \\
\hline $\begin{array}{l}\text { 1.28 The program provides the students with } \\
\text { feedback that would allow them to correct their } \\
\text { mistakes. }\end{array}$ & 0 & $\begin{array}{c}\text { (low) } \\
1\end{array}$ & 2 & 3 & $\begin{array}{c}\text { (high) } \\
4\end{array}$ \\
\hline
\end{tabular}

\begin{tabular}{|c|c|c|c|c|c|}
\hline \multicolumn{6}{|c|}{ Media Attributes } \\
\hline 2.29 Graphics aid understanding. & 0 & $\begin{array}{c}\text { (low) } \\
1\end{array}$ & 2 & 3 & $\begin{array}{c}\text { (high) } \\
4\end{array}$ \\
\hline $\begin{array}{l}\text { 2.30 The program allows for different routes and } \\
\text { choices for learning. }\end{array}$ & 0 & $\begin{array}{c}\text { (low) } \\
1\end{array}$ & 2 & 3 & $\begin{array}{c}\text { (high) } \\
4\end{array}$ \\
\hline $\begin{array}{l}\text { 2.31 The program allows for review of old } \\
\text { information. }\end{array}$ & 0 & $\begin{array}{c}\text { (low) } \\
1\end{array}$ & 2 & 3 & $\begin{array}{c}\text { (high) } \\
4\end{array}$ \\
\hline $\begin{array}{l}2.32 \text { The program allows branching to new } \\
\text { information. }\end{array}$ & 0 & $\begin{array}{c}\text { (low) } \\
1\end{array}$ & 2 & 3 & $\begin{array}{c}\text { (high) } \\
4\end{array}$ \\
\hline $\begin{array}{l}2.33 \text { The program allows students to select } \\
\text { activities according to their ages. }\end{array}$ & 0 & $\begin{array}{c}\text { (low) } \\
1\end{array}$ & 2 & 3 & $\begin{array}{c}\text { (high) } \\
4\end{array}$ \\
\hline $\begin{array}{l}\text { 2.34 The program allows students to select } \\
\text { activities according to their learning styles. }\end{array}$ & 0 & $\begin{array}{c}\text { (low) } \\
1\end{array}$ & 2 & 3 & $\begin{array}{c}\text { (high) } \\
4\end{array}$ \\
\hline $\begin{array}{l}2.35 \text { The program allows students to select } \\
\text { activities according to their interests. }\end{array}$ & 0 & $\begin{array}{c}\text { (low) } \\
1\end{array}$ & 2 & 3 & $\begin{array}{c}\text { (high) } \\
4\end{array}$ \\
\hline $\begin{array}{l}\text { 2.36 The program adapts to the responses } \\
\text { given by the learners, branching to more or less } \\
\text { complicated questions as appropriate. }\end{array}$ & 0 & $\begin{array}{c}\text { (low) } \\
1\end{array}$ & 2 & 3 & $\begin{array}{c}\text { (high) } \\
4\end{array}$ \\
\hline $\begin{array}{l}2.37 \text { The program allows learners to go through } \\
\text { its content at their own pace and rhythm. }\end{array}$ & 0 & $\begin{array}{c}\text { (low) } \\
1\end{array}$ & 2 & 3 & $\begin{array}{c}\text { (high) } \\
4\end{array}$ \\
\hline $\begin{array}{l}2.38 \text { The program prevents learners from } \\
\text { repeating exercises, therefore, minimizing } \\
\text { guessing. }\end{array}$ & 0 & $\begin{array}{c}\text { (low) } \\
1\end{array}$ & 2 & 3 & $\begin{array}{c}\text { (high) } \\
4\end{array}$ \\
\hline $\begin{array}{l}\text { 2.39 The program keeps records of learners' } \\
\text { performance to allow them to continue activities } \\
\text { from where they left off. }\end{array}$ & 0 & $\begin{array}{c}\text { (low) } \\
1\end{array}$ & 2 & 3 & $\begin{array}{c}\text { (high) } \\
4\end{array}$ \\
\hline $\begin{array}{l}2.40 \text { The program keeps track of students' } \\
\text { scores. }\end{array}$ & 0 & $\begin{array}{c}\text { (low) } \\
1\end{array}$ & 2 & 3 & $\begin{array}{c}\text { (high) } \\
4\end{array}$ \\
\hline $\begin{array}{l}\text { 2.41 The program provides feedback for both } \\
\text { correct and incorrect answers. }\end{array}$ & 0 & $\begin{array}{c}\text { (low) } \\
1\end{array}$ & 2 & 3 & $\begin{array}{c}\text { (high) } \\
4\end{array}$ \\
\hline $\begin{array}{l}2.42 \text { The program gives learners the chance to } \\
\text { correct their errors. }\end{array}$ & 0 & $\begin{array}{c}\text { (low) } \\
1\end{array}$ & 2 & 3 & $\begin{array}{c}\text { (high) } \\
4\end{array}$ \\
\hline $\begin{array}{l}\text { 2.43 The program effectively signals the } \\
\text { mistakes before providing the right answers. }\end{array}$ & 0 & $\begin{array}{c}\text { (low) } \\
1\end{array}$ & 2 & 3 & $\begin{array}{c}\text { (high) } \\
4\end{array}$ \\
\hline
\end{tabular}




\begin{tabular}{|c|c|c|c|c|c|}
\hline $\begin{array}{l}\text { 2.44 The program effectively specifies different } \\
\text { types of errors, such as differences between a } \\
\text { syntactic error and an incorrect word choice. }\end{array}$ & 0 & $\begin{array}{c}\text { (low) } \\
1\end{array}$ & 2 & 3 & $\begin{array}{c}\text { (high) } \\
4\end{array}$ \\
\hline \multicolumn{6}{|c|}{ Sub-totals $=25$} \\
\hline \multicolumn{6}{|c|}{ User-Friendly Attributes } \\
\hline $\begin{array}{l}\text { 3.45 Menu items are understandable and } \\
\text { descriptive. }\end{array}$ & 0 & $\begin{array}{c}\text { (low) } \\
1\end{array}$ & 2 & 3 & $\begin{array}{l}\text { (high) } \\
4\end{array}$ \\
\hline $\begin{array}{l}3.46 \text { The commands and instructions for the } \\
\text { activities are clear and objective. }\end{array}$ & 0 & $\begin{array}{c}\text { (low) } \\
1\end{array}$ & 2 & 3 & $\begin{array}{c}\text { (high) } \\
4\end{array}$ \\
\hline $\begin{array}{l}\text { 3.47 The program gives the learners effective } \\
\text { clues to clarify their doubts about its use. }\end{array}$ & 0 & $\begin{array}{c}\text { (low) } \\
1\end{array}$ & 2 & 3 & $\begin{array}{c}\text { (high) } \\
4\end{array}$ \\
\hline $\begin{array}{l}3.48 \text { Each screen uses text and } \\
\text { graphic/animation to make a particular teaching } \\
\text { point clear. }\end{array}$ & 0 & $\begin{array}{c}\text { (low) } \\
1\end{array}$ & 2 & 3 & $\begin{array}{c}\text { (high) } \\
4\end{array}$ \\
\hline $\begin{array}{l}\text { 3.49 The program is effectively integrated with } \\
\text { other technological resources (such as } \\
\text { dictionaries on the web, grammar on line, etc) } \\
\text { as the learner uses it. }\end{array}$ & 0 & $\begin{array}{c}\text { (low) } \\
1\end{array}$ & 2 & 3 & $\begin{array}{c}\text { (high) } \\
4\end{array}$ \\
\hline $\begin{array}{l}3.50 \text { Icons, buttons and menus allow learners to } \\
\text { readily search for additional information while } \\
\text { doing an activity. }\end{array}$ & 0 & $\begin{array}{c}\text { (low) } \\
1\end{array}$ & 2 & 3 & $\begin{array}{c}\text { (high) } \\
4\end{array}$ \\
\hline $\begin{array}{l}3.51 \text { Buttons, icons or menu items make Help or } \\
\text { Hint-type options easily accessible. }\end{array}$ & 0 & $\begin{array}{c}\text { (low) } \\
1\end{array}$ & 2 & 3 & $\begin{array}{c}\text { (high) } \\
4\end{array}$ \\
\hline $\begin{array}{l}\text { 3.52 The program arouses sensory and } \\
\text { cognitive curiosity }\end{array}$ & 0 & $\begin{array}{c}\text { (low) } \\
1\end{array}$ & 2 & 3 & $\begin{array}{l}\text { (high) } \\
4\end{array}$ \\
\hline $\begin{array}{l}3.53 \text { The program maintains attention } \\
\text { throughout the lesson. }\end{array}$ & 0 & $\begin{array}{c}\text { (low) } \\
1\end{array}$ & 2 & 3 & $\begin{array}{c}\text { (high) } \\
4\end{array}$ \\
\hline $\begin{array}{l}3.54 \text { The use of animation invites learners' } \\
\text { reaction or input. }\end{array}$ & 0 & $\begin{array}{c}\text { (low) } \\
1\end{array}$ & 2 & 3 & $\begin{array}{c}\text { (high) } \\
4\end{array}$ \\
\hline $\begin{array}{l}3.55 \text { The program gives teachers a clear } \\
\text { explanation of its purposes and methodological } \\
\text { orientation. }\end{array}$ & 0 & $\begin{array}{c}\text { (low) } \\
1\end{array}$ & 2 & 3 & $\begin{array}{c}\text { (high) } \\
4\end{array}$ \\
\hline \multicolumn{6}{|c|}{ Sub-total $=21$} \\
\hline \multicolumn{6}{|c|}{ Total $=100$} \\
\hline
\end{tabular}

\begin{tabular}{|c|c|}
\hline 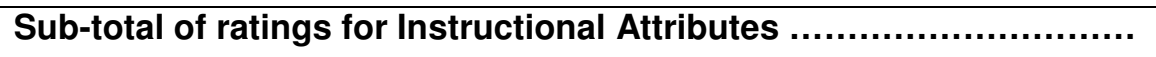 & 54 \\
\hline Sub-total of ratings for Media Attributes. & 25 \\
\hline Sub-total of ratings for User-Friendly Attributes $\ldots \ldots \ldots \ldots \ldots \ldots \ldots \ldots$ & 21 \\
\hline Total rating & 100 \\
\hline
\end{tabular}




\section{ESL/EFL SOFTWARE EVALUATION INSTRUMENT}

Title of the program: English Discoveries

Publisher/date: Techno-Ware

\section{DESCRIPTIVE ANALYSIS}

Please place a checkmark next to the item that best describes the program and/or its features.

\section{TECHNICAL FEATURES}

1.1 Components of the program:

\begin{tabular}{|l|l|l|}
\hline $\begin{array}{l}\text { Number of CD's: } \\
\mathbf{0 3} \text { CDs per level; } \\
\mathbf{1 2} \text { total }\end{array}$ & Teacher's guide_X_Yes___No & $\begin{array}{l}\text { Support materials_X_Yes_N_No } \\
\text { What type? Reproducible } \\
\text { worksheets; Lesson Text Files }\end{array}$ \\
\hline
\end{tabular}

1.2 Platform

\begin{tabular}{|l|l|}
\hline Mac_Mhz $\_$MB of RAM & $\begin{array}{l}\text { Windows 95, 98, NT, and XP } \\
\text { RAM Mhz 32 (64 reccomended) MB of }\end{array}$ \\
\hline
\end{tabular}

1.3 Tools

\begin{tabular}{|c|c|c|}
\hline $\begin{array}{l}\mathbf{X} \text { Word processing } \\
\text { Online forums } \\
\text { Online collaboration }\end{array}$ & $\begin{array}{l}\mathbf{X} \quad \text { Speech recognition } \\
-\mathbf{X}-\text { Web browsing } \\
\text { Encyclopedia or compendia }\end{array}$ & $\begin{array}{l}\text { E-mail } \\
\text { Others }\end{array}$ \\
\hline
\end{tabular}

1.4 Other technological resources integrated into the program:

\begin{tabular}{|l|l|l|l|}
\hline$\frac{\text { web }}{\text { dictionaries on the }}$ & grammar on line & - other web sites & _ none \\
\hline
\end{tabular}

1.5 Directions for use:

\begin{tabular}{|l|l|l|}
\hline${ }_{-} \mathbf{X}_{-}$are on the screen & $\begin{array}{l}\mathbf{X}_{-} \text {are in the } \\
\text { documentation }\end{array}$ & \begin{tabular}{l}
$\mathbf{X}_{-}$can be skipped at option of \\
\hline
\end{tabular} \\
\hline
\end{tabular}

\section{PEDAGOGICAL ORIENTATION}

2.6 Program's theory of language

\begin{tabular}{|c|l|l|}
\hline structural & $\mathbf{X}$ - functional & $\ldots$ \\
\hline
\end{tabular}

2.7 Type of program

\begin{tabular}{|c|c|c|c|}
\hline $\begin{array}{c}\mathbf{X} \text { _remediation } \\
\mathbf{X} \text { _enrichment } \\
\text { tutoring }\end{array}$ & $\begin{array}{l}\mathbf{X} \text { - demonstration } \\
\mathbf{X}_{-} \text {assessment }\end{array}$ & $\begin{array}{c}\mathbf{X}_{-}{ }^{\text {game }} \\
\text { collucation } \\
\text { projects }\end{array}$ & $\begin{array}{c}\mathbf{X} \text { _ problem solving } \\
\mathbf{X} \text { _drill and practice } \\
\text { simulation }\end{array}$ \\
\hline
\end{tabular}


2.8 Curriculum capability

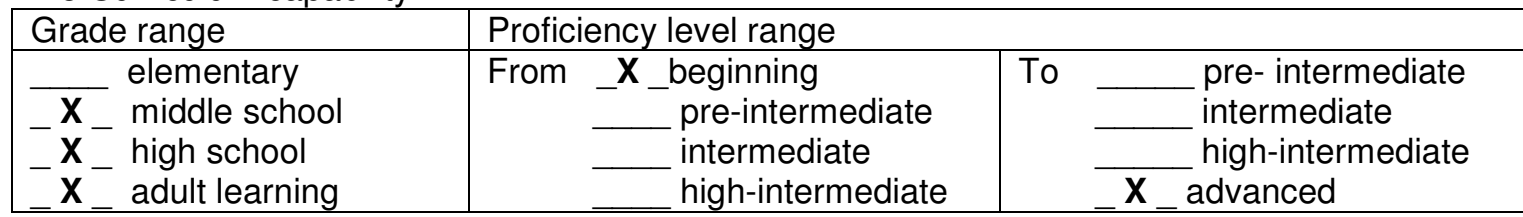

2.9 Method of language teaching claimed by the program

The Direct Method

The Natural Approach

Total Physical Response

The Audio-lingual Method

_ $\mathbf{X}_{\text {_ }}$ The Communicative Approach

2.10 Language skills developed in the program

\begin{tabular}{|l|l|l|l|}
\hline${ }_{-} \mathbf{X} \_$speaking & $\mathbf{X}_{-} \mathbf{X}$ listening & $\mathbf{X}_{-}$reading & $\mathbf{X}_{-}$writing \\
\hline
\end{tabular}

2.11 Type of activities offered by the program

\begin{tabular}{|l|l|l|l|}
\hline $\begin{array}{l}-\mathbf{X} \text {-games } \\
-\mathbf{X} \text { - quizzes } \\
\text { others }\end{array}$ & - simulation & $\begin{array}{l}\mathbf{X} \text { tutorial } \\
-\mathbf{X}_{-} \text {text } \\
\text { construction }\end{array}$ & $\begin{array}{l}\mathbf{X}_{-} \text {drill and practice } \\
\text { problem solving }\end{array}$ \\
\hline
\end{tabular}

2.12 Orientation of how to use program and its feature

\begin{tabular}{|c|c|}
\hline $\mathbf{X}$ for the teacher & on the screen \\
\hline for the student & on hard copy documentation \\
\hline for both & $\mathbf{X}$ _ on both \\
\hline
\end{tabular}

2.13 Role of the teacher

\begin{tabular}{|l|l|l|l|}
\hline $\mathbf{X}_{-} \mathbf{X}$ instructor & _ $_{\text {facilitator }}$ & $\mathbf{X}_{-}$lab manager & _ evaluator \\
\hline
\end{tabular}

2.14 Learners interact

\begin{tabular}{|l|l|l|}
\hline$\_$with one another & $\ldots$ with the teacher & $\mathbf{X}_{-}$with neither \\
\hline
\end{tabular}

2.15 In case learners interact with one another, they can interact

\begin{tabular}{|l|l|}
\hline in all activities & in some activities \\
\hline
\end{tabular}

2.16 In case learners interact with the teacher, they can interact

\begin{tabular}{|c|c|}
\hline $\begin{array}{l}\text { at any time } \\
\text { at the end of the lesson }\end{array}$ & $\begin{array}{l}\text { at the end of the activities } \\
\text { there's no interaction }\end{array}$ \\
\hline
\end{tabular}

\section{CRITICAL ANALYSIS}

For each item, circle the numbers 1 (for low) to 4 (for high) to indicate your judgment of the degree to which the program possesses or demonstrates the feature identified in each item. Circle 0 if the feature is not present in the program. 


\begin{tabular}{|c|c|c|c|c|c|}
\hline \multicolumn{6}{|c|}{ Instructional Attributes } \\
\hline Graphics and sound enhance learning. & 0 & $\begin{array}{l}\text { (low) } \\
1\end{array}$ & 2 & 3 & $\begin{array}{l}\text { (high) } \\
4\end{array}$ \\
\hline $\begin{array}{l}1.2 \text { The animation is effective in minimizing } \\
\text { boredom by motivating learners. }\end{array}$ & 0 & $\begin{array}{l}\text { (low) } \\
1\end{array}$ & 2 & 3 & $\begin{array}{l}\text { (high) } \\
4\end{array}$ \\
\hline 1.3Screen displays are uncluttered. & 0 & $\begin{array}{l}\text { (low) } \\
1\end{array}$ & 2 & 3 & $\begin{array}{l}\text { (high) } \\
4\end{array}$ \\
\hline 1.4 Graphics make information attractive. & 0 & $\begin{array}{ll}\text { (low) } \\
1\end{array}$ & 2 & 3 & $\begin{array}{l}\text { (high) } \\
4\end{array}$ \\
\hline $\begin{array}{l}1.5 \text { Graphics help memorization of key } \\
\text { information. }\end{array}$ & 0 & $\begin{array}{l}\text { (low) } \\
1\end{array}$ & 2 & 3 & $\begin{array}{l}\text { (high) } \\
4\end{array}$ \\
\hline $\begin{array}{l}\text { 1.6 The program makes use of authentic } \\
\text { texts and other realia. }\end{array}$ & 0 & $\begin{array}{l}\text { (low) } \\
1\end{array}$ & 2 & 3 & $\begin{array}{l}\text { (high) } \\
4\end{array}$ \\
\hline $\begin{array}{l}1.7 \text { The program integrates information } \\
\text { about culture/daily situations into the } \\
\text { presentations and activities. }\end{array}$ & 0 & $\begin{array}{l}\text { (low) } \\
1\end{array}$ & 2 & 3 & $\begin{array}{l}\text { (high) } \\
4\end{array}$ \\
\hline $\begin{array}{l}1.8 \text { Lessons present and practice language } \\
\text { structures in meaningful communicative } \\
\text { contexts. }\end{array}$ & 0 & $\begin{array}{l}\text { (low) } \\
1\end{array}$ & 2 & 3 & $\begin{array}{l}\text { (high) } \\
4\end{array}$ \\
\hline $\begin{array}{l}1.9 \text { Lessons present and practice } \\
\text { vocabulary in meaningful communicative } \\
\text { contexts. }\end{array}$ & 0 & $\begin{array}{l}\text { (low) } \\
1\end{array}$ & 2 & 3 & $\begin{array}{l}\text { (high) } \\
4\end{array}$ \\
\hline $\begin{array}{l}1.10 \text { Lessons develop the communicative } \\
\text { skills the program aims to develop. }\end{array}$ & 0 & $\begin{array}{l}\text { (low) } \\
1\end{array}$ & 2 & 3 & $\begin{array}{l}\text { (high) } \\
4\end{array}$ \\
\hline $\begin{array}{l}1.11 \text { Lessons develop the level of language } \\
\text { proficiency the program aims to develop. }\end{array}$ & 0 & $\begin{array}{ll}\text { (low) } \\
1\end{array}$ & 2 & 3 & $\begin{array}{l}\text { (high) } \\
4\end{array}$ \\
\hline $\begin{array}{l}1.12 \text { The course syllabus reflects a } \\
\text { communicative approach to language } \\
\text { teaching/learning. }\end{array}$ & 0 & $\begin{array}{l}\text { (low) } \\
1\end{array}$ & 2 & 3 & $\begin{array}{l}\text { (high) } \\
4\end{array}$ \\
\hline $\begin{array}{l}1.13 \text { Content selection is determined by } \\
\text { communicative skills and/or themes. }\end{array}$ & 0 & $\begin{array}{l}\text { (low) } \\
1\end{array}$ & 2 & 3 & $\begin{array}{l}\text { (high) } \\
4\end{array}$ \\
\hline $\begin{array}{l}1.14 \text { Content is sequenced from simple } \\
\text { communicative functions, such as } \\
\text { introducing oneself, greeting, etc, to } \\
\text { complex ones, such as stating an opinion, } \\
\text { disagreeing, etc. }\end{array}$ & 0 & $\begin{array}{l}\text { (low) } \\
1\end{array}$ & 2 & 3 & $\begin{array}{l}\text { (high) } \\
4\end{array}$ \\
\hline $\begin{array}{l}1.15 \text { Content is presented } \\
\text { communicatively. }\end{array}$ & 0 & $\begin{array}{ll}\text { (low) } \\
1\end{array}$ & 2 & 3 & $\begin{array}{l}\text { (high) } \\
4\end{array}$ \\
\hline $\begin{array}{l}1.16 \text { The program develops the content at } \\
\text { appropriate levels of language proficiency. }\end{array}$ & 0 & $\begin{array}{l}\text { (low) } \\
1\end{array}$ & 2 & 3 & $\begin{array}{l}\text { (high) } \\
4\end{array}$ \\
\hline $\begin{array}{l}1.17 \text { The program content is educationally } \\
\text { relevant and interesting for the learner. }\end{array}$ & 0 & $\begin{array}{l}\text { (low) } \\
1\end{array}$ & 2 & 3 & $\begin{array}{l}\text { (high) } \\
4\end{array}$ \\
\hline $\begin{array}{l}1.18 \text { The program content is appropriate } \\
\text { for intended learners. }\end{array}$ & 0 & $\begin{array}{l}\text { (low) } \\
1\end{array}$ & 2 & 3 & $\begin{array}{l}\text { (high) } \\
4\end{array}$ \\
\hline $\begin{array}{l}1.19 \text { The program content is applicable to } \\
\text { real life contexts. }\end{array}$ & 0 & $\begin{array}{l}\text { (low) } \\
1\end{array}$ & 2 & 3 & $\begin{array}{l}\text { (high) } \\
4\end{array}$ \\
\hline $\begin{array}{l}1.20 \text { The program allows learners to work } \\
\text { together in communicative activities. }\end{array}$ & 0 & (low) & 2 & 3 & $\begin{array}{l}\text { (high) } \\
4\end{array}$ \\
\hline $\begin{array}{l}1.21 \text { The activities allow unplanned and/or } \\
\text { unpredictable responses. }\end{array}$ & 0 & $\begin{array}{l}\text { (low) } \\
1\end{array}$ & 2 & 3 & $\begin{array}{l}\text { (high) } \\
4\end{array}$ \\
\hline $\begin{array}{l}1.22 \text { The activities lend themselves to } \\
\text { group discussions. }\end{array}$ & 0 & $\begin{array}{l}\text { (low) } \\
1\end{array}$ & 2 & 3 & $\begin{array}{l}\text { (high) } \\
4\end{array}$ \\
\hline
\end{tabular}




\begin{tabular}{|c|c|c|c|c|c|}
\hline $\begin{array}{l}\text { 1.23 The activities aim at developing other } \\
\text { competencies in addition to syntactical and } \\
\text { lexical }\end{array}$ & 0 & $\begin{array}{l}\text { (low) } \\
1\end{array}$ & 2 & 3 & $\begin{array}{l}\text { (high) } \\
4\end{array}$ \\
\hline $\begin{array}{l}1.24 \text { The program allows the teacher to } \\
\text { interact with students while they are doing } \\
\text { an activity. }\end{array}$ & 0 & $\begin{array}{l}\text { (low) } \\
1\end{array}$ & 2 & 3 & $\begin{array}{l}\text { (high) } \\
4\end{array}$ \\
\hline $\begin{array}{l}1.25 \text { The program provides non- } \\
\text { threatening feedback. }\end{array}$ & 0 & $\begin{array}{l}\text { (low) } \\
1\end{array}$ & 2 & 3 & $\begin{array}{l}\text { (high) } \\
4\end{array}$ \\
\hline $\begin{array}{l}1.26 \text { The program allows learners to repeat } \\
\text { an activity after feedback is provided. }\end{array}$ & 0 & $\begin{array}{l}\text { (low) } \\
1\end{array}$ & 2 & 3 & $\begin{array}{l}\text { (high) } \\
4\end{array}$ \\
\hline $\begin{array}{l}1.27 \text { Activities allow for more than one } \\
\text { correct response. }\end{array}$ & 0 & $\begin{array}{l}\text { (low) } \\
1\end{array}$ & 2 & 3 & $\begin{array}{l}\text { (high) } \\
4\end{array}$ \\
\hline $\begin{array}{l}\text { 1.28 The program provides the students } \\
\text { with feedback that would allow them to } \\
\text { correct their mistakes. }\end{array}$ & 0 & $\begin{array}{l}\text { (low) } \\
1\end{array}$ & 2 & 3 & $\begin{array}{l}\text { (high) } \\
4\end{array}$ \\
\hline \multicolumn{6}{|c|}{ Sub-total $=67$ (59.82\%) } \\
\hline
\end{tabular}

\begin{tabular}{|c|c|c|c|c|c|}
\hline \multicolumn{6}{|c|}{ Media Attributes } \\
\hline 2.29 Graphics aid understanding. & 0 & $\begin{array}{l}\text { (low) } \\
1\end{array}$ & 2 & 3 & $\begin{array}{l}\text { (high) } \\
4\end{array}$ \\
\hline $\begin{array}{l}\text { 2.30 The program allows for different routes } \\
\text { and choices for learning. }\end{array}$ & 0 & $\begin{array}{l}\text { (low) } \\
1\end{array}$ & 2 & 3 & $\begin{array}{l}\text { (high) } \\
4\end{array}$ \\
\hline $\begin{array}{l}\text { 2.31 The program allows for review of old } \\
\text { information. }\end{array}$ & 0 & $\begin{array}{ll}\text { (low) } \\
1\end{array}$ & 2 & 3 & $\begin{array}{l}\text { (high) } \\
4\end{array}$ \\
\hline $\begin{array}{l}\text { 2.32 The program allows branching to new } \\
\text { information. }\end{array}$ & 0 & $\begin{array}{l}\text { (low) } \\
1\end{array}$ & 2 & 3 & $\begin{array}{l}\text { (high) } \\
4\end{array}$ \\
\hline $\begin{array}{l}2.33 \text { The program allows students to select } \\
\text { activities according to their ages. }\end{array}$ & 0 & $\begin{array}{l}\text { (low) } \\
1\end{array}$ & 2 & 3 & $\begin{array}{l}\text { (high) } \\
4\end{array}$ \\
\hline $\begin{array}{l}\text { 2.34 The program allows students to select } \\
\text { activities according to their learning styles. }\end{array}$ & 0 & $\begin{array}{l}\text { (low) } \\
1\end{array}$ & 2 & 3 & $\begin{array}{l}\text { (high) } \\
4\end{array}$ \\
\hline $\begin{array}{l}\text { 2.35 The program allows students to select } \\
\text { activities according to their interests. }\end{array}$ & 0 & $\begin{array}{l}\text { (low) } \\
1\end{array}$ & 2 & 3 & $\begin{array}{l}\text { (high) } \\
4\end{array}$ \\
\hline $\begin{array}{l}\text { 2.36 The program adapts to the responses } \\
\text { given by the learners, branching to more or } \\
\text { less complicated questions as appropriate. }\end{array}$ & 0 & $\begin{array}{l}\text { (low) } \\
1\end{array}$ & 2 & 3 & $\begin{array}{l}\text { (high) } \\
4\end{array}$ \\
\hline $\begin{array}{l}2.37 \text { The program allows learners to go } \\
\text { through its content at their own pace and } \\
\text { rhythm. }\end{array}$ & 0 & $\begin{array}{l}\text { (low) } \\
1\end{array}$ & 2 & 3 & $\begin{array}{l}\text { (high) } \\
4\end{array}$ \\
\hline $\begin{array}{l}2.38 \text { The program prevents learners from } \\
\text { repeating exercises, therefore, minimizing } \\
\text { guessing. }\end{array}$ & 0 & $\begin{array}{l}\text { (low) } \\
1\end{array}$ & 2 & 3 & $\begin{array}{l}\text { (high) } \\
4\end{array}$ \\
\hline $\begin{array}{l}2.39 \text { The program keeps records of } \\
\text { learners' performance to allow them to } \\
\text { continue activities from where they left off. }\end{array}$ & 0 & $\begin{array}{l}\text { (low) } \\
1\end{array}$ & 2 & 3 & $\begin{array}{l}\text { (high) } \\
4\end{array}$ \\
\hline $\begin{array}{l}2.40 \text { The program keeps track of students' } \\
\text { scores. }\end{array}$ & 0 & $\begin{array}{ll}\text { (low) } \\
1\end{array}$ & 2 & 3 & $\begin{array}{l}\text { (high) } \\
4\end{array}$ \\
\hline $\begin{array}{l}\text { 2.41 The program provides feedback for } \\
\text { both correct and incorrect answers. }\end{array}$ & 0 & $\begin{array}{l}\text { (low) } \\
1\end{array}$ & 2 & 3 & $\begin{array}{l}\text { (high) } \\
4\end{array}$ \\
\hline $\begin{array}{l}\text { 2.42 The program gives learners the } \\
\text { chance to correct their errors. }\end{array}$ & 0 & $\begin{array}{l}\text { (low) } \\
1\end{array}$ & 2 & 3 & $\begin{array}{l}\text { (high) } \\
4\end{array}$ \\
\hline
\end{tabular}




\begin{tabular}{|c|c|c|c|c|c|}
\hline $\begin{array}{l}2.43 \text { The program effectively signals the } \\
\text { mistakes before providing the right answers. }\end{array}$ & 0 & $\begin{array}{l}\text { (low) } \\
1\end{array}$ & 2 & 3 & $\begin{array}{l}\text { (high) } \\
4\end{array}$ \\
\hline $\begin{array}{l}\text { 2.44 The program effectively specifies } \\
\text { different types of errors, such as differences } \\
\text { between a syntactic error and an incorrect } \\
\text { word choice. }\end{array}$ & 0 & $\begin{array}{l}\text { (low) } \\
1\end{array}$ & 2 & 3 & $\begin{array}{l}\text { (high) } \\
4\end{array}$ \\
\hline \multicolumn{6}{|c|}{ Sub-totals $=43(67.18 \%)$} \\
\hline \multicolumn{6}{|c|}{ User-Friendly Attributes } \\
\hline $\begin{array}{l}\text { 3.45 Menu items are understandable and } \\
\text { descriptive. }\end{array}$ & 0 & $\begin{array}{l}\text { (low) } \\
1\end{array}$ & 2 & 3 & $\begin{array}{l}\text { (high) } \\
4\end{array}$ \\
\hline $\begin{array}{l}3.46 \text { The commands and instructions for the } \\
\text { activities are clear and objective. }\end{array}$ & 0 & $\begin{array}{l}\text { (low) } \\
1\end{array}$ & 2 & 3 & $\begin{array}{l}\text { (high) } \\
4\end{array}$ \\
\hline $\begin{array}{l}\text { 3.47 The program gives the learners } \\
\text { effective clues to clarify their doubts about } \\
\text { its use. }\end{array}$ & 0 & $\begin{array}{l}\text { (low) } \\
1\end{array}$ & 2 & 3 & $\begin{array}{l}\text { (high) } \\
4\end{array}$ \\
\hline $\begin{array}{l}3.48 \text { Each screen uses text and } \\
\text { graphic/animation to make a particular } \\
\text { teaching point clear. }\end{array}$ & 0 & $\begin{array}{l}\text { (low) } \\
1\end{array}$ & 2 & 3 & $\begin{array}{l}\text { (high) } \\
4\end{array}$ \\
\hline $\begin{array}{l}\text { 3.49 The program is effectively integrated } \\
\text { with other technological resources (such as } \\
\text { dictionaries on the web, grammar on line, } \\
\text { etc) as the learner uses it. }\end{array}$ & 0 & $\begin{array}{l}\text { (low) } \\
1\end{array}$ & 2 & 3 & $\begin{array}{l}\text { (high) } \\
4\end{array}$ \\
\hline $\begin{array}{l}3.50 \text { Icons, buttons and menus allow } \\
\text { learners to readily search for additional } \\
\text { information while doing an activity. }\end{array}$ & 0 & $\begin{array}{l}\text { (low) } \\
1\end{array}$ & 2 & 3 & $\begin{array}{l}\text { (high) } \\
4\end{array}$ \\
\hline $\begin{array}{l}3.51 \text { Buttons, icons or menu items make } \\
\text { Help or Hint-type options easily accessible. }\end{array}$ & 0 & $\begin{array}{l}\text { (low) } \\
1\end{array}$ & 2 & 3 & $\begin{array}{l}\text { (high) } \\
4\end{array}$ \\
\hline $\begin{array}{l}3.52 \text { The program arouses sensory and } \\
\text { cognitive curiosity }\end{array}$ & 0 & $\begin{array}{l}\text { (low) } \\
1\end{array}$ & 2 & 3 & $\begin{array}{l}\text { (high) } \\
4\end{array}$ \\
\hline $\begin{array}{l}3.53 \text { The program maintains attention } \\
\text { throughout the lesson. }\end{array}$ & 0 & $\begin{array}{l}\text { (low) } \\
1\end{array}$ & 2 & 3 & $\begin{array}{l}\text { (high) } \\
4\end{array}$ \\
\hline $\begin{array}{l}\text { 3.54 The use of animation invites learners' } \\
\text { reaction or input. }\end{array}$ & 0 & $\begin{array}{l}\text { (low) } \\
1\end{array}$ & 2 & 3 & $\begin{array}{l}\text { (high) } \\
4\end{array}$ \\
\hline $\begin{array}{l}\text { 3.55 The program gives teachers a clear } \\
\text { explanation of its purposes and } \\
\text { methodological orientation. }\end{array}$ & 0 & $\begin{array}{l}\text { (low) } \\
1\end{array}$ & 2 & 3 & $\begin{array}{l}\text { (high) } \\
4\end{array}$ \\
\hline \multicolumn{6}{|c|}{ Sub-total $=21(47.72 \%)$} \\
\hline \multicolumn{6}{|c|}{ Total $=131(59.54 \%)$} \\
\hline
\end{tabular}

\begin{tabular}{|c|c|}
\hline 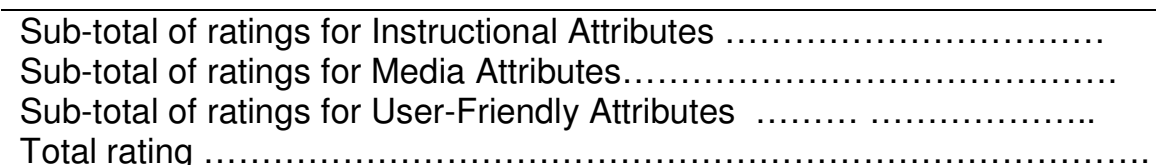 & $\begin{array}{l}67(59.82 \%) \\
43(67.18 \%) \\
21(47.72 \%) \\
131(59.54 \%)\end{array}$ \\
\hline
\end{tabular}




\section{ESL/EFL SOFTWARE EVALUATION INSTRUMENT}

Title of the program: Dynamic English

Publisher: DynEd International

\section{DESCRIPTIVE ANALYSIS}

Please place a checkmark next to the item that best describes the program and/or its features.

\section{TECHNICAL FEATURES}

1.1 Components of the program:

\begin{tabular}{|l|l|l|}
\hline $\begin{array}{l}\text { Number of CDs: } \\
\mathbf{2} \text { Per level }\end{array}$ & Teacher's guide_X_Yes__No & $\begin{array}{l}\text { Support materials___ Yes__ No } \\
\text { What type? }\end{array}$ \\
\hline
\end{tabular}

1.2 Platform

\begin{tabular}{|c|l|}
\hline $\begin{array}{c}\text { Mac OS 7.0 or later } \\
\text { Mhz _ } \_ \text {MB of RAM }\end{array}$ & $\begin{array}{l}\text { Windows 95, NT } \\
\text { Mhz _ 16_ MB of RAM }\end{array}$ \\
\hline
\end{tabular}

1.3 Tools

\begin{tabular}{|l|l|l|}
$\begin{array}{l}\mathbf{X} \text { X Word processing } \\
\text { Online forums } \\
\text { Online collaboration }\end{array}$ & $\begin{array}{l}\mathbf{X}-\text { Speech recognition } \\
\text { Web browsing } \\
\text { Encyclopedia or compendia }\end{array}$ & - E-mail \\
\hline & Others \\
\hline
\end{tabular}

1.4 The program integrates other technological resources such as

\begin{tabular}{|l|l|l|l|}
\hline$\frac{1}{\text { web }}$ dictionaries on the & grammar on line & other web sites & X_ none \\
\hline
\end{tabular}

1.5 Directions for use:

\begin{tabular}{|l|l|l|}
\hline $\mathbf{X}_{-}$are on the screen & $\mathbf{X}_{-}$are in the documentation & $\begin{array}{l}\mathbf{X} \text { _can be skipped at option of } \\
\text { user }\end{array}$ \\
\hline
\end{tabular}

\section{PEDAGOGICAL ORIENTATION}

2.6 Program's theory of language

\begin{tabular}{|l|l|l|}
\hline structural & $\mathbf{X}_{-}$functional & interactional \\
\hline
\end{tabular}

2.7 Type of program

\begin{tabular}{|c|c|c|c|}
\hline $\begin{array}{l}\text { X_remediation } \\
\text { X_enrichment } \\
\text { X_tutoring }\end{array}$ & $\begin{array}{c}\mathbf{X} \text { __ demonstration } \\
\text { assessment }\end{array}$ & $\begin{array}{c}\overline{g a m e}^{\text {education }} \\
\text { collaborative } \\
\text { projects }\end{array}$ & $\begin{array}{c}\text { problem solving } \\
\mathbf{X} \text { drill and practice } \\
\text { simulation }\end{array}$ \\
\hline
\end{tabular}

2.8 Curriculum capability 


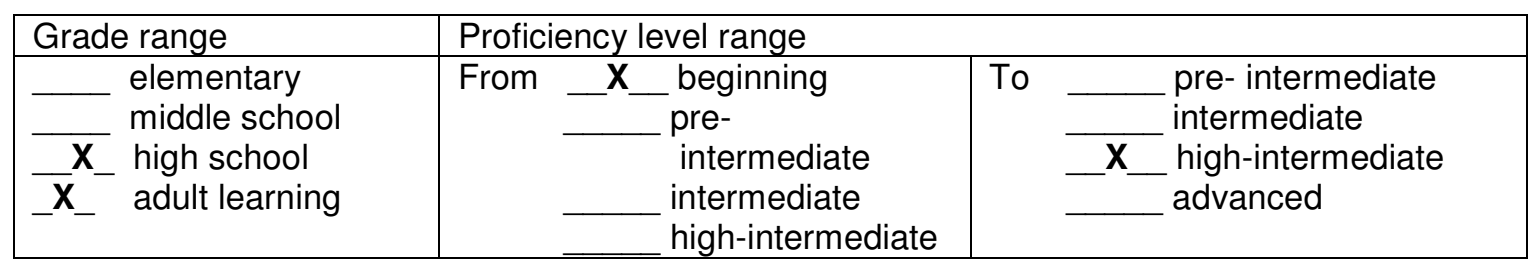

2.9 Method of language teaching:

The Direct Method

The Natural Approach

Total Physical Response

The Audio-lingual Method

_.

2.10 Language skills developed in the program

\begin{tabular}{|l|l|l|l|}
\hline X_speaking & X_listening & X_reading & X_writing \\
\hline
\end{tabular}

2.11 Type of activities offered by the program

\begin{tabular}{|l|l|l|l|}
\hline $\begin{array}{l}\text { X_games } \\
\mathbf{X} \text { X_quizzes } \\
\text { others }\end{array}$ & $\begin{array}{l}\text { simulation } \\
\text { exploratory }\end{array}$ & $\begin{array}{l}-\mathbf{X} \text { - tutorial } \\
\text { text } \\
\text { construction }\end{array}$ & $\begin{array}{l}\text { X_drill and practice } \\
\text { problem solving }\end{array}$ \\
\hline
\end{tabular}

2.12 Orientation of how to use program and its feature

\begin{tabular}{|c|c|}
\hline for the teacher & on the screen \\
\hline for the student & on hard copy documentation \\
\hline $\mathbf{X} \quad$ for both & $\mathbf{X} \quad$ on both \\
\hline
\end{tabular}

2.13 Role of the teacher

\begin{tabular}{|l|l|l|l|}
\hline - X_ instructor & _ facilitator & X_lab manager & _ evaluator \\
\hline
\end{tabular}

2.14 Learners interact

\begin{tabular}{|l|l|l|}
\hline _ with one another & _ with the teacher & X_with neither \\
\hline
\end{tabular}

2.15 In case learners interact with one another, they can interact

\begin{tabular}{|c|c|}
\hline in all activities & in some activities \\
\hline
\end{tabular}

2.16 In case learners interact with the teacher, they can interact

at any time

at the end of the lesson

at the end of the activities

there's no interaction

\section{CRITICAL ANALYSIS}

For each item, circle the numbers 1 (for low) to 4 (for high) to indicate your judgment of the degree to which the program possesses or demonstrates the feature identified in each item. Circle 0 if the feature is not present in the program. 


\begin{tabular}{|c|c|c|c|c|c|}
\hline 1.1Graphics and sound enhance learning. & 0 & $\begin{array}{l}\text { (low) } \\
1\end{array}$ & 2 & 3 & $\begin{array}{l}\text { (high) } \\
4\end{array}$ \\
\hline $\begin{array}{l}1.2 \text { The animation is effective in minimizing } \\
\text { boredom by motivating learners. }\end{array}$ & 0 & $\begin{array}{l}\text { (low) } \\
1 \\
\end{array}$ & 2 & 3 & $\begin{array}{l}\text { (high) } \\
4\end{array}$ \\
\hline 1.3Screen displays are uncluttered. & 0 & $\begin{array}{l}\text { (low) } \\
1\end{array}$ & 2 & 3 & $\begin{array}{l}\text { (high) } \\
4\end{array}$ \\
\hline 1.4 Graphics make information attractive. & 0 & $\begin{array}{l}\text { (low) } \\
1\end{array}$ & 2 & 3 & $\begin{array}{l}\text { (high) } \\
4\end{array}$ \\
\hline $\begin{array}{l}1.5 \text { Graphics help memorization of key } \\
\text { information. }\end{array}$ & 0 & $\begin{array}{l}\text { (low) } \\
1\end{array}$ & 2 & 3 & $\begin{array}{l}\text { (high) } \\
4\end{array}$ \\
\hline $\begin{array}{l}\text { 1.6 The program makes use of authentic } \\
\text { texts and other realia. }\end{array}$ & 0 & $\begin{array}{l}\text { (low) } \\
1\end{array}$ & 2 & 3 & $\begin{array}{l}\text { (high) } \\
4\end{array}$ \\
\hline $\begin{array}{l}1.7 \text { The program integrates information } \\
\text { about culture/daily situations into the } \\
\text { presentations and activities. }\end{array}$ & 0 & $\begin{array}{l}\text { (low) } \\
1\end{array}$ & 2 & 3 & $\begin{array}{l}\text { (high) } \\
4\end{array}$ \\
\hline $\begin{array}{l}1.8 \text { Lessons present and practice language } \\
\text { structures in meaningful communicative } \\
\text { contexts. }\end{array}$ & 0 & $\begin{array}{l}\text { (low) } \\
1\end{array}$ & 2 & 3 & $\begin{array}{l}\text { (high) } \\
4\end{array}$ \\
\hline $\begin{array}{l}1.9 \text { Lessons present and practice } \\
\text { vocabulary in meaningful communicative } \\
\text { contexts. }\end{array}$ & 0 & $\begin{array}{l}\text { (low) } \\
1\end{array}$ & 2 & 3 & $\begin{array}{l}\text { (high) } \\
4\end{array}$ \\
\hline $\begin{array}{l}1.10 \text { Lessons develop the communicative } \\
\text { skills the program aims to develop. }\end{array}$ & 0 & $\begin{array}{l}\text { (low) } \\
1\end{array}$ & 2 & 3 & $\begin{array}{l}\text { (high) } \\
4\end{array}$ \\
\hline $\begin{array}{l}1.11 \text { Lessons develop the level of language } \\
\text { proficiency the program aims to develop. }\end{array}$ & 0 & $\begin{array}{l}\text { (low) } \\
1\end{array}$ & 2 & 3 & $\begin{array}{l}\text { (high) } \\
4\end{array}$ \\
\hline $\begin{array}{l}1.12 \text { The course syllabus reflects a } \\
\text { communicative approach to language } \\
\text { teaching/learning. }\end{array}$ & 0 & $\begin{array}{l}\text { (low) } \\
1\end{array}$ & 2 & 3 & $\begin{array}{l}\text { (high) } \\
4\end{array}$ \\
\hline $\begin{array}{l}1.13 \text { Content selection is determined by } \\
\text { communicative skills and/or themes. }\end{array}$ & 0 & $\begin{array}{l}\text { (low) } \\
1\end{array}$ & 2 & 3 & $\begin{array}{l}\text { (high) } \\
4\end{array}$ \\
\hline $\begin{array}{l}1.14 \text { Content is sequenced from simple } \\
\text { communicative functions, such as } \\
\text { introducing oneself, greeting, etc, to } \\
\text { complex ones, such as stating an opinion, } \\
\text { disagreeing, etc. }\end{array}$ & 0 & $\begin{array}{l}\text { (low) } \\
1\end{array}$ & 2 & 3 & $\begin{array}{l}\text { (high) } \\
4\end{array}$ \\
\hline $\begin{array}{l}1.15 \text { Content is presented } \\
\text { communicatively. }\end{array}$ & 0 & $\begin{array}{l}\text { (low) } \\
1\end{array}$ & 2 & 3 & $\begin{array}{l}\text { (high) } \\
4\end{array}$ \\
\hline $\begin{array}{l}1.16 \text { The program develops the content at } \\
\text { appropriate levels of language proficiency. }\end{array}$ & 0 & $\begin{array}{l}\text { (low) } \\
1\end{array}$ & 2 & 3 & $\begin{array}{l}\text { (high) } \\
4\end{array}$ \\
\hline $\begin{array}{l}1.17 \text { The program content is educationally } \\
\text { relevant and interesting for the learner. }\end{array}$ & 0 & $\begin{array}{l}\text { (low) } \\
1\end{array}$ & 2 & 3 & $\begin{array}{l}\text { (high) } \\
4\end{array}$ \\
\hline $\begin{array}{l}1.18 \text { The program content is appropriate } \\
\text { for intended learners. }\end{array}$ & 0 & $\begin{array}{l}\text { (low) } \\
1\end{array}$ & 2 & 3 & $\begin{array}{l}\text { (high) } \\
4\end{array}$ \\
\hline $\begin{array}{l}1.19 \text { The program content is applicable to } \\
\text { real life contexts. }\end{array}$ & 0 & $\begin{array}{l}\text { (low) } \\
1\end{array}$ & 2 & 3 & $\begin{array}{l}\text { (high) } \\
4\end{array}$ \\
\hline $\begin{array}{l}1.20 \text { The program allows learners to work } \\
\text { together in communicative activities. }\end{array}$ & 0 & $\begin{array}{l}\text { (low) } \\
1\end{array}$ & 2 & 3 & $\begin{array}{l}\text { (high) } \\
4\end{array}$ \\
\hline $\begin{array}{l}1.21 \text { The activities allow unplanned and/or } \\
\text { unpredictable responses. }\end{array}$ & 0 & $\begin{array}{l}\text { (low) } \\
1\end{array}$ & 2 & 3 & $\begin{array}{l}\text { (high) } \\
4\end{array}$ \\
\hline $\begin{array}{l}1.22 \text { The activities lend themselves to } \\
\text { group discussions. }\end{array}$ & 0 & $\begin{array}{l}\text { (low) } \\
1\end{array}$ & 2 & 3 & $\begin{array}{l}\text { (high) } \\
4\end{array}$ \\
\hline $\begin{array}{l}1.23 \text { The activities aim at developing other } \\
\text { competencies in addition to syntactical and } \\
\text { lexical }\end{array}$ & 0 & $\begin{array}{l}\text { (low) } \\
1\end{array}$ & 2 & 3 & $\begin{array}{l}\text { (high) } \\
4\end{array}$ \\
\hline
\end{tabular}




\begin{tabular}{|c|c|c|c|c|c|}
\hline $\begin{array}{l}1.24 \text { The program allows the teacher to } \\
\text { interact with students while they are doing } \\
\text { an activity. }\end{array}$ & 0 & $\begin{array}{l}\text { (low) } \\
1\end{array}$ & 2 & 3 & $\begin{array}{l}\text { (high) } \\
4\end{array}$ \\
\hline $\begin{array}{l}1.25 \text { The program provides non- } \\
\text { threatening feedback. }\end{array}$ & 0 & $\begin{array}{l}\text { (low) } \\
1\end{array}$ & 2 & 3 & $\begin{array}{l}\text { (high) } \\
4\end{array}$ \\
\hline $\begin{array}{l}1.26 \text { The program allows learners to repeat } \\
\text { an activity after feedback is provided. }\end{array}$ & 0 & $\begin{array}{l}\text { (low) } \\
1\end{array}$ & 2 & 3 & $\begin{array}{l}\text { (high) } \\
4\end{array}$ \\
\hline $\begin{array}{l}1.27 \text { Activities allow for more than one } \\
\text { correct response. }\end{array}$ & 0 & $\begin{array}{l}\text { (low) } \\
1\end{array}$ & 2 & 3 & $\begin{array}{l}\text { (high) } \\
4\end{array}$ \\
\hline $\begin{array}{l}1.28 \text { The program provides the students } \\
\text { with feedback that would allow them to } \\
\text { correct their mistakes. }\end{array}$ & 0 & $\begin{array}{l}\text { (low) } \\
1\end{array}$ & 2 & 3 & $\begin{array}{l}\text { (high) } \\
4\end{array}$ \\
\hline
\end{tabular}

\begin{tabular}{|c|c|c|c|c|c|}
\hline \multicolumn{6}{|l|}{ Media Attributes } \\
\hline 2.29 Graphics aid understanding. & 0 & $\begin{array}{l}\text { (low) } \\
1\end{array}$ & 2 & 3 & $\begin{array}{l}\text { (high) } \\
4\end{array}$ \\
\hline $\begin{array}{l}\text { 2.30 The program allows for different routes } \\
\text { and choices for learning. }\end{array}$ & 0 & $\begin{array}{l}\text { (low) } \\
1\end{array}$ & 2 & 3 & $\begin{array}{l}\text { (high) } \\
4\end{array}$ \\
\hline $\begin{array}{l}2.31 \text { The program allows for review of old } \\
\text { information. }\end{array}$ & 0 & $\begin{array}{l}\text { (low) } \\
1\end{array}$ & 2 & 3 & $\begin{array}{l}\text { (high) } \\
4\end{array}$ \\
\hline $\begin{array}{l}2.32 \text { The program allows branching to new } \\
\text { information. }\end{array}$ & 0 & $\begin{array}{ll}\text { (low) } \\
1\end{array}$ & 2 & 3 & $\begin{array}{l}\text { (high) } \\
4\end{array}$ \\
\hline $\begin{array}{l}\text { 2.33 The program allows students to select } \\
\text { activities according to their ages. }\end{array}$ & 0 & $\begin{array}{l}\text { (low) } \\
1\end{array}$ & 2 & 3 & $\begin{array}{l}\text { (high) } \\
4\end{array}$ \\
\hline $\begin{array}{l}\text { 2.34 The program allows students to select } \\
\text { activities according to their learning styles. }\end{array}$ & 0 & $\begin{array}{l}\text { (low) } \\
1\end{array}$ & 2 & 3 & $\begin{array}{l}\text { (high) } \\
4\end{array}$ \\
\hline $\begin{array}{l}2.35 \text { The program allows students to select } \\
\text { activities according to their interests. }\end{array}$ & 0 & $\begin{array}{l}\text { (low) } \\
1\end{array}$ & 2 & 3 & $\begin{array}{l}\text { (high) } \\
4\end{array}$ \\
\hline $\begin{array}{l}\text { 2.36 The program adapts to the responses } \\
\text { given by the learners, branching to more or } \\
\text { less complicated questions as appropriate. }\end{array}$ & 0 & $\begin{array}{l}\text { (low) } \\
1\end{array}$ & 2 & 3 & $\begin{array}{l}\text { (high) } \\
4\end{array}$ \\
\hline $\begin{array}{l}2.37 \text { The program allows learners to go } \\
\text { through its content at their own pace and } \\
\text { rhythm. }\end{array}$ & 0 & $\begin{array}{l}\text { (low) } \\
1\end{array}$ & 2 & 3 & $\begin{array}{l}\text { (high) } \\
4\end{array}$ \\
\hline $\begin{array}{l}2.38 \text { The program prevents learners from } \\
\text { repeating exercises, therefore, minimizing } \\
\text { guessing. }\end{array}$ & 0 & $\begin{array}{l}\text { (low) } \\
1\end{array}$ & 2 & 3 & $\begin{array}{l}\text { (high) } \\
4\end{array}$ \\
\hline $\begin{array}{l}\text { 2.39 The program keeps records of } \\
\text { learners' performance to allow them to } \\
\text { continue activities from where they left off. }\end{array}$ & 0 & $\begin{array}{l}\text { (low) } \\
1\end{array}$ & 2 & 3 & $\begin{array}{l}\text { (high) } \\
4\end{array}$ \\
\hline $\begin{array}{l}2.40 \text { The program keeps track of students' } \\
\text { scores. }\end{array}$ & 0 & $\begin{array}{l}\text { (low) } \\
1\end{array}$ & 2 & 3 & $\begin{array}{l}\text { (high) } \\
4\end{array}$ \\
\hline $\begin{array}{l}2.41 \text { The program provides feedback for } \\
\text { both correct and incorrect answers. The } \\
\text { program provides feedback for both correct } \\
\text { and incorrect answers. }\end{array}$ & 0 & $\begin{array}{ll}\text { (low) } \\
1\end{array}$ & 2 & 3 & $\begin{array}{l}\text { (high) } \\
4\end{array}$ \\
\hline $\begin{array}{l}2.42 \text { The program gives learners the } \\
\text { chance to correct their errors. }\end{array}$ & 0 & $\begin{array}{l}\text { (low) } \\
1\end{array}$ & 2 & 3 & $\begin{array}{l}\text { (high) } \\
4\end{array}$ \\
\hline
\end{tabular}




\begin{tabular}{|c|c|c|c|c|c|}
\hline $\begin{array}{l}2.43 \text { The program effectively signals the } \\
\text { mistakes before providing the right answers. }\end{array}$ & 0 & $\begin{array}{ll}\text { (low) } \\
1\end{array}$ & 2 & 3 & $\begin{array}{l}\text { (high) } \\
4\end{array}$ \\
\hline $\begin{array}{l}\text { 2.44 The program effectively specifies } \\
\text { different types of errors, such as differences } \\
\text { between a syntactic error and an incorrect } \\
\text { word choice. }\end{array}$ & 0 & $\begin{array}{l}\text { (low) } \\
1\end{array}$ & 2 & 3 & $\begin{array}{l}\text { (high) } \\
4\end{array}$ \\
\hline \multicolumn{6}{|l|}{ Sub-total $=22(34.37)$} \\
\hline \multicolumn{6}{|l|}{ User-Friendly Attributes } \\
\hline $\begin{array}{l}\text { 3.45 Menu items are understandable and } \\
\text { descriptive. }\end{array}$ & 0 & $\begin{array}{l}\text { (low) } \\
1\end{array}$ & 2 & 3 & $\begin{array}{l}\text { (high) } \\
4\end{array}$ \\
\hline $\begin{array}{l}\text { 3.46 The commands and instructions for the } \\
\text { activities are clear and objective. }\end{array}$ & 0 & $\begin{array}{l}\text { (low) } \\
1\end{array}$ & 2 & 3 & $\begin{array}{l}\text { (high) } \\
4\end{array}$ \\
\hline $\begin{array}{l}\text { 3.47 The program gives the learners } \\
\text { effective clues to clarify their doubts about } \\
\text { its use. }\end{array}$ & 0 & $\begin{array}{l}\text { (low) } \\
1\end{array}$ & 2 & 3 & $\begin{array}{l}\text { (high) } \\
4\end{array}$ \\
\hline $\begin{array}{l}3.48 \text { Each screen uses text and } \\
\text { graphic/animation to make a particular } \\
\text { teaching point clear. }\end{array}$ & 0 & $\begin{array}{l}\text { (low) } \\
1\end{array}$ & 2 & 3 & $\begin{array}{l}\text { (high) } \\
4\end{array}$ \\
\hline $\begin{array}{l}\text { 3.49 The program is effectively integrated } \\
\text { with other technological resources (such as } \\
\text { dictionaries on the web, grammar on line, } \\
\text { etc) as the learner uses it. }\end{array}$ & 0 & $\begin{array}{l}\text { (low) } \\
1\end{array}$ & 2 & 3 & $\begin{array}{l}\text { (high) } \\
4\end{array}$ \\
\hline $\begin{array}{l}3.50 \text { Icons, buttons and menus allow } \\
\text { learners to readily search for additional } \\
\text { information while doing an activity. }\end{array}$ & 0 & $\begin{array}{l}\text { (low) } \\
1\end{array}$ & 2 & 3 & $\begin{array}{l}\text { (high) } \\
4\end{array}$ \\
\hline $\begin{array}{l}3.51 \text { Buttons, icons or menu items make } \\
\text { Help or Hint-type options easily accessible. }\end{array}$ & 0 & $\begin{array}{l}\text { (low) } \\
1\end{array}$ & 2 & 3 & $\begin{array}{l}\text { (high) } \\
4\end{array}$ \\
\hline $\begin{array}{l}\text { 3.52 The program arouses sensory and } \\
\text { cognitive curiosity }\end{array}$ & 0 & $\begin{array}{l}\text { (low) } \\
1\end{array}$ & 2 & 3 & $\begin{array}{l}\text { (high) } \\
4\end{array}$ \\
\hline $\begin{array}{l}3.53 \text { The program maintains attention } \\
\text { throughout the lesson. }\end{array}$ & 0 & $\begin{array}{ll}\text { (low) } \\
1\end{array}$ & 2 & 3 & $\begin{array}{l}\text { (high) } \\
4\end{array}$ \\
\hline $\begin{array}{l}3.54 \text { The use of animation invites learners' } \\
\text { reaction or input. }\end{array}$ & 0 & $\begin{array}{l}\text { (low) } \\
1\end{array}$ & 2 & 3 & $\begin{array}{l}\text { (high) } \\
4\end{array}$ \\
\hline $\begin{array}{l}\text { 3.55 The program gives teachers a clear } \\
\text { explanation of its purposes and } \\
\text { methodological orientation. }\end{array}$ & 0 & $\begin{array}{l}\text { (low) } \\
1\end{array}$ & 2 & 3 & $\begin{array}{l}\text { (high) } \\
4\end{array}$ \\
\hline \multicolumn{6}{|l|}{ Sub-total $=26(59.09 \%)$} \\
\hline Total = 95 (43.18\%) & & & & & \\
\hline
\end{tabular}

Sub-total of ratings for Instructional Attributes

$47(41.96 \%)$

Sub-total of ratings for Media Attributes

$22(34.37 \%)$

Sub-total of ratings for User-Friendly Attributes

$26(59.09 \%)$

Total rating

$95(43.18 \%)$ 


\section{ESL/EFL SOFTWARE EVALUATION INSTRUMENT}

Title of the program ELLIS Academic

Publisher: CALI

\section{DESCRIPTIVE ANALYSIS}

Please place a checkmark next to the item that best describes the program and/or its features.

\section{TECHNICAL FEATURES}

1.1 Components of the program:

\begin{tabular}{|c|l|l|}
\hline $\begin{array}{c}\text { Number of CD's: } \\
\begin{array}{c}\text { Per level } \\
\text { Total }\end{array}\end{array}$ & Teacher's guide_X_Yes__No & $\begin{array}{l}\text { Support materials___Yes_X_No } \\
\text { What type? }\end{array}$ \\
\hline
\end{tabular}

1.2 Platform

\begin{tabular}{l|l} 
Mac 7.1 through 9.0 maximum & Windows 95, 98, NT, ME, 2000, XP - Version 2.X
\end{tabular}

$33 \mathrm{Mhz} 32 \mathrm{MB}$ of RAM

Pentium Mhz $16+$ MB of RAM

1.3 Tools

\begin{tabular}{|l|l|l|}
\hline $\mathbf{X}$ - Word processing & $\mathbf{X}$ Speech recognition & E-mail \\
$\mathbf{X}$ Online forums & Others \\
\hline Online collaboration & $-\mathbf{X}$ Web browsing \\
\hline
\end{tabular}

1.4 Other technological resources integrated into program: \begin{tabular}{c|c|c|c} 
dictionaries on the web & X_ _ grammar on line & other web sites & none
\end{tabular}

1.5 Directions for use:

\begin{tabular}{|c|c|c|}
\hline $\mathbf{X}_{\text {_ }}$ are on the screen & _. $\mathbf{X}$ are in the documentation & _. \\
\hline
\end{tabular}

\section{PEDAGOGICAL ORIENTATION}

2.6 Program's theory of language

\begin{tabular}{|c|l|l|}
\hline structural & $\mathbf{X}$ _ functional & interactional \\
\hline
\end{tabular}

2.7 Type of program

\begin{tabular}{|c|c|c|c|}
\hline $\begin{array}{l}\text { X_remediation } \\
\mathbf{X} \text { _enrichment } \\
\text { X_tutoring }\end{array}$ & $\begin{array}{l}\text { X_demonstration } \\
\text { X_assessment }\end{array}$ & $\begin{array}{c}{ }_{\text {game }} \text { education } \\
\text { collaborative } \\
\text { projects }\end{array}$ & $\begin{array}{l}\text { problem solving } \\
\mathbf{X} \text { _drill and practice } \\
\mathbf{X} \text { _ simulation }\end{array}$ \\
\hline
\end{tabular}

2.8 Curriculum capability

\begin{tabular}{|c|l|l|}
\hline Grade range & Proficiency level range & \multicolumn{2}{|l|}{ To $\ldots$ pre-intermediate } \\
\hline
\end{tabular}




\begin{tabular}{|l|l|l|}
\hline \multicolumn{1}{c}{ middle school } & pre- intermediate & intermediate \\
intermediate & high-intermediate \\
$\mathbf{X}$. high school & high-intermediate & advanced \\
\hline
\end{tabular}

2.9 Method of language teaching:

\begin{tabular}{|c|c|}
\hline $\begin{array}{l}\text { The Direct Method } \\
\text { The Natural Approach }\end{array}$ & $\begin{array}{ll} & \text { The Audio-lingual Method } \\
\mathbf{X} & \text { The Communicative Approach }\end{array}$ \\
\hline Total Physical Response & \\
\hline
\end{tabular}

2.10 Language skills developed in the program

\begin{tabular}{|l|l|l|l|}
\hline $\mathbf{X}$ __ speaking & $-\mathbf{X} \_$listening & $\mathbf{X}$ __ reading & $\mathbf{X}$ _ writing \\
\hline
\end{tabular}

2.11 Type of activities offered by the program

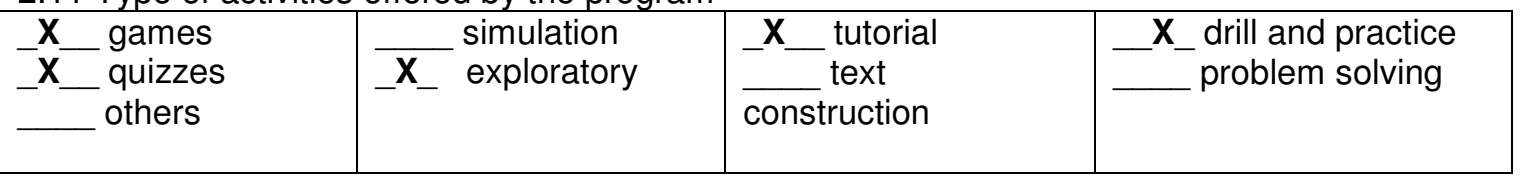

2.12 Orientation of how to use program and its feature

\begin{tabular}{|c|c|}
\hline for the teacher & on the screen \\
\hline $\mathbf{f}$ for the student & on hard copy documentation \\
\hline $\mathbf{X} \quad$ for both & $\mathbf{X}$ _ on both \\
\hline
\end{tabular}

2.13 Role of the teacher

\begin{tabular}{|l|l|l|l|}
\hline - X_ instructor & _ facilitator & X_lab manager & _ evaluator \\
\hline
\end{tabular}

2.14 Learners interact

\begin{tabular}{|l|l|l|}
\hline _ with one another & X_with the teacher & _ with neither \\
\hline
\end{tabular}

2.15 In case learners interact with one another, they can interact

\begin{tabular}{|l|l|}
\hline 2.15 In case learners interact with one another, they can interact \\
\hline in all activities & in some activities \\
\hline
\end{tabular}

2.16 In case learners interact with the teacher, they can interact

at any time
at the end of the lesson
at the end of the activities

\section{$\underline{\text { CRITICAL ANALYSIS }}$}

For each item, circle the numbers 1 (for low) to 4 (for high) to indicate your judgment of the degree to which the program possesses or demonstrates the feature identified in each item. Circle 0 if the feature is not present in the program. 


\begin{tabular}{|c|c|c|c|c|c|}
\hline \multicolumn{6}{|l|}{ Instructional Attributes } \\
\hline 1.1Graphics and sound enhance learning. & 0 & $\begin{array}{ll}\text { (low) } \\
1\end{array}$ & 2 & 3 & (high) \\
\hline $\begin{array}{l}1.2 \text { The animation is effective in minimizing } \\
\text { boredom by motivating learners. }\end{array}$ & 0 & $\begin{array}{l}\text { (low) } \\
1\end{array}$ & 2 & 3 & $\begin{array}{l}\text { (high) } \\
4\end{array}$ \\
\hline 1.3Screen displays are uncluttered. & 0 & $\begin{array}{l}\text { (low) } \\
1\end{array}$ & 2 & 3 & $\begin{array}{l}\text { (high) } \\
4\end{array}$ \\
\hline 1.4 Graphics make information attractive. & 0 & $\begin{array}{ll}\text { (low) } \\
1\end{array}$ & 2 & 3 & $\begin{array}{l}\text { (high) } \\
4\end{array}$ \\
\hline $\begin{array}{l}1.5 \text { Graphics help memorization of key } \\
\text { information. }\end{array}$ & 0 & $\begin{array}{l}\text { (low) } \\
1\end{array}$ & 2 & 3 & $\begin{array}{l}\text { (high) } \\
4\end{array}$ \\
\hline $\begin{array}{l}\text { 1.6 The program makes use of authentic } \\
\text { texts and other realia. }\end{array}$ & 0 & $\begin{array}{l}\text { (low) } \\
1\end{array}$ & 2 & 3 & $\begin{array}{l}\text { (high) } \\
4\end{array}$ \\
\hline $\begin{array}{l}\text { 1.7 The program integrates information about } \\
\text { culture/daily situations into the presentations } \\
\text { and activities. }\end{array}$ & 0 & $\begin{array}{ll}\text { (low) } \\
1\end{array}$ & 2 & 3 & $\begin{array}{l}\text { (high) } \\
4\end{array}$ \\
\hline $\begin{array}{l}1.8 \text { Lessons present and practice language } \\
\text { structures in meaningful communicative } \\
\text { contexts. }\end{array}$ & 0 & $\begin{array}{l}\text { (low) } \\
1\end{array}$ & 2 & 3 & $\begin{array}{l}\text { (high) } \\
4\end{array}$ \\
\hline $\begin{array}{l}1.9 \text { Lessons present and practice vocabulary } \\
\text { in meaningful communicative contexts. }\end{array}$ & 0 & $\begin{array}{ll}\text { (low) } \\
1\end{array}$ & 2 & 3 & $\begin{array}{l}\text { (high) } \\
4\end{array}$ \\
\hline $\begin{array}{l}\text { 1.10 Lessons develop the communicative } \\
\text { skills the program aims to develop. }\end{array}$ & 0 & $\begin{array}{l}\text { (low) } \\
1\end{array}$ & 2 & 3 & $\begin{array}{l}\text { (high) } \\
4\end{array}$ \\
\hline $\begin{array}{l}1.11 \text { Lessons develop the level of language } \\
\text { proficiency the program aims to develop. }\end{array}$ & 0 & $\begin{array}{l}\text { (low) } \\
1\end{array}$ & 2 & 3 & $\begin{array}{l}\text { (high) } \\
4\end{array}$ \\
\hline $\begin{array}{l}1.12 \text { The course syllabus reflects a } \\
\text { communicative approach to language } \\
\text { teaching/learning. }\end{array}$ & 0 & $\begin{array}{l}\text { (low) } \\
1\end{array}$ & 2 & 3 & $\begin{array}{l}\text { (high) } \\
4\end{array}$ \\
\hline $\begin{array}{l}1.13 \text { Content selection is determined by } \\
\text { communicative skills and/or themes. }\end{array}$ & 0 & $\begin{array}{l}\text { (low) } \\
1\end{array}$ & 2 & 3 & $\begin{array}{l}\text { (high) } \\
4\end{array}$ \\
\hline $\begin{array}{l}1.14 \text { Content is sequenced from simple } \\
\text { communicative functions, such as introducing } \\
\text { oneself, greeting, etc, to complex ones, such } \\
\text { as stating an opinion, disagreeing, etc. }\end{array}$ & 0 & $\begin{array}{l}\text { (low) } \\
1\end{array}$ & 2 & 3 & $\begin{array}{l}\text { (high) } \\
4\end{array}$ \\
\hline 1.15 Content is presented communicatively. & 0 & $\begin{array}{l}\text { (low) } \\
1\end{array}$ & 2 & 3 & $\begin{array}{l}\text { (high) } \\
4\end{array}$ \\
\hline $\begin{array}{l}\text { 1.16 The program develops the content at } \\
\text { appropriate levels of language proficiency. }\end{array}$ & 0 & $\begin{array}{l}\text { (low) } \\
1\end{array}$ & 2 & 3 & $\begin{array}{l}\text { (high) } \\
4\end{array}$ \\
\hline $\begin{array}{l}1.17 \text { The program content is educationally } \\
\text { relevant and interesting for the learner. }\end{array}$ & 0 & $\begin{array}{l}\text { (low) } \\
1\end{array}$ & 2 & 3 & $\begin{array}{l}\text { (high) } \\
4\end{array}$ \\
\hline $\begin{array}{l}1.18 \text { The program content is appropriate for } \\
\text { intended learners. }\end{array}$ & 0 & $\begin{array}{l}\text { (low) } \\
1\end{array}$ & 2 & 3 & $\begin{array}{l}\text { (high) } \\
4\end{array}$ \\
\hline $\begin{array}{l}1.19 \text { The program content is applicable to } \\
\text { real life contexts. }\end{array}$ & 0 & $\begin{array}{l}\text { (low) } \\
1\end{array}$ & 2 & 3 & $\begin{array}{l}\text { (high) } \\
4\end{array}$ \\
\hline $\begin{array}{l}1.20 \text { The program allows learners to work } \\
\text { together in communicative activities. }\end{array}$ & 0 & $\begin{array}{ll}\text { (low) } \\
1\end{array}$ & 2 & 3 & $\begin{array}{l}\text { (high) } \\
4\end{array}$ \\
\hline $\begin{array}{l}1.21 \text { The activities allow unplanned and/or } \\
\text { unpredictable responses. }\end{array}$ & 0 & (low) & 2 & 3 & $\begin{array}{l}\text { (high) } \\
4\end{array}$ \\
\hline $\begin{array}{l}\text { 1.22 The activities lend themselves to group } \\
\text { discussions. }\end{array}$ & 0 & $\begin{array}{l}\text { (low) } \\
1\end{array}$ & 2 & 3 & $\begin{array}{l}\text { (high) } \\
4\end{array}$ \\
\hline $\begin{array}{l}\text { 1.23 The activities aim at developing other } \\
\text { competencies in addition to syntactical and } \\
\text { lexical }\end{array}$ & 0 & $\begin{array}{l}\text { (low) } \\
1\end{array}$ & 2 & 3 & $\begin{array}{l}\text { (high) } \\
4\end{array}$ \\
\hline
\end{tabular}




\begin{tabular}{|c|c|c|c|c|c|}
\hline $\begin{array}{l}1.24 \text { The program allows the teacher to } \\
\text { interact with students while they are doing an } \\
\text { activity. }\end{array}$ & 0 & $\begin{array}{l}\text { (low) } \\
1\end{array}$ & 2 & 3 & $\begin{array}{l}\text { (high) } \\
4\end{array}$ \\
\hline $\begin{array}{l}\text { 1.25 The program provides non-threatening } \\
\text { feedback. }\end{array}$ & 0 & $\begin{array}{l}\text { (low) } \\
1\end{array}$ & 2 & 3 & (high) \\
\hline $\begin{array}{l}1.26 \text { The program allows learners to repeat } \\
\text { an activity after feedback is provided. }\end{array}$ & 0 & $\begin{array}{l}\text { (low) } \\
1\end{array}$ & 2 & 3 & $\begin{array}{l}\text { (high) } \\
4\end{array}$ \\
\hline $\begin{array}{l}1.27 \text { Activities allow for more than one } \\
\text { correct response. }\end{array}$ & 0 & $\begin{array}{l}\text { (low) } \\
1\end{array}$ & 2 & 3 & $\begin{array}{l}\text { (high) } \\
4\end{array}$ \\
\hline $\begin{array}{l}\text { 1.28 The program provides the students with } \\
\text { feedback that would allow them to correct } \\
\text { their mistakes. }\end{array}$ & 0 & $\begin{array}{l}\text { (low) } \\
1\end{array}$ & 2 & 3 & $\begin{array}{l}\text { (high) } \\
4\end{array}$ \\
\hline
\end{tabular}

\begin{tabular}{|c|c|c|c|c|c|}
\hline \multicolumn{6}{|l|}{ Media Attributes } \\
\hline 2.29 Graphics aid understanding. & 0 & $\begin{array}{l}\text { (low) } \\
1\end{array}$ & 2 & 3 & $\begin{array}{l}\text { (high) } \\
4\end{array}$ \\
\hline $\begin{array}{l}\text { 2.30 The program allows for different routes } \\
\text { and choices for learning. }\end{array}$ & 0 & $\begin{array}{l}\text { (low) } \\
1\end{array}$ & 2 & 3 & $\begin{array}{l}\text { (high) } \\
4\end{array}$ \\
\hline $\begin{array}{l}\text { 2.31 The program allows for review of old } \\
\text { information. }\end{array}$ & 0 & $\begin{array}{l}\text { (low) } \\
1\end{array}$ & 2 & 3 & $\begin{array}{l}\text { (high) } \\
4\end{array}$ \\
\hline $\begin{array}{l}2.32 \text { The program allows branching to new } \\
\text { information. }\end{array}$ & 0 & $\begin{array}{ll}\text { (low) } \\
1\end{array}$ & 2 & 3 & $\begin{array}{l}\text { (high) } \\
4\end{array}$ \\
\hline $\begin{array}{l}2.33 \text { The program allows students to select } \\
\text { activities according to their ages. }\end{array}$ & 0 & $\begin{array}{l}\text { (low) } \\
1\end{array}$ & 2 & 3 & $\begin{array}{l}\text { (high) } \\
4\end{array}$ \\
\hline $\begin{array}{l}\text { 2.34 The program allows students to select } \\
\text { activities according to their learning styles. }\end{array}$ & 0 & $\begin{array}{l}\text { (low) } \\
1\end{array}$ & 2 & 3 & $\begin{array}{l}\text { (high) } \\
4\end{array}$ \\
\hline $\begin{array}{l}2.35 \text { The program allows students to select } \\
\text { activities according to their interests. }\end{array}$ & 0 & $\begin{array}{l}\text { (low) } \\
1 \\
\end{array}$ & 2 & 3 & $\begin{array}{l}\text { (high) } \\
4\end{array}$ \\
\hline $\begin{array}{l}2.36 \text { The program adapts to the responses } \\
\text { given by the learners, branching to more or } \\
\text { less complicated questions as appropriate. }\end{array}$ & 0 & $\begin{array}{l}\text { (low) } \\
1\end{array}$ & 2 & 3 & $\begin{array}{l}\text { (high) } \\
4\end{array}$ \\
\hline $\begin{array}{l}2.37 \text { The program allows learners to go } \\
\text { through its content at their own pace and } \\
\text { rhythm. }\end{array}$ & 0 & $\begin{array}{l}\text { (low) } \\
1\end{array}$ & 2 & 3 & (high) \\
\hline $\begin{array}{l}2.38 \text { The program prevents learners from } \\
\text { repeating exercises, therefore, minimizing } \\
\text { guessing. }\end{array}$ & 0 & $\begin{array}{l}\text { (low) } \\
1\end{array}$ & 2 & 3 & $\begin{array}{l}\text { (high) } \\
4\end{array}$ \\
\hline $\begin{array}{l}\text { 2.39 The program keeps records of learners' } \\
\text { performance to allow them to continue } \\
\text { activities from where they left off. }\end{array}$ & 0 & $\begin{array}{l}\text { (low) } \\
1\end{array}$ & 2 & 3 & $\begin{array}{l}\text { (high) } \\
4\end{array}$ \\
\hline $\begin{array}{l}2.40 \text { The program keeps track of students' } \\
\text { scores. }\end{array}$ & 0 & $\begin{array}{ll}\text { (low) } \\
1\end{array}$ & 2 & 3 & (high) \\
\hline $\begin{array}{l}2.41 \text { The program provides feedback for both } \\
\text { correct and incorrect answers. The program } \\
\text { provides feedback for both correct and } \\
\text { incorrect answers. }\end{array}$ & 0 & $\begin{array}{l}\text { (low) } \\
1\end{array}$ & 2 & 3 & $\begin{array}{l}\text { (high) } \\
4\end{array}$ \\
\hline $\begin{array}{l}2.42 \text { The program gives learners the chance } \\
\text { to correct their errors. }\end{array}$ & 0 & $\begin{array}{l}\text { (low) } \\
1\end{array}$ & 2 & 3 & $\begin{array}{l}\text { (high) } \\
4\end{array}$ \\
\hline
\end{tabular}




\begin{tabular}{|c|c|c|c|c|c|}
\hline $\begin{array}{l}\text { 2.43 The program effectively signals the } \\
\text { mistakes before providing the right answers. }\end{array}$ & 0 & $\begin{array}{ll}\text { (low) } \\
1\end{array}$ & 2 & 3 & $\begin{array}{l}\text { (high) } \\
4\end{array}$ \\
\hline $\begin{array}{l}\text { 2.44 The program effectively specifies } \\
\text { different types of errors, such as differences } \\
\text { between a syntactic error and an incorrect } \\
\text { word choice. }\end{array}$ & 0 & $\begin{array}{l}\text { (low) } \\
1\end{array}$ & 2 & 3 & $\begin{array}{l}\text { (high) } \\
4\end{array}$ \\
\hline \multicolumn{6}{|l|}{ Sub-totals $=39(60.93 \%)$} \\
\hline \multicolumn{6}{|l|}{ User-Friendly Attributes } \\
\hline $\begin{array}{l}3.45 \text { Menu items are understandable and } \\
\text { descriptive. }\end{array}$ & 0 & $\begin{array}{l}\text { (low) } \\
1\end{array}$ & 2 & 3 & $\begin{array}{l}\text { (high) } \\
4\end{array}$ \\
\hline $\begin{array}{l}3.46 \text { The commands and instructions for the } \\
\text { activities are clear and objective. }\end{array}$ & 0 & $\begin{array}{l}\text { (low) } \\
1\end{array}$ & 2 & 3 & $\begin{array}{l}\text { (high) } \\
4\end{array}$ \\
\hline $\begin{array}{l}\text { 3.47 The program gives the learners effective } \\
\text { clues to clarify their doubts about its use. }\end{array}$ & 0 & $\begin{array}{ll}\text { (low) } \\
1\end{array}$ & 2 & 3 & $\begin{array}{l}\text { (high) } \\
4\end{array}$ \\
\hline $\begin{array}{l}3.48 \text { Each screen uses text and } \\
\text { graphic/animation to make a particular } \\
\text { teaching point clear. }\end{array}$ & 0 & $\begin{array}{l}\text { (low) } \\
1\end{array}$ & 2 & 3 & $\begin{array}{l}\text { (high) } \\
4\end{array}$ \\
\hline $\begin{array}{l}\text { 3.49 The program is effectively integrated with } \\
\text { other technological resources (such as } \\
\text { dictionaries on the web, grammar on line, etc) } \\
\text { as the learner uses it. }\end{array}$ & 0 & $\begin{array}{l}\text { (low) } \\
1\end{array}$ & 2 & 3 & $\begin{array}{l}\text { (high) } \\
4\end{array}$ \\
\hline $\begin{array}{l}3.50 \text { lcons, buttons and menus allow learners } \\
\text { to readily search for additional information } \\
\text { while doing an activity. }\end{array}$ & 0 & $\begin{array}{l}\text { (low) } \\
1\end{array}$ & 2 & 3 & $\begin{array}{l}\text { (high) } \\
4\end{array}$ \\
\hline $\begin{array}{l}3.51 \text { Buttons, icons or menu items make Help } \\
\text { or Hint-type options easily accessible. }\end{array}$ & 0 & $\begin{array}{l}\text { (low) } \\
1\end{array}$ & 2 & 3 & $\begin{array}{l}\text { (high) } \\
4\end{array}$ \\
\hline $\begin{array}{l}\text { 3.52 The program arouses sensory and } \\
\text { cognitive curiosity }\end{array}$ & 0 & $\begin{array}{l}\text { (low) } \\
1\end{array}$ & 2 & 3 & $\begin{array}{l}\text { (high) } \\
4\end{array}$ \\
\hline $\begin{array}{l}3.53 \text { The program maintains attention } \\
\text { throughout the lesson. }\end{array}$ & 0 & $\begin{array}{ll}\text { (low) } \\
1\end{array}$ & 2 & 3 & $\begin{array}{l}\text { (high) } \\
4\end{array}$ \\
\hline $\begin{array}{l}3.54 \text { The use of animation invites learners' } \\
\text { reaction or input. }\end{array}$ & 0 & $\begin{array}{l}\text { (low) } \\
1\end{array}$ & 2 & 3 & $\begin{array}{l}\text { (high) } \\
4\end{array}$ \\
\hline $\begin{array}{l}\text { 3.55 The program gives teachers a clear } \\
\text { explanation of its purposes and } \\
\text { methodological orientation. }\end{array}$ & 0 & $\begin{array}{l}\text { (low) } \\
1\end{array}$ & 2 & 3 & $\begin{array}{l}\text { (high) } \\
4\end{array}$ \\
\hline \multicolumn{6}{|l|}{ Sub-total $=39(88.63 \%)$} \\
\hline Total = $166(75.45 \%)$ & & & & & \\
\hline
\end{tabular}

Sub-total of ratings for Instructional Attributes ...

Sub-total of ratings for User-Friendly Attributes

Total rating 


\section{ESL/EFL SOFTWARE EVALUATION INSTRUMENT}

Title of the program ISSUES IN ENGLISH

Publisher/date PROTEA TEXTWARE

\section{DESCRIPTIVE ANALYSIS}

Please place a checkmark next to the item that best describes the program and/or its features.

\section{TECHNICAL FEATURES}

1.1 Components of the program:

\begin{tabular}{|c|l|l|}
\hline $\begin{array}{c}\text { Number of CD's: } \\
01\end{array}$ Per level & Teacher's guide_X_Yes___No & $\begin{array}{l}\text { Support materials___ Yes_X_No } \\
\text { Wh }\end{array}$ Total
\end{tabular}

\subsection{Platform}

\begin{tabular}{|l|l|}
\hline Mac_ _ Mhz MB of RAM & $\begin{array}{l}\text { Windows 3.1 or higher } \\
\text { Mhz _ _ } \_ \text {MB of RAM }\end{array}$ \\
\hline
\end{tabular}

\subsection{Tools}

Word processing

Online forums

Online collaboration
Speech recognition

Web browsing

Encyclopedia or compendia
E-mail Others

The program integrates other technological resources such as

\begin{tabular}{|l|l|l|l|}
\hline$\frac{1}{\text { web }}$ dictionaries on the & grammar on line & other web sites & X_none \\
\hline
\end{tabular}

1.5 Directions for use:

\begin{tabular}{|l|l|l|}
\hline X_ X $_{-}$are on the screen & $X_{-}$are in the documentation & X_can $_{-}$ce skipped at option of user \\
\hline
\end{tabular}

\section{PEDAGOGICAL ORIENTATION}

2.6 Program's theory of language

\begin{tabular}{|c|l|l|}
\hline structural & _ & functional \\
\hline
\end{tabular}

2.7 Type of program

\begin{tabular}{|c|c|c|c|}
\hline $\begin{array}{c}\text { remediation } \\
\mathrm{X} \text { enrichment } \\
\text { tutoring }\end{array}$ & $\begin{array}{l}\text { demonstration } \\
\text { assessment }\end{array}$ & $\begin{array}{l}\overline{\text { game }}^{\text {education }} \\
\text { X_collaborative } \\
\text { projects }\end{array}$ & $\begin{array}{c}\text { problem solving } \\
\text { X_drill and practice } \\
\text { simulation }\end{array}$ \\
\hline
\end{tabular}




\begin{tabular}{|c|c|c|c|c|}
\hline Grade range & Proficie & ency level range & & \\
\hline $\begin{array}{l}\text { elementary } \\
\text { middle school } \\
\mathrm{X} \text { high school } \\
\mathrm{X}_{-} \quad \text { adult learning }\end{array}$ & From & $\begin{array}{ll} & \text { beginning } \\
\text { pre- intermediate } \\
\text { intermediate } \\
\text { high-intermediate }\end{array}$ & & $\begin{array}{l}\text { pre- intermediate } \\
\text { intermediate } \\
\mathrm{X} \text { high-intermediate } \\
\mathrm{X} \quad \text { advanced }\end{array}$ \\
\hline
\end{tabular}

2.4 Method of language teaching claimed by the program

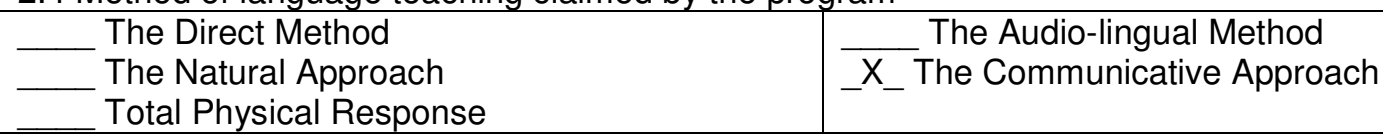

2.5 Language skills developed in the program

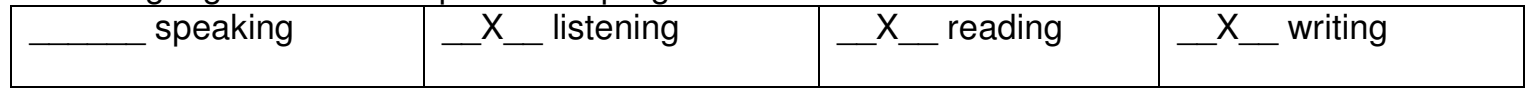

2.6 Type of activities offered by the program

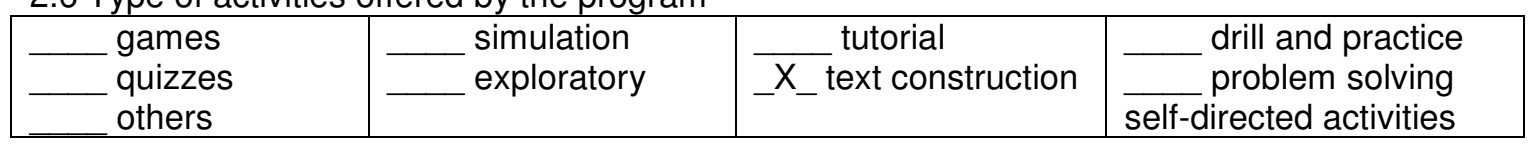

2.7 Orientation of how to use program and its feature

\begin{tabular}{|c|c|}
\hline for the teacher & on the screen \\
\hline $\mathrm{X}$ for the student & on hard copy documentation \\
\hline $\mathrm{X}$ for both & $\mathrm{X} \quad$ on both \\
\hline
\end{tabular}

2.7 Role of the teacher

\begin{tabular}{|l|l|l|l|}
\hline - X_ instructor & _ facilitator & _ lab manager & _ evaluator \\
\hline
\end{tabular}

2.8 Learners interact

\begin{tabular}{|l|l|l|}
\hline _ with one another & $\ldots$ with the teacher & _ X_ with neither \\
\hline
\end{tabular}

2.9 In case learners interact with one another, they can interact

\begin{tabular}{|l|l|}
\hline in all activities & in some activities \\
\hline
\end{tabular}

2.10 In case learners interact with the teacher, they can interact

\begin{tabular}{l|l} 
at any time & at the end of the activities \\
at the end of the lesson & there's no interaction
\end{tabular}

\section{CRITICAL ANALYSIS}

For each item, circle the numbers 1 (for low) to 4 (for high) to indicate your judgment of the degree to which the program possesses or demonstrates the feature identified in each item. Circle 0 if the feature is not present in the program. 


\begin{tabular}{|c|c|c|c|c|c|}
\hline \multicolumn{6}{|c|}{ Instructional Attributes } \\
\hline Graphics and sound enhance learning. & 0 & $\begin{array}{l}\text { (low) } \\
1\end{array}$ & 2 & 3 & $\begin{array}{l}\text { (high) } \\
4\end{array}$ \\
\hline $\begin{array}{l}1.2 \text { The animation is effective in minimizing } \\
\text { boredom by motivating learners. }\end{array}$ & 0 & $\begin{array}{l}\text { (low) } \\
1\end{array}$ & 2 & 3 & $\begin{array}{l}\text { (high) } \\
4\end{array}$ \\
\hline 1.3Screen displays are uncluttered. & 0 & $\begin{array}{l}\text { (low) } \\
1\end{array}$ & 2 & 3 & (high) \\
\hline 1.4 Graphics make information attractive. & 0 & $\begin{array}{l}\text { (low) } \\
1\end{array}$ & 2 & 3 & (high) \\
\hline $\begin{array}{l}1.5 \text { Graphics help memorization of key } \\
\text { information. }\end{array}$ & 0 & $\begin{array}{l}\text { (low) } \\
1\end{array}$ & 2 & 3 & $\begin{array}{l}\text { (high) } \\
4\end{array}$ \\
\hline $\begin{array}{l}\text { 1.6 The program makes use of authentic } \\
\text { texts and other realia. }\end{array}$ & 0 & $\begin{array}{l}\text { (low) } \\
1\end{array}$ & 2 & 3 & $\begin{array}{l}\text { (high) } \\
4\end{array}$ \\
\hline $\begin{array}{l}1.7 \text { The program integrates information } \\
\text { about culture/daily situations into the } \\
\text { presentations and activities. }\end{array}$ & 0 & $\begin{array}{l}\text { (low) } \\
1\end{array}$ & 2 & 3 & (high) \\
\hline $\begin{array}{l}1.8 \text { Lessons present and practice language } \\
\text { structures in meaningful communicative } \\
\text { contexts. }\end{array}$ & 0 & $\begin{array}{l}\text { (low) } \\
1\end{array}$ & 2 & 3 & $\begin{array}{l}\text { (high) } \\
4\end{array}$ \\
\hline $\begin{array}{l}1.9 \text { Lessons present and practice vocabulary } \\
\text { in meaningful communicative contexts. }\end{array}$ & 0 & $\begin{array}{l}\text { (low) } \\
1\end{array}$ & 2 & 3 & $\begin{array}{l}\text { (high) } \\
4\end{array}$ \\
\hline $\begin{array}{l}1.10 \text { Lessons develop the communicative } \\
\text { skills the program aims to develop. }\end{array}$ & 0 & $\begin{array}{l}\text { (low) } \\
1\end{array}$ & 2 & 3 & (high) \\
\hline $\begin{array}{l}\text { 1.11 Lessons develop the level of language } \\
\text { proficiency the program aims to develop. }\end{array}$ & 0 & $\begin{array}{l}\text { (low) } \\
1\end{array}$ & 2 & 3 & $\begin{array}{l}\text { (high) } \\
4\end{array}$ \\
\hline $\begin{array}{l}1.12 \text { The course syllabus reflects a } \\
\text { communicative approach to language } \\
\text { teaching/learning. }\end{array}$ & 0 & $\begin{array}{l}\text { (low) } \\
1\end{array}$ & 2 & 3 & $\begin{array}{l}\text { (high) } \\
4\end{array}$ \\
\hline $\begin{array}{l}1.13 \text { Content selection is determined by } \\
\text { communicative skills and/or themes. }\end{array}$ & 0 & $\begin{array}{ll}\text { (low) } \\
1\end{array}$ & 2 & 3 & $\begin{array}{l}\text { (high) } \\
4\end{array}$ \\
\hline $\begin{array}{l}\text { 1.14 Content is sequenced from simple } \\
\text { communicative functions, such as } \\
\text { introducing oneself, greeting, etc, to complex } \\
\text { ones, such as stating an opinion, } \\
\text { disagreeing, etc. }\end{array}$ & 0 & $\begin{array}{l}\text { (low) } \\
1\end{array}$ & 2 & 3 & $\begin{array}{l}\text { (high) } \\
4\end{array}$ \\
\hline 1.15 Content is presented communicatively. & 0 & $\begin{array}{l}\text { (low) } \\
1\end{array}$ & 2 & 3 & $\begin{array}{l}\text { (high) } \\
4\end{array}$ \\
\hline $\begin{array}{l}1.16 \text { The program develops the content at } \\
\text { appropriate levels of language proficiency. }\end{array}$ & 0 & $\begin{array}{l}\text { (low) } \\
1\end{array}$ & 2 & 3 & $\begin{array}{l}\text { (high) } \\
4\end{array}$ \\
\hline $\begin{array}{l}1.17 \text { The program content is educationally } \\
\text { relevant and interesting for the learner. }\end{array}$ & 0 & $\begin{array}{l}\text { (low) } \\
1\end{array}$ & 2 & 3 & $\begin{array}{l}\text { (high) } \\
4\end{array}$ \\
\hline $\begin{array}{l}\text { 1.18 The program content is appropriate for } \\
\text { intended learners. }\end{array}$ & 0 & $\begin{array}{ll}\text { (low) } \\
1\end{array}$ & 2 & 3 & $\begin{array}{l}\text { (high) } \\
4\end{array}$ \\
\hline $\begin{array}{l}1.19 \text { The program content is applicable to } \\
\text { real life contexts. }\end{array}$ & 0 & $\begin{array}{l}\text { (low) } \\
1\end{array}$ & 2 & 3 & $\begin{array}{l}\text { (high) } \\
4\end{array}$ \\
\hline $\begin{array}{l}1.20 \text { The program allows learners to work } \\
\text { together in communicative activities. }\end{array}$ & 0 & $\begin{array}{l}\text { (low) } \\
1\end{array}$ & 2 & 3 & $\begin{array}{l}\text { (high) } \\
4\end{array}$ \\
\hline $\begin{array}{l}\text { 1.21 The activities allow unplanned and/or } \\
\text { unpredictable responses. }\end{array}$ & 0 & $\begin{array}{l}\text { (low) } \\
1\end{array}$ & 2 & 3 & $\begin{array}{l}\text { (high) } \\
4\end{array}$ \\
\hline $\begin{array}{l}\text { 1.22 The activities lend themselves to group } \\
\text { discussions. }\end{array}$ & 0 & $\begin{array}{l}\text { (low) } \\
1\end{array}$ & 2 & 3 & $\begin{array}{l}\text { (high) } \\
4\end{array}$ \\
\hline $\begin{array}{l}\text { 1.23 The activities aim at developing other } \\
\text { competencies in addition to syntactical and } \\
\text { lexical }\end{array}$ & 0 & $\begin{array}{l}\text { (low) } \\
1\end{array}$ & 2 & 3 & $\begin{array}{l}\text { (high) } \\
4\end{array}$ \\
\hline
\end{tabular}




\begin{tabular}{|c|c|c|c|c|c|}
\hline $\begin{array}{l}1.24 \text { The program allows the teacher to } \\
\text { interact with students while they are doing } \\
\text { an activity. }\end{array}$ & 0 & $\begin{array}{ll}\text { (low) } \\
1\end{array}$ & 2 & 3 & $\begin{array}{l}\text { (high) } \\
4\end{array}$ \\
\hline $\begin{array}{l}\text { 1.25 The program provides non-threatening } \\
\text { feedback. }\end{array}$ & 0 & $\begin{array}{l}\text { (low) } \\
1\end{array}$ & 2 & 3 & $\begin{array}{l}\text { (high) } \\
4\end{array}$ \\
\hline $\begin{array}{l}1.26 \text { The program allows learners to repeat } \\
\text { an activity after feedback is provided. }\end{array}$ & 0 & $\begin{array}{l}\text { (low) } \\
1\end{array}$ & 2 & 3 & $\begin{array}{l}\text { (high) } \\
4\end{array}$ \\
\hline $\begin{array}{l}1.27 \text { Activities allow for more than one } \\
\text { correct response. }\end{array}$ & 0 & $\begin{array}{l}\text { (low) } \\
1\end{array}$ & 2 & 3 & $\begin{array}{l}\text { (high) } \\
4\end{array}$ \\
\hline $\begin{array}{l}1.28 \text { The program provides the students with } \\
\text { feedback that would allow them to correct } \\
\text { their mistakes. }\end{array}$ & 0 & $\begin{array}{l}\text { (low) } \\
1\end{array}$ & 2 & 3 & $\begin{array}{l}\text { (high) } \\
4\end{array}$ \\
\hline \multicolumn{6}{|c|}{ Sub-total $=79$} \\
\hline
\end{tabular}

\begin{tabular}{|c|c|c|c|c|c|}
\hline \multicolumn{6}{|c|}{ Media Attributes } \\
\hline 2.29 Graphics aid understanding. & 0 & $\begin{array}{l}\text { (low) } \\
1\end{array}$ & 2 & 3 & $\begin{array}{l}\text { (high) } \\
4\end{array}$ \\
\hline $\begin{array}{l}2.30 \text { The program allows for different routes } \\
\text { and choices for learning. }\end{array}$ & 0 & $\begin{array}{l}\text { (low) } \\
1\end{array}$ & 2 & 3 & $\begin{array}{l}\text { (high) } \\
4\end{array}$ \\
\hline $\begin{array}{l}\text { 2.31 The program allows for review of old } \\
\text { information. }\end{array}$ & 0 & $\begin{array}{l}\text { (low) } \\
1\end{array}$ & 2 & 3 & $\begin{array}{l}\text { (high) } \\
4\end{array}$ \\
\hline $\begin{array}{l}2.32 \text { The program allows branching to new } \\
\text { information. }\end{array}$ & 0 & $\begin{array}{l}\text { (low) } \\
1\end{array}$ & 2 & 3 & $\begin{array}{l}\text { (high) } \\
4\end{array}$ \\
\hline $\begin{array}{l}2.33 \text { The program allows students to select } \\
\text { activities according to their ages. }\end{array}$ & 0 & $\begin{array}{l}\text { (low) } \\
1\end{array}$ & 2 & 3 & $\begin{array}{l}\text { (high) } \\
4\end{array}$ \\
\hline $\begin{array}{l}\text { 2.34 The program allows students to select } \\
\text { activities according to their learning styles. }\end{array}$ & 0 & $\begin{array}{l}\text { (low) } \\
1\end{array}$ & 2 & 3 & $\begin{array}{l}\text { (high) } \\
4\end{array}$ \\
\hline $\begin{array}{l}2.35 \text { The program allows students to select } \\
\text { activities according to their interests. }\end{array}$ & 0 & $\begin{array}{l}\text { (low) } \\
1\end{array}$ & 2 & 3 & $\begin{array}{l}\text { (high) } \\
4\end{array}$ \\
\hline $\begin{array}{l}2.36 \text { The program adapts to the responses } \\
\text { given by the learners, branching to more or } \\
\text { less complicated questions as appropriate. }\end{array}$ & 0 & $\begin{array}{ll}\text { (low) } \\
1\end{array}$ & 2 & 3 & $\begin{array}{l}\text { (high) } \\
4\end{array}$ \\
\hline $\begin{array}{l}2.37 \text { The program allows learners to go } \\
\text { through its content at their own pace and } \\
\text { rhythm. }\end{array}$ & 0 & $\begin{array}{l}\text { (low) } \\
1\end{array}$ & 2 & 3 & $\begin{array}{l}\text { (high) } \\
4\end{array}$ \\
\hline $\begin{array}{l}2.38 \text { The program prevents learners from } \\
\text { repeating exercises, therefore, minimizing } \\
\text { guessing. }\end{array}$ & 0 & $\begin{array}{l}\text { (low) } \\
1\end{array}$ & 2 & 3 & $\begin{array}{l}\text { (high) } \\
4\end{array}$ \\
\hline $\begin{array}{l}\text { 2.39 The program keeps records of learners' } \\
\text { performance to allow them to continue } \\
\text { activities from where they left off. }\end{array}$ & 0 & $\begin{array}{l}\text { (low) } \\
1\end{array}$ & 2 & 3 & $\begin{array}{l}\text { (high) } \\
4\end{array}$ \\
\hline $\begin{array}{l}2.40 \text { The program keeps track of students' } \\
\text { scores. }\end{array}$ & 0 & $\begin{array}{l}\text { (low) } \\
1\end{array}$ & 2 & 3 & $\begin{array}{l}\text { (high) } \\
4\end{array}$ \\
\hline $\begin{array}{l}\text { 2.41 The program provides feedback for both } \\
\text { correct and incorrect answers. }\end{array}$ & 0 & $\begin{array}{l}\text { (low) } \\
1\end{array}$ & 2 & 3 & $\begin{array}{l}\text { (high) } \\
4\end{array}$ \\
\hline $\begin{array}{l}2.42 \text { The program gives learners the chance } \\
\text { to correct their errors. }\end{array}$ & 0 & $\begin{array}{l}\text { (low) } \\
1\end{array}$ & 2 & 3 & $\begin{array}{l}\text { (high) } \\
4\end{array}$ \\
\hline
\end{tabular}




\begin{tabular}{|c|c|c|c|c|c|}
\hline $\begin{array}{l}2.43 \text { The program effectively signals the } \\
\text { mistakes before providing the right answers. }\end{array}$ & 0 & $\begin{array}{l}\text { (low) } \\
1\end{array}$ & 2 & 3 & $\begin{array}{l}\text { (high) } \\
4\end{array}$ \\
\hline $\begin{array}{l}\text { 2.44 The program effectively specifies } \\
\text { different types of errors, such as differences } \\
\text { between a syntactic error and an incorrect } \\
\text { word choice. }\end{array}$ & 0 & $\begin{array}{l}\text { (low) } \\
1\end{array}$ & 2 & 3 & $\begin{array}{l}\text { (high) } \\
4\end{array}$ \\
\hline \multicolumn{6}{|c|}{ Sub-totals $=35$} \\
\hline \multicolumn{6}{|c|}{ User-Friendly Attributes } \\
\hline $\begin{array}{l}\text { 3.45 Menu items are understandable and } \\
\text { descriptive. }\end{array}$ & 0 & $\begin{array}{l}\text { (low) } \\
1\end{array}$ & 2 & 3 & $\begin{array}{l}\text { (high) } \\
4\end{array}$ \\
\hline $\begin{array}{l}3.46 \text { The commands and instructions for the } \\
\text { activities are clear and objective. }\end{array}$ & 0 & $\begin{array}{l}\text { (low) } \\
1\end{array}$ & 2 & 3 & $\begin{array}{l}\text { (high) } \\
4\end{array}$ \\
\hline $\begin{array}{l}\text { 3.47 The program gives the learners effective } \\
\text { clues to clarify their doubts about its use. }\end{array}$ & 0 & $\begin{array}{l}\text { (low) } \\
1\end{array}$ & 2 & 3 & $\begin{array}{l}\text { (high) } \\
4\end{array}$ \\
\hline $\begin{array}{l}3.48 \text { Each screen uses text and } \\
\text { graphic/animation to make a particular } \\
\text { teaching point clear. }\end{array}$ & 0 & $\begin{array}{l}\text { (low) } \\
1\end{array}$ & 2 & 3 & $\begin{array}{l}\text { (high) } \\
4\end{array}$ \\
\hline $\begin{array}{l}\text { 3.49 The program is effectively integrated with } \\
\text { other technological resources (such as } \\
\text { dictionaries on the web, grammar on line, etc) } \\
\text { as the learner uses it. }\end{array}$ & 0 & $\begin{array}{l}\text { (low) } \\
1\end{array}$ & 2 & 3 & $\begin{array}{l}\text { (high) } \\
4\end{array}$ \\
\hline $\begin{array}{l}3.50 \text { Icons, buttons and menus allow learners } \\
\text { to readily search for additional information } \\
\text { while doing an activity. }\end{array}$ & 0 & $\begin{array}{l}\text { (low) } \\
1\end{array}$ & 2 & 3 & $\begin{array}{l}\text { (high) } \\
4\end{array}$ \\
\hline $\begin{array}{l}3.51 \text { Buttons, icons or menu items make Help } \\
\text { or Hint-type options easily accessible. }\end{array}$ & 0 & $\begin{array}{l}\text { (low) } \\
1\end{array}$ & 2 & 3 & $\begin{array}{l}\text { (high) } \\
4\end{array}$ \\
\hline $\begin{array}{l}\text { 3.52 The program arouses sensory and } \\
\text { cognitive curiosity }\end{array}$ & 0 & $\begin{array}{l}\text { (low) } \\
1\end{array}$ & 2 & 3 & $\begin{array}{l}\text { (high) } \\
4\end{array}$ \\
\hline $\begin{array}{l}3.53 \text { The program maintains attention } \\
\text { throughout the lesson. }\end{array}$ & 0 & $\begin{array}{l}\text { (low) } \\
1\end{array}$ & 2 & 3 & $\begin{array}{l}\text { (high) } \\
4\end{array}$ \\
\hline $\begin{array}{l}3.54 \text { The use of animation invites learners' } \\
\text { reaction or input. }\end{array}$ & 0 & $\begin{array}{l}\text { (low) } \\
1\end{array}$ & 2 & 3 & $\begin{array}{l}\text { (high) } \\
4\end{array}$ \\
\hline $\begin{array}{l}\text { 3.55 The program gives teachers a clear } \\
\text { explanation of its purposes and } \\
\text { methodological orientation. }\end{array}$ & 0 & $\begin{array}{l}\text { (low) } \\
1\end{array}$ & 2 & 3 & $\begin{array}{l}\text { (high) } \\
4\end{array}$ \\
\hline \multicolumn{6}{|c|}{ Sub-total $=31$} \\
\hline \multicolumn{6}{|c|}{ Total $=145$} \\
\hline
\end{tabular}

\begin{tabular}{|c|c|}
\hline 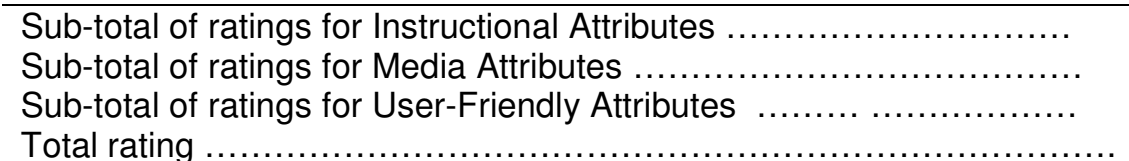 & $\begin{array}{c}79 \\
35 \\
31 \\
145\end{array}$ \\
\hline
\end{tabular}




\section{ESL/EFL SOFTWARE EVALUATION INSTRUMENT}

Title of the program: Learn English Now (version 8)

Publisher: Transparent Language

\section{DESCRIPTIVE ANALYSIS}

Please place a checkmark next to the item that best describes the program and/or its features.

\section{TECHNICAL FEATURES}

1.1 Components of the program:

\begin{tabular}{|c|l|l|}
\hline $\begin{array}{c}\text { Number of CD's: } 1 \\
\text { Per level } \\
\text { Total }\end{array}$ & $\begin{array}{l}\text { Teacher's guide___Yes } \\
\text { No }\end{array}$ & $\begin{array}{l}\text { Support materials__Yes_X_No } \\
\text { What type? }\end{array}$ \\
\hline
\end{tabular}

\subsection{Platform}

Mac II or better 7.5 .5 or higher Mhz 16 MB of RAM Windows 95, 98, 2000, or NT
$400+$ Mhz $32+$ MB of RAM

\subsection{Tools}

\begin{tabular}{|l|l|l|}
\hline $\begin{array}{l}\text { Word processing } \\
\text { Online forums } \\
\text { Online collaboration }\end{array}$ & $-\mathrm{X}-\begin{array}{c}\text { Speech recognition } \\
\text { Web browsing } \\
\text { Encyclopedia or compendia }\end{array}$ & $-\begin{array}{l}\text { E-mail } \\
\text { Others }\end{array}$ \\
\hline
\end{tabular}

Other technological resources integrated into the program:

\begin{tabular}{|l|l|l|l|}
\hline$\frac{1}{\text { web }}$ dictionaries on the & grammar on line & other web sites & none \\
\hline
\end{tabular}

1.5 Directions for use:

\begin{tabular}{|l|l|l|}
\hline - X_ are on the screen & _ are in the documentation & - X_can be skipped at option of user \\
\hline
\end{tabular}

\section{PEDAGOGICAL ORIENTATION}

\subsection{Program's theory of language}

\begin{tabular}{|c|c|l|}
\hline _ structural & X_f functional $_{-}$ & \\
\hline
\end{tabular}

2.7 Type of program

\begin{tabular}{|c|c|c|c|}
\hline $\begin{array}{l}\text { X_remediation } \\
\text { X_ enrichment } \\
\text { X_ } \\
\text { X_tutoring }\end{array}$ & $\begin{array}{c}\text { X_demonstration } \\
\text { assessment }\end{array}$ & $\begin{array}{c}\overline{\text { game }}^{\text {education }} \\
\text { collaborative } \\
\text { projects }\end{array}$ & $\begin{array}{l}\text { problem solving } \\
\mathrm{X}_{-} \text {drill and practice } \\
\text { simulation }\end{array}$ \\
\hline
\end{tabular}

2.8 Curriculum capability

\begin{tabular}{|l|l|}
\hline Grade range & Proficiency level range \\
\hline
\end{tabular}




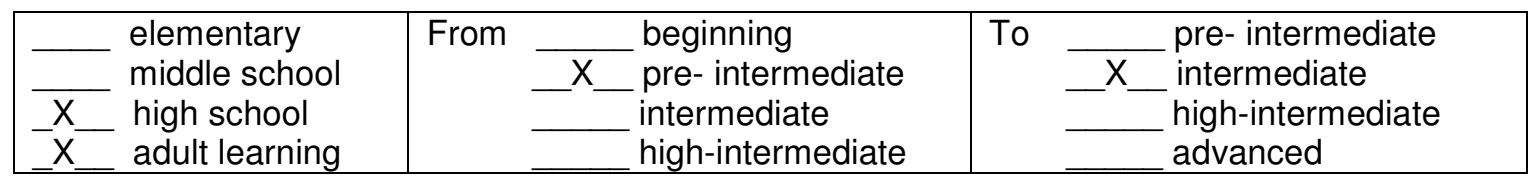

2.9 Method of language teaching claimed by the program

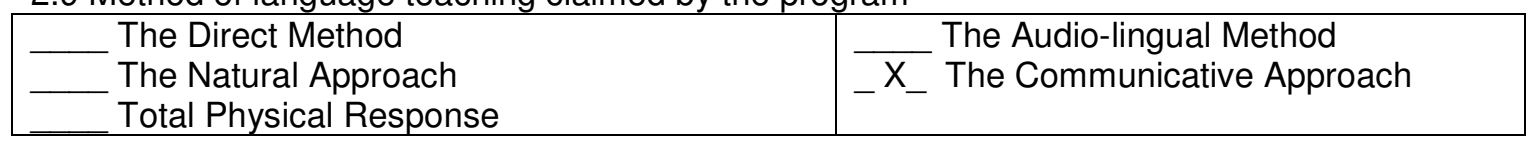

2.10 Language skills developed in the program

\begin{tabular}{|l|l|l|l|}
\hline X_ X speaking & X_listening & X_reading & _ writing \\
\hline
\end{tabular}

2.11 Type of activities offered by the program

\begin{tabular}{|l|l|l|l|}
\hline $\begin{array}{l}\mathbf{X} \text { _games } \\
\mathbf{X} \text { _quizzes } \\
\text { others }\end{array}$ & $\begin{array}{c}\text { simulation } \\
\text { exploratory }\end{array}$ & $\begin{array}{l}\text { tutorial } \\
\text { text } \\
\text { construction }\end{array}$ & $\begin{array}{l}\text { X_drill and practice } \\
\text { problem solving }\end{array}$ \\
\hline
\end{tabular}

2.12 Orientation of how to use program and its feature

\begin{tabular}{|c|c|}
\hline for the teacher & $\mathbf{X}$ _on the screen \\
\hline for the student & on hard copy documentation \\
\hline for both & _ on both \\
\hline
\end{tabular}

2.13 Role of the teacher

\begin{tabular}{|l|l|l|l|}
\hline _ X_ instructor & _ facilitator & _ X_lab manager & _ evaluator \\
\hline
\end{tabular}

2.14 Learners interact

\begin{tabular}{|c|l|l|}
\hline _ with one another & _ with the teacher & X_with neither \\
\hline
\end{tabular}

2.15 In case learners interact with one another, they can interact

\begin{tabular}{|l|l|}
\hline in all activities & in some activities \\
\hline
\end{tabular}

2.16 In case learners interact with the teacher, they can interact at any time
at the end of the lesson at the end of the activities there's no interaction

\section{CRITICAL ANALYSIS}

For each item, circle the numbers 1 (for low) to 4 (for high) to indicate your judgment of the degree to which the program possesses or demonstrates the feature identified in each item. Circle 0 if the feature is not present in the program. 


\begin{tabular}{|c|c|c|c|c|c|}
\hline Graphics and sound enhance learning. & 0 & $\begin{array}{l}\text { (low) } \\
1\end{array}$ & 2 & 3 & $\begin{array}{l}\text { (high) } \\
4\end{array}$ \\
\hline $\begin{array}{l}1.2 \text { The animation is effective in minimizing } \\
\text { boredom by motivating learners. }\end{array}$ & 0 & $\begin{array}{l}\text { (low) } \\
1\end{array}$ & 2 & 3 & $\begin{array}{l}\text { (high) } \\
4\end{array}$ \\
\hline 1.3Screen displays are uncluttered. & 0 & $\begin{array}{ll}\text { (low) } \\
1\end{array}$ & 2 & 3 & $\begin{array}{l}\text { (high) } \\
4\end{array}$ \\
\hline 1.4 Graphics make information attractive. & 0 & $\begin{array}{l}\text { (low) } \\
1\end{array}$ & 2 & 3 & $\begin{array}{l}\text { (high) } \\
4\end{array}$ \\
\hline $\begin{array}{l}1.5 \text { Graphics help memorization of key } \\
\text { information. }\end{array}$ & 0 & $\begin{array}{ll}\text { (low) } \\
1\end{array}$ & 2 & 3 & $\begin{array}{l}\text { (high) } \\
4\end{array}$ \\
\hline $\begin{array}{l}\text { 1.6 The program makes use of authentic texts } \\
\text { and other realia. }\end{array}$ & 0 & $\begin{array}{ll}\text { (low) } \\
1\end{array}$ & 2 & 3 & $\begin{array}{l}\text { (high) } \\
4\end{array}$ \\
\hline $\begin{array}{l}1.7 \text { The program integrates information about } \\
\text { culture/daily situations into the presentations } \\
\text { and activities. }\end{array}$ & 0 & $\begin{array}{l}\text { (low) } \\
1\end{array}$ & 2 & 3 & $\begin{array}{l}\text { (high) } \\
4\end{array}$ \\
\hline $\begin{array}{l}1.8 \text { Lessons present and practice language } \\
\text { structures in meaningful communicative } \\
\text { contexts. }\end{array}$ & 0 & $\begin{array}{ll}\text { (low) } \\
1\end{array}$ & 2 & 3 & $\begin{array}{l}\text { (high) } \\
4\end{array}$ \\
\hline $\begin{array}{l}1.9 \text { Lessons present and practice vocabulary in } \\
\text { meaningful communicative contexts. }\end{array}$ & 0 & $\begin{array}{l}\text { (low) } \\
1\end{array}$ & 2 & 3 & $\begin{array}{l}\text { (high) } \\
4\end{array}$ \\
\hline $\begin{array}{l}1.10 \text { Lessons develop the communicative skills } \\
\text { the program aims to develop. }\end{array}$ & 0 & $\begin{array}{ll}\text { (low) } \\
1\end{array}$ & 2 & 3 & $\begin{array}{l}\text { (high) } \\
4\end{array}$ \\
\hline $\begin{array}{l}1.11 \text { Lessons develop the level of language } \\
\text { proficiency the program aims to develop. }\end{array}$ & 0 & $\begin{array}{l}\text { (low) } \\
1 \\
\end{array}$ & 2 & 3 & $\begin{array}{l}\text { (high) } \\
4\end{array}$ \\
\hline $\begin{array}{l}1.12 \text { The course syllabus reflects a } \\
\text { communicative approach to language } \\
\text { teaching/learning. }\end{array}$ & 0 & $\begin{array}{ll}\text { (low) } \\
1\end{array}$ & 2 & 3 & $\begin{array}{l}\text { (high) } \\
4\end{array}$ \\
\hline $\begin{array}{l}1.13 \text { Content selection is determined by } \\
\text { communicative skills and/or themes. }\end{array}$ & 0 & $\begin{array}{l}\text { (low) } \\
1\end{array}$ & 2 & 3 & $\begin{array}{l}\text { (high) } \\
4\end{array}$ \\
\hline $\begin{array}{l}\text { 1.14 Content is sequenced from simple } \\
\text { communicative functions, such as introducing } \\
\text { oneself, greeting, etc, to complex ones, such } \\
\text { as stating an opinion, disagreeing, etc. }\end{array}$ & 0 & $\begin{array}{ll}\text { (low) } \\
1\end{array}$ & 2 & 3 & $\begin{array}{l}\text { (high) } \\
4\end{array}$ \\
\hline 1.15 Content is presented communicatively. & 0 & $\begin{array}{ll}\text { (low) } \\
1\end{array}$ & 2 & 3 & $\begin{array}{l}\text { (high) } \\
4\end{array}$ \\
\hline $\begin{array}{l}\text { 1.16 The program develops the content at } \\
\text { appropriate levels of language proficiency. }\end{array}$ & 0 & $\begin{array}{ll}\text { (low) } \\
1\end{array}$ & 2 & 3 & $\begin{array}{l}\text { (high) } \\
4\end{array}$ \\
\hline $\begin{array}{l}1.17 \text { The program content is educationally } \\
\text { relevant and interesting for the learner. }\end{array}$ & 0 & $\begin{array}{ll}\text { (low) } \\
1\end{array}$ & 2 & 3 & $\begin{array}{l}\text { (high) } \\
4\end{array}$ \\
\hline $\begin{array}{l}\text { 1.18 The program content is appropriate for } \\
\text { intended learners. }\end{array}$ & 0 & $\begin{array}{l}\text { (low) } \\
1\end{array}$ & 2 & 3 & $\begin{array}{l}\text { (high) } \\
4\end{array}$ \\
\hline $\begin{array}{l}\text { 1.19 The program content is applicable to real } \\
\text { life contexts. }\end{array}$ & 0 & $\begin{array}{ll}\text { (low) } \\
1\end{array}$ & 2 & 3 & $\begin{array}{l}\text { (high) } \\
4\end{array}$ \\
\hline $\begin{array}{l}1.20 \text { The program allows learners to work } \\
\text { together in communicative activities. }\end{array}$ & 0 & $\begin{array}{ll}\text { (low) } \\
1\end{array}$ & 2 & 3 & $\begin{array}{l}\text { (high) } \\
4\end{array}$ \\
\hline $\begin{array}{l}\text { 1.21 The activities allow unplanned and/or } \\
\text { unpredictable responses. }\end{array}$ & 0 & $\begin{array}{ll}\text { (low) } \\
1\end{array}$ & 2 & 3 & $\begin{array}{l}\text { (high) } \\
4\end{array}$ \\
\hline $\begin{array}{l}\text { 1.22 The activities lend themselves to group } \\
\text { discussions. }\end{array}$ & 0 & $\begin{array}{ll}\text { (low) } \\
1\end{array}$ & 2 & 3 & $\begin{array}{l}\text { (high) } \\
4\end{array}$ \\
\hline $\begin{array}{l}1.23 \text { The activities aim at developing other } \\
\text { competencies in addition to syntactical and } \\
\text { lexical }\end{array}$ & 0 & $\begin{array}{l}\text { (low) } \\
1\end{array}$ & 2 & 3 & $\begin{array}{l}\text { (high) } \\
4\end{array}$ \\
\hline $\begin{array}{l}\text { 1.24 The program allows the teacher to interact } \\
\text { with students while they are doing an activity. }\end{array}$ & 0 & $\begin{array}{l}\text { (low) } \\
1\end{array}$ & 2 & 3 & $\begin{array}{l}\text { (high) } \\
4\end{array}$ \\
\hline
\end{tabular}




\begin{tabular}{|l|l|l|l|l|l|}
\hline $\begin{array}{l}1.25 \text { The program provides non-threatening } \\
\text { feedback. }\end{array}$ & 0 & $\begin{array}{l}\text { (low) } \\
1\end{array}$ & 2 & 3 & $\begin{array}{l}\text { (high) } \\
4\end{array}$ \\
\hline $\begin{array}{l}1.26 \text { The program allows learners to repeat an } \\
\text { activity after feedback is provided. }\end{array}$ & 0 & $\begin{array}{l}\text { (low) } \\
1\end{array}$ & 2 & 3 & $\begin{array}{l}\text { (high) } \\
4\end{array}$ \\
\hline $\begin{array}{l}1.27 \text { Activities allow for more than one correct } \\
\text { response. }\end{array}$ & 0 & $\begin{array}{l}\text { (low) } \\
1\end{array}$ & 2 & 3 & $\begin{array}{l}\text { (high) } \\
4\end{array}$ \\
\hline $\begin{array}{l}1.28 \text { The program provides the students with } \\
\text { feedback that would allow them to correct their } \\
\text { mistakes. }\end{array}$ & 0 & $\begin{array}{l}\text { (low) } \\
1\end{array}$ & 2 & 3 & $\begin{array}{l}\text { (high) } \\
4\end{array}$ \\
\hline \begin{tabular}{l} 
Sub-total $=53(47.32 \%)$ \\
\hline
\end{tabular}
\end{tabular}

\begin{tabular}{|c|c|c|c|c|c|}
\hline \multicolumn{6}{|l|}{ Media Attributes } \\
\hline 2.29 Graphics aid understanding. & 0 & $\begin{array}{ll}\text { (low) } \\
1\end{array}$ & 2 & 3 & $\begin{array}{l}\text { (high) } \\
4\end{array}$ \\
\hline $\begin{array}{l}\text { 2.30 The program allows for different routes and } \\
\text { choices for learning. }\end{array}$ & 0 & $\begin{array}{l}\text { (low) } \\
1\end{array}$ & 2 & 3 & $\begin{array}{l}\text { (high) } \\
4\end{array}$ \\
\hline $\begin{array}{l}\text { 2.31 The program allows for review of old } \\
\text { information. }\end{array}$ & 0 & $\begin{array}{l}\text { (low) } \\
1\end{array}$ & 2 & 3 & $\begin{array}{l}\text { (high) } \\
4\end{array}$ \\
\hline $\begin{array}{l}\text { 2.32 The program allows branching to new } \\
\text { information. }\end{array}$ & 0 & (low) & 2 & 3 & $\begin{array}{l}\text { (high) } \\
4\end{array}$ \\
\hline $\begin{array}{l}\text { 2.33 The program allows students to select } \\
\text { activities according to their ages. }\end{array}$ & 0 & $\begin{array}{ll}\text { (low) } \\
1\end{array}$ & 2 & 3 & $\begin{array}{l}\text { (high) } \\
4\end{array}$ \\
\hline $\begin{array}{l}2.34 \text { The program allows students to select } \\
\text { activities according to their learning styles. }\end{array}$ & 0 & (low) & 2 & 3 & $\begin{array}{l}\text { (high) } \\
4\end{array}$ \\
\hline $\begin{array}{l}2.35 \text { The program allows students to select } \\
\text { activities according to their interests. }\end{array}$ & 0 & $\begin{array}{l}\text { (low) } \\
1\end{array}$ & 2 & 3 & $\begin{array}{l}\text { (high) } \\
4\end{array}$ \\
\hline $\begin{array}{l}\text { 2.36 The program adapts to the responses } \\
\text { given by the learners, branching to more or less } \\
\text { complicated questions as appropriate. }\end{array}$ & 0 & $\begin{array}{l}\text { (low) } \\
1\end{array}$ & 2 & 3 & $\begin{array}{l}\text { (high) } \\
4\end{array}$ \\
\hline $\begin{array}{l}2.37 \text { The program allows learners to go through } \\
\text { its content at their own pace and rhythm. }\end{array}$ & 0 & $\begin{array}{l}\text { (low) } \\
1\end{array}$ & 2 & 3 & $\begin{array}{l}\text { (high) } \\
4\end{array}$ \\
\hline $\begin{array}{l}2.38 \text { The program prevents learners from } \\
\text { repeating exercises, therefore, minimizing } \\
\text { guessing. }\end{array}$ & 0 & $\begin{array}{ll}(\text { low) } \\
1\end{array}$ & 2 & 3 & $\begin{array}{l}\text { (high) } \\
4\end{array}$ \\
\hline $\begin{array}{l}\text { 2.39 The program keeps records of learners' } \\
\text { performance to allow them to continue activities } \\
\text { from where they left off. }\end{array}$ & 0 & $\begin{array}{l}\text { (low) } \\
1\end{array}$ & 2 & 3 & $\begin{array}{l}\text { (high) } \\
4\end{array}$ \\
\hline $\begin{array}{l}2.40 \text { The program keeps track of students' } \\
\text { scores. }\end{array}$ & 0 & $\begin{array}{l}\text { (low) } \\
1\end{array}$ & 2 & 3 & $\begin{array}{l}\text { (high) } \\
4\end{array}$ \\
\hline $\begin{array}{l}2.41 \text { The program provides feedback for both } \\
\text { correct and incorrect answers. The program } \\
\text { provides feedback for both correct and incorrect } \\
\text { answers. }\end{array}$ & 0 & $\begin{array}{l}\text { (low) } \\
1\end{array}$ & 2 & 3 & $\begin{array}{l}\text { (high) } \\
4\end{array}$ \\
\hline $\begin{array}{l}\text { 2.42 The program gives learners the chance to } \\
\text { correct their errors. }\end{array}$ & 0 & $\begin{array}{l}\text { (low) } \\
1\end{array}$ & 2 & 3 & $\begin{array}{l}\text { (high) } \\
4\end{array}$ \\
\hline $\begin{array}{l}2.43 \text { The program effectively signals the } \\
\text { mistakes before providing the right answers. }\end{array}$ & 0 & $\begin{array}{ll}\text { (low) } \\
1\end{array}$ & 2 & 3 & $\begin{array}{l}\text { (high) } \\
4\end{array}$ \\
\hline
\end{tabular}




\begin{tabular}{|c|c|c|c|c|c|}
\hline $\begin{array}{l}\text { 2.44 The program effectively specifies different } \\
\text { types of errors, such as differences between a } \\
\text { syntactic error and an incorrect word choice. }\end{array}$ & 0 & $\begin{array}{l}\text { (low) } \\
1\end{array}$ & 2 & 3 & $\begin{array}{l}\text { (high) } \\
4\end{array}$ \\
\hline \multicolumn{6}{|l|}{ Sub-total $=28(43.75 \%)$} \\
\hline \multicolumn{6}{|l|}{ User-Friendly Attributes } \\
\hline $\begin{array}{l}\text { 3.45 Menu items are understandable and } \\
\text { descriptive. }\end{array}$ & 0 & $\begin{array}{l}\text { (low) } \\
1\end{array}$ & 2 & 3 & $\begin{array}{l}\text { (high) } \\
4\end{array}$ \\
\hline $\begin{array}{l}\text { 3.46 The commands and instructions for the } \\
\text { activities are clear and objective. }\end{array}$ & 0 & $\begin{array}{l}\text { (low) } \\
1\end{array}$ & 2 & 3 & $\begin{array}{l}\text { (high) } \\
4\end{array}$ \\
\hline $\begin{array}{l}\text { 3.47 The program gives the learners effective } \\
\text { clues to clarify their doubts about its use. }\end{array}$ & 0 & $\begin{array}{l}\text { (low) } \\
1\end{array}$ & 2 & 3 & $\begin{array}{l}\text { (high) } \\
4\end{array}$ \\
\hline $\begin{array}{l}3.48 \text { Each screen uses text and } \\
\text { graphic/animation to make a particular teaching } \\
\text { point clear. }\end{array}$ & 0 & $\begin{array}{ll}(\text { low }) \\
1\end{array}$ & 2 & 3 & $\begin{array}{l}\text { (high) } \\
4\end{array}$ \\
\hline $\begin{array}{l}\text { 3.49 The program is effectively integrated with } \\
\text { other technological resources (such as } \\
\text { dictionaries on the web, grammar on line, etc) } \\
\text { as the learner uses it. }\end{array}$ & 0 & $\begin{array}{l}\text { (low) } \\
1\end{array}$ & 2 & 3 & $\begin{array}{l}\text { (high) } \\
4\end{array}$ \\
\hline $\begin{array}{l}3.50 \text { Icons, buttons and menus allow learners to } \\
\text { readily search for additional information while } \\
\text { doing an activity. }\end{array}$ & 0 & $\begin{array}{l}\text { (low) } \\
1\end{array}$ & 2 & 3 & $\begin{array}{l}\text { (high) } \\
4\end{array}$ \\
\hline $\begin{array}{l}\text { 3.51 Buttons, icons or menu items make Help or } \\
\text { Hint-type options easily accessible. }\end{array}$ & 0 & $\begin{array}{l}\text { (low) } \\
1\end{array}$ & 2 & 3 & $\begin{array}{l}\text { (high) } \\
4\end{array}$ \\
\hline $\begin{array}{l}\text { 3.52 The program arouses sensory and } \\
\text { cognitive curiosity }\end{array}$ & 0 & $\begin{array}{ll}\text { (low) } \\
1\end{array}$ & 2 & 3 & $\begin{array}{l}\text { (high) } \\
4\end{array}$ \\
\hline $\begin{array}{l}3.53 \text { The program maintains attention } \\
\text { throughout the lesson. }\end{array}$ & 0 & $\begin{array}{l}\text { (low) } \\
1\end{array}$ & 2 & 3 & $\begin{array}{l}\text { (high) } \\
4\end{array}$ \\
\hline $\begin{array}{l}3.54 \text { The use of animation invites learners' } \\
\text { reaction or input. }\end{array}$ & 0 & (low) & 2 & 3 & $\begin{array}{l}\text { (high) } \\
4\end{array}$ \\
\hline $\begin{array}{l}3.55 \text { The program gives teachers a clear } \\
\text { explanation of its purposes and methodological } \\
\text { orientation. }\end{array}$ & 0 & $\begin{array}{l}\text { (low) } \\
1\end{array}$ & 2 & 3 & $\begin{array}{l}\text { (high) } \\
4\end{array}$ \\
\hline \multicolumn{6}{|l|}{ Sub-total $=21(47.72 \%)$} \\
\hline Total & & & & & \\
\hline
\end{tabular}

Sub-total of ratings for Instructional Attributes ......................

Sub-total of ratings for Media Attributes ................................

Sub-total of ratings for User-Friendly Attributes .......................

$53(47.32 \%)$

Total rating 


\section{ESL/EFL SOFTWARE EVALUATION INSTRUMENT}

Title of the program: Learn to Speak English

Publisher: The Language Company

\section{DESCRIPTIVE ANALYSIS}

Please place a checkmark next to the item that best describes the program and/or its features.

\section{TECHNICAL FEATURES}

1.1 Components of the program:

\begin{tabular}{|c|c|c|}
\hline \begin{tabular}{|cl} 
Number of CD's: \\
$\mathbf{1}$ & Per level \\
$\mathbf{3}$ & Total \\
\end{tabular} & Teacher's guide_X_Yes___No & $\begin{array}{l}\text { Support materials __ Yes__ _ No } \\
\text { What type? }\end{array}$ \\
\hline
\end{tabular}

1.2 Platform

\begin{tabular}{|c|c|}
\hline $\begin{array}{c}\text { Mac OS 7.0 + } \\
\text { Mhz _ MB of RAM }\end{array}$ & $\begin{array}{c}\text { Windows 95, 98, XP, 2000 } \\
\text { Mhz _ MB of RAM }\end{array}$ \\
\hline
\end{tabular}

1.3 Tools

\begin{tabular}{|c|c|c|}
\hline $\begin{array}{l}\text { Word processing } \\
\text { Online forums } \\
\text { Online collaboration }\end{array}$ & $\begin{array}{l}\text { X_Speech recognition } \\
\text { Web browsing } \\
\text { Encyclopedia or compendia }\end{array}$ & $\begin{array}{l}\text { E-mail } \\
\text { Others }\end{array}$ \\
\hline
\end{tabular}

1.4 Other technological resources integrated into the program:

\begin{tabular}{|l|l|l|l|}
\hline$\frac{\text { web }}{\text { dictionaries on the }}$ & grammar on line & other web sites & __ none \\
\hline
\end{tabular}

1.5 Directions for use:

\begin{tabular}{|l|l|l|}
\hline _. $\mathbf{X}_{-}$are on the screen & $\ldots$ are in the documentation & - $\mathbf{X}_{-}$can be skipped at option of user \\
\hline
\end{tabular}

\section{PEDAGOGICAL ORIENTATION}

\subsection{Program's theory of language}

\begin{tabular}{|l|l|l|}
\hline structural & interactional \\
\hline
\end{tabular}

2.7 Type of program

\begin{tabular}{|c|c|c|c|}
\hline $\begin{array}{l}\mathbf{X} \text { _ remediation } \\
\mathbf{X} \text { _enrichment } \\
\text { tutoring }\end{array}$ & $\begin{array}{c}\text { X_demonstration } \\
\text { assessment }\end{array}$ & $\begin{array}{c}{ }_{\text {game }} \text { education } \\
\text { collaborative } \\
\text { projects }\end{array}$ & $\begin{array}{c}\mathbf{X} \text { problem solving } \\
\text { drill and practice } \\
\text { simulation }\end{array}$ \\
\hline
\end{tabular}


2.8 Curriculum capability

\begin{tabular}{|c|c|c|c|c|}
\hline Grade range & Proficie & ncy level range & & \\
\hline $\begin{array}{l}\text { elementary } \\
\text { middle school }\end{array}$ & From & $\mathbf{X}$ _ beginning & & $\begin{array}{c}\text { pre- intermediate } \\
\text { intermediate }\end{array}$ \\
\hline high school & & intermediate & & high-intermediate \\
\hline
\end{tabular}

2.9 Method of language teaching claimed by the program

The Direct Method

The Natural Approach

Total Physical Response

The Audio-lingual Method

X_ The Communicative Approach

2.10 Language skills developed in the program

\begin{tabular}{|l|l|l|l|}
\hline X_ X speaking & X_listening & X_reading & __ _ writing \\
\hline
\end{tabular}

2.11 Type of activities offered by the program

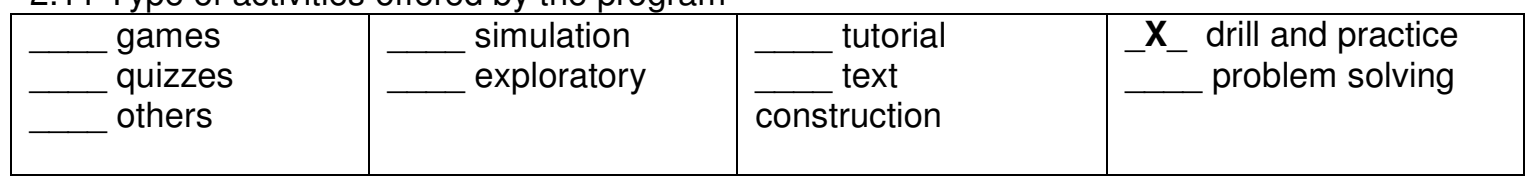

2.12 Orientation of how to use program and its feature

\begin{tabular}{|c|c|}
\hline $\mathbf{X}$ for the teacher & on the screen \\
\hline for the student & on hard copy documentation \\
\hline for both & $\mathbf{X}$ _ on both \\
\hline
\end{tabular}

2.13 Role of the teacher

\begin{tabular}{|l|l|l|l|}
\hline - X_ instructor & _ facilitator & X_lab manager & _ evaluator \\
\hline
\end{tabular}

2.14 Learners interact

\begin{tabular}{|c|l|l|}
\hline _ with one another & _ with the teacher & X_with neither \\
\hline
\end{tabular}

2.15 In case learners interact with one another, they can interact

\begin{tabular}{|l|l|}
\hline in all activities & in some activities \\
\hline
\end{tabular}

2.16 In case learners interact with the teacher, they can interact

\begin{tabular}{|l|l}
\hline at any time & at the end of the lesson
\end{tabular}
at the end of the activities there's no interaction

\section{$\underline{\text { CRITICAL ANALYSIS }}$}

For each item, circle the numbers 1 (for low) to 4 (for high) to indicate your judgment of the degree to which the program possesses or demonstrates the feature identified in each item. Circle 0 if the feature is not present in the program. 


\begin{tabular}{|c|c|c|c|c|c|}
\hline \multicolumn{6}{|l|}{ Instructional Attributes } \\
\hline Graphics and sound enhance learning. & 0 & $\begin{array}{l}\text { (low) } \\
1\end{array}$ & 2 & 3 & $\begin{array}{l}\text { (high) } \\
4\end{array}$ \\
\hline $\begin{array}{l}1.2 \text { The animation is effective in minimizing } \\
\text { boredom by motivating learners. }\end{array}$ & 0 & $\begin{array}{ll}\text { (low) } \\
1\end{array}$ & 2 & 3 & $\begin{array}{l}\text { (high) } \\
4\end{array}$ \\
\hline 1.3Screen displays are uncluttered. & 0 & $\begin{array}{l}\text { (low) } \\
1\end{array}$ & 2 & 3 & $\begin{array}{l}\text { (high) } \\
4\end{array}$ \\
\hline 1.4 Graphics make information attractive. & 0 & $\begin{array}{l}\text { (low) } \\
1\end{array}$ & 2 & 3 & $\begin{array}{l}\text { (high) } \\
4\end{array}$ \\
\hline $\begin{array}{l}1.5 \text { Graphics help memorization of key } \\
\text { information. }\end{array}$ & 0 & $\begin{array}{l}\text { (low) } \\
1\end{array}$ & 2 & 3 & $\begin{array}{l}\text { (high) } \\
4\end{array}$ \\
\hline $\begin{array}{l}\text { 1.6 The program makes use of authentic texts } \\
\text { and other realia. }\end{array}$ & 0 & $\begin{array}{l}\text { (low) } \\
1\end{array}$ & 2 & 3 & $\begin{array}{l}\text { (high) } \\
4\end{array}$ \\
\hline $\begin{array}{l}\text { 1.7 The program integrates information about } \\
\text { culture/daily situations into the presentations } \\
\text { and activities. }\end{array}$ & 0 & $\begin{array}{l}\text { (low) } \\
1\end{array}$ & 2 & 3 & $\begin{array}{l}\text { (high) } \\
4\end{array}$ \\
\hline $\begin{array}{l}1.8 \text { Lessons present and practice language } \\
\text { structures in meaningful communicative } \\
\text { contexts. }\end{array}$ & 0 & $\begin{array}{l}\text { (low) } \\
1\end{array}$ & 2 & 3 & $\begin{array}{l}\text { (high) } \\
4\end{array}$ \\
\hline $\begin{array}{l}1.9 \text { Lessons present and practice vocabulary in } \\
\text { meaningful communicative contexts. }\end{array}$ & 0 & $\begin{array}{l}\text { (low) } \\
1\end{array}$ & 2 & 3 & $\begin{array}{l}\text { (high) } \\
4\end{array}$ \\
\hline $\begin{array}{l}1.10 \text { Lessons develop the communicative skills } \\
\text { the program aims to develop. }\end{array}$ & 0 & $\begin{array}{l}\text { (low) } \\
1\end{array}$ & 2 & 3 & $\begin{array}{l}\text { (high) } \\
4\end{array}$ \\
\hline $\begin{array}{l}1.11 \text { Lessons develop the level of language } \\
\text { proficiency the program aims to develop. }\end{array}$ & 0 & $\begin{array}{l}\text { (low) } \\
1\end{array}$ & 2 & 3 & $\begin{array}{l}\text { (high) } \\
4\end{array}$ \\
\hline $\begin{array}{l}1.12 \text { The course syllabus reflects a } \\
\text { communicative approach to language } \\
\text { teaching/learning. }\end{array}$ & 0 & $\begin{array}{l}\text { (low) } \\
1\end{array}$ & 2 & 3 & $\begin{array}{l}\text { (high) } \\
4\end{array}$ \\
\hline $\begin{array}{l}1.13 \text { Content selection is determined by } \\
\text { communicative skills and/or themes. }\end{array}$ & 0 & $\begin{array}{ll}\text { (low) } \\
1\end{array}$ & 2 & 3 & $\begin{array}{l}\text { (high) } \\
4\end{array}$ \\
\hline $\begin{array}{l}\text { 1.14 Content is sequenced from simple } \\
\text { communicative functions, such as introducing } \\
\text { oneself, greeting, etc, to complex ones, such } \\
\text { as stating an opinion, disagreeing, etc. }\end{array}$ & 0 & $\begin{array}{l}\text { (low) } \\
1\end{array}$ & 2 & 3 & $\begin{array}{l}\text { (high) } \\
4\end{array}$ \\
\hline 1.15 Content is presented communicatively. & 0 & $\begin{array}{l}\text { (low) } \\
1\end{array}$ & 2 & 3 & $\begin{array}{l}\text { (high) } \\
4\end{array}$ \\
\hline $\begin{array}{l}1.16 \text { The program develops the content at } \\
\text { appropriate levels of language proficiency. }\end{array}$ & 0 & $\begin{array}{l}\text { (low) } \\
1\end{array}$ & 2 & 3 & $\begin{array}{l}\text { (high) } \\
4\end{array}$ \\
\hline $\begin{array}{l}1.17 \text { The program content is educationally } \\
\text { relevant and interesting for the learner. }\end{array}$ & 0 & $\begin{array}{l}\text { (low) } \\
1\end{array}$ & 2 & 3 & $\begin{array}{l}\text { (high) } \\
4\end{array}$ \\
\hline $\begin{array}{l}1.18 \text { The program content is appropriate for } \\
\text { intended learners. }\end{array}$ & 0 & $\begin{array}{ll}\text { (low) } \\
1\end{array}$ & 2 & 3 & $\begin{array}{l}\text { (high) } \\
4\end{array}$ \\
\hline $\begin{array}{l}1.19 \text { The program content is applicable to real } \\
\text { life contexts. }\end{array}$ & 0 & $\begin{array}{l}\text { (low) } \\
1\end{array}$ & 2 & 3 & $\begin{array}{l}\text { (high) } \\
4\end{array}$ \\
\hline $\begin{array}{l}\text { 1.20 The program allows learners to work } \\
\text { together in communicative activities. }\end{array}$ & 0 & $\begin{array}{l}\text { (low) } \\
1\end{array}$ & 2 & 3 & $\begin{array}{l}\text { (high) } \\
4\end{array}$ \\
\hline $\begin{array}{l}\text { 1.21 The activities allow unplanned and/or } \\
\text { unpredictable responses. }\end{array}$ & 0 & $\begin{array}{ll}\text { (low) } \\
1\end{array}$ & 2 & 3 & $\begin{array}{l}\text { (high) } \\
4\end{array}$ \\
\hline $\begin{array}{l}\text { 1.22 The activities lend themselves to group } \\
\text { discussions. }\end{array}$ & 0 & $\begin{array}{l}\text { (low) } \\
1\end{array}$ & 2 & 3 & $\begin{array}{l}\text { (high) } \\
4\end{array}$ \\
\hline $\begin{array}{l}1.23 \text { The activities aim at developing other } \\
\text { competencies in addition to syntactical and } \\
\text { lexical }\end{array}$ & 0 & $\begin{array}{l}\text { (low) } \\
1\end{array}$ & 2 & 3 & $\begin{array}{l}\text { (high) } \\
4\end{array}$ \\
\hline
\end{tabular}




\begin{tabular}{|c|c|c|c|c|c|}
\hline $\begin{array}{l}1.24 \text { The program allows the teacher to interact } \\
\text { with students while they are doing an activity. }\end{array}$ & 0 & $\begin{array}{l}\text { (low) } \\
1\end{array}$ & 2 & 3 & $\begin{array}{l}\text { (high) } \\
4\end{array}$ \\
\hline $\begin{array}{l}1.25 \text { The program provides non-threatening } \\
\text { feedback. }\end{array}$ & 0 & $\begin{array}{l}\text { (low) } \\
1\end{array}$ & 2 & 3 & $\begin{array}{l}\text { (high) } \\
4\end{array}$ \\
\hline $\begin{array}{l}1.26 \text { The program allows learners to repeat an } \\
\text { activity after feedback is provided. }\end{array}$ & 0 & $\begin{array}{ll}\text { (low) } \\
1\end{array}$ & 2 & 3 & $\begin{array}{l}\text { (high) } \\
4\end{array}$ \\
\hline $\begin{array}{l}1.27 \text { Activities allow for more than one correct } \\
\text { response. }\end{array}$ & 0 & $\begin{array}{l}\text { (low) } \\
1\end{array}$ & 2 & 3 & $\begin{array}{l}\text { (high) } \\
4\end{array}$ \\
\hline $\begin{array}{l}\text { 1.28 The program provides the students with } \\
\text { feedback that would allow them to correct their } \\
\text { mistakes. }\end{array}$ & 0 & $\begin{array}{l}\text { (low) } \\
1\end{array}$ & 2 & 3 & $\begin{array}{l}\text { (high) } \\
4\end{array}$ \\
\hline
\end{tabular}

\begin{tabular}{|c|c|c|c|c|c|}
\hline \multicolumn{6}{|l|}{ Media Attributes } \\
\hline 2.29 Graphics aid understanding. & 0 & $\begin{array}{l}\text { (low) } \\
1\end{array}$ & 2 & 3 & $\begin{array}{l}\text { (high) } \\
4\end{array}$ \\
\hline $\begin{array}{l}\text { 2.30 The program allows for different routes and } \\
\text { choices for learning. }\end{array}$ & 0 & $\begin{array}{ll}\text { (low) } \\
1\end{array}$ & 2 & 3 & $\begin{array}{l}\text { (high) } \\
4\end{array}$ \\
\hline $\begin{array}{l}\text { 2.31 The program allows for review of old } \\
\text { information. }\end{array}$ & 0 & $\begin{array}{l}\text { (low) } \\
1\end{array}$ & 2 & 3 & $\begin{array}{l}\text { (high) } \\
4\end{array}$ \\
\hline $\begin{array}{l}2.32 \text { The program allows branching to new } \\
\text { information. }\end{array}$ & 0 & (low) & 2 & 3 & $\begin{array}{l}\text { (high) } \\
4\end{array}$ \\
\hline $\begin{array}{l}2.33 \text { The program allows students to select } \\
\text { activities according to their ages. }\end{array}$ & 0 & $\begin{array}{l}\text { (low) } \\
1\end{array}$ & 2 & 3 & $\begin{array}{l}\text { (high) } \\
4\end{array}$ \\
\hline $\begin{array}{l}\text { 2.34 The program allows students to select } \\
\text { activities according to their learning styles. }\end{array}$ & 0 & $\begin{array}{l}\text { (low) } \\
1\end{array}$ & 2 & 3 & $\begin{array}{l}\text { (high) } \\
4\end{array}$ \\
\hline $\begin{array}{l}\text { 2.35 The program allows students to select } \\
\text { activities according to their interests. }\end{array}$ & 0 & $\begin{array}{l}\text { (low) } \\
1\end{array}$ & 2 & 3 & $\begin{array}{l}\text { (high) } \\
4\end{array}$ \\
\hline $\begin{array}{l}\text { 2.36 The program adapts to the responses } \\
\text { given by the learners, branching to more or less } \\
\text { complicated questions as appropriate. }\end{array}$ & 0 & $\begin{array}{l}\text { (low) } \\
1\end{array}$ & 2 & 3 & $\begin{array}{l}\text { (high) } \\
4\end{array}$ \\
\hline $\begin{array}{l}2.37 \text { The program allows learners to go through } \\
\text { its content at their own pace and rhythm. }\end{array}$ & 0 & $\begin{array}{l}\text { (low) } \\
1\end{array}$ & 2 & 3 & $\begin{array}{l}\text { (high) } \\
4\end{array}$ \\
\hline $\begin{array}{l}2.38 \text { The program prevents learners from } \\
\text { repeating exercises, therefore, minimizing } \\
\text { guessing. }\end{array}$ & 0 & $\begin{array}{l}\text { (low) } \\
1\end{array}$ & 2 & 3 & $\begin{array}{l}\text { (high) } \\
4\end{array}$ \\
\hline $\begin{array}{l}\text { 2.39 The program keeps records of learners' } \\
\text { performance to allow them to continue activities } \\
\text { from where they left off. }\end{array}$ & 0 & $\begin{array}{l}\text { (low) } \\
1\end{array}$ & 2 & 3 & $\begin{array}{l}\text { (high) } \\
4\end{array}$ \\
\hline $\begin{array}{l}2.40 \text { The program keeps track of students' } \\
\text { scores. }\end{array}$ & 0 & $\begin{array}{ll}\text { (low) } \\
1\end{array}$ & 2 & 3 & $\begin{array}{l}\text { (high) } \\
4\end{array}$ \\
\hline $\begin{array}{l}2.41 \text { The program provides feedback for both } \\
\text { correct and incorrect answers. The program } \\
\text { provides feedback for both correct and incorrect } \\
\text { answers. }\end{array}$ & 0 & $\begin{array}{l}\text { (low) } \\
1\end{array}$ & 2 & 3 & $\begin{array}{l}\text { (high) } \\
4\end{array}$ \\
\hline $\begin{array}{l}\text { 2.42 The program gives learners the chance to } \\
\text { correct their errors. }\end{array}$ & 0 & $\begin{array}{l}\text { (low) } \\
1\end{array}$ & 2 & 3 & $\begin{array}{l}\text { (high) } \\
4\end{array}$ \\
\hline $\begin{array}{l}2.43 \text { The program effectively signals the } \\
\text { mistakes before providing the right answers. }\end{array}$ & 0 & $\begin{array}{l}\text { (low) } \\
1\end{array}$ & 2 & 3 & $\begin{array}{l}\text { (high) } \\
4\end{array}$ \\
\hline
\end{tabular}




\begin{tabular}{|c|c|c|c|c|c|}
\hline $\begin{array}{l}2.44 \text { The program effectively specifies different } \\
\text { types of errors, such as differences between a } \\
\text { syntactic error and an incorrect word choice. }\end{array}$ & 0 & $\begin{array}{l}\text { (low) } \\
1\end{array}$ & 2 & 3 & $\begin{array}{l}\text { (high) } \\
4\end{array}$ \\
\hline \multicolumn{6}{|l|}{ Sub-total $=24(37.5 \%)$} \\
\hline \multicolumn{6}{|l|}{ User-Friendly Attributes } \\
\hline $\begin{array}{l}\text { 3.45 Menu items are understandable and } \\
\text { descriptive. }\end{array}$ & 0 & $\begin{array}{l}\text { (low) } \\
1\end{array}$ & 2 & 3 & $\begin{array}{l}\text { (high) } \\
4\end{array}$ \\
\hline $\begin{array}{l}\text { 3.46 The commands and instructions for the } \\
\text { activities are clear and objective. }\end{array}$ & 0 & $\begin{array}{ll}\text { (low) } \\
1\end{array}$ & 2 & 3 & $\begin{array}{l}\text { (high) } \\
4\end{array}$ \\
\hline $\begin{array}{l}\text { 3.47 The program gives the learners effective } \\
\text { clues to clarify their doubts about its use. }\end{array}$ & 0 & $\begin{array}{ll}\text { (low) } \\
1\end{array}$ & 2 & 3 & $\begin{array}{l}\text { (high) } \\
4\end{array}$ \\
\hline $\begin{array}{l}3.48 \text { Each screen uses text and } \\
\text { graphic/animation to make a particular teaching } \\
\text { point clear. }\end{array}$ & 0 & $\begin{array}{l}\text { (low) } \\
1\end{array}$ & 2 & 3 & $\begin{array}{l}\text { (high) } \\
4\end{array}$ \\
\hline $\begin{array}{l}\text { 3.49 The program is effectively integrated with } \\
\text { other technological resources (such as } \\
\text { dictionaries on the web, grammar on line, etc) } \\
\text { as the learner uses it. }\end{array}$ & 0 & $\begin{array}{l}\text { (low) } \\
1\end{array}$ & 2 & 3 & $\begin{array}{l}\text { (high) } \\
4\end{array}$ \\
\hline $\begin{array}{l}3.50 \text { Icons, buttons and menus allow learners to } \\
\text { readily search for additional information while } \\
\text { doing an activity. }\end{array}$ & 0 & $\begin{array}{ll}\text { (low) } \\
1\end{array}$ & 2 & 3 & $\begin{array}{l}\text { (high) } \\
4\end{array}$ \\
\hline $\begin{array}{l}3.51 \text { Buttons, icons or menu items make Help or } \\
\text { Hint-type options easily accessible. }\end{array}$ & 0 & $\begin{array}{l}\text { (low) } \\
1\end{array}$ & 2 & 3 & $\begin{array}{l}\text { (high) } \\
4\end{array}$ \\
\hline $\begin{array}{l}\text { 3.52 The program arouses sensory and } \\
\text { cognitive curiosity }\end{array}$ & 0 & $\begin{array}{ll}\text { (low) } \\
1\end{array}$ & 2 & 3 & $\begin{array}{l}\text { (high) } \\
4\end{array}$ \\
\hline $\begin{array}{l}3.53 \text { The program maintains attention } \\
\text { throughout the lesson. }\end{array}$ & 0 & $\begin{array}{l}\text { (low) } \\
1\end{array}$ & 2 & 3 & $\begin{array}{l}\text { (high) } \\
4\end{array}$ \\
\hline $\begin{array}{l}3.54 \text { The use of animation invites learners' } \\
\text { reaction or input. }\end{array}$ & 0 & $\begin{array}{l}\text { (low) } \\
1\end{array}$ & 2 & 3 & $\begin{array}{l}\text { (high) } \\
4\end{array}$ \\
\hline $\begin{array}{l}3.55 \text { The program gives teachers a clear } \\
\text { explanation of its purposes and methodological } \\
\text { orientation. }\end{array}$ & 0 & $\begin{array}{l}\text { (low) } \\
1\end{array}$ & 2 & 3 & $\begin{array}{l}\text { (high) } \\
4\end{array}$ \\
\hline \multicolumn{6}{|l|}{ Sub-total $=20(45.45 \%)$} \\
\hline Total $=104(47.27 \%)$ & & & & & \\
\hline
\end{tabular}

Sub-total of ratings for Instructional Attributes ...................... 60 (53.57\%)

Sub-total of ratings for Media Attributes ............................ 24 (37.5\%)

Sub-total of ratings for User-Friendly Attributes .................... 20 (45.45\%)

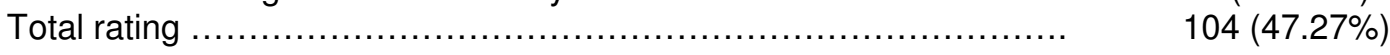




\section{ESL/EFL SOFTWARE EVALUATION INSTRUMENT}

Title of the program: Live Action English Interactive - TPR on a Computer

Publisher: Command Performance Language Institute

\section{DESCRIPTIVE ANALYSIS}

Please place a checkmark next to the item that best describes the program and/or its features.

\section{TECHNICAL FEATURES}

1.1 Components of the program:

\begin{tabular}{|c|l|l|}
\hline $\begin{array}{c}\text { Number of CD's: } \\
\text { 4CD per level } \\
\text { total }\end{array}$ & Teacher's guide _Y Yes ___No & $\begin{array}{l}\text { Support materials___ Yes __ No } \\
\text { What type? }\end{array}$ \\
\hline
\end{tabular}

1.2 Platform

\section{Mac Power Mac}

$150 \mathrm{Mhz} 10 \mathrm{MB}$ of RAM
Windows Pentium

$150 \mathrm{Mhz} 10 \mathrm{MB}$ of RAM

1.3 Tools

Word processing

Online forums

Online collaboration
Speech recognition

Web browsing

Encyclopedia or compendia
E-mail

Others

1.4 The program integrates other technological resources such as

\begin{tabular}{|l|l|l|l|}
\hline$\frac{\text { web }}{\text { dictionaries on the }}$ & grammar on line & other web sites & __ none \\
\hline
\end{tabular}

1.5 Directions for use:

\begin{tabular}{|l|l|l|}
\hline $\mathbf{X}_{-}$are on the screen & $\mathbf{X}$ are in the documentation & _ can be skipped at option of user \\
\hline
\end{tabular}

\section{PEDAGOGICAL ORIENTATION}

2.6 Program's theory of language

\begin{tabular}{|l|l|l|}
\hline structural & $-\mathbf{X}_{-}$functional & interactional \\
\hline
\end{tabular}

2.7 Type of program

\begin{tabular}{|c|c|c|c|}
\hline $\begin{array}{c}\text { remediation } \\
-\mathbf{X} \text { enrichment } \\
\text { tutoring }\end{array}$ & demonstration & education & $\begin{array}{c}\text { problem solving } \\
\text { assessment } \\
\text { drill and practice } \\
\text { simulation }\end{array}$ \\
\hline
\end{tabular}


2.8 Curriculum capability

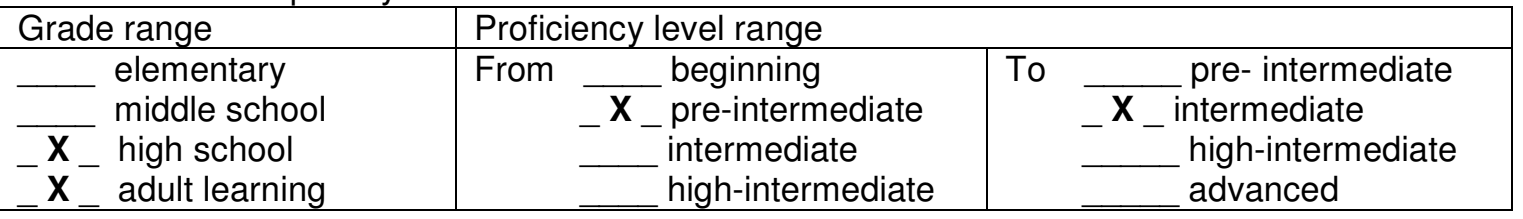

2.9 Method of language teaching claimed by the program

\begin{tabular}{|l|l|}
\hline $\begin{array}{l}\text { The Direct Method } \\
\text { The Natural Approach } \\
\text { Total Physical Response }\end{array}$ & The Audio-lingual Method \\
\hline $\mathbf{X}$ The Communicative Approach \\
\hline
\end{tabular}

2.10 Language skills developed in the program

\begin{tabular}{|c|l|l|l|}
\hline speaking & $-\mathbf{X}_{-}$listening & $\mathbf{X}_{-}$reading & _writing \\
\hline
\end{tabular}

2.11 Type of activities offered by the program

\begin{tabular}{|c|c|c|c|}
\hline $\begin{array}{c}\text { games } \\
\text { quizzes } \\
\text { others }\end{array}$ & $\begin{array}{l}\text { simulation } \\
\text { exploratory }\end{array}$ & \begin{tabular}{|c} 
tutorial \\
text \\
construction
\end{tabular} & $\begin{array}{c}\mathbf{X}_{-} \text {drill and practice } \\
\text { problem solving }\end{array}$ \\
\hline
\end{tabular}

2.12 Orientation of how to use program and its feature

\begin{tabular}{|c|c|}
\hline for the teacher & on the screen \\
\hline for the student & on hard copy documentation \\
\hline $\mathrm{X}_{-}$for both & $\mathrm{X}_{\text {_ on both }}$ \\
\hline
\end{tabular}

2.13 Role of the teacher

\begin{tabular}{|l|l|l|l|}
\hline${ }_{-} X_{-}$instructor & _ facilitator & $-X_{-}$lab manager & _evaluator \\
\hline
\end{tabular}

2.14 Learners interact

\begin{tabular}{|l|l|l|}
\hline _ with one another & _ with the teacher & - \\
\hline
\end{tabular}

2.15 In case learners interact with one another, they can interact in all activities in some activities

2.16 In case learners interact with the teacher, they can interact at any time at the end of the lesson at the end of the activities there's no interaction

\section{CRITICAL ANALYSIS}

For each item, circle the numbers 1 (for low) to 4 (for high) to indicate your judgment of the degree to which the program possesses or demonstrates the feature identified in each item. Circle 0 if the feature is not present in the program. 


\begin{tabular}{|c|c|c|c|c|c|}
\hline \multicolumn{6}{|l|}{ Instructional Attributes } \\
\hline Graphics and sound enhance learning. & 0 & $\begin{array}{l}\text { (low) } \\
1\end{array}$ & 2 & 3 & $\begin{array}{l}\text { (high) } \\
4\end{array}$ \\
\hline $\begin{array}{l}1.2 \text { The animation is effective in minimizing } \\
\text { boredom by motivating learners. }\end{array}$ & 0 & $\begin{array}{l}\text { (low) } \\
1\end{array}$ & 2 & 3 & $\begin{array}{l}\text { (high) } \\
4\end{array}$ \\
\hline 1.3Screen displays are uncluttered. & 0 & $\begin{array}{l}\text { (low) } \\
1\end{array}$ & 2 & 3 & $\begin{array}{l}\text { (high) } \\
4\end{array}$ \\
\hline 1.4 Graphics make information attractive. & 0 & $\begin{array}{l}\text { (low) } \\
1\end{array}$ & 2 & 3 & $\begin{array}{l}\text { (high) } \\
4\end{array}$ \\
\hline $\begin{array}{l}1.5 \text { Graphics help memorization of key } \\
\text { information. }\end{array}$ & 0 & $\begin{array}{l}\text { (low) } \\
1\end{array}$ & 2 & 3 & $\begin{array}{l}\text { (high) } \\
4\end{array}$ \\
\hline $\begin{array}{l}\text { 1.6 The program makes use of authentic texts } \\
\text { and other realia. }\end{array}$ & 0 & $\begin{array}{l}\text { (low) } \\
1\end{array}$ & 2 & 3 & $\begin{array}{l}\text { (high) } \\
4\end{array}$ \\
\hline $\begin{array}{l}\text { 1.7 The program integrates information about } \\
\text { culture/daily situations into the presentations } \\
\text { and activities. }\end{array}$ & 0 & $\begin{array}{ll}\text { (low) } \\
1\end{array}$ & 2 & 3 & $\begin{array}{l}\text { (high) } \\
4\end{array}$ \\
\hline $\begin{array}{l}1.8 \text { Lessons present and practice language } \\
\text { structures in meaningful communicative } \\
\text { contexts. }\end{array}$ & 0 & $\begin{array}{l}\text { (low) } \\
1\end{array}$ & 2 & 3 & $\begin{array}{l}\text { (high) } \\
4\end{array}$ \\
\hline $\begin{array}{l}1.9 \text { Lessons present and practice vocabulary in } \\
\text { meaningful communicative contexts. }\end{array}$ & 0 & $\begin{array}{l}\text { (low) } \\
1\end{array}$ & 2 & 3 & $\begin{array}{l}\text { (high) } \\
4\end{array}$ \\
\hline $\begin{array}{l}1.10 \text { Lessons develop the communicative skills } \\
\text { the program aims to develop. }\end{array}$ & 0 & $\begin{array}{ll}\text { (low) } \\
1\end{array}$ & 2 & 3 & $\begin{array}{l}\text { (high) } \\
4\end{array}$ \\
\hline $\begin{array}{l}1.11 \text { Lessons develop the level of language } \\
\text { proficiency the program aims to develop. }\end{array}$ & 0 & $\begin{array}{ll}\text { (low) } \\
1\end{array}$ & 2 & 3 & $\begin{array}{l}\text { (high) } \\
4\end{array}$ \\
\hline $\begin{array}{l}1.12 \text { The course syllabus reflects a } \\
\text { communicative approach to language } \\
\text { teaching/learning. }\end{array}$ & 0 & $\begin{array}{l}\text { (low) } \\
1\end{array}$ & 2 & 3 & $\begin{array}{l}\text { (high) } \\
4\end{array}$ \\
\hline $\begin{array}{l}1.13 \text { Content selection is determined by } \\
\text { communicative skills and/or themes. }\end{array}$ & 0 & $\begin{array}{ll}\text { (low) } \\
1\end{array}$ & 2 & 3 & $\begin{array}{l}\text { (high) } \\
4\end{array}$ \\
\hline $\begin{array}{l}\text { 1.14 Content is sequenced from simple } \\
\text { communicative functions, such as introducing } \\
\text { oneself, greeting, etc, to complex ones, such } \\
\text { as stating an opinion, disagreeing, etc. }\end{array}$ & 0 & $\begin{array}{l}\text { (low) } \\
1\end{array}$ & 2 & 3 & $\begin{array}{l}\text { (high) } \\
4\end{array}$ \\
\hline 1.15 Content is presented communicatively. & 0 & $\begin{array}{ll}\text { (low) } \\
1\end{array}$ & 2 & 3 & $\begin{array}{l}\text { (high) } \\
4\end{array}$ \\
\hline $\begin{array}{l}\text { 1.16 The program develops the content at } \\
\text { appropriate levels of language proficiency. }\end{array}$ & 0 & $\begin{array}{l}\text { (low) } \\
1\end{array}$ & 2 & 3 & $\begin{array}{l}\text { (high) } \\
4\end{array}$ \\
\hline $\begin{array}{l}1.17 \text { The program content is educationally } \\
\text { relevant and interesting for the learner. }\end{array}$ & 0 & $\begin{array}{l}\text { (low) } \\
1\end{array}$ & 2 & 3 & $\begin{array}{l}\text { (high) } \\
4\end{array}$ \\
\hline $\begin{array}{l}1.18 \text { The program content is appropriate for } \\
\text { intended learners. }\end{array}$ & 0 & $\begin{array}{ll}\text { (low) } \\
1\end{array}$ & 2 & 3 & $\begin{array}{l}\text { (high) } \\
4\end{array}$ \\
\hline $\begin{array}{l}1.19 \text { The program content is applicable to real } \\
\text { life contexts. }\end{array}$ & 0 & $\begin{array}{l}\text { (low) } \\
1\end{array}$ & 2 & 3 & $\begin{array}{l}\text { (high) } \\
4\end{array}$ \\
\hline $\begin{array}{l}\text { 1.20 The program allows learners to work } \\
\text { together in communicative activities. }\end{array}$ & 0 & $\begin{array}{l}\text { (low) } \\
1\end{array}$ & 2 & 3 & $\begin{array}{l}\text { (high) } \\
4\end{array}$ \\
\hline $\begin{array}{l}1.21 \text { The activities allow unplanned and/or } \\
\text { unpredictable responses. }\end{array}$ & 0 & $\begin{array}{ll}\text { (low) } \\
1\end{array}$ & 2 & 3 & $\begin{array}{l}\text { (high) } \\
4\end{array}$ \\
\hline $\begin{array}{l}\text { 1.22 The activities lend themselves to group } \\
\text { discussions. }\end{array}$ & 0 & $\begin{array}{l}\text { (low) } \\
1\end{array}$ & 2 & 3 & $\begin{array}{l}\text { (high) } \\
4\end{array}$ \\
\hline
\end{tabular}




\begin{tabular}{|c|c|c|c|c|c|}
\hline $\begin{array}{l}1.23 \text { The activities aim at developing other } \\
\text { competencies in addition to syntactical and } \\
\text { lexical }\end{array}$ & 0 & $\begin{array}{l}\text { (low) } \\
1\end{array}$ & 2 & 3 & $\begin{array}{l}\text { (high) } \\
4\end{array}$ \\
\hline $\begin{array}{l}1.24 \text { The program allows the teacher to interact } \\
\text { with students while they are doing an activity. }\end{array}$ & 0 & $\begin{array}{l}\text { (low) } \\
1 \\
\end{array}$ & 2 & 3 & $\begin{array}{l}\text { (high) } \\
4\end{array}$ \\
\hline $\begin{array}{l}\text { 1.25 The program provides non-threatening } \\
\text { feedback. }\end{array}$ & 0 & $\begin{array}{l}\text { (low) } \\
1\end{array}$ & 2 & 3 & $\begin{array}{l}\text { (high) } \\
4\end{array}$ \\
\hline $\begin{array}{l}1.26 \text { The program allows learners to repeat an } \\
\text { activity after feedback is provided. }\end{array}$ & 0 & $\begin{array}{l}\text { (low) } \\
1\end{array}$ & 2 & 3 & $\begin{array}{l}\text { (high) } \\
4\end{array}$ \\
\hline $\begin{array}{l}1.27 \text { Activities allow for more than one correct } \\
\text { response. }\end{array}$ & 0 & $\begin{array}{l}\text { (low) } \\
1\end{array}$ & 2 & 3 & $\begin{array}{l}\text { (high) } \\
4\end{array}$ \\
\hline $\begin{array}{l}\text { 1.28 The program provides the students with } \\
\text { feedback that would allow them to correct their } \\
\text { mistakes. }\end{array}$ & 0 & $\begin{array}{l}\text { (low) } \\
1\end{array}$ & 2 & 3 & $\begin{array}{l}\text { (high) } \\
4\end{array}$ \\
\hline
\end{tabular}

\begin{tabular}{|c|c|c|c|c|c|}
\hline \multicolumn{6}{|l|}{ Media Attributes } \\
\hline 2.29 Graphics aid understanding. & 0 & $\begin{array}{ll}\text { (low) } \\
1\end{array}$ & 2 & 3 & $\begin{array}{l}\text { (high) } \\
4\end{array}$ \\
\hline $\begin{array}{l}2.30 \text { The program allows for different routes and } \\
\text { choices for learning. }\end{array}$ & 0 & $\begin{array}{l}\text { (low) } \\
1\end{array}$ & 2 & 3 & $\begin{array}{l}\text { (high) } \\
4\end{array}$ \\
\hline $\begin{array}{l}\text { 2.31 The program allows for review of old } \\
\text { information. }\end{array}$ & 0 & $\begin{array}{l}\text { (low) } \\
1\end{array}$ & 2 & 3 & $\begin{array}{l}\text { (high) } \\
4\end{array}$ \\
\hline $\begin{array}{l}2.32 \text { The program allows branching to new } \\
\text { information. }\end{array}$ & 0 & $\begin{array}{l}\text { (low) } \\
1\end{array}$ & 2 & 3 & $\begin{array}{l}\text { (high) } \\
4\end{array}$ \\
\hline $\begin{array}{l}2.33 \text { The program allows students to select } \\
\text { activities according to their ages. }\end{array}$ & 0 & $\begin{array}{l}\text { (low) } \\
1\end{array}$ & 2 & 3 & $\begin{array}{l}\text { (high) } \\
4\end{array}$ \\
\hline $\begin{array}{l}\text { 2.34 The program allows students to select } \\
\text { activities according to their learning styles. }\end{array}$ & 0 & $\begin{array}{l}\text { (low) } \\
1\end{array}$ & 2 & 3 & $\begin{array}{l}\text { (high) } \\
4\end{array}$ \\
\hline $\begin{array}{l}2.35 \text { The program allows students to select } \\
\text { activities according to their interests. }\end{array}$ & 0 & $\begin{array}{l}\text { (low) } \\
1\end{array}$ & 2 & 3 & $\begin{array}{l}\text { (high) } \\
4\end{array}$ \\
\hline $\begin{array}{l}2.36 \text { The program adapts to the responses } \\
\text { given by the learners, branching to more or less } \\
\text { complicated questions as appropriate. }\end{array}$ & 0 & $\begin{array}{l}\text { (low) } \\
1\end{array}$ & 2 & 3 & $\begin{array}{l}\text { (high) } \\
4\end{array}$ \\
\hline $\begin{array}{l}2.37 \text { The program allows learners to go through } \\
\text { its content at their own pace and rhythm. }\end{array}$ & 0 & $\begin{array}{l}\text { (low) } \\
1\end{array}$ & 2 & 3 & $\begin{array}{l}\text { (high) } \\
4\end{array}$ \\
\hline $\begin{array}{l}2.38 \text { The program prevents learners from } \\
\text { repeating exercises, therefore, minimizing } \\
\text { guessing. }\end{array}$ & 0 & (low) & 2 & 3 & $\begin{array}{l}\text { (high) } \\
4\end{array}$ \\
\hline $\begin{array}{l}\text { 2.39 The program keeps records of learners' } \\
\text { performance to allow them to continue activities } \\
\text { from where they left off. }\end{array}$ & 0 & $\begin{array}{l}\text { (low) } \\
1\end{array}$ & 2 & 3 & $\begin{array}{l}\text { (high) } \\
4\end{array}$ \\
\hline $\begin{array}{l}\text { 2.40 The program keeps track of students' } \\
\text { scores. }\end{array}$ & 0 & $\begin{array}{l}\text { (low) } \\
1\end{array}$ & 2 & 3 & $\begin{array}{l}\text { (high) } \\
4\end{array}$ \\
\hline $\begin{array}{l}2.41 \text { The program provides feedback for both } \\
\text { correct and incorrect answers. The program } \\
\text { provides feedback for both correct and incorrect } \\
\text { answers. }\end{array}$ & 0 & (low) & 2 & 3 & $\begin{array}{l}\text { (high) } \\
4\end{array}$ \\
\hline $\begin{array}{l}2.42 \text { The program gives learners the chance to } \\
\text { correct their errors. }\end{array}$ & 0 & $\begin{array}{ll}\text { (low) } \\
1\end{array}$ & 2 & 3 & $\begin{array}{l}\text { (high) } \\
4\end{array}$ \\
\hline
\end{tabular}




\begin{tabular}{|c|c|c|c|c|c|}
\hline $\begin{array}{l}\text { 2.43 The program effectively signals the } \\
\text { mistakes before providing the right answers. }\end{array}$ & 0 & $\begin{array}{l}\text { (low) } \\
1\end{array}$ & 2 & 3 & $\begin{array}{l}\text { (high) } \\
4\end{array}$ \\
\hline $\begin{array}{l}\text { 2.44 The program effectively specifies different } \\
\text { types of errors, such as differences between a } \\
\text { syntactic error and an incorrect word choice. }\end{array}$ & 0 & $\begin{array}{l}\text { (low) } \\
1\end{array}$ & 2 & 3 & $\begin{array}{l}\text { (high) } \\
4\end{array}$ \\
\hline \multicolumn{6}{|l|}{ Sub-total = $26(40.62 \%)$} \\
\hline \multicolumn{6}{|l|}{ User-Friendly Attributes } \\
\hline $\begin{array}{l}\text { 3.45 Menu items are understandable and } \\
\text { descriptive. }\end{array}$ & 0 & $\begin{array}{ll}\text { (low) } \\
1\end{array}$ & 2 & 3 & $\begin{array}{l}\text { (high) } \\
4\end{array}$ \\
\hline $\begin{array}{l}\text { 3.46 The commands and instructions for the } \\
\text { activities are clear and objective. }\end{array}$ & 0 & $\begin{array}{l}\text { (low) } \\
1\end{array}$ & 2 & 3 & $\begin{array}{l}\text { (high) } \\
4\end{array}$ \\
\hline $\begin{array}{l}\text { 3.47 The program gives the learners effective } \\
\text { clues to clarify their doubts about its use. }\end{array}$ & 0 & $\begin{array}{l}\text { (low) } \\
1\end{array}$ & 2 & 3 & $\begin{array}{l}\text { (high) } \\
4\end{array}$ \\
\hline $\begin{array}{l}3.48 \text { Each screen uses text and } \\
\text { graphic/animation to make a particular teaching } \\
\text { point clear. }\end{array}$ & 0 & $\begin{array}{l}\text { (low) } \\
1\end{array}$ & 2 & 3 & $\begin{array}{l}\text { (high) } \\
4\end{array}$ \\
\hline $\begin{array}{l}\text { 3.49 The program is effectively integrated with } \\
\text { other technological resources (such as } \\
\text { dictionaries on the web, grammar on line, etc) } \\
\text { as the learner uses it. }\end{array}$ & 0 & $\begin{array}{l}\text { (low) } \\
1\end{array}$ & 2 & 3 & $\begin{array}{l}\text { (high) } \\
4\end{array}$ \\
\hline $\begin{array}{l}3.50 \text { Icons, buttons and menus allow learners to } \\
\text { readily search for additional information while } \\
\text { doing an activity. }\end{array}$ & 0 & $\begin{array}{l}\text { (low) } \\
1\end{array}$ & 2 & 3 & $\begin{array}{l}\text { (high) } \\
4\end{array}$ \\
\hline $\begin{array}{l}\text { 3.51 Buttons, icons or menu items make Help or } \\
\text { Hint-type options easily accessible. }\end{array}$ & 0 & $\begin{array}{l}\text { (low) } \\
1\end{array}$ & 2 & 3 & $\begin{array}{l}\text { (high) } \\
4\end{array}$ \\
\hline $\begin{array}{l}\text { 3.52 The program arouses sensory and } \\
\text { cognitive curiosity }\end{array}$ & 0 & $\begin{array}{ll}\text { (low) } \\
1\end{array}$ & 2 & 3 & $\begin{array}{l}\text { (high) } \\
4\end{array}$ \\
\hline $\begin{array}{l}\text { 3.53 The program maintains attention } \\
\text { throughout the lesson. }\end{array}$ & 0 & $\begin{array}{l}\text { (low) } \\
1\end{array}$ & 2 & 3 & $\begin{array}{l}\text { (high) } \\
4\end{array}$ \\
\hline $\begin{array}{l}\text { 3.54 The use of animation invites learners' } \\
\text { reaction or input. }\end{array}$ & 0 & $\begin{array}{l}\text { (low) } \\
1\end{array}$ & 2 & 3 & $\begin{array}{l}\text { (high) } \\
4\end{array}$ \\
\hline $\begin{array}{l}\text { 3.55 The program gives teachers a clear } \\
\text { explanation of its purposes and methodological } \\
\text { orientation. }\end{array}$ & 0 & $\begin{array}{l}\text { (low) } \\
1\end{array}$ & 2 & 3 & $\begin{array}{l}\text { (high) } \\
4\end{array}$ \\
\hline \multicolumn{6}{|l|}{ Sub-total $=20(45.45 \%)$} \\
\hline Total $=102(46.36 \%)$ & & & & & \\
\hline
\end{tabular}

Sub-total of ratings for Instructional Attributes ........................

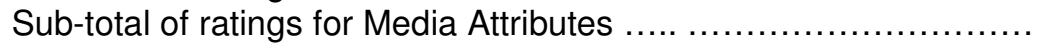

$56(50 \%)$

Sub-total of ratings for User-Friendly Attributes

$26(40.62)$

$20(46.36 \%)$

Total rating

$102(46.36 \%)$ 


\section{ESL/EFL SOFTWARE EVALUATION INSTRUMENT}

Title of the program: Longman English Interactive

Publisher: Pearson Longman Education

\section{DESCRIPTIVE ANALYSIS}

Please place a checkmark next to the item that best describes the program and/or its features.

\section{TECHNICAL FEATURES}

1.1 Components of the program:

\begin{tabular}{|c|l|l|}
\hline \begin{tabular}{c} 
Number of CD's: $\begin{array}{c}\text { Per level } \\
\text { Total }\end{array}$ \\
\hline
\end{tabular} & Teacher's guide_X_Yes_N_No & $\begin{array}{l}\text { Support materials_X_Yes_No } \\
\text { What type? Course textbook " } \\
\text { Communication Companion }\end{array}$ \\
\hline
\end{tabular}

1.2 Platform

\begin{tabular}{|l|l|}
\hline Mac_Mhz MB of RAM & $\begin{array}{l}\text { Windows 98, XP, 2000 } \\
400+\text { Mhz 64 + MB of RAM }\end{array}$ \\
\hline
\end{tabular}

1.3 Tools

\begin{tabular}{|l|l|l|}
\hline- X_ Word processing & Xnline forums \\
Online collaboration & $-X_{-}$Web browsing & E-mail \\
\hline & - Others \\
\hline
\end{tabular}

Other technological resources integrated into the program: dictionaries on the web grammar on line

X_other web sites
none

1.5 Directions for use:

\begin{tabular}{|l|l|l|}
\hline X_are on the screen & X_ are in the documentation & user $_{-}$can be skipped at option of \\
\hline
\end{tabular}

\section{PEDAGOGICAL ORIENTATION}

2.6 Program's theory of language

\begin{tabular}{|c|l|l|}
\hline structural & X_functional & interactional \\
\hline
\end{tabular}

2.7 Type of program

\begin{tabular}{|l|l|l|l|}
\hline $\begin{array}{l}\text { X_remediation } \\
\text { X_enrichment } \\
\text {-X_tutoring }\end{array}$ & $\begin{array}{c}\text { X_demonstration } \\
\text { assessment }\end{array}$ & $\begin{array}{l}\text { education } \\
\text { game } \\
\text { collaborative } \\
\text { projects }\end{array}$ & $\begin{array}{l}\text { problem solving } \\
\text { - X_ drill and practice } \\
\text { X_simulation }\end{array}$ \\
\hline
\end{tabular}

2.8 Curriculum capability

\begin{tabular}{|c|l|l|}
\hline Grade range & Proficiency level range \\
\hline elementary & From _ X_beginning & To _ _ pre- intermediate \\
\hline
\end{tabular}




\begin{tabular}{|c|c|c|}
\hline $\begin{array}{ll} & \text { middle school } \\
\mathrm{X} \text { _ high school } \\
\mathrm{X} \quad \text { adult learning }\end{array}$ & $\begin{array}{l}\text { pre-intermediate } \\
\text { intermediate } \\
\text { high-intermediate }\end{array}$ & $\begin{array}{c}\text { intermediate } \\
\mathrm{X} \text { high-intermediate } \\
\text { advanced }\end{array}$ \\
\hline
\end{tabular}

2.9 Method of language teaching claimed by the program

\begin{tabular}{|l|l|}
\hline $\begin{array}{l}\text { The Direct Method } \\
\text { The Natural Approach } \\
\text { Total Physical Response }\end{array}$ & $-\mathrm{X}_{-}$The Audio-lingual Method \\
\hline
\end{tabular}

2.10 Language skills developed in the program

\begin{tabular}{|l|l|l|l|}
\hline _X_speaking & _X_listening & _X_reading & _X_writing \\
\hline
\end{tabular}

2.11 Type of activities offered by the program

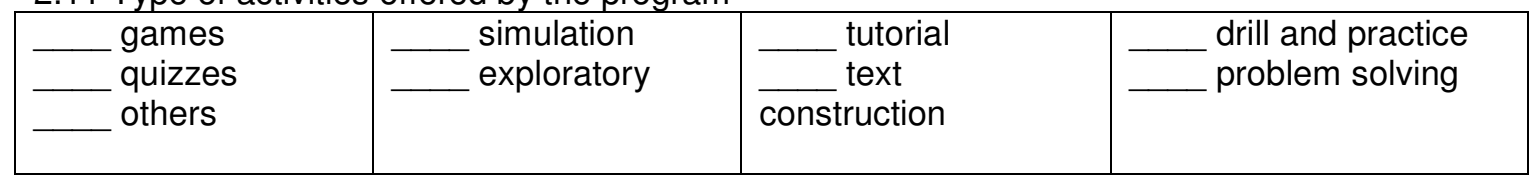

2.12 Orientation of how to use program and its feature

\begin{tabular}{|c|c|}
\hline for the teacher & on the screen \\
\hline for the student & on hard copy documentation \\
\hline $\mathrm{X}$ for both & $\mathrm{X}$ _ on both \\
\hline
\end{tabular}

2.13 Role of the teacher

\begin{tabular}{|l|l|l|l|}
\hline X_ instructor & _ facilitator & _X_lab manager & _ evaluator \\
\hline
\end{tabular}

2.14 Learners interact

\begin{tabular}{|l|l|l|}
\hline _ with one another & _ with the teacher & X_ with neither \\
\hline
\end{tabular}

2.15 In case learners interact with one another, they can interact

\begin{tabular}{|l|l|}
\hline in all activities & in some activities \\
\hline
\end{tabular}

2.16 In case learners interact with the teacher, they can interact at any time at the end of the lesson at the end of the activities there's no interaction

\section{$\underline{\text { CRITICAL ANALYSIS }}$}

For each item, circle the numbers 1 (for low) to 4 (for high) to indicate your judgment of the degree to which the program possesses or demonstrates the feature identified in each item. Circle 0 if the feature is not present in the program. 


\begin{tabular}{|c|c|c|c|c|c|}
\hline \multicolumn{6}{|l|}{ Instructional Attributes } \\
\hline Graphics and sound enhance learning. & 0 & $\begin{array}{l}\text { (low) } \\
1\end{array}$ & 2 & 3 & $\begin{array}{l}\text { (high) } \\
4\end{array}$ \\
\hline $\begin{array}{l}1.2 \text { The animation is effective in minimizing } \\
\text { boredom by motivating learners. }\end{array}$ & 0 & $\begin{array}{ll}\text { (low) } \\
1\end{array}$ & 2 & 3 & $\begin{array}{l}\text { (high) } \\
4\end{array}$ \\
\hline 1.3Screen displays are uncluttered. & 0 & $\begin{array}{l}\text { (low) } \\
1\end{array}$ & 2 & 3 & $\begin{array}{l}\text { (high) } \\
4\end{array}$ \\
\hline 1.4 Graphics make information attractive. & 0 & $\begin{array}{l}\text { (low) } \\
1\end{array}$ & 2 & 3 & $\begin{array}{l}\text { (high) } \\
4\end{array}$ \\
\hline $\begin{array}{l}1.5 \text { Graphics help memorization of key } \\
\text { information. }\end{array}$ & 0 & $\begin{array}{l}\text { (low) } \\
1\end{array}$ & 2 & 3 & $\begin{array}{l}\text { (high) } \\
4\end{array}$ \\
\hline $\begin{array}{l}\text { 1.6 The program makes use of authentic } \\
\text { texts and other realia. }\end{array}$ & 0 & $\begin{array}{l}\text { (low) } \\
1\end{array}$ & 2 & 3 & $\begin{array}{l}\text { (high) } \\
4\end{array}$ \\
\hline $\begin{array}{l}1.7 \text { The program integrates information about } \\
\text { culture/daily situations into the presentations } \\
\text { and activities. }\end{array}$ & 0 & $\begin{array}{l}\text { (low) } \\
1\end{array}$ & 2 & 3 & $\begin{array}{l}\text { (high) } \\
4\end{array}$ \\
\hline $\begin{array}{l}1.8 \text { Lessons present and practice language } \\
\text { structures in meaningful communicative } \\
\text { contexts. }\end{array}$ & 0 & $\begin{array}{l}\text { (low) } \\
1\end{array}$ & 2 & 3 & $\begin{array}{l}\text { (high) } \\
4\end{array}$ \\
\hline $\begin{array}{l}\text { 1.9 Lessons present and practice vocabulary } \\
\text { in meaningful communicative contexts. }\end{array}$ & 0 & $\begin{array}{ll}\text { (low) } \\
1\end{array}$ & 2 & 3 & $\begin{array}{l}\text { (high) } \\
4\end{array}$ \\
\hline $\begin{array}{l}\text { 1.10 Lessons develop the communicative } \\
\text { skills the program aims to develop. }\end{array}$ & 0 & $\begin{array}{ll}\text { (low) } \\
1\end{array}$ & 2 & 3 & $\begin{array}{l}\text { (high) } \\
4\end{array}$ \\
\hline $\begin{array}{l}1.11 \text { Lessons develop the level of language } \\
\text { proficiency the program aims to develop. }\end{array}$ & 0 & $\begin{array}{ll}\text { (low) } \\
1\end{array}$ & 2 & 3 & $\begin{array}{l}\text { (high) } \\
4\end{array}$ \\
\hline $\begin{array}{l}1.12 \text { The course syllabus reflects a } \\
\text { communicative approach to language } \\
\text { teaching/learning. }\end{array}$ & 0 & $\begin{array}{l}\text { (low) } \\
1\end{array}$ & 2 & 3 & $\begin{array}{l}\text { (high) } \\
4\end{array}$ \\
\hline $\begin{array}{l}1.13 \text { Content selection is determined by } \\
\text { communicative skills and/or themes. }\end{array}$ & 0 & $\begin{array}{l}\text { (low) } \\
1\end{array}$ & 2 & 3 & $\begin{array}{l}\text { (high) } \\
4\end{array}$ \\
\hline $\begin{array}{l}1.14 \text { Content is sequenced from simple } \\
\text { communicative functions, such as introducing } \\
\text { oneself, greeting, etc, to complex ones, such } \\
\text { as stating an opinion, disagreeing, etc. }\end{array}$ & 0 & $\begin{array}{l}\text { (low) } \\
1\end{array}$ & 2 & 3 & $\begin{array}{l}\text { (high) } \\
4\end{array}$ \\
\hline 1.15 Content is presented communicatively. & 0 & $\begin{array}{l}\text { (low) } \\
1\end{array}$ & 2 & 3 & $\begin{array}{l}\text { (high) } \\
4\end{array}$ \\
\hline $\begin{array}{l}1.16 \text { The program develops the content at } \\
\text { appropriate levels of language proficiency. }\end{array}$ & 0 & $\begin{array}{l}\text { (low) } \\
1\end{array}$ & 2 & 3 & $\begin{array}{l}\text { (high) } \\
4\end{array}$ \\
\hline $\begin{array}{l}1.17 \text { The program content is educationally } \\
\text { relevant and interesting for the learner. }\end{array}$ & 0 & $\begin{array}{l}\text { (low) } \\
1\end{array}$ & 2 & 3 & $\begin{array}{l}\text { (high) } \\
4\end{array}$ \\
\hline $\begin{array}{l}\text { 1.18 The program content is appropriate for } \\
\text { intended learners. }\end{array}$ & 0 & $\begin{array}{ll}\text { (low) } \\
1\end{array}$ & 2 & 3 & $\begin{array}{l}\text { (high) } \\
4\end{array}$ \\
\hline $\begin{array}{l}1.19 \text { The program content is applicable to } \\
\text { real life contexts. }\end{array}$ & 0 & $\begin{array}{l}\text { (low) } \\
1\end{array}$ & 2 & 3 & $\begin{array}{l}\text { (high) } \\
4\end{array}$ \\
\hline $\begin{array}{l}1.20 \text { The program allows learners to work } \\
\text { together in communicative activities. }\end{array}$ & 0 & $\begin{array}{ll}\text { (low) } \\
1\end{array}$ & 2 & 3 & $\begin{array}{l}\text { (high) } \\
4\end{array}$ \\
\hline $\begin{array}{l}1.21 \text { The activities allow unplanned and/or } \\
\text { unpredictable responses. }\end{array}$ & 0 & $\begin{array}{l}\text { (low) } \\
1\end{array}$ & 2 & 3 & $\begin{array}{l}\text { (high) } \\
4\end{array}$ \\
\hline $\begin{array}{l}\text { 1.22 The activities lend themselves to group } \\
\text { discussions. }\end{array}$ & 0 & $\begin{array}{l}\text { (low) } \\
1\end{array}$ & 2 & 3 & $\begin{array}{l}\text { (high) } \\
4\end{array}$ \\
\hline $\begin{array}{l}1.23 \text { The activities aim at developing other } \\
\text { competencies in addition to syntactical and } \\
\text { lexical }\end{array}$ & 0 & $\begin{array}{l}\text { (low) } \\
1\end{array}$ & 2 & 3 & $\begin{array}{l}\text { (high) } \\
4\end{array}$ \\
\hline
\end{tabular}




\begin{tabular}{|c|c|c|c|c|c|}
\hline $\begin{array}{l}1.24 \text { The program allows the teacher to } \\
\text { interact with students while they are doing an } \\
\text { activity. }\end{array}$ & 0 & $\begin{array}{l}\text { (low) } \\
1\end{array}$ & 2 & 3 & $\begin{array}{l}\text { (high) } \\
4\end{array}$ \\
\hline $\begin{array}{l}\text { 1.25 The program provides non-threatening } \\
\text { feedback. }\end{array}$ & 0 & $\begin{array}{l}\text { (low) } \\
1\end{array}$ & 2 & 3 & $\begin{array}{l}\text { (high) } \\
4\end{array}$ \\
\hline $\begin{array}{l}1.26 \text { The program allows learners to repeat } \\
\text { an activity after feedback is provided. }\end{array}$ & 0 & $\begin{array}{l}\text { (low) } \\
1\end{array}$ & 2 & 3 & $\begin{array}{l}\text { (high) } \\
4\end{array}$ \\
\hline $\begin{array}{l}1.27 \text { Activities allow for more than one } \\
\text { correct response. }\end{array}$ & 0 & $\begin{array}{l}\text { (low) } \\
1 \\
\end{array}$ & 2 & 3 & $\begin{array}{l}\text { (high) } \\
4\end{array}$ \\
\hline $\begin{array}{l}1.28 \text { The program provides the students with } \\
\text { feedback that would allow them to correct } \\
\text { their mistakes. }\end{array}$ & 0 & $\begin{array}{l}\text { (low) } \\
1\end{array}$ & 2 & 3 & $\begin{array}{l}\text { (high) } \\
4\end{array}$ \\
\hline
\end{tabular}

\begin{tabular}{|c|c|c|c|c|c|}
\hline \multicolumn{6}{|l|}{ Media Attributes } \\
\hline 2.29 Graphics aid understanding. & 0 & $\begin{array}{l}\text { (low) } \\
1\end{array}$ & 2 & 3 & $\begin{array}{l}\text { (high) } \\
4\end{array}$ \\
\hline $\begin{array}{l}\text { 2.30 The program allows for different routes } \\
\text { and choices for learning. }\end{array}$ & 0 & $\begin{array}{l}\text { (low) } \\
1\end{array}$ & 2 & 3 & $\begin{array}{l}\text { (high) } \\
4\end{array}$ \\
\hline $\begin{array}{l}\text { 2.31 The program allows for review of old } \\
\text { information. }\end{array}$ & 0 & $\begin{array}{l}\text { (low) } \\
1\end{array}$ & 2 & 3 & $\begin{array}{l}\text { (high) } \\
4\end{array}$ \\
\hline $\begin{array}{l}2.32 \text { The program allows branching to new } \\
\text { information. }\end{array}$ & 0 & $\begin{array}{l}\text { (low) } \\
1\end{array}$ & 2 & 3 & $\begin{array}{l}\text { (high) } \\
4\end{array}$ \\
\hline $\begin{array}{l}2.33 \text { The program allows students to select } \\
\text { activities according to their ages. }\end{array}$ & 0 & $\begin{array}{l}\text { (low) } \\
1\end{array}$ & 2 & 3 & $\begin{array}{l}\text { (high) } \\
4\end{array}$ \\
\hline $\begin{array}{l}2.34 \text { The program allows students to select } \\
\text { activities according to their learning styles. }\end{array}$ & 0 & $\begin{array}{l}\text { (low) } \\
1\end{array}$ & 2 & 3 & $\begin{array}{l}\text { (high) } \\
4\end{array}$ \\
\hline $\begin{array}{l}2.35 \text { The program allows students to select } \\
\text { activities according to their interests. }\end{array}$ & 0 & $\begin{array}{l}\text { (low) } \\
1\end{array}$ & 2 & 3 & $\begin{array}{l}\text { (high) } \\
4\end{array}$ \\
\hline $\begin{array}{l}2.36 \text { The program adapts to the responses } \\
\text { given by the learners, branching to more or } \\
\text { less complicated questions as appropriate. }\end{array}$ & 0 & $\begin{array}{l}\text { (low) } \\
1\end{array}$ & 2 & 3 & $\begin{array}{l}\text { (high) } \\
4\end{array}$ \\
\hline $\begin{array}{l}2.37 \text { The program allows learners to go } \\
\text { through its content at their own pace and } \\
\text { rhythm. }\end{array}$ & 0 & $\begin{array}{l}\text { (low) } \\
1\end{array}$ & 2 & 3 & $\begin{array}{l}\text { (high) } \\
4\end{array}$ \\
\hline $\begin{array}{l}2.38 \text { The program prevents learners from } \\
\text { repeating exercises, therefore, minimizing } \\
\text { guessing. }\end{array}$ & 0 & $\begin{array}{l}\text { (low) } \\
1\end{array}$ & 2 & 3 & $\begin{array}{l}\text { (high) } \\
4\end{array}$ \\
\hline $\begin{array}{l}\text { 2.39 The program keeps records of learners' } \\
\text { performance to allow them to continue } \\
\text { activities from where they left off. }\end{array}$ & 0 & $\begin{array}{l}\text { (low) } \\
1\end{array}$ & 2 & 3 & $\begin{array}{l}\text { (high) } \\
4\end{array}$ \\
\hline $\begin{array}{l}2.40 \text { The program keeps track of students' } \\
\text { scores. }\end{array}$ & 0 & $\begin{array}{l}\text { (low) } \\
1\end{array}$ & 2 & 3 & $\begin{array}{l}\text { (high) } \\
4\end{array}$ \\
\hline $\begin{array}{l}2.41 \text { The program provides feedback for both } \\
\text { correct and incorrect answers. The program } \\
\text { provides feedback for both correct and } \\
\text { incorrect answers. }\end{array}$ & 0 & $\begin{array}{l}\text { (low) } \\
1\end{array}$ & 2 & 3 & $\begin{array}{l}\text { (high) } \\
4\end{array}$ \\
\hline $\begin{array}{l}2.42 \text { The program gives learners the chance } \\
\text { to correct their errors. }\end{array}$ & 0 & $\begin{array}{l}\text { (low) } \\
1\end{array}$ & 2 & 3 & $\begin{array}{l}\text { (high) } \\
4\end{array}$ \\
\hline
\end{tabular}




\begin{tabular}{|c|c|c|c|c|c|}
\hline $\begin{array}{l}\text { 2.43 The program effectively signals the } \\
\text { mistakes before providing the right answers. }\end{array}$ & 0 & $\begin{array}{l}\text { (low) } \\
1\end{array}$ & 2 & 3 & $\begin{array}{l}\text { (high) } \\
4\end{array}$ \\
\hline $\begin{array}{l}\text { 2.44 The program effectively specifies } \\
\text { different types of errors, such as differences } \\
\text { between a syntactic error and an incorrect } \\
\text { word choice. }\end{array}$ & 0 & $\begin{array}{l}\text { (low) } \\
1\end{array}$ & 2 & 3 & $\begin{array}{l}\text { (high) } \\
4\end{array}$ \\
\hline \multicolumn{6}{|l|}{ Sub-total $=27(42.18 \%)$} \\
\hline \multicolumn{6}{|l|}{ User-Friendly Attributes } \\
\hline $\begin{array}{l}\text { 3.45 Menu items are understandable and } \\
\text { descriptive. }\end{array}$ & 0 & $\begin{array}{l}\text { (low) } \\
1\end{array}$ & 2 & 3 & $\begin{array}{l}\text { (high) } \\
4\end{array}$ \\
\hline $\begin{array}{l}\text { 3.46 The commands and instructions for the } \\
\text { activities are clear and objective. }\end{array}$ & 0 & $\begin{array}{ll}\text { (low) } \\
1\end{array}$ & 2 & 3 & $\begin{array}{l}\text { (high) } \\
4\end{array}$ \\
\hline $\begin{array}{l}\text { 3.47 The program gives the learners effective } \\
\text { clues to clarify their doubts about its use. }\end{array}$ & 0 & $\begin{array}{ll}\text { (low) } \\
1\end{array}$ & 2 & 3 & $\begin{array}{l}\text { (high) } \\
4\end{array}$ \\
\hline $\begin{array}{l}3.48 \text { Each screen uses text and } \\
\text { graphic/animation to make a particular } \\
\text { teaching point clear. }\end{array}$ & 0 & $\begin{array}{l}\text { (low) } \\
1\end{array}$ & 2 & 3 & $\begin{array}{l}\text { (high) } \\
4\end{array}$ \\
\hline $\begin{array}{l}\text { 3.49 The program is effectively integrated with } \\
\text { other technological resources (such as } \\
\text { dictionaries on the web, grammar on line, etc) } \\
\text { as the learner uses it. }\end{array}$ & 0 & $\begin{array}{l}\text { (low) } \\
1\end{array}$ & 2 & 3 & $\begin{array}{l}\text { (high) } \\
4\end{array}$ \\
\hline $\begin{array}{l}3.50 \text { lcons, buttons and menus allow learners } \\
\text { to readily search for additional information } \\
\text { while doing an activity. }\end{array}$ & 0 & $\begin{array}{l}\text { (low) } \\
1\end{array}$ & 2 & 3 & $\begin{array}{l}\text { (high) } \\
4\end{array}$ \\
\hline $\begin{array}{l}3.51 \text { Buttons, icons or menu items make Help } \\
\text { or Hint-type options easily accessible. }\end{array}$ & 0 & $\begin{array}{ll}\text { (low) } \\
1\end{array}$ & 2 & 3 & $\begin{array}{l}\text { (high) } \\
4\end{array}$ \\
\hline $\begin{array}{l}\text { 3.52 The program arouses sensory and } \\
\text { cognitive curiosity }\end{array}$ & 0 & $\begin{array}{l}\text { (low) } \\
1\end{array}$ & 2 & 3 & $\begin{array}{l}\text { (high) } \\
4\end{array}$ \\
\hline $\begin{array}{l}3.53 \text { The program maintains attention } \\
\text { throughout the lesson. }\end{array}$ & 0 & $\begin{array}{l}\text { (low) } \\
1\end{array}$ & 2 & 3 & $\begin{array}{l}\text { (high) } \\
4\end{array}$ \\
\hline $\begin{array}{l}3.54 \text { The use of animation invites learners' } \\
\text { reaction or input. }\end{array}$ & 0 & $\begin{array}{l}\text { (low) } \\
1\end{array}$ & 2 & 3 & $\begin{array}{l}\text { (high) } \\
4\end{array}$ \\
\hline $\begin{array}{l}3.55 \text { The program gives teachers a clear } \\
\text { explanation of its purposes and } \\
\text { methodological orientation. }\end{array}$ & 0 & $\begin{array}{l}\text { (low) } \\
1\end{array}$ & 2 & 3 & $\begin{array}{l}\text { (high) } \\
4\end{array}$ \\
\hline \multicolumn{6}{|l|}{ Sub-total $=33(75 \%)$} \\
\hline Total & & & & & \\
\hline
\end{tabular}

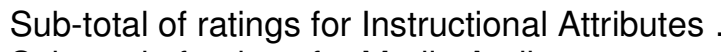

$82(73.21 \%)$

Sub-total of ratings for Media Attributes

$27(42.18 \%)$

Sub-total of ratings for User-Friendly Attributes

$33(75 \%)$

Total rating

$142(64.54 \%)$ 


\section{ESL/EFL SOFTWARE EVALUATION INSTRUMENT}

Title of the program: Making Connections

Publisher: Heinle \& Heinle

\section{DESCRIPTIVE ANALYSIS}

Please place a checkmark next to the item that best describes the program and/or its features.

\section{TECHNICAL FEATURES}

1.1 Components of the program:

\begin{tabular}{|c|c|c|}
\hline \begin{tabular}{|c|} 
Number of CD's \\
1 Per level \\
3 Total
\end{tabular} & $\begin{array}{l}\text { Teacher's guide_X_Yes } \\
\text { No }\end{array}$ & $\begin{array}{l}\text { Support materials __ Yes } \\
\text { X_No } \\
\text { What type? }\end{array}$ \\
\hline
\end{tabular}

1.2 Platform

\begin{tabular}{|c|l|}
\hline $\begin{array}{l}\text { Mac Comprehensive } \\
\text { Mhz }\end{array}$ & $\begin{array}{l}\text { Windows Comprehensive } \\
\text { MBz of RAM }\end{array}$ \\
\hline
\end{tabular}

1.3 Tools

\begin{tabular}{|l|l|l|}
\hline $\begin{array}{l}\text { Word processing } \\
\text { Online forums } \\
\text { Online collaboration }\end{array}$ & $\begin{array}{l}\text { Speech recognition } \\
\text { Web browsing } \\
\text { Encyclopedia or compendia }\end{array}$ & \begin{tabular}{l} 
Others \\
\hline
\end{tabular} \\
\hline
\end{tabular}

1.4 Other technological resources integrated into the program: \begin{tabular}{l|l} 
dictionaries on the web & grammar on line
\end{tabular} other web sites $\quad$ X_none

1.5 Directions for use: are on the screen $\quad \mathbf{X}_{-}$are in the documentation $\quad$ _ can be skipped at option of user

\section{PEDAGOGICAL ORIENTATION}

2.6 Program's theory of language

\begin{tabular}{|c|l|l|}
\hline structural & $\mathbf{X}$ _functional & interactional \\
\hline
\end{tabular}

2.7 Type of program

\begin{tabular}{|c|c|c|c|}
\hline $\begin{array}{c}\mathbf{X} \text { _remediation } \\
\text { enrichment } \\
\text { tutoring }\end{array}$ & $\begin{array}{l}\text { demonstration } \\
\text { assessment }\end{array}$ & $\begin{array}{c}\overline{\text { game }}^{\text {education }} \\
\text { collaborative } \\
\text { projects }\end{array}$ & $\begin{array}{c}\text { problem solving } \\
\mathbf{X} \text { _drill and practice } \\
\text { simulation }\end{array}$ \\
\hline
\end{tabular}

2.8 Curriculum capability

\begin{tabular}{|c|l|l|}
\hline Grade range & Proficiency level range & \\
\hline elementary & From $\quad \mathbf{X}$ beginning & To _ pre- intermediate \\
\hline
\end{tabular}




\begin{tabular}{|l|l|l|}
\hline $\begin{array}{c}\text { middle school } \\
\mathbf{X} \text { high school } \\
\mathbf{X} \text { - adult learning }\end{array}$ & pre-intermediate & intermediate \\
\hline
\end{tabular}

2.9 Method of language teaching claimed by the program

\begin{tabular}{|l|l|}
\hline $\begin{array}{l}\text { The Direct Method } \\
\text { The Natural Approach } \\
\text { Total Physical Response }\end{array}$ & $\mathbf{X}$ The Audio-lingual Method \\
\hline
\end{tabular}

2.10 Language skills developed in the program

\begin{tabular}{|l|l|l|l|}
\hline - X_speaking & - X_listening & _ X_reading & - X_writing \\
\hline
\end{tabular}

2.11 Type of activities offered by the program

\begin{tabular}{|l|l|l|l|}
\hline $\begin{array}{l}\text { games } \\
\text { quizzes } \\
\text { others }\end{array}$ & $\begin{array}{l}\text { simulation } \\
\text { exploratory }\end{array}$ & $\begin{array}{l}\text { - } \mathbf{X}_{-} \text {tutorial } \\
\text { construction }\end{array}$ & $\begin{array}{l}\text { X_drill and practice } \\
\text { problem solving }\end{array}$ \\
\hline
\end{tabular}

2.12 Orientation of how to use program and its feature

\begin{tabular}{|c|c|}
\hline $\mathbf{X}$ for the teacher & on the screen \\
\hline for the student & $\mathbf{X}$ _ on hard copy documentation \\
\hline for both & on both \\
\hline
\end{tabular}

2.13 Role of the teacher

\begin{tabular}{|l|l|l|l|}
\hline - X_ instructor & _ facilitator & X_lab manager & _ evaluator \\
\hline
\end{tabular}

2.14 Learners interact

\begin{tabular}{|l|l|l|}
\hline _ with one another & _ with the teacher & X_with neither \\
\hline
\end{tabular}

2.15 In case learners interact with one another, they can interact

\begin{tabular}{|l|l|}
2.15 In case learners interact with one another, they can interact \\
\hline in all activities & - in some activities \\
\hline
\end{tabular}

2.16 In case learners interact with the teacher, they can interact

\begin{tabular}{|l|l|}
\hline $\begin{array}{l}\text { at any time } \\
\text { at the end of the lesson }\end{array}$ & at the end of the activities \\
& there's no interaction \\
\hline
\end{tabular}

\section{CRITICAL ANALYSIS}

For each item, circle the numbers 1 (for low) to 4 (for high) to indicate your judgment of the degree to which the program possesses or demonstrates the feature identified in each item. Circle 0 if the feature is not present in the program. 


\begin{tabular}{|c|c|c|c|c|c|}
\hline 1.1Graphics and sound enhance learning. & 0 & $\begin{array}{l}\text { (low) } \\
1\end{array}$ & 2 & 3 & $\begin{array}{l}\text { (high) } \\
4\end{array}$ \\
\hline $\begin{array}{l}1.2 \text { The animation is effective in minimizing } \\
\text { boredom by motivating learners. }\end{array}$ & 0 & $\begin{array}{l}\text { (low) } \\
1\end{array}$ & 2 & 3 & $\begin{array}{l}\text { (high) } \\
4\end{array}$ \\
\hline 1.3Screen displays are uncluttered. & 0 & $\begin{array}{l}\text { (low) } \\
1\end{array}$ & 2 & 3 & $\begin{array}{l}\text { (high) } \\
4\end{array}$ \\
\hline 1.4 Graphics make information attractive. & 0 & $\begin{array}{l}\text { (low) } \\
1\end{array}$ & 2 & 3 & $\begin{array}{l}\text { (high) } \\
4\end{array}$ \\
\hline $\begin{array}{l}1.5 \text { Graphics help memorization of key } \\
\text { information. }\end{array}$ & 0 & $\begin{array}{l}\text { (low) } \\
1\end{array}$ & 2 & 3 & $\begin{array}{l}\text { (high) } \\
4\end{array}$ \\
\hline $\begin{array}{l}1.6 \text { The program makes use of authentic texts } \\
\text { and other realia. }\end{array}$ & 0 & $\begin{array}{l}\text { (low) } \\
1\end{array}$ & 2 & 3 & $\begin{array}{l}\text { (high) } \\
4\end{array}$ \\
\hline $\begin{array}{l}1.7 \text { The program integrates information about } \\
\text { culture/daily situations into the presentations } \\
\text { and activities. }\end{array}$ & 0 & $\begin{array}{l}\text { (low) } \\
1\end{array}$ & 2 & 3 & $\begin{array}{l}\text { (high) } \\
4\end{array}$ \\
\hline $\begin{array}{l}1.8 \text { Lessons present and practice language } \\
\text { structures in meaningful communicative } \\
\text { contexts. }\end{array}$ & 0 & $\begin{array}{l}\text { (low) } \\
1\end{array}$ & 2 & 3 & $\begin{array}{l}\text { (high) } \\
4\end{array}$ \\
\hline $\begin{array}{l}1.9 \text { Lessons present and practice vocabulary in } \\
\text { meaningful communicative contexts. }\end{array}$ & 0 & $\begin{array}{l}\text { (low) } \\
1\end{array}$ & 2 & 3 & $\begin{array}{l}\text { (high) } \\
4\end{array}$ \\
\hline $\begin{array}{l}1.10 \text { Lessons develop the communicative skills } \\
\text { the program aims to develop. }\end{array}$ & 0 & $\begin{array}{l}\text { (low) } \\
1\end{array}$ & 2 & 3 & $\begin{array}{l}\text { (high) } \\
4\end{array}$ \\
\hline $\begin{array}{l}1.11 \text { Lessons develop the level of language } \\
\text { proficiency the program aims to develop. }\end{array}$ & 0 & $\begin{array}{l}\text { (low) } \\
1\end{array}$ & 2 & 3 & $\begin{array}{l}\text { (high) } \\
4\end{array}$ \\
\hline $\begin{array}{l}1.12 \text { The course syllabus reflects a } \\
\text { communicative approach to language } \\
\text { teaching/learning. }\end{array}$ & 0 & $\begin{array}{l}\text { (low) } \\
1\end{array}$ & 2 & 3 & $\begin{array}{l}\text { (high) } \\
4\end{array}$ \\
\hline $\begin{array}{l}1.13 \text { Content selection is determined by } \\
\text { communicative skills and/or themes. }\end{array}$ & 0 & $\begin{array}{l}\text { (low) } \\
1\end{array}$ & 2 & 3 & $\begin{array}{l}\text { (high) } \\
4\end{array}$ \\
\hline $\begin{array}{l}1.14 \text { Content is sequenced from simple } \\
\text { communicative functions, such as introducing } \\
\text { oneself, greeting, etc, to complex ones, such } \\
\text { as stating an opinion, disagreeing, etc. }\end{array}$ & 0 & $\begin{array}{l}\text { (low) } \\
1\end{array}$ & 2 & 3 & $\begin{array}{l}\text { (high) } \\
4\end{array}$ \\
\hline 1.15 Content is presented communicatively. & 0 & $\begin{array}{l}\text { (low) } \\
1\end{array}$ & 2 & 3 & $\begin{array}{l}\text { (high) } \\
4\end{array}$ \\
\hline $\begin{array}{l}1.16 \text { The program develops the content at } \\
\text { appropriate levels of language proficiency. }\end{array}$ & 0 & $\begin{array}{l}\text { (low) } \\
1\end{array}$ & 2 & 3 & $\begin{array}{l}\text { (high) } \\
4\end{array}$ \\
\hline $\begin{array}{l}1.17 \text { The program content is educationally } \\
\text { relevant and interesting for the learner. }\end{array}$ & 0 & $\begin{array}{l}\text { (low) } \\
1\end{array}$ & 2 & 3 & $\begin{array}{l}\text { (high) } \\
4\end{array}$ \\
\hline $\begin{array}{l}1.18 \text { The program content is appropriate for } \\
\text { intended learners. }\end{array}$ & 0 & $\begin{array}{l}\text { (low) } \\
1\end{array}$ & 2 & 3 & $\begin{array}{l}\text { (high) } \\
4\end{array}$ \\
\hline $\begin{array}{l}1.19 \text { The program content is applicable to real } \\
\text { life contexts. }\end{array}$ & 0 & $\begin{array}{l}\text { (low) } \\
1\end{array}$ & 2 & 3 & $\begin{array}{l}\text { (high) } \\
4\end{array}$ \\
\hline $\begin{array}{l}1.20 \text { The program allows learners to work } \\
\text { together in communicative activities. }\end{array}$ & 0 & $\begin{array}{l}\text { (low) } \\
1\end{array}$ & 2 & 3 & $\begin{array}{l}\text { (high) } \\
4\end{array}$ \\
\hline $\begin{array}{l}1.21 \text { The activities allow unplanned and/or } \\
\text { unpredictable responses. }\end{array}$ & 0 & $\begin{array}{l}\text { (low) } \\
1\end{array}$ & 2 & 3 & $\begin{array}{l}\text { (high) } \\
4\end{array}$ \\
\hline $\begin{array}{l}1.22 \text { The activities lend themselves to group } \\
\text { discussions. }\end{array}$ & 0 & $\begin{array}{l}\text { (low) } \\
1\end{array}$ & 2 & 3 & $\begin{array}{l}\text { (high) } \\
4\end{array}$ \\
\hline $\begin{array}{l}1.23 \text { The activities aim at developing other } \\
\text { competencies in addition to syntactical and } \\
\text { lexical }\end{array}$ & 0 & $\begin{array}{l}\text { (low) } \\
1\end{array}$ & 2 & 3 & $\begin{array}{l}\text { (high) } \\
4\end{array}$ \\
\hline $\begin{array}{l}\text { 1.24 The program allows the teacher to interact } \\
\text { with students while they are doing an activity. }\end{array}$ & 0 & $\begin{array}{l}\text { (low) } \\
1\end{array}$ & 2 & 3 & $\begin{array}{l}\text { (high) } \\
4\end{array}$ \\
\hline
\end{tabular}




\begin{tabular}{|l|l|l|l|l|l|}
\hline $\begin{array}{l}1.25 \text { The program provides non-threatening } \\
\text { feedback. }\end{array}$ & 0 & $\begin{array}{l}\text { (low) } \\
1\end{array}$ & 2 & 3 & $\begin{array}{l}\text { (high) } \\
4\end{array}$ \\
\hline $\begin{array}{l}1.26 \text { The program allows learners to repeat an } \\
\text { activity after feedback is provided. }\end{array}$ & 0 & $\begin{array}{l}\text { (low) } \\
1\end{array}$ & 2 & 3 & $\begin{array}{l}\text { (high) } \\
4\end{array}$ \\
\hline $\begin{array}{l}1.27 \text { Activities allow for more than one correct } \\
\text { response. }\end{array}$ & 0 & $\begin{array}{l}\text { (low) } \\
1\end{array}$ & 2 & 3 & $\begin{array}{l}\text { (high) } \\
4\end{array}$ \\
\hline $\begin{array}{l}1.28 \text { The program provides the students with } \\
\text { feedback that would allow them to correct their } \\
\text { mistakes. }\end{array}$ & 0 & $\begin{array}{l}\text { (low) } \\
1\end{array}$ & 2 & 3 & $\begin{array}{l}\text { (high) } \\
4\end{array}$ \\
\hline \begin{tabular}{l} 
Sub-total $=42(37.5 \%)$ \\
\hline
\end{tabular}
\end{tabular}

\begin{tabular}{|c|c|c|c|c|c|}
\hline \multicolumn{6}{|l|}{ Media Attributes } \\
\hline 2.29 Graphics aid understanding. & 0 & $\begin{array}{ll}\text { (low) } \\
1\end{array}$ & 2 & 3 & $\begin{array}{l}\text { (high) } \\
4\end{array}$ \\
\hline $\begin{array}{l}\text { 2.30 The program allows for different routes and } \\
\text { choices for learning. }\end{array}$ & 0 & $\begin{array}{l}\text { (low) } \\
1\end{array}$ & 2 & 3 & $\begin{array}{l}\text { (high) } \\
4\end{array}$ \\
\hline $\begin{array}{l}\text { 2.31 The program allows for review of old } \\
\text { information. }\end{array}$ & 0 & $\begin{array}{l}\text { (low) } \\
1\end{array}$ & 2 & 3 & $\begin{array}{l}\text { (high) } \\
4\end{array}$ \\
\hline $\begin{array}{l}\text { 2.32 The program allows branching to new } \\
\text { information. }\end{array}$ & 0 & $\begin{array}{ll}\text { (low) } \\
1\end{array}$ & 2 & 3 & $\begin{array}{l}\text { (high) } \\
4\end{array}$ \\
\hline $\begin{array}{l}\text { 2.33 The program allows students to select } \\
\text { activities according to their ages. }\end{array}$ & 0 & $\begin{array}{l}\text { (low) } \\
1\end{array}$ & 2 & 3 & $\begin{array}{l}\text { (high) } \\
4\end{array}$ \\
\hline $\begin{array}{l}\text { 2.34 The program allows students to select } \\
\text { activities according to their learning styles. }\end{array}$ & 0 & (low) & 2 & 3 & $\begin{array}{l}\text { (high) } \\
4\end{array}$ \\
\hline $\begin{array}{l}2.35 \text { The program allows students to select } \\
\text { activities according to their interests. }\end{array}$ & 0 & $\begin{array}{l}\text { (low) } \\
1\end{array}$ & 2 & 3 & $\begin{array}{l}\text { (high) } \\
4\end{array}$ \\
\hline $\begin{array}{l}\text { 2.36 The program adapts to the responses } \\
\text { given by the learners, branching to more or less } \\
\text { complicated questions as appropriate. }\end{array}$ & 0 & $\begin{array}{l}\text { (low) } \\
1\end{array}$ & 2 & 3 & $\begin{array}{l}\text { (high) } \\
4\end{array}$ \\
\hline $\begin{array}{l}\text { 2.37 The program allows learners to go through } \\
\text { its content at their own pace and rhythm. }\end{array}$ & 0 & $\begin{array}{l}\text { (low) } \\
1\end{array}$ & 2 & 3 & $\begin{array}{l}\text { (high) } \\
4\end{array}$ \\
\hline $\begin{array}{l}2.38 \text { The program prevents learners from } \\
\text { repeating exercises, therefore, minimizing } \\
\text { guessing. }\end{array}$ & 0 & $\begin{array}{l}\text { (low) } \\
1\end{array}$ & 2 & 3 & $\begin{array}{l}\text { (high) } \\
4\end{array}$ \\
\hline $\begin{array}{l}2.39 \text { The program keeps records of learners' } \\
\text { performance to allow them to continue activities } \\
\text { from where they left off. }\end{array}$ & 0 & $\begin{array}{l}\text { (low) } \\
1\end{array}$ & 2 & 3 & $\begin{array}{l}\text { (high) } \\
4\end{array}$ \\
\hline $\begin{array}{l}2.40 \text { The program keeps track of students' } \\
\text { scores. }\end{array}$ & 0 & $\begin{array}{l}\text { (low) } \\
1\end{array}$ & 2 & 3 & $\begin{array}{l}\text { (high) } \\
4\end{array}$ \\
\hline $\begin{array}{l}2.41 \text { The program provides feedback for both } \\
\text { correct and incorrect answers. The program } \\
\text { provides feedback for both correct and incorrect } \\
\text { answers. }\end{array}$ & 0 & $\begin{array}{l}\text { (low) } \\
1\end{array}$ & 2 & 3 & $\begin{array}{l}\text { (high) } \\
4\end{array}$ \\
\hline $\begin{array}{l}2.42 \text { The program gives learners the chance to } \\
\text { correct their errors. }\end{array}$ & 0 & $\begin{array}{ll}\text { (low) } \\
1\end{array}$ & 2 & 3 & $\begin{array}{l}\text { (high) } \\
4\end{array}$ \\
\hline $\begin{array}{l}2.43 \text { The program effectively signals the } \\
\text { mistakes before providing the right answers. }\end{array}$ & 0 & $\begin{array}{l}\text { (low) } \\
1\end{array}$ & 2 & 3 & $\begin{array}{l}\text { (high) } \\
4\end{array}$ \\
\hline
\end{tabular}




\begin{tabular}{|c|c|c|c|c|c|}
\hline $\begin{array}{l}2.44 \text { The program effectively specifies different } \\
\text { types of errors, such as differences between a } \\
\text { syntactic error and an incorrect word choice. }\end{array}$ & 0 & $\begin{array}{l}\text { (low) } \\
1\end{array}$ & 2 & 3 & $\begin{array}{l}\text { (high) } \\
4\end{array}$ \\
\hline \multicolumn{6}{|l|}{ Sub-total = $28(43.75 \%)$} \\
\hline \multicolumn{6}{|l|}{ User-Friendly Attributes } \\
\hline $\begin{array}{l}3.45 \text { Menu items are understandable and } \\
\text { descriptive. }\end{array}$ & 0 & $\begin{array}{l}\text { (low) } \\
1\end{array}$ & 2 & 3 & $\begin{array}{l}\text { (high) } \\
4\end{array}$ \\
\hline $\begin{array}{l}\text { 3.46 The commands and instructions for the } \\
\text { activities are clear and objective. }\end{array}$ & 0 & $\begin{array}{l}\text { (low) } \\
1\end{array}$ & 2 & 3 & $\begin{array}{l}\text { (high) } \\
4\end{array}$ \\
\hline $\begin{array}{l}\text { 3.47 The program gives the learners effective } \\
\text { clues to clarify their doubts about its use. }\end{array}$ & 0 & $\begin{array}{l}\text { (low) } \\
1\end{array}$ & 2 & 3 & $\begin{array}{l}\text { (high) } \\
4\end{array}$ \\
\hline $\begin{array}{l}3.48 \text { Each screen uses text and } \\
\text { graphic/animation to make a particular teaching } \\
\text { point clear. }\end{array}$ & 0 & $\begin{array}{l}\text { (low) } \\
1\end{array}$ & 2 & 3 & $\begin{array}{l}\text { (high) } \\
4\end{array}$ \\
\hline $\begin{array}{l}\text { 3.49 The program is effectively integrated with } \\
\text { other technological resources (such as } \\
\text { dictionaries on the web, grammar on line, etc) } \\
\text { as the learner uses it. }\end{array}$ & 0 & $\begin{array}{l}\text { (low) } \\
1\end{array}$ & 2 & 3 & $\begin{array}{l}\text { (high) } \\
4\end{array}$ \\
\hline $\begin{array}{l}3.50 \text { Icons, buttons and menus allow learners to } \\
\text { readily search for additional information while } \\
\text { doing an activity. }\end{array}$ & 0 & $\begin{array}{l}\text { (low) } \\
1\end{array}$ & 2 & 3 & $\begin{array}{l}\text { (high) } \\
4\end{array}$ \\
\hline $\begin{array}{l}3.51 \text { Buttons, icons or menu items make Help or } \\
\text { Hint-type options easily accessible. }\end{array}$ & 0 & $\begin{array}{l}\text { (low) } \\
1\end{array}$ & 2 & 3 & $\begin{array}{l}\text { (high) } \\
4\end{array}$ \\
\hline $\begin{array}{l}\text { 3.52 The program arouses sensory and } \\
\text { cognitive curiosity }\end{array}$ & 0 & $\begin{array}{l}\text { (low) } \\
1\end{array}$ & 2 & 3 & $\begin{array}{l}\text { (high) } \\
4\end{array}$ \\
\hline $\begin{array}{l}\text { 3.53 The program maintains attention } \\
\text { throughout the lesson. }\end{array}$ & 0 & $\begin{array}{l}\text { (low) } \\
1\end{array}$ & 2 & 3 & $\begin{array}{l}\text { (high) } \\
4\end{array}$ \\
\hline $\begin{array}{l}3.54 \text { The use of animation invites learners' } \\
\text { reaction or input. }\end{array}$ & 0 & $\begin{array}{l}\text { (low) } \\
1\end{array}$ & 2 & 3 & $\begin{array}{l}\text { (high) } \\
4\end{array}$ \\
\hline $\begin{array}{l}\text { 3.55 The program gives teachers a clear } \\
\text { explanation of its purposes and methodological } \\
\text { orientation. }\end{array}$ & 0 & $\begin{array}{l}\text { (low) } \\
1\end{array}$ & 2 & 3 & $\begin{array}{l}\text { (high) } \\
4\end{array}$ \\
\hline \multicolumn{6}{|l|}{ Sub-total $=22(50 \%)$} \\
\hline Total $=92(41.81 \%)$ & & & & & \\
\hline
\end{tabular}

Sub-total of ratings for Instructional Attributes

$42(37.5 \%)$

Sub-total of ratings for Media Attributes ................................

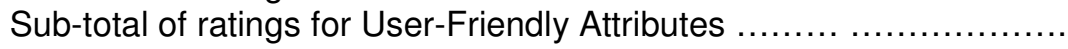

$28(43.75 \%)$

Total rating

$22(50 \%)$

$92(41.81 \%)$ 


\section{ESL/EFL SOFTWARE EVALUATION INSTRUMENT}

Title of the program: $\underline{\text { Rosetta Stone }}$

Publisher: Fairfield Language Technology

\section{DESCRIPTIVE ANALYSIS}

Please place a checkmark next to the item that best describes the program and/or its features.

\section{TECHNICAL FEATURES}

1.1 Components of the program:

\begin{tabular}{|c|l|l|}
\hline $\begin{array}{c}\text { Number of CD's: } \\
\text { Per level } \\
\text { Total }\end{array}$ & Teacher's guide_XYes_N_No & $\begin{array}{l}\text { Support materials_X_Yes } \\
\text { What type? Workbook, Study Guide, } \\
\text { Quizzes, Tests }\end{array}$ \\
\hline
\end{tabular}

1.2 Platform

\begin{tabular}{|l|l|}
\hline $\begin{array}{l}\text { Mac OS 8.1 or later } \\
\text { Mhz }\end{array}$ & $\begin{array}{l}\text { Windows 95, 98, XP } \\
\text { MB of RAM }\end{array}$ \\
\hline
\end{tabular}

1.3 Tools

\begin{tabular}{|l|l|l|}
\hline $\begin{array}{l}\mathbf{X} \_ \text {Word processing } \\
\text { Online forums } \\
\text { Online collaboration }\end{array}$ & $\begin{array}{c}\text { Speech recognition } \\
\mathbf{X} \text { Web browsing }\end{array}$ & $\begin{array}{l}\text { E-mail } \\
\mathbf{X} \text { Others } \\
\text { online instruction } \\
\text { and practice }\end{array}$ \\
\hline
\end{tabular}

1.4 Other technological resources integrated into the program: \begin{tabular}{|l|l} 
dictionaries on the web & grammar on line
\end{tabular}

1.5 Directions for use:

\begin{tabular}{|l|l|l|}
\hline $\mathbf{X} \mathbf{X}_{-}$are on the screen & $\mathbf{X}_{-}$are in the documentation & $\mathbf{X}$ _ can be skipped at option of user \\
\hline
\end{tabular}

\section{PEDAGOGICAL ORIENTATION}

2.6 Program's theory of language

\begin{tabular}{|l|l|l|}
\hline X_structural & functional & interactional \\
\hline
\end{tabular}

2.7 Type of program

\begin{tabular}{|c|c|c|c|}
\hline $\begin{array}{ll} & \begin{array}{l}\text { remediation } \\
\text { enrichment } \\
\mathbf{X}_{\mathbf{X}}\end{array} \text { tutoring }\end{array}$ & $\begin{array}{l}\mathbf{X} \text { _demonstration } \\
\mathbf{X} \text { __assessment }\end{array}$ & $\begin{array}{l}\overline{\text { game }}^{\text {education }} \\
\text { collaborative } \\
\text { projects }\end{array}$ & $\begin{array}{ll}\mathbf{X} & \begin{array}{l}\text { problem solving } \\
\text { drill and practice } \\
\text { simulation }\end{array} \\
\end{array}$ \\
\hline
\end{tabular}

2.8 Curriculum capability

\begin{tabular}{|l|l|}
\hline Grade range & Proficiency level range \\
\hline
\end{tabular}




\begin{tabular}{|c|c|c|c|c|c|}
\hline X & $\begin{array}{l}\text { elementary } \\
\text { middle school } \\
\text { high school } \\
\text { adult learnina }\end{array}$ & From & $\begin{array}{cl}\mathbf{X} \_ \text {beginning } \\
\text { pre-intermediate } \\
\text { intermediate } \\
\text { hiah-intermediate }\end{array}$ & To & $\begin{array}{c}\text { pre- intermediate } \\
\text { intermediate } \\
\mathbf{X} \text { high-intermediate }\end{array}$ \\
\hline
\end{tabular}

2.9 Method of language teaching

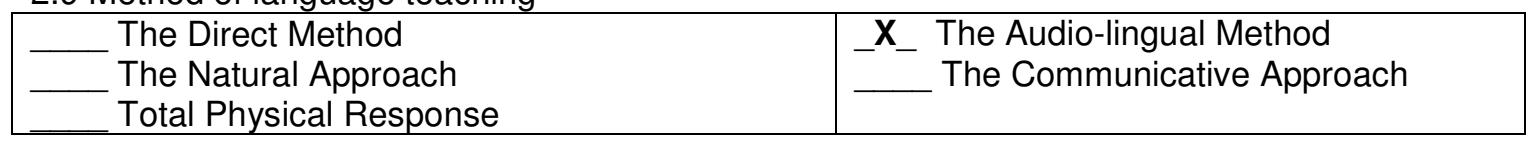

2.10 Language skills developed in the program

\begin{tabular}{|l|l|l|l|}
\hline - X_ speaking & - X_listening & X_reading & __ \\
\hline
\end{tabular}

2.11 Type of activities offered by the program

\begin{tabular}{|l|l|l|l|}
\hline $\begin{array}{l}\text { games } \\
\text { quizzes } \\
\text { others }\end{array}$ & simulation & tutorial & drill and practice \\
exploratory & text & problem solving \\
\hline
\end{tabular}

2.12 Orientation of how to use program and its feature

\begin{tabular}{|c|c|}
\hline $\mathbf{X} \_$for the teacher & on the screen \\
\hline $\mathbf{X} \quad$ for the student & on hard copy documentation \\
\hline $\mathbf{X}$. for both & $\mathbf{X}$ _ on both \\
\hline
\end{tabular}

2.13 Role of the teacher

\begin{tabular}{|l|l|l|l|}
\hline _ instructor & _ facilitator & X_lab manager & _ evaluator \\
\hline
\end{tabular}

2.14 Learners interact

\begin{tabular}{|l|l|l|}
\hline _ with one another & _ with the teacher & X_with neither \\
\hline
\end{tabular}

2.15 In case learners interact with one another, they can interact in all activities in some activities

2.16 In case learners interact with the teacher, they can interact at any time end of the lesson at the end of the activities there's no interaction

\section{$\underline{\text { CRITICAL ANALYSIS }}$}

For each item, circle the numbers 1 (for low) to 4 (for high) to indicate your judgment of the degree to which the program possesses or demonstrates the feature identified in each item. Circle 0 if the feature is not present in the program. 


\begin{tabular}{|c|c|c|c|c|c|}
\hline 1.1Graphics and sound enhance learning. & 0 & $\begin{array}{l}\text { (low) } \\
1\end{array}$ & 2 & 3 & $\begin{array}{l}\text { (high) } \\
4\end{array}$ \\
\hline $\begin{array}{l}1.2 \text { The animation is effective in minimizing } \\
\text { boredom by motivating learners. }\end{array}$ & 0 & $\begin{array}{l}\text { (low) } \\
1 \\
\end{array}$ & 2 & 3 & $\begin{array}{l}\text { (high) } \\
4\end{array}$ \\
\hline 1.3Screen displays are uncluttered. & 0 & $\begin{array}{l}\text { (low) } \\
1\end{array}$ & 2 & 3 & $\begin{array}{l}\text { (high) } \\
4\end{array}$ \\
\hline 1.4 Graphics make information attractive. & 0 & $\begin{array}{l}\text { (low) } \\
1\end{array}$ & 2 & 3 & $\begin{array}{l}\text { (high) } \\
4\end{array}$ \\
\hline $\begin{array}{l}1.5 \text { Graphics help memorization of key } \\
\text { information. }\end{array}$ & 0 & $\begin{array}{l}\text { (low) } \\
1 \\
\end{array}$ & 2 & 3 & $\begin{array}{l}\text { (high) } \\
4\end{array}$ \\
\hline $\begin{array}{l}1.6 \text { The program makes use of authentic texts } \\
\text { and other realia. }\end{array}$ & 0 & $\begin{array}{l}\text { (low) } \\
1\end{array}$ & 2 & 3 & $\begin{array}{l}\text { (high) } \\
4\end{array}$ \\
\hline $\begin{array}{l}1.7 \text { The program integrates information about } \\
\text { culture/daily situations into the presentations } \\
\text { and activities. }\end{array}$ & 0 & $\begin{array}{l}\text { (low) } \\
1\end{array}$ & 2 & 3 & $\begin{array}{l}\text { (high) } \\
4\end{array}$ \\
\hline $\begin{array}{l}1.8 \text { Lessons present and practice language } \\
\text { structures in meaningful communicative } \\
\text { contexts. }\end{array}$ & 0 & $\begin{array}{l}\text { (low) } \\
1\end{array}$ & 2 & 3 & $\begin{array}{l}\text { (high) } \\
4\end{array}$ \\
\hline $\begin{array}{l}1.9 \text { Lessons present and practice vocabulary in } \\
\text { meaningful communicative contexts. }\end{array}$ & 0 & $\begin{array}{l}\text { (low) } \\
1\end{array}$ & 2 & 3 & $\begin{array}{l}\text { (high) } \\
4\end{array}$ \\
\hline $\begin{array}{l}1.10 \text { Lessons develop the communicative skills } \\
\text { the program aims to develop. }\end{array}$ & 0 & $\begin{array}{l}\text { (low) } \\
1\end{array}$ & 2 & 3 & $\begin{array}{l}\text { (high) } \\
4\end{array}$ \\
\hline $\begin{array}{l}1.11 \text { Lessons develop the level of language } \\
\text { proficiency the program aims to develop. }\end{array}$ & 0 & $\begin{array}{l}\text { (low) } \\
1\end{array}$ & 2 & 3 & $\begin{array}{l}\text { (high) } \\
4\end{array}$ \\
\hline $\begin{array}{l}1.12 \text { The course syllabus reflects a } \\
\text { communicative approach to language } \\
\text { teaching/learning. }\end{array}$ & 0 & $\begin{array}{l}\text { (low) } \\
1\end{array}$ & 2 & 3 & $\begin{array}{l}\text { (high) } \\
4\end{array}$ \\
\hline $\begin{array}{l}1.13 \text { Content selection is determined by } \\
\text { communicative skills and/or themes. }\end{array}$ & 0 & $\begin{array}{l}\text { (low) } \\
1\end{array}$ & 2 & 3 & $\begin{array}{l}\text { (high) } \\
4\end{array}$ \\
\hline $\begin{array}{l}1.14 \text { Content is sequenced from simple } \\
\text { communicative functions, such as introducing } \\
\text { oneself, greeting, etc, to complex ones, such } \\
\text { as stating an opinion, disagreeing, etc. }\end{array}$ & 0 & $\begin{array}{l}\text { (low) } \\
1\end{array}$ & 2 & 3 & $\begin{array}{l}\text { (high) } \\
4\end{array}$ \\
\hline 1.15 Content is presented communicatively. & 0 & $\begin{array}{l}\text { (low) } \\
1 \\
\end{array}$ & 2 & 3 & $\begin{array}{l}\text { (high) } \\
4\end{array}$ \\
\hline $\begin{array}{l}1.16 \text { The program develops the content at } \\
\text { appropriate levels of language proficiency. }\end{array}$ & 0 & $\begin{array}{l}\text { (low) } \\
1 \\
\end{array}$ & 2 & 3 & $\begin{array}{l}\text { (high) } \\
4\end{array}$ \\
\hline $\begin{array}{l}1.17 \text { The program content is educationally } \\
\text { relevant and interesting for the learner. }\end{array}$ & 0 & $\begin{array}{l}\text { (low) } \\
1\end{array}$ & 2 & 3 & $\begin{array}{l}\text { (high) } \\
4\end{array}$ \\
\hline $\begin{array}{l}1.18 \text { The program content is appropriate for } \\
\text { intended learners. }\end{array}$ & 0 & $\begin{array}{l}\text { (low) } \\
1\end{array}$ & 2 & 3 & $\begin{array}{l}\text { (high) } \\
4\end{array}$ \\
\hline $\begin{array}{l}\text { 1.19 The program content is applicable to real } \\
\text { life contexts. }\end{array}$ & 0 & $\begin{array}{l}\text { (low) } \\
1 \\
\end{array}$ & 2 & 3 & $\begin{array}{l}\text { (high) } \\
4\end{array}$ \\
\hline $\begin{array}{l}1.20 \text { The program allows learners to work } \\
\text { together in communicative activities. }\end{array}$ & 0 & $\begin{array}{l}\text { (low) } \\
1\end{array}$ & 2 & 3 & $\begin{array}{l}\text { (high) } \\
4\end{array}$ \\
\hline $\begin{array}{l}1.21 \text { The activities allow unplanned and/or } \\
\text { unpredictable responses. }\end{array}$ & 0 & $\begin{array}{ll}\text { (low) } \\
1\end{array}$ & 2 & 3 & $\begin{array}{l}\text { (high) } \\
4\end{array}$ \\
\hline $\begin{array}{l}\text { 1.22 The activities lend themselves to group } \\
\text { discussions. }\end{array}$ & 0 & $\begin{array}{l}\text { (low) } \\
1\end{array}$ & 2 & 3 & $\begin{array}{l}\text { (high) } \\
4\end{array}$ \\
\hline $\begin{array}{l}1.23 \text { The activities aim at developing other } \\
\text { competencies in addition to syntactical and } \\
\text { lexical }\end{array}$ & 0 & $\begin{array}{l}\text { (low) } \\
1\end{array}$ & 2 & 3 & $\begin{array}{l}\text { (high) } \\
4\end{array}$ \\
\hline $\begin{array}{l}1.24 \text { The program allows the teacher to interact } \\
\text { with students while they are doing an activity. }\end{array}$ & 0 & $\begin{array}{l}\text { (low) } \\
1\end{array}$ & 2 & 3 & $\begin{array}{l}\text { (high) } \\
4\end{array}$ \\
\hline
\end{tabular}




\begin{tabular}{|l|l|l|l|l|l|}
\hline $\begin{array}{l}1.25 \text { The program provides non-threatening } \\
\text { feedback. }\end{array}$ & 0 & $\begin{array}{l}\text { (low) } \\
1\end{array}$ & 2 & 3 & $\begin{array}{l}\text { (high) } \\
4\end{array}$ \\
\hline $\begin{array}{l}1.26 \text { The program allows learners to repeat an } \\
\text { activity after feedback is provided. }\end{array}$ & 0 & $\begin{array}{l}\text { (low) } \\
1\end{array}$ & 2 & 3 & $\begin{array}{l}\text { (high) } \\
4\end{array}$ \\
\hline $\begin{array}{l}1.27 \text { Activities allow for more than one correct } \\
\text { response. }\end{array}$ & 0 & $\begin{array}{l}\text { (low) } \\
1\end{array}$ & 2 & 3 & $\begin{array}{l}\text { (high) } \\
4\end{array}$ \\
\hline $\begin{array}{l}1.28 \text { The program provides the students with } \\
\text { feedback that would allow them to correct their } \\
\text { mistakes. }\end{array}$ & 0 & $\begin{array}{l}\text { (low) } \\
1\end{array}$ & 2 & 3 & $\begin{array}{l}\text { (high) } \\
4\end{array}$ \\
\hline \begin{tabular}{l} 
Sub-total $=28(25 \%)$ \\
\hline
\end{tabular}
\end{tabular}

\begin{tabular}{|c|c|c|c|c|c|}
\hline \multicolumn{6}{|l|}{ Media Attributes } \\
\hline 2.29 Graphics aid understanding. & 0 & $\begin{array}{l}\text { (low) } \\
1\end{array}$ & 2 & 3 & $\begin{array}{l}\text { (high) } \\
4\end{array}$ \\
\hline $\begin{array}{l}2.30 \text { The program allows for different routes and } \\
\text { choices for learning. }\end{array}$ & 0 & $\begin{array}{l}\text { (low) } \\
1\end{array}$ & 2 & 3 & $\begin{array}{l}\text { (high) } \\
4\end{array}$ \\
\hline $\begin{array}{l}\text { 2.31 The program allows for review of old } \\
\text { information. }\end{array}$ & 0 & $\begin{array}{ll}\text { (low) } \\
1\end{array}$ & 2 & 3 & $\begin{array}{l}\text { (high) } \\
4\end{array}$ \\
\hline $\begin{array}{l}2.32 \text { The program allows branching to new } \\
\text { information. }\end{array}$ & 0 & $\begin{array}{l}\text { (low) } \\
1\end{array}$ & 2 & 3 & $\begin{array}{l}\text { (high) } \\
4\end{array}$ \\
\hline $\begin{array}{l}2.33 \text { The program allows students to select } \\
\text { activities according to their ages. }\end{array}$ & 0 & $\begin{array}{l}\text { (low) } \\
1\end{array}$ & 2 & 3 & $\begin{array}{l}\text { (high) } \\
4\end{array}$ \\
\hline $\begin{array}{l}\text { 2.34 The program allows students to select } \\
\text { activities according to their learning styles. }\end{array}$ & 0 & $\begin{array}{ll}\text { (low) } \\
1\end{array}$ & 2 & 3 & $\begin{array}{l}\text { (high) } \\
4\end{array}$ \\
\hline $\begin{array}{l}2.35 \text { The program allows students to select } \\
\text { activities according to their interests. }\end{array}$ & 0 & $\begin{array}{l}\text { (low) } \\
1\end{array}$ & 2 & 3 & $\begin{array}{l}\text { (high) } \\
4\end{array}$ \\
\hline $\begin{array}{l}2.36 \text { The program adapts to the responses } \\
\text { given by the learners, branching to more or less } \\
\text { complicated questions as appropriate. }\end{array}$ & 0 & $\begin{array}{l}\text { (low) } \\
1\end{array}$ & 2 & 3 & $\begin{array}{l}\text { (high) } \\
4\end{array}$ \\
\hline $\begin{array}{l}2.37 \text { The program allows learners to go through } \\
\text { its content at their own pace and rhythm. }\end{array}$ & 0 & $\begin{array}{ll}\text { (low) } \\
1\end{array}$ & 2 & 3 & $\begin{array}{l}\text { (high) } \\
4\end{array}$ \\
\hline $\begin{array}{l}2.38 \text { The program prevents learners from } \\
\text { repeating exercises, therefore, minimizing } \\
\text { guessing. }\end{array}$ & 0 & (low) & 2 & 3 & $\begin{array}{l}\text { (high) } \\
4\end{array}$ \\
\hline $\begin{array}{l}\text { 2.39 The program keeps records of learners' } \\
\text { performance to allow them to continue activities } \\
\text { from where they left off. }\end{array}$ & 0 & $\begin{array}{l}\text { (low) } \\
1\end{array}$ & 2 & 3 & $\begin{array}{l}\text { (high) } \\
4\end{array}$ \\
\hline $\begin{array}{l}2.40 \text { The program keeps track of students' } \\
\text { scores. }\end{array}$ & 0 & $\begin{array}{l}\text { (low) } \\
1\end{array}$ & 2 & 3 & $\begin{array}{l}\text { (high) } \\
4\end{array}$ \\
\hline $\begin{array}{l}2.41 \text { The program provides feedback for both } \\
\text { correct and incorrect answers. The program } \\
\text { provides feedback for both correct and incorrect } \\
\text { answers. }\end{array}$ & 0 & $\begin{array}{l}\text { (low) } \\
1\end{array}$ & 2 & 3 & $\begin{array}{l}\text { (high) } \\
4\end{array}$ \\
\hline $\begin{array}{l}2.42 \text { The program gives learners the chance to } \\
\text { correct their errors. }\end{array}$ & 0 & $\begin{array}{l}\text { (low) } \\
1 \\
\end{array}$ & 2 & 3 & $\begin{array}{l}\text { (high) } \\
4\end{array}$ \\
\hline $\begin{array}{l}2.43 \text { The program effectively signals the } \\
\text { mistakes before providing the right answers. }\end{array}$ & 0 & $\begin{array}{l}\text { (low) } \\
1\end{array}$ & 2 & 3 & $\begin{array}{l}\text { (high) } \\
4\end{array}$ \\
\hline $\begin{array}{l}\text { 2.44 The program effectively specifies different } \\
\text { types of errors, such as differences between a } \\
\text { syntactic error and an incorrect word choice. }\end{array}$ & 0 & $\begin{array}{l}\text { (low) } \\
1\end{array}$ & 2 & 3 & $\begin{array}{l}\text { (high) } \\
4\end{array}$ \\
\hline
\end{tabular}


Sub-total $=21(32.81 \%)$

User-Friendly Attributes

3.45 Menu items are understandable and descriptive.

3.46 The commands and instructions for the activities are clear and objective.

3.47 The program gives the learners effective clues to clarify their doubts about its use.

3.48 Each screen uses text and graphic/animation to make a particular teaching point clear.

3.49 The program is effectively integrated with other technological resources (such as dictionaries on the web, grammar on line, etc) as the learner uses it.

3.50 Icons, buttons and menus allow learners to readily search for additional information while doing an activity.

3.51 Buttons, icons or menu items make Help or Hint-type options easily accessible.

3.52 The program arouses sensory and cognitive curiosity

3.53 The program maintains attention throughout the lesson.

3.54 The use of animation invites learners' reaction or input.

3.55 The program gives teachers a clear explanation of its purposes and methodological orientation.

\begin{tabular}{|l|l|l|l|l|}
\hline 0 & $\begin{array}{l}\text { (low) } \\
1\end{array}$ & 2 & 3 & $\begin{array}{l}\text { (high) } \\
4\end{array}$ \\
\hline 0 & $\begin{array}{l}\text { (low) } \\
1\end{array}$ & 2 & 3 & $\begin{array}{l}\text { (high) } \\
4\end{array}$ \\
\hline 0 & $\begin{array}{l}\text { (low) } \\
1\end{array}$ & 2 & 3 & $\begin{array}{l}\text { (high) } \\
4\end{array}$ \\
\hline 0 & $\begin{array}{l}\text { (low) } \\
1\end{array}$ & 2 & 3 & $\begin{array}{l}\text { (high) } \\
4\end{array}$ \\
\hline 0 & $\begin{array}{l}\text { (low) } \\
1\end{array}$ & 2 & 3 & $\begin{array}{l}\text { (high) } \\
4\end{array}$ \\
0 & $\begin{array}{l}\text { (low) } \\
1\end{array}$ & 2 & 3 & $\begin{array}{l}\text { (high) } \\
4\end{array}$ \\
\hline 0 & $\begin{array}{l}\text { (low) } \\
1\end{array}$ & 2 & 3 & $\begin{array}{l}\text { (high) } \\
4\end{array}$ \\
\hline 0 & $\begin{array}{l}\text { (low) } \\
1\end{array}$ & 2 & 3 & $\begin{array}{l}\text { (high) } \\
4\end{array}$ \\
\hline 0 & $\begin{array}{l}\text { (low) } \\
1\end{array}$ & 2 & 3 & $\begin{array}{l}\text { (high) } \\
4\end{array}$ \\
\hline 0 & $\begin{array}{l}\text { (low) } \\
1\end{array}$ & 2 & 3 & $\begin{array}{l}\text { (high) } \\
4\end{array}$ \\
\hline 0 & $\begin{array}{l}\text { (low) } \\
1\end{array}$ & 2 & 3 & $\begin{array}{l}\text { (high) } \\
4\end{array}$ \\
\hline
\end{tabular}

Sub-total $=14(31.81 \%)$

Total $=63(28.63 \%)$

Sub-total of ratings for Instructional Attributes

Sub-total of ratings for User-Friendly Attributes 


\section{ESL/EFL SOFTWARE EVALUATION INSTRUMENT}

Title of the program: Side by Side

Publisher/date: Pearson/Longman

\section{DESCRIPTIVE ANALYSIS}

Please place a checkmark next to the item that best describes the program and/or its features.

\section{TECHNICAL FEATURES}

1.1 Components of the program:

\begin{tabular}{|l|l|l|}
$\begin{array}{l}\text { Number of CD's: } \\
01 \text { per level } \\
\mathbf{0 2} \text { total }\end{array}$ & $\begin{array}{l}\text { Teacher's guide __ Yes } \\
\mathbf{X} \_ \text {No }\end{array}$ & $\begin{array}{l}\text { Support materials __ Yes } \\
\underline{\mathbf{X}} \text { No } \\
\text { What type? }\end{array}$ \\
\hline
\end{tabular}

1.2 Platform

\begin{tabular}{|c|c|}
\hline Mac_OS 8.1, 8.5, 9.0, 9.2 & Windows 95/98 4.0/2000/XP \\
\hline $200 \mathrm{Mhz} \underline{64} \mathrm{MB}$ of RAM & $\underline{200}$ Mhz $\underline{200}$ \\
\hline
\end{tabular}

1.3 Tools

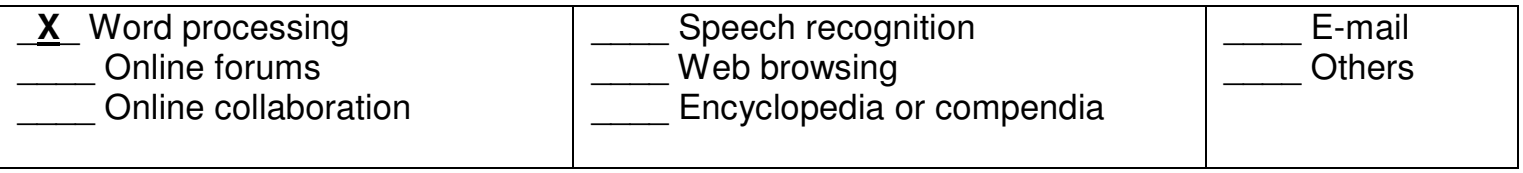

1.4 The program integrates other technological resources such as dictionaries on the web grammar on line other web sites

$\underline{\mathbf{X}}$ none

1.5 Directions for use:

$\underline{\mathbf{X}}$ are on the screen are in the documentation can be skipped at option of user

\section{PEDAGOGICAL ORIENTATION}

2.6 Program's theory of language

\begin{tabular}{|l|l|l|}
$\underline{\mathbf{X}}$ structural & $\underline{\mathbf{X}}$ functional & interactional \\
\hline
\end{tabular}

2.7 Type of program

\begin{tabular}{|c|c|c|c|}
\hline $\begin{array}{l}\mathbf{X} \text { - remediation } \\
\overline{\mathbf{X}}-\text { enrichment } \\
\text { tutoring }\end{array}$ & $\underline{\underline{\mathbf{X}}} \begin{array}{c}\text { demonstration } \\
\text { assessment }\end{array}$ & $\begin{array}{l}\text { game education } \\
\text { collaborative }\end{array}$ & $\begin{array}{c}\text { problem solving } \\
\underline{\mathbf{X}} \text { drill and practice } \\
\text { simulation }\end{array}$ \\
\hline
\end{tabular}




\begin{tabular}{|l|l|l|l|}
\hline & projects & \\
\hline
\end{tabular}

2.8 Curriculum capability

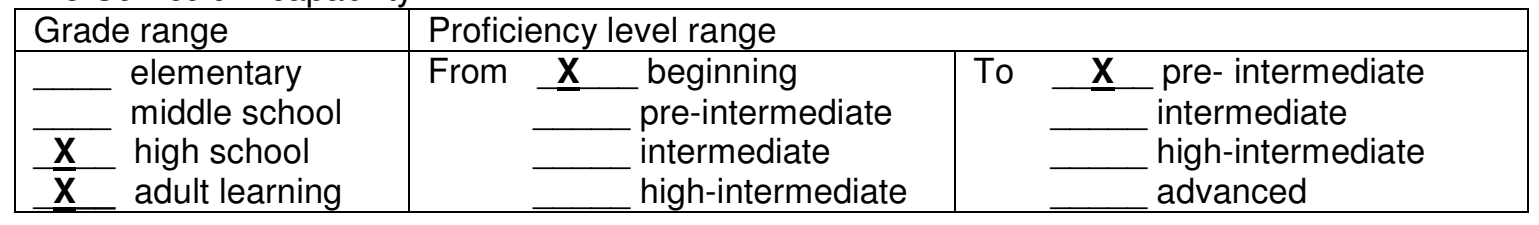

2.9 Method of language teaching claimed by the program

\begin{tabular}{|l|l|}
\hline $\begin{array}{l}\text { The Direct Method } \\
\text { The Natural Approach } \\
\text { Total Physical Response }\end{array}$ & $\underline{\mathbf{X}}$ The Audio-lingual Method \\
\hline
\end{tabular}

2.10 Language skills developed in the program

\begin{tabular}{|c|l|l|l|}
\hline \multicolumn{1}{c}{ speaking } & $\underline{\mathbf{X}}$ listening & $\underline{\mathbf{X}}$ reading & $\underline{\mathbf{X}}$ writing \\
\hline
\end{tabular}

2.11 Type of activities offered by the program

\begin{tabular}{|c|c|c|c|}
\hline $\begin{array}{c}\underline{\mathbf{X}} \text { games } \\
\underline{\underline{x}} \text { quizzes } \\
\text { others }\end{array}$ & $\begin{array}{l}\text { simulation } \\
\text { exploratory }\end{array}$ & $\begin{array}{l}\mathbf{X}_{-} \text {tutorial } \\
\text { text } \\
\text { construction }\end{array}$ & $\begin{array}{c}\underline{\mathbf{X}} \text { drill and practice } \\
\text { problem solving }\end{array}$ \\
\hline
\end{tabular}

2.12 Orientation of how to use program and its feature

\begin{tabular}{|c|c|}
\hline$\ldots$ for the teacher & on the screen \\
\hline for the student & on hard copy documentation \\
\hline for both & on both \\
\hline
\end{tabular}

2.13 Role of the teacher

\begin{tabular}{|l|l|l|l|}
\hline _ instructor & _ facilitator & X_lab manager & _ evaluator \\
\hline
\end{tabular}

2.14 Learners interact

\begin{tabular}{|c|l|l|}
\hline _ with one another & _ with the teacher & $\underline{\mathbf{X}}$ with neither \\
\hline
\end{tabular}

2.15 In case learners interact with one another, they can interact

\begin{tabular}{l|l} 
in all activities & in some activities
\end{tabular}

2.16 In case learners interact with the teacher, they can interact at any time at the end of the lesson at the end of the activities there's no interaction

\section{CRITICAL ANALYSIS}

For each item, circle the numbers 1 (for low) to 4 (for high) to indicate your judgment of the degree to which the program possesses or demonstrates the feature identified in each item. Circle 0 if the feature is not present in the program. 


\begin{tabular}{|c|c|c|c|c|c|}
\hline \multicolumn{6}{|l|}{ Instructional Attributes } \\
\hline Graphics and sound enhance learning. & 0 & $\begin{array}{l}\text { (low) } \\
1\end{array}$ & 2 & 3 & $\begin{array}{l}\text { (high) } \\
4\end{array}$ \\
\hline $\begin{array}{l}1.2 \text { The animation is effective in minimizing } \\
\text { boredom by motivating learners. }\end{array}$ & 0 & $\begin{array}{l}\text { (low) } \\
1\end{array}$ & 2 & 3 & $\begin{array}{l}\text { (high) } \\
4\end{array}$ \\
\hline 1.3Screen displays are uncluttered. & 0 & $\begin{array}{l}\text { (low) } \\
1\end{array}$ & 2 & 3 & $\begin{array}{l}\text { (high) } \\
4\end{array}$ \\
\hline 1.4 Graphics make information attractive. & 0 & $\begin{array}{ll}\text { (low) } \\
1\end{array}$ & 2 & 3 & $\begin{array}{l}\text { (high) } \\
4\end{array}$ \\
\hline $\begin{array}{l}1.5 \text { Graphics help memorization of key } \\
\text { information. }\end{array}$ & 0 & $\begin{array}{l}\text { (low) } \\
1\end{array}$ & 2 & 3 & $\begin{array}{l}\text { (high) } \\
4\end{array}$ \\
\hline $\begin{array}{l}\text { 1.6 The program makes use of authentic texts } \\
\text { and other realia. }\end{array}$ & 0 & $\begin{array}{l}\text { (low) } \\
1\end{array}$ & 2 & 3 & $\begin{array}{l}\text { (high) } \\
4\end{array}$ \\
\hline $\begin{array}{l}1.7 \text { The program integrates information about } \\
\text { culture/daily situations into the presentations } \\
\text { and activities. }\end{array}$ & 0 & $\begin{array}{ll}\text { (low) } \\
1\end{array}$ & 2 & 3 & $\begin{array}{l}\text { (high) } \\
4\end{array}$ \\
\hline $\begin{array}{l}1.8 \text { Lessons present and practice language } \\
\text { structures in meaningful communicative } \\
\text { contexts. }\end{array}$ & 0 & $\begin{array}{l}\text { (low) } \\
1\end{array}$ & 2 & 3 & $\begin{array}{l}\text { (high) } \\
4\end{array}$ \\
\hline $\begin{array}{l}1.9 \text { Lessons present and practice vocabulary in } \\
\text { meaningful communicative contexts. }\end{array}$ & 0 & $\begin{array}{ll}\text { (low) } \\
1\end{array}$ & 2 & 3 & $\begin{array}{l}\text { (high) } \\
4\end{array}$ \\
\hline $\begin{array}{l}\text { 1.10 Lessons develop the communicative skills } \\
\text { the program aims to develop. }\end{array}$ & 0 & $\begin{array}{l}\text { (low) } \\
1\end{array}$ & 2 & 3 & $\begin{array}{l}\text { (high) } \\
4\end{array}$ \\
\hline $\begin{array}{l}1.11 \text { Lessons develop the level of language } \\
\text { proficiency the program aims to develop. }\end{array}$ & 0 & $\begin{array}{l}\text { (low) } \\
1\end{array}$ & 2 & 3 & $\begin{array}{l}\text { (high) } \\
4\end{array}$ \\
\hline $\begin{array}{l}1.12 \text { The course syllabus reflects a } \\
\text { communicative approach to language } \\
\text { teaching/learning. }\end{array}$ & 0 & $\begin{array}{l}\text { (low) } \\
1\end{array}$ & 2 & 3 & $\begin{array}{l}\text { (high) } \\
4\end{array}$ \\
\hline $\begin{array}{l}1.13 \text { Content selection is determined by } \\
\text { communicative skills and/or themes. }\end{array}$ & 0 & $\begin{array}{ll}\text { (low) } \\
1\end{array}$ & 2 & 3 & $\begin{array}{l}\text { (high) } \\
4\end{array}$ \\
\hline $\begin{array}{l}\text { 1.14 Content is sequenced from simple } \\
\text { communicative functions, such as introducing } \\
\text { oneself, greeting, etc, to complex ones, such } \\
\text { as stating an opinion, disagreeing, etc. }\end{array}$ & 0 & $\begin{array}{l}\text { (low) } \\
1\end{array}$ & 2 & 3 & $\begin{array}{l}\text { (high) } \\
4\end{array}$ \\
\hline 1.15 Content is presented communicatively. & 0 & $\begin{array}{l}\text { (low) } \\
1\end{array}$ & 2 & 3 & $\begin{array}{l}\text { (high) } \\
4\end{array}$ \\
\hline $\begin{array}{l}\text { 1.16 The program develops the content at } \\
\text { appropriate levels of language proficiency. }\end{array}$ & 0 & $\begin{array}{l}\text { (low) } \\
1\end{array}$ & 2 & 3 & $\begin{array}{l}\text { (high) } \\
4\end{array}$ \\
\hline $\begin{array}{l}1.17 \text { The program content is educationally } \\
\text { relevant and interesting for the learner. }\end{array}$ & 0 & $\begin{array}{l}\text { (low) } \\
1\end{array}$ & 2 & 3 & $\begin{array}{l}\text { (high) } \\
4\end{array}$ \\
\hline $\begin{array}{l}\text { 1.18 The program content is appropriate for } \\
\text { intended learners. }\end{array}$ & 0 & $\begin{array}{ll}\text { (low) } \\
1\end{array}$ & 2 & 3 & $\begin{array}{l}\text { (high) } \\
4\end{array}$ \\
\hline $\begin{array}{l}1.19 \text { The program content is applicable to real } \\
\text { life contexts. }\end{array}$ & 0 & $\begin{array}{ll}\text { (low) } \\
1\end{array}$ & 2 & 3 & $\begin{array}{l}\text { (high) } \\
4\end{array}$ \\
\hline $\begin{array}{l}\text { 1.20 The program allows learners to work } \\
\text { together in communicative activities. }\end{array}$ & 0 & $\begin{array}{ll}\text { (low) } \\
1\end{array}$ & 2 & 3 & $\begin{array}{l}\text { (high) } \\
4\end{array}$ \\
\hline $\begin{array}{l}1.21 \text { The activities allow unplanned and/or } \\
\text { unpredictable responses. }\end{array}$ & 0 & $\begin{array}{l}\text { (low) } \\
1\end{array}$ & 2 & 3 & $\begin{array}{l}\text { (high) } \\
4\end{array}$ \\
\hline $\begin{array}{l}\text { 1.22 The activities lend themselves to group } \\
\text { discussions. }\end{array}$ & 0 & $\begin{array}{l}\text { (low) } \\
1\end{array}$ & 2 & 3 & $\begin{array}{l}\text { (high) } \\
4\end{array}$ \\
\hline $\begin{array}{l}\text { 1.23 The activities aim at developing other } \\
\text { competencies in addition to syntactical and } \\
\text { lexical }\end{array}$ & 0 & $\begin{array}{l}\text { (low) } \\
1\end{array}$ & 2 & 3 & $\begin{array}{l}\text { (high) } \\
4\end{array}$ \\
\hline
\end{tabular}




\begin{tabular}{|c|c|c|c|c|c|}
\hline $\begin{array}{l}\text { 1.24 The program allows the teacher to interact } \\
\text { with students while they are doing an activity. }\end{array}$ & 0 & $\begin{array}{l}\text { (low) } \\
1\end{array}$ & 2 & 3 & $\begin{array}{l}\text { (high) } \\
4\end{array}$ \\
\hline $\begin{array}{l}\text { 1.25 The program provides non-threatening } \\
\text { feedback. }\end{array}$ & 0 & $\begin{array}{l}\text { (low) } \\
1\end{array}$ & 2 & 3 & $\begin{array}{l}\text { (high) } \\
4\end{array}$ \\
\hline $\begin{array}{l}1.26 \text { The program allows learners to repeat an } \\
\text { activity after feedback is provided. }\end{array}$ & 0 & $\begin{array}{ll}\text { (low) } \\
1\end{array}$ & 2 & 3 & $\begin{array}{l}\text { (high) } \\
4\end{array}$ \\
\hline $\begin{array}{l}1.27 \text { Activities allow for more than one correct } \\
\text { response. }\end{array}$ & 0 & $\begin{array}{ll}\text { (low) } \\
1\end{array}$ & 2 & 3 & $\begin{array}{l}\text { (high) } \\
4\end{array}$ \\
\hline $\begin{array}{l}1.28 \text { The program provides the students with } \\
\text { feedback that would allow them to correct their } \\
\text { mistakes. }\end{array}$ & 0 & $\begin{array}{l}\text { (low) } \\
1\end{array}$ & 2 & 3 & $\begin{array}{l}\text { (high) } \\
4\end{array}$ \\
\hline
\end{tabular}

\begin{tabular}{|c|c|c|c|c|c|}
\hline \multicolumn{6}{|l|}{ Media Attributes } \\
\hline 2.29 Graphics aid understanding. & 0 & $\begin{array}{l}\text { (low) } \\
1\end{array}$ & 2 & 3 & $\begin{array}{l}\text { (high) } \\
4\end{array}$ \\
\hline $\begin{array}{l}\text { 2.30 The program allows for different routes and } \\
\text { choices for learning. }\end{array}$ & 0 & $\begin{array}{l}\text { (low) } \\
1\end{array}$ & 2 & 3 & $\begin{array}{l}\text { (high) } \\
4\end{array}$ \\
\hline $\begin{array}{l}2.31 \text { The program allows for review of old } \\
\text { information. }\end{array}$ & 0 & $\begin{array}{l}\text { (low) } \\
1\end{array}$ & 2 & 3 & $\begin{array}{l}\text { (high) } \\
4\end{array}$ \\
\hline $\begin{array}{l}2.32 \text { The program allows branching to new } \\
\text { information. }\end{array}$ & 0 & $\begin{array}{ll}\text { (low) } \\
1\end{array}$ & 2 & 3 & $\begin{array}{l}\text { (high) } \\
4\end{array}$ \\
\hline $\begin{array}{l}2.33 \text { The program allows students to select } \\
\text { activities according to their ages. }\end{array}$ & 0 & $\begin{array}{l}\text { (low) } \\
1\end{array}$ & 2 & 3 & $\begin{array}{l}\text { (high) } \\
4\end{array}$ \\
\hline $\begin{array}{l}\text { 2.34 The program allows students to select } \\
\text { activities according to their learning styles. }\end{array}$ & 0 & $\begin{array}{l}\text { (low) } \\
1\end{array}$ & 2 & 3 & $\begin{array}{l}\text { (high) } \\
4\end{array}$ \\
\hline $\begin{array}{l}\text { 2.35 The program allows students to select } \\
\text { activities according to their interests. }\end{array}$ & 0 & $\begin{array}{ll}\text { (low) } \\
1\end{array}$ & 2 & 3 & $\begin{array}{l}\text { (high) } \\
4\end{array}$ \\
\hline $\begin{array}{l}2.36 \text { The program adapts to the responses } \\
\text { given by the learners, branching to more or less } \\
\text { complicated questions as appropriate. }\end{array}$ & 0 & $\begin{array}{l}\text { (low) } \\
1\end{array}$ & 2 & 3 & $\begin{array}{l}\text { (high) } \\
4\end{array}$ \\
\hline $\begin{array}{l}\text { 2.37 The program allows learners to go through } \\
\text { its content at their own pace and rhythm. }\end{array}$ & 0 & $\begin{array}{ll}\text { (low) } \\
1\end{array}$ & 2 & 3 & $\begin{array}{l}\text { (high) } \\
4\end{array}$ \\
\hline $\begin{array}{l}2.38 \text { The program prevents learners from } \\
\text { repeating exercises, therefore, minimizing } \\
\text { guessing. }\end{array}$ & 0 & $\begin{array}{l}\text { (low) } \\
1\end{array}$ & 2 & 3 & $\begin{array}{l}\text { (high) } \\
4\end{array}$ \\
\hline $\begin{array}{l}2.39 \text { The program keeps records of learners' } \\
\text { performance to allow them to continue activities } \\
\text { from where they left off. }\end{array}$ & 0 & $\begin{array}{l}\text { (low) } \\
1\end{array}$ & 2 & 3 & $\begin{array}{l}\text { (high) } \\
4\end{array}$ \\
\hline $\begin{array}{l}2.40 \text { The program keeps track of students' } \\
\text { scores. }\end{array}$ & 0 & $\begin{array}{l}\text { (low) } \\
1\end{array}$ & 2 & 3 & $\begin{array}{l}\text { (high) } \\
4\end{array}$ \\
\hline $\begin{array}{l}2.41 \text { The program provides feedback for both } \\
\text { correct and incorrect answers. The program } \\
\text { provides feedback for both correct and incorrect } \\
\text { answers. }\end{array}$ & 0 & $\begin{array}{l}\text { (low) } \\
1\end{array}$ & 2 & 3 & $\begin{array}{l}\text { (high) } \\
4\end{array}$ \\
\hline $\begin{array}{l}2.42 \text { The program gives learners the chance to } \\
\text { correct their errors. }\end{array}$ & 0 & $\begin{array}{l}\text { (low) } \\
1\end{array}$ & 2 & 3 & $\begin{array}{l}\text { (high) } \\
4\end{array}$ \\
\hline $\begin{array}{l}2.43 \text { The program effectively signals the } \\
\text { mistakes before providing the right answers. }\end{array}$ & 0 & $\begin{array}{l}\text { (low) } \\
1\end{array}$ & 2 & 3 & $\begin{array}{l}\text { (high) } \\
4\end{array}$ \\
\hline
\end{tabular}




\begin{tabular}{|c|c|c|c|c|c|}
\hline $\begin{array}{l}2.44 \text { The program effectively specifies different } \\
\text { types of errors, such as differences between a } \\
\text { syntactic error and an incorrect word choice. }\end{array}$ & 0 & $\begin{array}{l}\text { (low) } \\
1\end{array}$ & 2 & 3 & $\begin{array}{l}\text { (high) } \\
4\end{array}$ \\
\hline \multicolumn{6}{|l|}{ Sub-total $=20(31.25 \%)$} \\
\hline \multicolumn{6}{|l|}{ User-Friendly Attributes } \\
\hline $\begin{array}{l}\text { 3.45 Menu items are understandable and } \\
\text { descriptive. }\end{array}$ & 0 & $\begin{array}{l}\text { (low) } \\
1\end{array}$ & 2 & 3 & $\begin{array}{l}\text { (high) } \\
4\end{array}$ \\
\hline $\begin{array}{l}\text { 3.46 The commands and instructions for the } \\
\text { activities are clear and objective. }\end{array}$ & 0 & $\begin{array}{l}\text { (low) } \\
1\end{array}$ & 2 & 3 & $\begin{array}{l}\text { (high) } \\
4\end{array}$ \\
\hline $\begin{array}{l}\text { 3.47 The program gives the learners effective } \\
\text { clues to clarify their doubts about its use. }\end{array}$ & 0 & $\begin{array}{l}\text { (low) } \\
1\end{array}$ & 2 & 3 & $\begin{array}{l}\text { (high) } \\
4\end{array}$ \\
\hline $\begin{array}{l}3.48 \text { Each screen uses text and } \\
\text { graphic/animation to make a particular teaching } \\
\text { point clear. }\end{array}$ & 0 & $\begin{array}{l}\text { (low) } \\
1\end{array}$ & 2 & 3 & $\begin{array}{l}\text { (high) } \\
4\end{array}$ \\
\hline $\begin{array}{l}\text { 3.49 The program is effectively integrated with } \\
\text { other technological resources (such as } \\
\text { dictionaries on the web, grammar on line, etc) } \\
\text { as the learner uses it. }\end{array}$ & 0 & $\begin{array}{l}\text { (low) } \\
1\end{array}$ & 2 & 3 & $\begin{array}{l}\text { (high) } \\
4\end{array}$ \\
\hline $\begin{array}{l}3.50 \text { lcons, buttons and menus allow learners to } \\
\text { readily search for additional information while } \\
\text { doing an activity. }\end{array}$ & 0 & $\begin{array}{l}\text { (low) } \\
1\end{array}$ & 2 & 3 & $\begin{array}{l}\text { (high) } \\
4\end{array}$ \\
\hline $\begin{array}{l}3.51 \text { Buttons, icons or menu items make Help or } \\
\text { Hint-type options easily accessible. }\end{array}$ & 0 & $\begin{array}{l}\text { (low) } \\
1 \\
\end{array}$ & 2 & 3 & $\begin{array}{l}\text { (high) } \\
4\end{array}$ \\
\hline $\begin{array}{l}\text { 3.52 The program arouses sensory and } \\
\text { cognitive curiosity }\end{array}$ & 0 & $\begin{array}{l}(\text { low }) \\
1\end{array}$ & 2 & 3 & $\begin{array}{l}\text { (high) } \\
4\end{array}$ \\
\hline $\begin{array}{l}3.53 \text { The program maintains attention } \\
\text { throughout the lesson. }\end{array}$ & 0 & $\begin{array}{l}\text { (low) } \\
1\end{array}$ & 2 & 3 & $\begin{array}{l}\text { (high) } \\
4\end{array}$ \\
\hline $\begin{array}{l}3.54 \text { The use of animation invites learners' } \\
\text { reaction or input. }\end{array}$ & 0 & $\begin{array}{l}\text { (low) } \\
1 \\
\end{array}$ & 2 & 3 & $\begin{array}{l}\text { (high) } \\
4\end{array}$ \\
\hline $\begin{array}{l}3.55 \text { The program gives teachers a clear } \\
\text { explanation of its purposes and methodological } \\
\text { orientation. }\end{array}$ & 0 & $\begin{array}{l}\text { (low) } \\
1\end{array}$ & 2 & 3 & $\begin{array}{l}\text { (high) } \\
4\end{array}$ \\
\hline \multicolumn{6}{|l|}{ Sub-total = $22(50 \%)$} \\
\hline Total $=103(46.81 \%)$ & & & & & \\
\hline
\end{tabular}

Sub-total of ratings for Instructional Attributes ..........................

Sub-total of ratings for Media Attributes ................................

Sub-total of ratings for User-Friendly Attributes .......................

$61(54.46 \%)$

Total rating 


\section{ESL/EFL SOFTWARE EVALUATION INSTRUMENT}

Title of the program Talk Now! Talk More! World Talk (Instant Immersion)

Publisher/date EuroTalk Interactive

\section{DESCRIPTIVE ANALYSIS}

Please place a checkmark next to the item that best describes the program and/or its features.

\section{TECHNICAL FEATURES}

1.1 Components of the program:

\begin{tabular}{|l|l|l|}
\hline $\begin{array}{c}\text { Number of CD's: } \\
\text { Per level: } \mathbf{1} \\
\text { Total: } \underline{\mathbf{3}}\end{array}$ & Teacher's guide_X_Yes__No & $\begin{array}{l}\text { Support materials__Yes_X_No } \\
\text { What type? }\end{array}$ \\
\hline
\end{tabular}

1.2 Platform

\begin{tabular}{|c|c|c|}
\hline SX & & Windows 98/2000/ME/XP \\
\hline
\end{tabular}

1.3 Tools

\begin{tabular}{|l|l|l|}
\hline $\begin{array}{l}\text { Word processing } \\
\text { Online forums } \\
\text { Online collaboration }\end{array}$ & $\begin{array}{l}\mathbf{X} \text { - Speech recognition } \\
\text { Web browsing } \\
\text { Encyclopedia or compendia }\end{array}$ & $\begin{array}{l}\text { E-mail } \\
\text { Others }\end{array}$ \\
\hline
\end{tabular}

1.4 Other technological resources integrated into the program:

\begin{tabular}{|l|l|l|l|}
\hline$\frac{1}{\text { web }}$ dictionaries on the & grammar on line & other web sites & $\mathbf{X}$ _ none \\
\hline
\end{tabular}

1.5 Directions for use:

\begin{tabular}{|l|l|l|}
\hline $\mathbf{X}_{-}$are on the screen & are in the documentation & $\begin{array}{l}\mathbf{X} \text { _can be skipped at option of } \\
\text { user }\end{array}$ \\
\hline
\end{tabular}

\section{PEDAGOGICAL ORIENTATION}

2.6 Program's theory of language

\begin{tabular}{|l|l|l|}
\hline structural & $\mathbf{X} \_$functional & interactional \\
\hline
\end{tabular}

2.7 Type of program

\begin{tabular}{|c|c|c|c|}
\hline $\begin{array}{c}\mathbf{X} \text { _remediation } \\
\mathbf{X} \text { _enrichment } \\
\text { tutoring }\end{array}$ & $\begin{array}{c}\mathbf{X} \text { _ demonstration } \\
\text { assessment }\end{array}$ & $\begin{array}{c}\mathbf{X}_{-} \text {education } \\
\text { game } \\
\text { collaborative } \\
\text { projects }\end{array}$ & $\begin{array}{c}\mathbf{X} \text { problem solving } \\
\text { drill and practice } \\
\text { simulation }\end{array}$ \\
\hline
\end{tabular}




\begin{tabular}{|c|c|c|c|}
\hline Grade range & Proficiency level range & & \\
\hline $\begin{array}{ll} & \text { elementary } \\
& \text { middle school } \\
\mathbf{X} & \text { high school } \\
\mathbf{X} & \text { adult learning }\end{array}$ & From $\begin{aligned} \mathbf{X} \quad \text { beginning } \\
\text { pre-intermediate } \\
\text { intermediate } \\
\text { high-intermediate }\end{aligned}$ & & $\begin{array}{c}\text { X_pre- intermediate } \\
\text { intermediate } \\
\text { high-intermediate } \\
\text { advanced }\end{array}$ \\
\hline
\end{tabular}

2.9 Method of language teaching claimed by the program

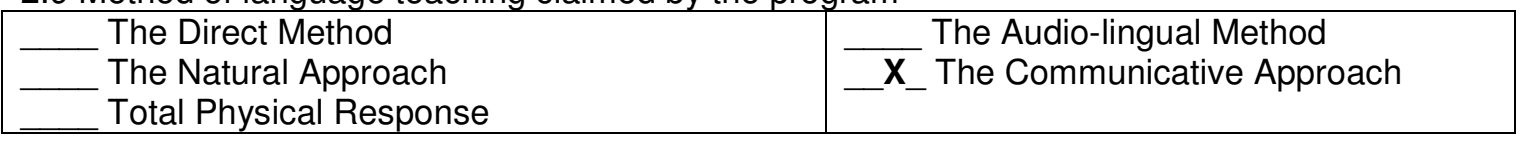

2.10 Language skills developed in the program

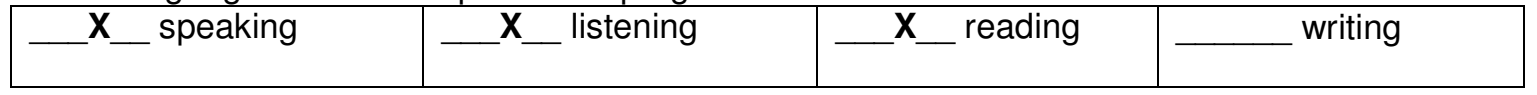

2.11 Type of activities offered by the program

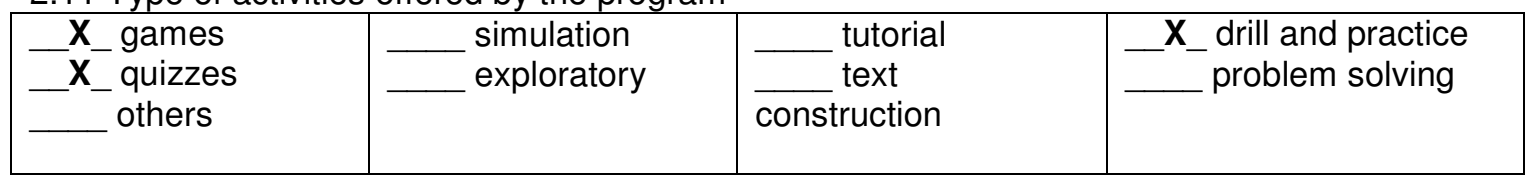

2.12 Orientation of how to use program and its feature

\begin{tabular}{|c|c|}
\hline $\mathbf{X}$ for the teacher & $\mathbf{X}$ on the screen \\
\hline $\mathbf{X}$ for both & on hard copy documentation \\
\hline
\end{tabular}

2.13 Role of the teacher

\begin{tabular}{|c|l|l|l|}
\hline instructor & _ facilitator & X_lab manager & _ evaluator \\
\hline
\end{tabular}

2.14 Learners interact

\begin{tabular}{|l|l|l|}
\hline _ with one another & _ with the teacher & X_with neither \\
\hline
\end{tabular}

2.15 In case learners interact with one another, they can interact

\begin{tabular}{|l|l|}
\hline in all activities & in some activities \\
\hline
\end{tabular}

2.16 In case learners interact with the teacher, they can interact at any time at the end of the lesson at the end of the activities there's no interaction

\section{CRITICAL ANALYSIS}

For each item, circle the numbers 1 (for low) to 4 (for high) to indicate your judgment of the degree to which the program possesses or demonstrates the feature identified in each item. Circle 0 if the feature is not present in the program. 


\begin{tabular}{|c|c|c|c|c|c|}
\hline Graphics and sound enhance learning. & 0 & $\begin{array}{l}\text { (low) } \\
1\end{array}$ & 2 & 3 & $\begin{array}{l}\text { (high) } \\
4\end{array}$ \\
\hline $\begin{array}{l}1.2 \text { The animation is effective in minimizing } \\
\text { boredom by motivating learners. }\end{array}$ & 0 & $\begin{array}{l}\text { (low) } \\
1\end{array}$ & 2 & 3 & $\begin{array}{l}\text { (high) } \\
4\end{array}$ \\
\hline 1.3Screen displays are uncluttered. & 0 & $\begin{array}{l}\text { (low) } \\
1\end{array}$ & 2 & 3 & $\begin{array}{l}\text { (high) } \\
4\end{array}$ \\
\hline 1.4 Graphics make information attractive. & 0 & $\begin{array}{l}\text { (low) } \\
1\end{array}$ & 2 & 3 & $\begin{array}{l}\text { (high) } \\
4\end{array}$ \\
\hline $\begin{array}{l}1.5 \text { Graphics help memorization of key } \\
\text { information. }\end{array}$ & 0 & $\begin{array}{l}\text { (low) } \\
1\end{array}$ & 2 & 3 & $\begin{array}{l}\text { (high) } \\
4\end{array}$ \\
\hline $\begin{array}{l}\text { 1.6 The program makes use of authentic } \\
\text { texts and other realia. }\end{array}$ & 0 & $\begin{array}{l}\text { (low) } \\
1\end{array}$ & 2 & 3 & $\begin{array}{l}\text { (high) } \\
4\end{array}$ \\
\hline $\begin{array}{l}1.7 \text { The program integrates information } \\
\text { about culture/daily situations into the } \\
\text { presentations and activities. }\end{array}$ & 0 & $\begin{array}{l}\text { (low) } \\
1\end{array}$ & 2 & 3 & $\begin{array}{l}\text { (high) } \\
4\end{array}$ \\
\hline $\begin{array}{l}1.8 \text { Lessons present and practice language } \\
\text { structures in meaningful communicative } \\
\text { contexts. }\end{array}$ & 0 & $\begin{array}{l}\text { (low) } \\
1\end{array}$ & 2 & 3 & $\begin{array}{l}\text { (high) } \\
4\end{array}$ \\
\hline $\begin{array}{l}1.9 \text { Lessons present and practice } \\
\text { vocabulary in meaningful communicative } \\
\text { contexts. }\end{array}$ & 0 & $\begin{array}{l}\text { (low) } \\
1\end{array}$ & 2 & 3 & $\begin{array}{l}\text { (high) } \\
4\end{array}$ \\
\hline $\begin{array}{l}\text { 1.10 Lessons develop the communicative } \\
\text { skills the program aims to develop. }\end{array}$ & 0 & $\begin{array}{l}\text { (low) } \\
1\end{array}$ & 2 & 3 & $\begin{array}{l}\text { (high) } \\
4\end{array}$ \\
\hline $\begin{array}{l}1.11 \text { Lessons develop the level of language } \\
\text { proficiency the program aims to develop. }\end{array}$ & 0 & $\begin{array}{l}\text { (low) } \\
1\end{array}$ & 2 & 3 & $\begin{array}{l}\text { (high) } \\
4\end{array}$ \\
\hline $\begin{array}{l}1.12 \text { The course syllabus reflects a } \\
\text { communicative approach to language } \\
\text { teaching/learning. }\end{array}$ & 0 & $\begin{array}{l}\text { (low) } \\
1\end{array}$ & 2 & 3 & $\begin{array}{l}\text { (high) } \\
4\end{array}$ \\
\hline $\begin{array}{l}1.13 \text { Content selection is determined by } \\
\text { communicative skills and/or themes. }\end{array}$ & 0 & $\begin{array}{l}\text { (low) } \\
1\end{array}$ & 2 & 3 & $\begin{array}{l}\text { (high) } \\
4\end{array}$ \\
\hline $\begin{array}{l}\text { 1.14 Content is sequenced from simple } \\
\text { communicative functions, such as } \\
\text { introducing oneself, greeting, etc, to } \\
\text { complex ones, such as stating an opinion, } \\
\text { disagreeing, etc. }\end{array}$ & 0 & $\begin{array}{l}\text { (low) } \\
1\end{array}$ & 2 & 3 & $\begin{array}{l}\text { (high) } \\
4\end{array}$ \\
\hline $\begin{array}{l}1.15 \text { Content is presented } \\
\text { communicatively. }\end{array}$ & 0 & $\begin{array}{l}\text { (low) } \\
1\end{array}$ & 2 & 3 & $\begin{array}{l}\text { (high) } \\
4\end{array}$ \\
\hline $\begin{array}{l}\text { 1.16 The program develops the content at } \\
\text { appropriate levels of language proficiency. }\end{array}$ & 0 & $\begin{array}{l}\text { (low) } \\
1\end{array}$ & 2 & 3 & $\begin{array}{l}\text { (high) } \\
4\end{array}$ \\
\hline $\begin{array}{l}1.17 \text { The program content is educationally } \\
\text { relevant and interesting for the learner. }\end{array}$ & 0 & $\begin{array}{l}\text { (low) } \\
1\end{array}$ & 2 & 3 & $\begin{array}{l}\text { (high) } \\
4\end{array}$ \\
\hline $\begin{array}{l}1.18 \text { The program content is appropriate } \\
\text { for intended learners. }\end{array}$ & 0 & $\begin{array}{l}\text { (low) } \\
1\end{array}$ & 2 & 3 & $\begin{array}{l}\text { (high) } \\
4\end{array}$ \\
\hline $\begin{array}{l}\text { 1.19 The program content is applicable to } \\
\text { real life contexts. }\end{array}$ & 0 & $\begin{array}{l}\text { (low) } \\
1\end{array}$ & 2 & 3 & $\begin{array}{l}\text { (high) } \\
4\end{array}$ \\
\hline $\begin{array}{l}1.20 \text { The program allows learners to work } \\
\text { together in communicative activities. }\end{array}$ & 0 & $\begin{array}{l}\text { (low) } \\
1\end{array}$ & 2 & 3 & $\begin{array}{l}\text { (high) } \\
4\end{array}$ \\
\hline $\begin{array}{l}\text { 1.21 The activities allow unplanned and/or } \\
\text { unpredictable responses. }\end{array}$ & 0 & $\begin{array}{l}\text { (low) } \\
1\end{array}$ & 2 & 3 & $\begin{array}{l}\text { (high) } \\
4\end{array}$ \\
\hline $\begin{array}{l}1.22 \text { The activities lend themselves to } \\
\text { group discussions. }\end{array}$ & 0 & $\begin{array}{l}\text { (low) } \\
1\end{array}$ & 2 & 3 & $\begin{array}{l}\text { (high) } \\
4\end{array}$ \\
\hline $\begin{array}{l}\text { 1.23 The activities aim at developing other } \\
\text { competencies in addition to syntactical and } \\
\text { lexical }\end{array}$ & 0 & $\begin{array}{l}\text { (low) } \\
1\end{array}$ & 2 & 3 & $\begin{array}{l}\text { (high) } \\
4\end{array}$ \\
\hline
\end{tabular}




\begin{tabular}{|c|c|c|c|c|c|}
\hline $\begin{array}{l}1.24 \text { The program allows the teacher to } \\
\text { interact with students while they are doing } \\
\text { an activity. }\end{array}$ & 0 & $\begin{array}{l}\text { (low) } \\
1\end{array}$ & 2 & 3 & $\begin{array}{l}\text { (high) } \\
4\end{array}$ \\
\hline $\begin{array}{l}1.25 \text { The program provides non- } \\
\text { threatening feedback. }\end{array}$ & 0 & $\begin{array}{l}\text { (low) } \\
1\end{array}$ & 2 & 3 & $\begin{array}{l}\text { (high) } \\
4\end{array}$ \\
\hline $\begin{array}{l}1.26 \text { The program allows learners to repeat } \\
\text { an activity after feedback is provided. }\end{array}$ & 0 & $\begin{array}{l}\text { (low) } \\
1\end{array}$ & 2 & 3 & $\begin{array}{l}\text { (high) } \\
4\end{array}$ \\
\hline $\begin{array}{l}1.27 \text { Activities allow for more than one } \\
\text { correct response. }\end{array}$ & 0 & $\begin{array}{l}\text { (low) } \\
1\end{array}$ & 2 & 3 & $\begin{array}{l}\text { (high) } \\
4\end{array}$ \\
\hline $\begin{array}{l}1.28 \text { The program provides the students } \\
\text { with feedback that would allow them to } \\
\text { correct their mistakes. }\end{array}$ & 0 & $\begin{array}{l}\text { (low) } \\
1\end{array}$ & 2 & 3 & $\begin{array}{l}\text { (high) } \\
4\end{array}$ \\
\hline
\end{tabular}

\begin{tabular}{|c|c|c|c|c|c|}
\hline \multicolumn{6}{|l|}{ Media Attributes } \\
\hline 2.29 Graphics aid understanding. & 0 & $\begin{array}{l}\text { (low) } \\
1\end{array}$ & 2 & 3 & $\begin{array}{l}\text { (high) } \\
4\end{array}$ \\
\hline $\begin{array}{l}2.30 \text { The program allows for different routes } \\
\text { and choices for learning. }\end{array}$ & 0 & $\begin{array}{l}\text { (low) } \\
1\end{array}$ & 2 & 3 & $\begin{array}{l}\text { (high) } \\
4\end{array}$ \\
\hline $\begin{array}{l}\text { 2.31 The program allows for review of old } \\
\text { information. }\end{array}$ & 0 & $\begin{array}{ll}\text { (low) } \\
1\end{array}$ & 2 & 3 & $\begin{array}{l}\text { (high) } \\
4\end{array}$ \\
\hline $\begin{array}{l}2.32 \text { The program allows branching to new } \\
\text { information. }\end{array}$ & 0 & $\begin{array}{ll}\text { (low) } \\
1\end{array}$ & 2 & 3 & $\begin{array}{l}\text { (high) } \\
4\end{array}$ \\
\hline $\begin{array}{l}2.33 \text { The program allows students to select } \\
\text { activities according to their ages. }\end{array}$ & 0 & $\begin{array}{l}\text { (low) } \\
1\end{array}$ & 2 & 3 & $\begin{array}{l}\text { (high) } \\
4\end{array}$ \\
\hline $\begin{array}{l}\text { 2.34 The program allows students to select } \\
\text { activities according to their learning styles. }\end{array}$ & 0 & $\begin{array}{l}\text { (low) } \\
1\end{array}$ & 2 & 3 & $\begin{array}{l}\text { (high) } \\
4\end{array}$ \\
\hline $\begin{array}{l}2.35 \text { The program allows students to select } \\
\text { activities according to their interests. }\end{array}$ & 0 & $\begin{array}{l}\text { (low) } \\
1\end{array}$ & 2 & 3 & $\begin{array}{l}\text { (high) } \\
4\end{array}$ \\
\hline $\begin{array}{l}2.36 \text { The program adapts to the responses } \\
\text { given by the learners, branching to more or } \\
\text { less complicated questions as appropriate. }\end{array}$ & 0 & $\begin{array}{l}\text { (low) } \\
1\end{array}$ & 2 & 3 & $\begin{array}{l}\text { (high) } \\
4\end{array}$ \\
\hline $\begin{array}{l}2.37 \text { The program allows learners to go } \\
\text { through its content at their own pace and } \\
\text { rhythm. }\end{array}$ & 0 & $\begin{array}{l}\text { (low) } \\
1\end{array}$ & 2 & 3 & $\begin{array}{l}\text { (high) } \\
4\end{array}$ \\
\hline $\begin{array}{l}2.38 \text { The program prevents learners from } \\
\text { repeating exercises, therefore, minimizing } \\
\text { guessing. }\end{array}$ & 0 & $\begin{array}{ll}\text { (low) } \\
1\end{array}$ & 2 & 3 & $\begin{array}{l}\text { (high) } \\
4\end{array}$ \\
\hline $\begin{array}{l}\text { 2.39 The program keeps records of } \\
\text { learners' performance to allow them to } \\
\text { continue activities from where they left off. }\end{array}$ & 0 & $\begin{array}{l}\text { (low) } \\
1\end{array}$ & 2 & 3 & $\begin{array}{l}\text { (high) } \\
4\end{array}$ \\
\hline $\begin{array}{l}2.40 \text { The program keeps track of students' } \\
\text { scores. }\end{array}$ & 0 & $\begin{array}{l}\text { (low) } \\
1\end{array}$ & 2 & 3 & $\begin{array}{l}\text { (high) } \\
4\end{array}$ \\
\hline $\begin{array}{l}2.41 \text { The program provides feedback for } \\
\text { both correct and incorrect answers. }\end{array}$ & 0 & $\begin{array}{ll}\text { (low) } \\
1\end{array}$ & 2 & 3 & $\begin{array}{l}\text { (high) } \\
4\end{array}$ \\
\hline $\begin{array}{l}\text { 2.42 The program gives learners the } \\
\text { chance to correct their errors. }\end{array}$ & 0 & $\begin{array}{l}\text { (low) } \\
1\end{array}$ & 2 & 3 & $\begin{array}{l}\text { (high) } \\
4\end{array}$ \\
\hline $\begin{array}{l}2.43 \text { The program effectively signals the } \\
\text { mistakes before providing the right answers. }\end{array}$ & 0 & $\begin{array}{ll}\text { (low) } \\
1\end{array}$ & 2 & 3 & $\begin{array}{l}\text { (high) } \\
4\end{array}$ \\
\hline
\end{tabular}




\begin{tabular}{|c|c|c|c|c|c|}
\hline $\begin{array}{l}2.44 \text { The program effectively specifies } \\
\text { different types of errors, such as differences } \\
\text { between a syntactic error and an incorrect } \\
\text { word choice. }\end{array}$ & 0 & $\begin{array}{l}\text { (low) } \\
1\end{array}$ & 2 & 3 & $\begin{array}{l}\text { (high) } \\
4\end{array}$ \\
\hline \multicolumn{6}{|l|}{ Sub-total = 25 (40.9\%) } \\
\hline \multicolumn{6}{|l|}{ User-Friendly Attributes } \\
\hline $\begin{array}{l}\text { 3.45 Menu items are understandable and } \\
\text { descriptive. }\end{array}$ & 0 & $\begin{array}{l}\text { (low) } \\
1\end{array}$ & 2 & 3 & $\begin{array}{l}\text { (high) } \\
4\end{array}$ \\
\hline $\begin{array}{l}\text { 3.46 The commands and instructions for the } \\
\text { activities are clear and objective. }\end{array}$ & 0 & $\begin{array}{l}\text { (low) } \\
1\end{array}$ & 2 & 3 & $\begin{array}{l}\text { (high) } \\
4\end{array}$ \\
\hline $\begin{array}{l}\text { 3.47 The program gives the learners } \\
\text { effective clues to clarify their doubts about } \\
\text { its use. }\end{array}$ & 0 & $\begin{array}{l}\text { (low) } \\
1\end{array}$ & 2 & 3 & $\begin{array}{l}\text { (high) } \\
4\end{array}$ \\
\hline $\begin{array}{l}\text { 3.48 Each screen uses text and } \\
\text { graphic/animation to make a particular } \\
\text { teaching point clear. }\end{array}$ & 0 & $\begin{array}{l}\text { (low) } \\
1\end{array}$ & 2 & 3 & $\begin{array}{l}\text { (high) } \\
4\end{array}$ \\
\hline $\begin{array}{l}3.49 \text { The program is effectively integrated } \\
\text { with other technological resources (such as } \\
\text { dictionaries on the web, grammar on line, } \\
\text { etc) as the learner uses it. }\end{array}$ & 0 & $\begin{array}{l}\text { (low) } \\
1\end{array}$ & 2 & 3 & $\begin{array}{l}\text { (high) } \\
4\end{array}$ \\
\hline $\begin{array}{l}3.50 \text { Icons, buttons and menus allow } \\
\text { learners to readily search for additional } \\
\text { information while doing an activity. }\end{array}$ & 0 & $\begin{array}{l}\text { (low) } \\
1\end{array}$ & 2 & 3 & $\begin{array}{l}\text { (high) } \\
4\end{array}$ \\
\hline $\begin{array}{l}3.51 \text { Buttons, icons or menu items make } \\
\text { Help or Hint-type options easily accessible. }\end{array}$ & 0 & $\begin{array}{l}\text { (low) } \\
1\end{array}$ & 2 & 3 & $\begin{array}{l}\text { (high) } \\
4\end{array}$ \\
\hline $\begin{array}{l}\text { 3.52 The program arouses sensory and } \\
\text { cognitive curiosity }\end{array}$ & 0 & $\begin{array}{l}\text { (low) } \\
1\end{array}$ & 2 & 3 & $\begin{array}{l}\text { (high) } \\
4\end{array}$ \\
\hline $\begin{array}{l}3.53 \text { The program maintains attention } \\
\text { throughout the lesson. }\end{array}$ & 0 & $\begin{array}{ll}\text { (low) } \\
1\end{array}$ & 2 & 3 & $\begin{array}{l}\text { (high) } \\
4\end{array}$ \\
\hline $\begin{array}{l}3.54 \text { The use of animation invites learners' } \\
\text { reaction or input. }\end{array}$ & 0 & $\begin{array}{ll}\text { (low) } \\
1\end{array}$ & 2 & 3 & $\begin{array}{l}\text { (high) } \\
4\end{array}$ \\
\hline $\begin{array}{l}3.55 \text { The program gives teachers a clear } \\
\text { explanation of its purposes and } \\
\text { methodological orientation. }\end{array}$ & 0 & $\begin{array}{l}\text { (low) } \\
1\end{array}$ & 2 & 3 & $\begin{array}{l}\text { (high) } \\
4\end{array}$ \\
\hline Sub-total $=22(50 \%)$ & & & & & \\
\hline
\end{tabular}

Sub-total of ratings for Instructional Attributes ......................... 42 (37.5\%)

Sub-total of ratings for Media Attributes .............................. $25(40.9 \%)$

Sub-total of ratings for User-Friendly Attributes ...................... $22(50 \%)$

Total rating .................................................................. 89 (40.45\%) 


\section{ESL/EFL SOFTWARE EVALUATION INSTRUMENT}

Title of the program: Tell me More

Publisher: Auralog Inc. USA

\section{DESCRIPTIVE ANALYSIS}

Please place a checkmark next to the item that best describes the program and/or its features.

\section{TECHNICAL FEATURES}

1.1 Components of the program:

\begin{tabular}{|c|c|l|}
$\begin{array}{c}\text { Number of CD's: } \\
\text { per level } \\
\text { Total }\end{array}$ & Teacher's guide__Yes _ X_No & $\begin{array}{l}\text { Support materials_X_Yes } \\
\text { What type? Printed User's Manual }\end{array}$ \\
\hline
\end{tabular}

1.2 Platform

\begin{tabular}{|l|l|}
\hline Mac_ _ Mhz MB of RAM & $\begin{array}{l}\text { Windows 95, 98, NT4, Millennium, 2000, XP } \\
\text { Celeron 333 Mhz 128 (minimum) MB of } \\
\text { RAM }\end{array}$ \\
\hline
\end{tabular}

1.3 Tools

\begin{tabular}{|l|l|l|}
\hline $\mathbf{X}$ X_Word processing \\
$\begin{array}{l}\text { Online forums } \\
\text { Online collaboration }\end{array}$ & $\begin{array}{l}\mathbf{X} \text { S Speech recognition } \\
\mathbf{X}-\text { Web browsing } \\
\text { Encyclopedia or compendia }\end{array}$ & - E-mail \\
\hline
\end{tabular}

1.4 Other technological resources such as

\begin{tabular}{|l|l|l|l|}
\hline$\frac{1}{\text { web }}$ dictionaries on the & grammar on line & $\begin{array}{l}\mathbf{X} \text { other web sites } \\
\text { online tutorials }\end{array}$ & none \\
\hline
\end{tabular}

1.5 Directions for use:

\begin{tabular}{|l|l|l|}
\hline $\mathbf{X}_{-}$are on the screen & $\mathbf{X}_{-}$are in the documentation & $\underset{\text { user }}{\mathbf{X}}$ can be skipped at option of \\
\hline
\end{tabular}

\section{PEDAGOGICAL ORIENTATION}

2.6 Program's theory of language

\begin{tabular}{|l|l|l|}
\hline structural & $\mathbf{X} \_$functional & interactional \\
\hline
\end{tabular}

2.7 Type of program

\begin{tabular}{|c|c|c|c|}
\hline $\begin{array}{l}\mathbf{X} \text { _remediation } \\
\mathbf{X} \text { _ enrichment } \\
\text { tutoring }\end{array}$ & $\begin{array}{l}\text { demonstration } \\
\mathbf{X} \text { _assessment }\end{array}$ & $\begin{array}{l}\overline{\text { game }}^{\text {education }} \\
\text { collaborative }\end{array}$ & $\begin{array}{c}\mathbf{X} \text { _ problem solving } \\
\mathbf{X} \text { drill and practice } \\
\text { simulation }\end{array}$ \\
\hline
\end{tabular}


2.8 Curriculum capability

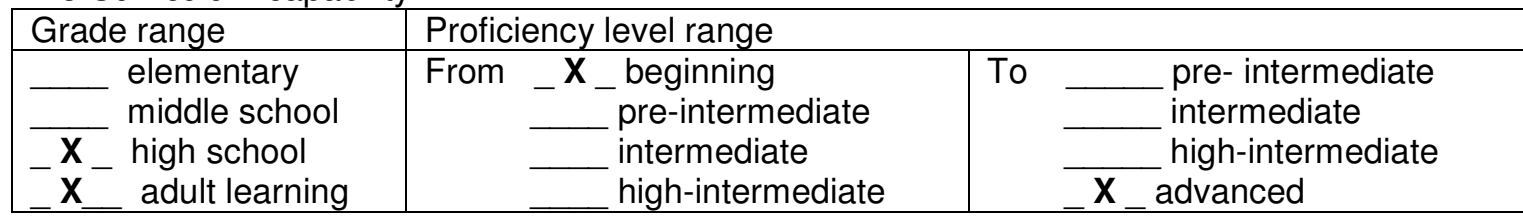

2.9 Method of language teaching claimed by the program

The Direct Method

The Natural Approach

Total Physical Response

The Audio-lingual Method

_ $\mathbf{X}_{\text {_ }}$ The Communicative Approach

2.10 Language skills developed in the program

\begin{tabular}{|c|c|c|c|}
\hline$\ldots$ & _ $\mathbf{X}$ _ listening & $\ldots$ & _ $\mathbf{X}$ _ writing \\
\hline
\end{tabular}

211 Type of activities offered by the program

\begin{tabular}{|l|l|l|l|}
\hline $\begin{array}{l}-\mathbf{X}-\text { games } \\
-\mathbf{X}_{-} \text {quizzes } \\
\text { others }\end{array}$ & $\begin{array}{l}\text { simulation } \\
\text { exploratory }\end{array}$ & $\begin{array}{l}-\mathbf{X}_{-} \text {tutorial } \\
-\mathbf{X}_{-} \text {text } \\
\text { construction }\end{array}$ & $\begin{array}{l}\mathbf{X}_{-} \text {drill and practice } \\
\text { problem solving }\end{array}$ \\
\hline
\end{tabular}

2.12 Orientation of how to use program and its feature

\begin{tabular}{|l|l|}
\hline $\mathbf{X} \_$for the teacher & $\mathbf{X}_{-}$on the screen \\
\hline $\mathbf{X} \_$for the student & $\mathbf{X}_{-}$on hard copy documentation \\
\hline $\mathbf{X}$. for both & $\mathbf{X}_{-}$on both \\
\hline
\end{tabular}

2.13 Role of the teacher

\begin{tabular}{|l|l|l|l|}
\hline${ }_{-} \mathbf{X}_{-}$instructor & _ facilitator & $\mathbf{X}_{-}$lab manager & _ evaluator \\
\hline
\end{tabular}

2.14 Learners interact

\begin{tabular}{|l|l|l|}
\hline _ with one another & $\mathbf{X}_{-}$with the teacher & _ with neither \\
\hline
\end{tabular}

2.15 In case learners interact with one another, they can interact

\begin{tabular}{|l|l|}
\hline in all activities & in some activities \\
\hline
\end{tabular}

2.16 In case learners interact with the teacher, they can interact

\begin{tabular}{|l|l|}
\hline at any time & \multicolumn{1}{c}{ at the end of the activities } \\
&
\end{tabular}

\section{CRITICAL ANALYSIS}

For each item, circle the numbers 1 (for low) to 4 (for high) to indicate your judgment of the degree to which the program possesses or demonstrates the feature identified in each item. Circle 0 if the feature is not present in the program. 


\begin{tabular}{|c|c|c|c|c|c|}
\hline \multicolumn{6}{|l|}{ Instructional Attributes } \\
\hline Graphics and sound enhance learning. & 0 & $\begin{array}{l}\text { (low) } \\
1\end{array}$ & 2 & 3 & $\begin{array}{l}\text { (high) } \\
4\end{array}$ \\
\hline $\begin{array}{l}1.2 \text { The animation is effective in minimizing } \\
\text { boredom by motivating learners. }\end{array}$ & 0 & $\begin{array}{ll}\text { (low) } \\
1\end{array}$ & 2 & 3 & $\begin{array}{l}\text { (high) } \\
4\end{array}$ \\
\hline Screen displays are uncluttered. & 0 & $\begin{array}{l}\text { (low) } \\
1\end{array}$ & 2 & 3 & $\begin{array}{l}\text { (high) } \\
4\end{array}$ \\
\hline 1.4 Graphics make information attractive. & 0 & $\begin{array}{l}\text { (low) } \\
1\end{array}$ & 2 & 3 & $\begin{array}{l}\text { (high) } \\
4\end{array}$ \\
\hline $\begin{array}{l}1.5 \text { Graphics help memorization of key } \\
\text { information. }\end{array}$ & 0 & $\begin{array}{l}\text { (low) } \\
1\end{array}$ & 2 & 3 & $\begin{array}{l}\text { (high) } \\
4\end{array}$ \\
\hline $\begin{array}{l}\text { 1.6 The program makes use of authentic } \\
\text { texts and other realia. }\end{array}$ & 0 & $\begin{array}{l}\text { (low) } \\
1\end{array}$ & 2 & 3 & $\begin{array}{l}\text { (high) } \\
4\end{array}$ \\
\hline $\begin{array}{l}1.7 \text { The program integrates information about } \\
\text { culture/daily situations into the presentations } \\
\text { and activities. }\end{array}$ & 0 & $\begin{array}{l}\text { (low) } \\
1\end{array}$ & 2 & 3 & $\begin{array}{l}\text { (high) } \\
4\end{array}$ \\
\hline $\begin{array}{l}1.8 \text { Lessons present and practice language } \\
\text { structures in meaningful communicative } \\
\text { contexts. }\end{array}$ & 0 & $\begin{array}{l}\text { (low) } \\
1\end{array}$ & 2 & 3 & $\begin{array}{l}\text { (high) } \\
4\end{array}$ \\
\hline $\begin{array}{l}\text { 1.9 Lessons present and practice vocabulary } \\
\text { in meaningful communicative contexts. }\end{array}$ & 0 & $\begin{array}{ll}\text { (low) } \\
1\end{array}$ & 2 & 3 & $\begin{array}{l}\text { (high) } \\
4\end{array}$ \\
\hline $\begin{array}{l}1.10 \text { Lessons develop the communicative } \\
\text { skills the program aims to develop. }\end{array}$ & 0 & $\begin{array}{l}\text { (low) } \\
1\end{array}$ & 2 & 3 & $\begin{array}{l}\text { (high) } \\
4\end{array}$ \\
\hline $\begin{array}{l}1.11 \text { Lessons develop the level of language } \\
\text { proficiency the program aims to develop. }\end{array}$ & 0 & $\begin{array}{ll}\text { (low) } \\
1\end{array}$ & 2 & 3 & $\begin{array}{l}\text { (high) } \\
4\end{array}$ \\
\hline $\begin{array}{l}1.12 \text { The course syllabus reflects a } \\
\text { communicative approach to language } \\
\text { teaching/learning. }\end{array}$ & 0 & $\begin{array}{l}\text { (low) } \\
1\end{array}$ & 2 & 3 & $\begin{array}{l}\text { (high) } \\
4\end{array}$ \\
\hline $\begin{array}{l}1.13 \text { Content selection is determined by } \\
\text { communicative skills and/or themes. }\end{array}$ & 0 & $\begin{array}{l}\text { (low) } \\
1\end{array}$ & 2 & 3 & $\begin{array}{l}\text { (high) } \\
4\end{array}$ \\
\hline $\begin{array}{l}1.14 \text { Content is sequenced from simple } \\
\text { communicative functions, such as introducing } \\
\text { oneself, greeting, etc, to complex ones, such } \\
\text { as stating an opinion, disagreeing, etc. }\end{array}$ & 0 & $\begin{array}{l}\text { (low) } \\
1\end{array}$ & 2 & 3 & $\begin{array}{l}\text { (high) } \\
4\end{array}$ \\
\hline 1.15 Content is presented communicatively. & 0 & $\begin{array}{ll}\text { (low) } \\
1\end{array}$ & 2 & 3 & $\begin{array}{l}\text { (high) } \\
4\end{array}$ \\
\hline $\begin{array}{l}1.16 \text { The program develops the content at } \\
\text { appropriate levels of language proficiency. }\end{array}$ & 0 & $\begin{array}{l}\text { (low) } \\
1\end{array}$ & 2 & 3 & $\begin{array}{l}\text { (high) } \\
4\end{array}$ \\
\hline $\begin{array}{l}1.17 \text { The program content is educationally } \\
\text { relevant and interesting for the learner. }\end{array}$ & 0 & $\begin{array}{l}\text { (low) } \\
1\end{array}$ & 2 & 3 & $\begin{array}{l}\text { (high) } \\
4\end{array}$ \\
\hline $\begin{array}{l}\text { 1.18 The program content is appropriate for } \\
\text { intended learners. }\end{array}$ & 0 & $\begin{array}{ll}\text { (low) } \\
1\end{array}$ & 2 & 3 & $\begin{array}{l}\text { (high) } \\
4\end{array}$ \\
\hline $\begin{array}{l}1.19 \text { The program content is applicable to } \\
\text { real life contexts. }\end{array}$ & 0 & $\begin{array}{l}\text { (low) } \\
1\end{array}$ & 2 & 3 & $\begin{array}{l}\text { (high) } \\
4\end{array}$ \\
\hline $\begin{array}{l}1.20 \text { The program allows learners to work } \\
\text { together in communicative activities. }\end{array}$ & 0 & $\begin{array}{l}\text { (low) } \\
1\end{array}$ & 2 & 3 & $\begin{array}{l}\text { (high) } \\
4\end{array}$ \\
\hline $\begin{array}{l}1.21 \text { The activities allow unplanned and/or } \\
\text { unpredictable responses. }\end{array}$ & 0 & $\begin{array}{ll}\text { (low) } \\
1\end{array}$ & 2 & 3 & $\begin{array}{l}\text { (high) } \\
4\end{array}$ \\
\hline $\begin{array}{l}\text { 1.22 The activities lend themselves to group } \\
\text { discussions. }\end{array}$ & 0 & $\begin{array}{l}\text { (low) } \\
1\end{array}$ & 2 & 3 & $\begin{array}{l}\text { (high) } \\
4\end{array}$ \\
\hline $\begin{array}{l}1.23 \text { The activities aim at developing other } \\
\text { competencies in addition to syntactical and } \\
\text { lexical }\end{array}$ & 0 & $\begin{array}{l}\text { (low) } \\
1\end{array}$ & 2 & 3 & $\begin{array}{l}\text { (high) } \\
4\end{array}$ \\
\hline
\end{tabular}




\begin{tabular}{|c|c|c|c|c|c|}
\hline $\begin{array}{l}1.24 \text { The program allows the teacher to } \\
\text { interact with students while they are doing an } \\
\text { activity. }\end{array}$ & 0 & $\begin{array}{l}\text { (low) } \\
1\end{array}$ & 2 & 3 & $\begin{array}{l}\text { (high) } \\
4\end{array}$ \\
\hline $\begin{array}{l}\text { 1.25 The program provides non-threatening } \\
\text { feedback. }\end{array}$ & 0 & $\begin{array}{l}\text { (low) } \\
1\end{array}$ & 2 & 3 & $\begin{array}{l}\text { (high) } \\
4\end{array}$ \\
\hline $\begin{array}{l}1.26 \text { The program allows learners to repeat } \\
\text { an activity after feedback is provided. }\end{array}$ & 0 & $\begin{array}{l}\text { (low) } \\
1\end{array}$ & 2 & 3 & $\begin{array}{l}\text { (high) } \\
4\end{array}$ \\
\hline $\begin{array}{l}1.27 \text { Activities allow for more than one } \\
\text { correct response. }\end{array}$ & 0 & $\begin{array}{l}\text { (low) } \\
1\end{array}$ & 2 & 3 & $\begin{array}{l}\text { (high) } \\
4\end{array}$ \\
\hline $\begin{array}{l}\text { 1.28 The program provides the students with } \\
\text { feedback that would allow them to correct } \\
\text { their mistakes. }\end{array}$ & 0 & $\begin{array}{l}\text { (low) } \\
1\end{array}$ & 2 & 3 & $\begin{array}{l}\text { (high) } \\
4\end{array}$ \\
\hline
\end{tabular}

\begin{tabular}{|c|c|c|c|c|c|}
\hline \multicolumn{6}{|l|}{ Media Attributes } \\
\hline 2.29 Graphics aid understanding. & 0 & $\begin{array}{l}\text { (low) } \\
1\end{array}$ & 2 & 3 & $\begin{array}{l}\text { (high) } \\
4\end{array}$ \\
\hline $\begin{array}{l}2.30 \text { The program allows for different } \\
\text { routes and choices for learning. }\end{array}$ & 0 & $\begin{array}{l}\text { (low) } \\
1\end{array}$ & 2 & 3 & $\begin{array}{l}\text { (high) } \\
4\end{array}$ \\
\hline $\begin{array}{l}2.31 \text { The program allows for review of old } \\
\text { information. }\end{array}$ & 0 & $\begin{array}{l}\text { (low) } \\
1\end{array}$ & 2 & 3 & $\begin{array}{l}\text { (high) } \\
4\end{array}$ \\
\hline $\begin{array}{l}2.32 \text { The program allows branching to new } \\
\text { information. }\end{array}$ & 0 & $\begin{array}{ll}\text { (low) } \\
1\end{array}$ & 2 & 3 & $\begin{array}{l}\text { (high) } \\
4\end{array}$ \\
\hline $\begin{array}{l}\text { 2.33 The program allows students to select } \\
\text { activities according to their ages. }\end{array}$ & 0 & $\begin{array}{l}\text { (low) } \\
1\end{array}$ & 2 & 3 & $\begin{array}{l}\text { (high) } \\
4\end{array}$ \\
\hline $\begin{array}{l}\text { 2.34 The program allows students to select } \\
\text { activities according to their learning styles. }\end{array}$ & 0 & $\begin{array}{l}\text { (low) } \\
1\end{array}$ & 2 & 3 & $\begin{array}{l}\text { (high) } \\
4\end{array}$ \\
\hline $\begin{array}{l}2.35 \text { The program allows students to select } \\
\text { activities according to their interests. }\end{array}$ & 0 & $\begin{array}{l}\text { (low) } \\
1\end{array}$ & 2 & 3 & $\begin{array}{l}\text { (high) } \\
4\end{array}$ \\
\hline $\begin{array}{l}2.36 \text { The program adapts to the responses } \\
\text { given by the learners, branching to more or } \\
\text { less complicated questions as appropriate. }\end{array}$ & 0 & $\begin{array}{l}\text { (low) } \\
1\end{array}$ & 2 & 3 & $\begin{array}{l}\text { (high) } \\
4\end{array}$ \\
\hline $\begin{array}{l}2.37 \text { The program allows learners to go } \\
\text { through its content at their own pace and } \\
\text { rhythm. }\end{array}$ & 0 & $\begin{array}{l}\text { (low) } \\
1\end{array}$ & 2 & 3 & $\begin{array}{l}\text { (high) } \\
4\end{array}$ \\
\hline $\begin{array}{l}2.38 \text { The program prevents learners from } \\
\text { repeating exercises, therefore, minimizing } \\
\text { guessing. }\end{array}$ & 0 & $\begin{array}{l}\text { (low) } \\
1\end{array}$ & 2 & 3 & $\begin{array}{l}\text { (high) } \\
4\end{array}$ \\
\hline $\begin{array}{l}2.39 \text { The program keeps records of } \\
\text { learners' performance to allow them to } \\
\text { continue activities from where they left off. }\end{array}$ & 0 & $\begin{array}{l}\text { (low) } \\
1\end{array}$ & 2 & 3 & $\begin{array}{l}\text { (high) } \\
4\end{array}$ \\
\hline $\begin{array}{l}2.40 \text { The program keeps track of students' } \\
\text { scores. }\end{array}$ & 0 & $\begin{array}{l}\text { (low) } \\
1\end{array}$ & 2 & 3 & $\begin{array}{l}\text { (high) } \\
4\end{array}$ \\
\hline $\begin{array}{l}2.41 \text { The program provides feedback for } \\
\text { both correct and incorrect answers. The } \\
\text { program provides feedback for both correct } \\
\text { and incorrect answers. }\end{array}$ & 0 & $\begin{array}{l}\text { (low) } \\
1\end{array}$ & 2 & 3 & $\begin{array}{l}\text { (high) } \\
4\end{array}$ \\
\hline $\begin{array}{l}2.42 \text { The program gives learners the } \\
\text { chance to correct their errors. }\end{array}$ & 0 & $\begin{array}{l}\text { (low) } \\
1\end{array}$ & 2 & 3 & (high) \\
\hline
\end{tabular}




\begin{tabular}{|c|c|c|c|c|c|}
\hline $\begin{array}{l}2.43 \text { The program effectively signals the } \\
\text { mistakes before providing the right } \\
\text { answers. }\end{array}$ & 0 & $\begin{array}{l}\text { (low) } \\
1\end{array}$ & 2 & 3 & $\begin{array}{l}\text { (high) } \\
4\end{array}$ \\
\hline $\begin{array}{l}\text { 2.44 The program effectively specifies } \\
\text { different types of errors, such as } \\
\text { differences between a syntactic error and } \\
\text { an incorrect word choice. }\end{array}$ & 0 & $\begin{array}{l}\text { (low) } \\
1\end{array}$ & 2 & 3 & $\begin{array}{l}\text { (high) } \\
4\end{array}$ \\
\hline \multicolumn{6}{|l|}{ Sub-totals $=46(71.87 \%)$} \\
\hline \multicolumn{6}{|l|}{ User-Friendly Attributes } \\
\hline $\begin{array}{l}\text { 3.45 Menu items are understandable and } \\
\text { descriptive. }\end{array}$ & 0 & $\begin{array}{l}\text { (low) } \\
1\end{array}$ & 2 & 3 & $\begin{array}{l}\text { (high) } \\
4\end{array}$ \\
\hline $\begin{array}{l}3.46 \text { The commands and instructions for the } \\
\text { activities are clear and objective. }\end{array}$ & 0 & $\begin{array}{l}\text { (low) } \\
1\end{array}$ & 2 & 3 & $\begin{array}{l}\text { (high) } \\
4\end{array}$ \\
\hline $\begin{array}{l}\text { 3.47 The program gives the learners } \\
\text { effective clues to clarify their doubts about } \\
\text { its use. }\end{array}$ & 0 & $\begin{array}{l}\text { (low) } \\
1\end{array}$ & 2 & 3 & $\begin{array}{l}\text { (high) } \\
4\end{array}$ \\
\hline $\begin{array}{l}3.48 \text { Each screen uses text and } \\
\text { graphic/animation to make a particular } \\
\text { teaching point clear. }\end{array}$ & 0 & $\begin{array}{l}\text { (low) } \\
1\end{array}$ & 2 & 3 & $\begin{array}{l}\text { (high) } \\
4\end{array}$ \\
\hline $\begin{array}{l}\text { 3.49 The program is effectively integrated } \\
\text { with other technological resources (such as } \\
\text { dictionaries on the web, grammar on line, } \\
\text { etc) as the learner uses it. }\end{array}$ & 0 & $\begin{array}{l}\text { (low) } \\
1\end{array}$ & 2 & 3 & $\begin{array}{l}\text { (high) } \\
4\end{array}$ \\
\hline $\begin{array}{l}3.50 \text { Icons, buttons and menus allow } \\
\text { learners to readily search for additional } \\
\text { information while doing an activity. }\end{array}$ & 0 & $\begin{array}{l}\text { (low) } \\
1\end{array}$ & 2 & 3 & $\begin{array}{l}\text { (high) } \\
4\end{array}$ \\
\hline $\begin{array}{l}3.51 \text { Buttons, icons or menu items make } \\
\text { Help or Hint-type options easily accessible. }\end{array}$ & 0 & $\begin{array}{l}\text { (low) } \\
1 \\
\end{array}$ & 2 & 3 & $\begin{array}{l}\text { (high) } \\
4\end{array}$ \\
\hline $\begin{array}{l}\text { 3.52 The program arouses sensory and } \\
\text { cognitive curiosity }\end{array}$ & 0 & \begin{tabular}{|l|} 
(low) \\
1 \\
\end{tabular} & 2 & 3 & $\begin{array}{l}\text { (high) } \\
4\end{array}$ \\
\hline $\begin{array}{l}3.53 \text { The program maintains attention } \\
\text { throughout the lesson. }\end{array}$ & 0 & $\begin{array}{l}\text { (low) } \\
1\end{array}$ & 2 & 3 & $\begin{array}{l}\text { (high) } \\
4\end{array}$ \\
\hline $\begin{array}{l}\text { 3.54 The use of animation invites learners' } \\
\text { reaction or input. }\end{array}$ & 0 & $\begin{array}{l}\text { (low) } \\
1\end{array}$ & 2 & 3 & $\begin{array}{l}\text { (high) } \\
4\end{array}$ \\
\hline $\begin{array}{l}\text { 3.55 The program gives teachers a clear } \\
\text { explanation of its purposes and } \\
\text { methodological orientation. }\end{array}$ & 0 & $\begin{array}{l}\text { (low) } \\
1\end{array}$ & 2 & 3 & $\begin{array}{l}\text { (high) } \\
4\end{array}$ \\
\hline \multicolumn{6}{|l|}{ Sub-total $=34(77.27 \%)$} \\
\hline Total = $176(80 \%)$ & & & & & \\
\hline
\end{tabular}

\begin{tabular}{|c|c|}
\hline 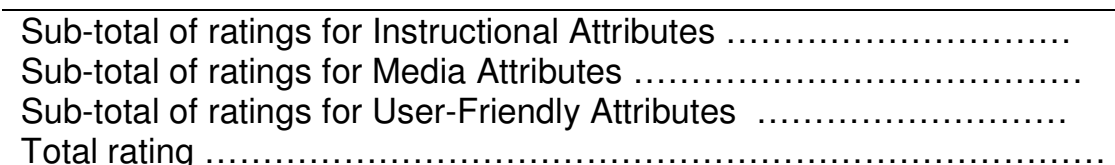 & $\begin{array}{l}96(85.71 \%) \\
46(71.87 \%) \\
34(77.27 \%) \\
176(80 \%)\end{array}$ \\
\hline
\end{tabular}




\section{ESL/EFL SOFTWARE EVALUATION INSTRUMENT}

Title of the program: Who's Oscar Lake?

Publisher: Topics Entertainment

\section{DESCRIPTIVE ANALYSIS}

Please place a checkmark next to the item that best describes the program and/or its features.

\section{TECHNICAL FEATURES}

1.1 Components of the program:

\begin{tabular}{|c|l|l|}
\hline $\begin{array}{c}\text { Number of CD's: } \\
\begin{array}{c}\text { Per level } \\
\text { Total }\end{array}\end{array}$ & $\begin{array}{l}\text { Teacher's guide __Yes } \\
\text { X_No }\end{array}$ & $\begin{array}{l}\text { Support materials_X_Yes } \\
\text { No } \\
\text { What type? User's Guide }\end{array}$ \\
\hline
\end{tabular}

1.2 Platform

Mac OSX

G3/G4 Mhz $128 \mathrm{MB}$ of RAM
Windows 98/2000/ME/XP

$500 \mathrm{Mhz} 128 \mathrm{MB}$ of RAM

1.3 Tools

Word processing

Online forums

Online collaboration

Speech recognition
Web browsing
Encyclopedia or compendia

E-mail

Others

1.5 Other technological resources integrated into the program:

dictionaries on the web grammar on line other web sites none

1.5 Directions for use:

\begin{tabular}{|c|c|c|}
\hline _ $\mathbf{X}_{\text {_ }}$ are on the screen & ___ are in the documentation & _. \\
\hline
\end{tabular}

\section{PEDAGOGICAL ORIENTATION}

2.6 Program's theory of language

\begin{tabular}{|c|l|l|}
\hline structural & _ functional & $\mathbf{X}$ interactional \\
\hline
\end{tabular}

2.7 Type of program

$$
\begin{gathered}
\text { X_emediation } \\
\mathbf{X} \text { enrichment } \\
\text { tutoring }
\end{gathered}
$$

\begin{tabular}{|l|l|}
$\begin{array}{l}\text { X_demonstration } \\
\text { assessment }\end{array}$ & $\begin{array}{l}\mathbf{X} \text { education } \\
\text { game } \\
\text { collaborative } \\
\text { projects }\end{array}$
\end{tabular} \mid

\begin{tabular}{l} 
problem solving \\
\hline drill and practice \\
\hline $\mathbf{X}$ simulation
\end{tabular}

\subsection{Curriculum capability}




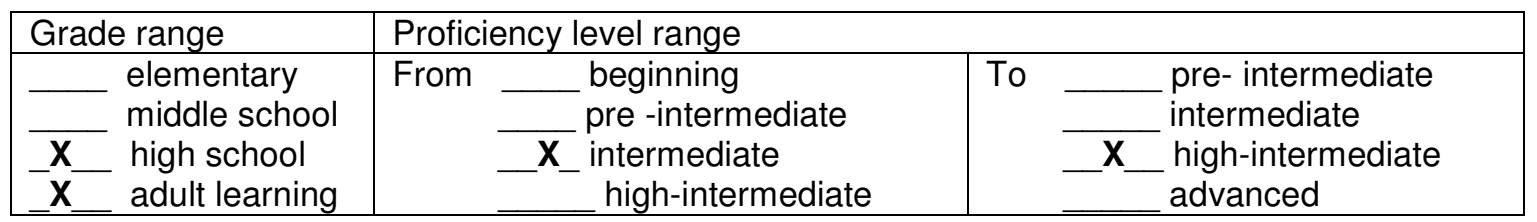

.9 Method of language teaching claimed by the program

\begin{tabular}{|l|l|}
\hline $\begin{array}{l}\text { The Direct Method } \\
\text { The Natural Approach } \\
\text { Total Physical Response }\end{array}$ & $-\mathbf{X}_{-}$The Audio-lingual Method \\
\hline
\end{tabular}

2.10 Language skills developed in the program

\begin{tabular}{|l|l|l|l|}
\hline - X_speaking & - X_listening & X_reading & _ writing \\
\hline
\end{tabular}

2.11 Type of activities offered by the program

\begin{tabular}{|l|l|l|l|}
\hline $\begin{array}{l}\text { X_games } \\
\text { quizzes } \\
\text { others }\end{array}$ & $\begin{array}{l}\mathbf{X} \text { _ simulation } \\
\text { exploratory }\end{array}$ & $\begin{array}{l}\text { tutorial } \\
\text { text } \\
\text { construction }\end{array}$ & $\begin{array}{l}\text { drill and practice } \\
\text { problem solving }\end{array}$ \\
\hline
\end{tabular}

2.12 Orientation of how to use program and its feature

\begin{tabular}{|c|c|}
\hline$X \_$for the teacher & $X \_$on the screen \\
\hline for the student & on hard copy documentation \\
\hline for both & on both \\
\hline
\end{tabular}

2.13 Role of the teacher

\begin{tabular}{|l|l|l|l|}
\hline - X_ instructor & _ facilitator & _ X_lab manager & _ evaluator \\
\hline
\end{tabular}

2.14 Learners interact

\begin{tabular}{|c|l|l|}
\hline _ with one another & _ with the teacher & X_ with neither \\
\hline
\end{tabular}

2.15 In case learners interact with one another, they can interact

\begin{tabular}{|l|l|}
\hline in all activities & in some activities \\
\hline
\end{tabular}

2.16 In case learners interact with the teacher, they can interact

\begin{tabular}{|c|c|}
\hline $\begin{array}{l}\text { at any time } \\
\text { at the end of the lesson }\end{array}$ & $\begin{array}{l}\text { at the end of the activities } \\
\text { there's no interaction }\end{array}$ \\
\hline
\end{tabular}

\section{CRITICAL ANALYSIS}

For each item, circle the numbers 1 (for low) to 4 (for high) to indicate your judgment of the degree to which the program possesses or demonstrates the feature identified in each item. Circle 0 if the feature is not present in the program. 


\begin{tabular}{|c|c|c|c|c|c|}
\hline \multicolumn{6}{|l|}{ Instructional Attributes } \\
\hline Graphics and sound enhance learning. & 0 & $\begin{array}{l}\text { (low) } \\
1\end{array}$ & 2 & 3 & $\begin{array}{l}\text { (high) } \\
4\end{array}$ \\
\hline $\begin{array}{l}1.2 \text { The animation is effective in minimizing } \\
\text { boredom by motivating learners. }\end{array}$ & 0 & $\begin{array}{l}\text { (low) } \\
1\end{array}$ & 2 & 3 & $\begin{array}{l}\text { (high) } \\
4\end{array}$ \\
\hline 1.3Screen displays are uncluttered. & 0 & $\begin{array}{l}\text { (low) } \\
1\end{array}$ & 2 & 3 & $\begin{array}{l}\text { (high) } \\
4\end{array}$ \\
\hline 1.4 Graphics make information attractive. & 0 & $\begin{array}{l}\text { (low) } \\
1\end{array}$ & 2 & 3 & $\begin{array}{l}\text { (high) } \\
4\end{array}$ \\
\hline $\begin{array}{l}1.5 \text { Graphics help memorization of key } \\
\text { information. }\end{array}$ & 0 & $\begin{array}{l}\text { (low) } \\
1\end{array}$ & 2 & 3 & $\begin{array}{l}\text { (high) } \\
4\end{array}$ \\
\hline $\begin{array}{l}\text { 1.6 The program makes use of authentic } \\
\text { texts and other realia. }\end{array}$ & 0 & $\begin{array}{l}\text { (low) } \\
1\end{array}$ & 2 & 3 & $\begin{array}{l}\text { (high) } \\
4\end{array}$ \\
\hline $\begin{array}{l}\text { 1.7 The program integrates information about } \\
\text { culture/daily situations into the presentations } \\
\text { and activities. }\end{array}$ & 0 & $\begin{array}{l}\text { (low) } \\
1\end{array}$ & 2 & 3 & $\begin{array}{l}\text { (high) } \\
4\end{array}$ \\
\hline $\begin{array}{l}1.8 \text { Lessons present and practice language } \\
\text { structures in meaningful communicative } \\
\text { contexts. }\end{array}$ & 0 & $\begin{array}{l}\text { (low) } \\
1\end{array}$ & 2 & 3 & $\begin{array}{l}\text { (high) } \\
4\end{array}$ \\
\hline $\begin{array}{l}1.9 \text { Lessons present and practice vocabulary } \\
\text { in meaningful communicative contexts. }\end{array}$ & 0 & $\begin{array}{l}\text { (low) } \\
1\end{array}$ & 2 & 3 & $\begin{array}{l}\text { (high) } \\
4\end{array}$ \\
\hline $\begin{array}{l}1.10 \text { Lessons develop the communicative } \\
\text { skills the program aims to develop. }\end{array}$ & 0 & $\begin{array}{l}\text { (low) } \\
1\end{array}$ & 2 & 3 & $\begin{array}{l}\text { (high) } \\
4\end{array}$ \\
\hline $\begin{array}{l}1.11 \text { Lessons develop the level of language } \\
\text { proficiency the program aims to develop. }\end{array}$ & 0 & $\begin{array}{l}\text { (low) } \\
1\end{array}$ & 2 & 3 & $\begin{array}{l}\text { (high) } \\
4\end{array}$ \\
\hline $\begin{array}{l}1.12 \text { The course syllabus reflects a } \\
\text { communicative approach to language } \\
\text { teaching/learning. }\end{array}$ & 0 & $\begin{array}{l}\text { (low) } \\
1\end{array}$ & 2 & 3 & $\begin{array}{l}\text { (high) } \\
4\end{array}$ \\
\hline $\begin{array}{l}1.13 \text { Content selection is determined by } \\
\text { communicative skills and/or themes. }\end{array}$ & 0 & $\begin{array}{l}\text { (low) } \\
1\end{array}$ & 2 & 3 & $\begin{array}{l}\text { (high) } \\
4\end{array}$ \\
\hline $\begin{array}{l}\text { 1.14 Content is sequenced from simple } \\
\text { communicative functions, such as introducing } \\
\text { oneself, greeting, etc, to complex ones, such } \\
\text { as stating an opinion, disagreeing, etc. }\end{array}$ & 0 & $\begin{array}{ll}\text { (low) } \\
1\end{array}$ & 2 & 3 & $\begin{array}{l}\text { (high) } \\
4\end{array}$ \\
\hline 1.15 Content is presented communicatively. & 0 & $\begin{array}{l}\text { (low) } \\
1\end{array}$ & 2 & 3 & $\begin{array}{l}\text { (high) } \\
4\end{array}$ \\
\hline $\begin{array}{l}1.16 \text { The program develops the content at } \\
\text { appropriate levels of language proficiency. }\end{array}$ & 0 & $\begin{array}{l}\text { (low) } \\
1\end{array}$ & 2 & 3 & $\begin{array}{l}\text { (high) } \\
4\end{array}$ \\
\hline $\begin{array}{l}1.17 \text { The program content is educationally } \\
\text { relevant and interesting for the learner. }\end{array}$ & 0 & $\begin{array}{l}\text { (low) } \\
1\end{array}$ & 2 & 3 & $\begin{array}{l}\text { (high) } \\
4\end{array}$ \\
\hline $\begin{array}{l}1.18 \text { The program content is appropriate for } \\
\text { intended learners. }\end{array}$ & 0 & $\begin{array}{l}\text { (low) } \\
1\end{array}$ & 2 & 3 & $\begin{array}{l}\text { (high) } \\
4\end{array}$ \\
\hline $\begin{array}{l}1.19 \text { The program content is applicable to } \\
\text { real life contexts. }\end{array}$ & 0 & $\begin{array}{l}\text { (low) } \\
1\end{array}$ & 2 & 3 & $\begin{array}{l}\text { (high) } \\
4\end{array}$ \\
\hline $\begin{array}{l}\text { 1.20 The program allows learners to work } \\
\text { together in communicative activities. }\end{array}$ & 0 & $\begin{array}{l}\text { (low) } \\
1\end{array}$ & 2 & 3 & $\begin{array}{l}\text { (high) } \\
4\end{array}$ \\
\hline $\begin{array}{l}1.21 \text { The activities allow unplanned and/or } \\
\text { unpredictable responses. }\end{array}$ & 0 & $\begin{array}{l}\text { (low) } \\
1\end{array}$ & 2 & 3 & $\begin{array}{l}\text { (high) } \\
4\end{array}$ \\
\hline $\begin{array}{l}\text { 1.22 The activities lend themselves to group } \\
\text { discussions. }\end{array}$ & 0 & $\begin{array}{l}\text { (low) } \\
1\end{array}$ & 2 & 3 & $\begin{array}{l}\text { (high) } \\
4\end{array}$ \\
\hline $\begin{array}{l}1.23 \text { The activities aim at developing other } \\
\text { competencies in addition to syntactical and } \\
\text { lexical }\end{array}$ & 0 & $\begin{array}{l}\text { (low) } \\
1\end{array}$ & 2 & 3 & $\begin{array}{l}\text { (high) } \\
4\end{array}$ \\
\hline
\end{tabular}




\begin{tabular}{|c|c|c|c|c|c|}
\hline $\begin{array}{l}1.24 \text { The program allows the teacher to } \\
\text { interact with students while they are doing an } \\
\text { activity. }\end{array}$ & 0 & $\begin{array}{l}\text { (low) } \\
1\end{array}$ & 2 & 3 & $\begin{array}{l}\text { (high) } \\
4\end{array}$ \\
\hline $\begin{array}{l}\text { 1.25 The program provides non-threatening } \\
\text { feedback. }\end{array}$ & 0 & $\begin{array}{l}\text { (low) } \\
1\end{array}$ & 2 & 3 & $\begin{array}{l}\text { (high) } \\
4\end{array}$ \\
\hline $\begin{array}{l}1.26 \text { The program allows learners to repeat } \\
\text { an activity after feedback is provided. }\end{array}$ & 0 & $\begin{array}{l}\text { (low) } \\
1\end{array}$ & 2 & 3 & $\begin{array}{l}\text { (high) } \\
4\end{array}$ \\
\hline $\begin{array}{l}1.27 \text { Activities allow for more than one } \\
\text { correct response. }\end{array}$ & 0 & $\begin{array}{l}\text { (low) } \\
1\end{array}$ & 2 & 3 & $\begin{array}{l}\text { (high) } \\
4\end{array}$ \\
\hline $\begin{array}{l}1.28 \text { The program provides the students with } \\
\text { feedback that would allow them to correct } \\
\text { their mistakes. }\end{array}$ & 0 & $\begin{array}{ll}(\text { low }) \\
1\end{array}$ & 2 & 3 & $\begin{array}{l}\text { (high) } \\
4\end{array}$ \\
\hline
\end{tabular}

\begin{tabular}{|c|c|c|c|c|c|}
\hline \multicolumn{6}{|l|}{ Media Attributes } \\
\hline 2.29 Graphics aid understanding. & 0 & $\begin{array}{l}\text { (low) } \\
1\end{array}$ & 2 & 3 & $\begin{array}{l}\text { (high) } \\
4\end{array}$ \\
\hline $\begin{array}{l}\text { 2.30 The program allows for different routes } \\
\text { and choices for learning. }\end{array}$ & 0 & $\begin{array}{l}\text { (low) } \\
1\end{array}$ & 2 & 3 & $\begin{array}{l}\text { (high) } \\
4\end{array}$ \\
\hline $\begin{array}{l}\text { 2.31 The program allows for review of old } \\
\text { information. }\end{array}$ & 0 & $\begin{array}{l}\text { (low) } \\
1\end{array}$ & 2 & 3 & $\begin{array}{l}\text { (high) } \\
4\end{array}$ \\
\hline $\begin{array}{l}2.32 \text { The program allows branching to new } \\
\text { information. }\end{array}$ & 0 & $\begin{array}{l}\text { (low) } \\
1\end{array}$ & 2 & 3 & $\begin{array}{l}\text { (high) } \\
4\end{array}$ \\
\hline $\begin{array}{l}2.33 \text { The program allows students to select } \\
\text { activities according to their ages. }\end{array}$ & 0 & $\begin{array}{l}\text { (low) } \\
1\end{array}$ & 2 & 3 & $\begin{array}{l}\text { (high) } \\
4\end{array}$ \\
\hline $\begin{array}{l}\text { 2.34 The program allows students to select } \\
\text { activities according to their learning styles. }\end{array}$ & 0 & $\begin{array}{l}\text { (low) } \\
1\end{array}$ & 2 & 3 & $\begin{array}{l}\text { (high) } \\
4\end{array}$ \\
\hline $\begin{array}{l}2.35 \text { The program allows students to select } \\
\text { activities according to their interests. }\end{array}$ & 0 & $\begin{array}{l}\text { (low) } \\
1\end{array}$ & 2 & 3 & $\begin{array}{l}\text { (high) } \\
4\end{array}$ \\
\hline $\begin{array}{l}2.36 \text { The program adapts to the responses } \\
\text { given by the learners, branching to more or } \\
\text { less complicated questions as appropriate. }\end{array}$ & 0 & $\begin{array}{l}\text { (low) } \\
1\end{array}$ & 2 & 3 & $\begin{array}{l}\text { (high) } \\
4\end{array}$ \\
\hline $\begin{array}{l}2.37 \text { The program allows learners to go } \\
\text { through its content at their own pace and } \\
\text { rhythm. }\end{array}$ & 0 & $\begin{array}{l}\text { (low) } \\
1\end{array}$ & 2 & 3 & $\begin{array}{l}\text { (high) } \\
4\end{array}$ \\
\hline $\begin{array}{l}2.38 \text { The program prevents learners from } \\
\text { repeating exercises, therefore, minimizing } \\
\text { guessing. }\end{array}$ & 0 & $\begin{array}{l}\text { (low) } \\
1\end{array}$ & 2 & 3 & $\begin{array}{l}\text { (high) } \\
4\end{array}$ \\
\hline $\begin{array}{l}\text { 2.39 The program keeps records of learners' } \\
\text { performance to allow them to continue } \\
\text { activities from where they left off. }\end{array}$ & 0 & $\begin{array}{ll}\text { (low) } \\
1\end{array}$ & 2 & 3 & $\begin{array}{l}\text { (high) } \\
4\end{array}$ \\
\hline $\begin{array}{l}2.40 \text { The program keeps track of students' } \\
\text { scores. }\end{array}$ & 0 & $\begin{array}{l}\text { (low) } \\
1\end{array}$ & 2 & 3 & $\begin{array}{l}\text { (high) } \\
4\end{array}$ \\
\hline $\begin{array}{l}2.41 \text { The program provides feedback for both } \\
\text { correct and incorrect answers. The program } \\
\text { provides feedback for both correct and } \\
\text { incorrect answers. }\end{array}$ & 0 & $\begin{array}{l}\text { (low) } \\
1\end{array}$ & 2 & 3 & $\begin{array}{l}\text { (high) } \\
4\end{array}$ \\
\hline $\begin{array}{l}2.42 \text { The program gives learners the chance } \\
\text { to correct their errors. }\end{array}$ & 0 & $\begin{array}{l}\text { (low) } \\
1\end{array}$ & 2 & 3 & $\begin{array}{l}\text { (high) } \\
4\end{array}$ \\
\hline
\end{tabular}




\begin{tabular}{|c|c|c|c|c|c|}
\hline $\begin{array}{l}2.43 \text { The program effectively signals the } \\
\text { mistakes before providing the right answers. }\end{array}$ & 0 & $\begin{array}{ll}\text { (low) } \\
1\end{array}$ & 2 & 3 & $\begin{array}{l}\text { (high) } \\
4\end{array}$ \\
\hline $\begin{array}{l}\text { 2.44 The program effectively specifies } \\
\text { different types of errors, such as differences } \\
\text { between a syntactic error and an incorrect } \\
\text { word choice. }\end{array}$ & 0 & $\begin{array}{l}\text { (low) } \\
1\end{array}$ & 2 & 3 & $\begin{array}{l}\text { (high) } \\
4\end{array}$ \\
\hline \multicolumn{6}{|l|}{ Sub-total $=20(31.25 \%)$} \\
\hline \multicolumn{6}{|l|}{ User-Friendly Attributes } \\
\hline $\begin{array}{l}\text { 3.45 Menu items are understandable and } \\
\text { descriptive. }\end{array}$ & 0 & $\begin{array}{l}\text { (low) } \\
1\end{array}$ & 2 & 3 & $\begin{array}{l}\text { (high) } \\
4\end{array}$ \\
\hline $\begin{array}{l}\text { 3.46 The commands and instructions for the } \\
\text { activities are clear and objective. }\end{array}$ & 0 & $\begin{array}{ll}\text { (low) } \\
1\end{array}$ & 2 & 3 & $\begin{array}{l}\text { (high) } \\
4\end{array}$ \\
\hline $\begin{array}{l}\text { 3.47 The program gives the learners effective } \\
\text { clues to clarify their doubts about its use. }\end{array}$ & 0 & $\begin{array}{ll}\text { (low) } \\
1\end{array}$ & 2 & 3 & $\begin{array}{l}\text { (high) } \\
4\end{array}$ \\
\hline $\begin{array}{l}3.48 \text { Each screen uses text and } \\
\text { graphic/animation to make a particular } \\
\text { teaching point clear. }\end{array}$ & 0 & $\begin{array}{l}\text { (low) } \\
1\end{array}$ & 2 & 3 & $\begin{array}{l}\text { (high) } \\
4\end{array}$ \\
\hline $\begin{array}{l}\text { 3.49 The program is effectively integrated with } \\
\text { other technological resources (such as } \\
\text { dictionaries on the web, grammar on line, etc) } \\
\text { as the learner uses it. }\end{array}$ & 0 & $\begin{array}{l}\text { (low) } \\
1\end{array}$ & 2 & 3 & $\begin{array}{l}\text { (high) } \\
4\end{array}$ \\
\hline $\begin{array}{l}3.50 \text { Icons, buttons and menus allow learners } \\
\text { to readily search for additional information } \\
\text { while doing an activity. }\end{array}$ & 0 & $\begin{array}{l}\text { (low) } \\
1\end{array}$ & 2 & 3 & $\begin{array}{l}\text { (high) } \\
4\end{array}$ \\
\hline $\begin{array}{l}3.51 \text { Buttons, icons or menu items make Help } \\
\text { or Hint-type options easily accessible. }\end{array}$ & 0 & $\begin{array}{ll}\text { (low) } \\
1\end{array}$ & 2 & 3 & $\begin{array}{l}\text { (high) } \\
4\end{array}$ \\
\hline $\begin{array}{l}\text { 3.52 The program arouses sensory and } \\
\text { cognitive curiosity }\end{array}$ & 0 & $\begin{array}{l}\text { (low) } \\
1\end{array}$ & 2 & 3 & $\begin{array}{l}\text { (high) } \\
4\end{array}$ \\
\hline $\begin{array}{l}3.53 \text { The program maintains attention } \\
\text { throughout the lesson. }\end{array}$ & 0 & $\begin{array}{l}\text { (low) } \\
1 \\
\end{array}$ & 2 & 3 & $\begin{array}{l}\text { (high) } \\
4\end{array}$ \\
\hline $\begin{array}{l}3.54 \text { The use of animation invites learners' } \\
\text { reaction or input. }\end{array}$ & 0 & $\begin{array}{l}\text { (low) } \\
1\end{array}$ & 2 & 3 & $\begin{array}{l}\text { (high) } \\
4\end{array}$ \\
\hline $\begin{array}{l}\text { 3.55 The program gives teachers a clear } \\
\text { explanation of its purposes and } \\
\text { methodological orientation. }\end{array}$ & 0 & $\begin{array}{l}\text { (low) } \\
1\end{array}$ & 2 & 3 & $\begin{array}{l}\text { (high) } \\
4\end{array}$ \\
\hline \multicolumn{6}{|l|}{ Sub-total = $15(29.33 \%)$} \\
\hline Total =98 $(22.45 \%)$ & & & & & \\
\hline
\end{tabular}

Sub-total of ratings for Instructional Attributes .....

Sub-total of ratings for Media Attributes .................................

Sub-total of ratings for User-Friendly Attributes

Total rating 


\section{BIBLIOGRAPHY}

Abraham, R. (1985). Field independence-dependence and the teaching of grammar. TESOL Quarterly, 20, 689-702.

Abraham, R. \& Liou, H-C. (1991). Interaction generated by three computer programs: analysis of functions of spoken language. In P. Dunkel (Ed.), Computer-assisted language learning and testing (pp.85-109). Rowley, MA: Newbury House.

Adair-Hauck, B., Willingham-Mclain, L., \& Youngs, B. E. (1999). Evaluating the integration of technology and second language learning. CALICO Journal, 17, 269-306.

Adams, D. \& Hamm, M. (1996). Cooperative learning: Critical thinking and collaboration across curriculum. Springfield, IL: Charles Thomas.

Al-Juhani, S.O. (1992). The effectiveness of computer-assisted instruction in teaching English as a foreign language in Saudi secondary school. Dissertation Abstracts International, 52, 2383-A.

Al-Kahtani, S., \& Abalhassan, K. (1999). Software review: MacReader and Storyboard programs in ESL reading classrooms. Retrieved June 7, 2000, from http://www.lerc.ritsumei.ac.jp/caUej/index.html

Anderson, R., Kulhavey, R. , \& Andre, T. (1971). Feedback procedures in programmed instruction. Journal of Educational Psychology, 62, 148-156.

Ayoun, D. (2001). The role of negative and positive feedback in the second language acquisition of the Passé Composé and the Imparfait. Modern Language Journal, 85, 226-243.

Barnes, D. (1992). The role of talk in learning. In K. Norman (Ed.). Thinking voices: The national oracy project. London: Croom Helm.

Bates, A.W. (1995). Technology, Open Learning, and Distance Education. London, UK: Routledge 
Beagle, J. (2002). Is communicative language teaching a thing of the past?. Babel, 37, 12-16.

Beatty, K. (2003). Teaching and researching computer-assisted language learning. Great Britain: Pearson Education Limited.

Beauvois, M. H. (1992). Computer-assisted classroom discussion in the foreign language classroom: Conversation in slow motion. Foreign Language Annals, $25,455-464$.

Berge, Z. (1998). Changing roles of teachers and learners are transforming the online classroom. Retrieved December 10, 1999, from http://www.edfac.unimelb.edu.au/online-ed/mailouts/1998/aug30.html

Berge, Z., \& Collins, M. (1993). Computer conferencing and online education. The Arachnet Electronic Journal on Virtual Culture, 1.

Berge, Z., \& Collins, M. (1995). Computer-mediated communication and the online classroom in distance learning. Computer-Mediated Communication Magazine, 2.

Blake, R. (2000). Computer-mediated communication: A window on L2 Spanish interlanguage. Language Learning \& Technology, 4, 120-136.

Blumenstyk, G. (1999). The marketing intensifies in distance learning. Chronicle of Higher Education, April, A27.

Bohlke, O. (2003). A comparison of student participation levels by group size and language stages during chatroom and face-to-face discussions in German. CALICO Journal, $21,67-87$.

Bonk, C., \& Cunningham, D. (1998). Searching for learner-centered, constructivist, and sociocultural components of collaborative educational learning tools. In C. Bonk \& K. King (Eds.), Electronic collaborators (pp. 25-50). Mahwah, NJ: Lawrence Erlbaum. 
Bonk, C., \& King, K. (Eds.). (1998). Electronic collaborators. Mahwah, NJ: Lawrence Erlbaum.

Borras, I. (1993). Developing and assessing "Practicing Spoken French": A multimedia program for improving speaking skills. Educational Technology Research and Development, 41, 91-103.

Botiono, B.D. (1992). The effect of three feedback forms on learning through a computer-based tutorial. CALICO Journal, 10, 45-52.

Bradley, T., \& Lomicka, L. (2000). A case study of learner interaction in technologyenhanced language learning environment. Journal of Educational Computing Research, 22, 347-368.

Braidi, S. (2002). Reexamining the role of recasts in native-speaker/nonnative-speaker interactions. Language Learning, 52, 1-42.

Brett, P. A. 1995. Multimedia for listening comprehension: the design of a multimediabased resource for developing listening skills. System, 23, 77- 86.

Brett, P. A. 1996. 'Using multimedia: an investigation of learners' attitudes', Computer Assisted Language Learning Journal, 9.

Brett, P. (1997). A comparative study of the effects of the use of multimedia on listening comprehension. System, 25, 39-53.

Brown, H.D. (1987). Principles of language learning and teaching. Englewood Cliffs, N.J.: Prentice Hall.

Brown, H.D. (1991). TESOL at twenty-five: what are the issues? TESOL Quarterly, 25, 245-260.

Brown, H.D. 1994. Teaching By Principles: An Interactive Approach to Language Pedagogy. New Jersey: Prentice Hall Regents.

Brown, R. (1973). A first language: The early stages. Cambridge, MA: Harvard University. 
Brumfit, C. J. \& Johnson, K. (1979). The communicative approach to language teaching. Oxford: Oxford University Press.

Buckwalter, P. (2001). Repair sequences in Spanish L2 dyadic discourse: A descriptive study. Modern Language Journal, 85, 380-397.

Burston, J. (2003). Software selection: A primer on sources and evaluation. CALICO Journal 21, 29-40.

Canale, M. \& Swain, M. (1980). Theoretical Bases of communicative approaches to second language teaching and testing. Applied Linguistics, 1, 1-47.

Carmines, E., \& Zeller, R. (1979). Reliability and Validity Assessment. Newbury Park: Sage Publications.

Carroll, J. (1967). Foreign language proficiency levels attained by language major near graduation from college. Foreign Language Annals, 1, 131-151.

Carter, R., \& Nunan, D. (2000). The Cambridge guide to teaching English to speakers of other languages. Cambridge: Cambridge University Press.

Castells, M. (1996). The rise of the network society. Malden, MA: Blackwell.

Chang, K.-Y. R., \& Smith, W. F. (1991). Cooperative Learning and CALL/IVD in beginning Spanish: An experiment. Modern Language Journal, 75, 205-211.

Chapelle, C. \& Jamieson, J. (1986). Computer assisted language learning as a predictor of success in acquiring English as a second language. TESOL Quarterly, 20, 27-46.

Chapelle, C. \& Jamieson, J. (1989). Research trends in computer-assisted language learning. In M. Pennington (Ed.), Teaching languages with computers (pp.4559). La Jolla, CA: Athelstan.

Chapelle, C. (1990). The discourse of computer-assisted language learning: toward a context for descriptive research. TESOL Quarterly, 24, 199-225. 
Chapelle, C. \& Jamieson, J. (1991). Internal and external validity issues in research on CALL effectiveness. In P. Dunkel (Ed.), Computer-assisted language learning and testing (pp. 37-57). Rowley, MA: Newbury House.

Chapelle, C. (1995). A framework for the investigation of CALL as a context for SLA. CAELL Journal, 6, 2-8.

Chapelle, C. A. (1997). CALL in the year 2000: Still in search of research paradigms? Language Learning and Technology, 1, 19-43.

Chapelle, C. A. (1998).Multimedia CALL: Lessons to be learned from research on instructed SLA. Language Learning \& Technology, 2, 22-34

Chapelle, C. (2001). Computer Applications in Second Language Acquisition. Cambridge, MA: Cambridge University Press.

Chaudron, C. (1988). Second language classrooms: Research on teaching and learning. Cambridge, England: Cambridge University Press.

Chen, J.F. (1997). Computer generated error feedback and writing process: A link. TESL-EJ, 2.

Chi, M.T.H. , Bassok, M. , Lewis, M.W., Reimann, P., \& Glaser, R. (1989). Selfexplanations: How students study and use examples in learning to solve problems. Cognitive Science, 13,145-182.

Chong, S-M. (1998). Models of asynchronous computer conferencing for collaborative learning in large college classes. In C. J. Bonk \& K. S. King (Eds.), Electronic collaborators (pp. 157-182). Mahwah, NJ: Lawrence Erlbaum.

Chun, D. (1994). Using computer networking to facilitate the acquisition of interactive competence. System, 22, 17-31.

Chun, D., \& Plass, J. (1996). Effects of multimedia annotations on vocabulary acquisition. Modern Language Journal, 80, 183-198. 
Cobb, P. (1994). Where is mind? Constructivist and sociocultural perspectives on mathematical development. Educational Researcher, 23, 13-20.

Collins, M., \& Berge, Z. (1996). Facilitating interaction in computer mediated online courses. Retrieved June 15, 2000, from http://www.emoderators.com/moderators/flcc.html

Coniam, D. (1998). The use of speech recognition software as an English language oral assessment instrument: An exploratory study. CALICO Journal, 15, 7-23.

Cook, T.D. and Campbell, D.T. (1979). Quasi-Experimentation: Design and Analysis for Field Settings. Chicago, IL: Rand McNally.

Cox, M. I. P., \& Assis-Peterson, A. A. d. (1999). Critical pedagogy in ELT: Images of Brazilian teachers of English. TESOL Quarterly, 33, 433-484.

Creswell, J. W. (2003). Research design: Qualitative, quantitative and mixed methods approaches. Thousand Oaks, CA: Sage.

Cunningham, P. (1995). Evaluating callware for your classroom. CAELL Journal, 6, 1319.

Daiute, C. (1985). Writing and computers. Reading, MA: Addison-Wesley. Dalgish, G.M. (1991). Computer-assisted error analysis and courseware design: Applications for ESL in a Swedish context. CALICO Journal, 9, 39-56.

Davis, B., \& Thiede, R. (2000). Writing into change: Style shifting in asynchronous electronic discourse. In M. Warschauer \& R. Kern (Eds.), Network-based language teaching: Concepts and practice (pp. 87-120). Cambridge, England: Cambridge University Press.

Davis, J. N., \& Lyman-Hager, M. A. (1997). Computers and L2 reading: Student performance, student attitude. Foreign Language Annals, 30, 58-72. 
De Felix, J.W., Johnson, R.T., \& Schick, J.E. (1990). Socio- and psycholinguistic considerations in interactive video instruction for limited English proficient students. Computers in the Schools, 7, 173-190.

Dede, C. (1997). Rethinking how to invest in technology. Educational Leadership, 55.

DeLoach, S. B., \& Greenlaw, S. A. (2002). Do electronic discussions create criticalthinking spillovers? Manuscript submitted for publication.

Derwing, T., Munro, M., \& Carbonaro, M. (2000). Does popular speech recognition software work with ESL Speech? TESOL Quarterly, 34, 592-602.

Dick, W., \& Carey, L. (1978). The systematic design of instruction. Glenview, IL: Scott, Foresman.

Donaldson, M. (1978). Children's minds. New York: Norton.

Donaldson, R., \& Kotter, M. (1999). Language learning in cyberspace: Teleporting the classroom into the target culture. CALICO Journal, 16, 530-557.

Doughty, C. (1994). Fine tuning of feedback by competent speakers to language learners. In J. Alatis (Ed.), Georgetown University Round Table (GURT) 1993 (pp. 96-108). Washington, DC: Georgetown University Press.

Doughty, C., \& Long, M. H. (2003). Optimal psycholinguistic environments for distance foreign language learning. Language Learning \& Technology, 7, 50-80.

Doughty, C., Long, M. H., Kim, Y., \& Lee, J. (2005) From task-based needs analysis to task-based materials: principles and practice. Paper presented at Georgetown University Round Table. Washington, D.C.: Georgetown University, March 12.

Doughty, C., \& Williams, J. (1998). Pedagogical choices in focus on form. In C.

Doughty \& J. Williams (Eds.), Focus on form in classroom second language acquisition (pp. 197-261). Cambridge: Cambridge University Press.

Dudley, A. (1995). Communicative CALL: Student interaction using non-EFL software. CAELL Journal, 6, 25-33. 
Dudley-Marling, C. \& Owston, R.D. (1988). A field-testing approach to software evaluation. Computers in the Schools, 5, 241-249.

Dunkel, P. (1991) (Ed.), Computer-assisted language learning and testing . Rowley, MA: Newbury House.

Dziombak, C.E. (1991). Searching for collaboration in the ESL computer lab and the ESL classroom. Dissertation Abstracts International, A: The Humanities and Social Sciences, 51, 2296-A.

Egbert, J., \& Hanson-Smith, E. (1999) (Eds.), CALL environments: Research, practice, and critical issues. Alexandria, VA: TESOL.

Ellis, N. (1995). Consciousness in second language acquisition: A review of field studies and laboratory experiments. Language Awareness, 4, 123-146.

Ellis, R. (1994). The study of second language acquisition. Oxford: Oxford University Press.

Ellis, R., Basturkmen, H., \& Lowen, S. (2001). Learner uptake in Communicative ESL lessons. Language Learning, 51, 281-318.

Ellis, R., Tanaka, Y., \& Yamazaki, A. (1994). Classroom interaction, comprehension, and the acquisition of L2 word meanings. Language Learning, 44, 449-491.

Englesberg, R. (1997). An evaluation study of a multimedia package for learning English. CAELL Journal, 8, 15-20.

Evans, M. (1993). Nicolas: Using HyperCard with intermediate-level French learners. System, 10, 213-229.

Fanselow, J. (1977). The treatment of error in oral work. Foreign Language Annals, 10, 583-593.

Feenberg, A. (1999a). Distance learning: Promise or threat. Retrieved May 30, 1999, from http://www-rohan.sdsu.edu/faculty/feenberg/TELE3. 
Feenberg, A. (1999b). No frills in the virtual classroom. Academe, 85. ). Retrieved in November 20, 1999 from http://www.aaup.org/SO1999Feen.htm

Fernández-García, M., \& Martínez-Arbelaiz, A. (2002). Negotiation of meaning in nonnative speaker-non-native speaker synchronous discussions. CALICO Journal, 19, 279-294.

Fitze, M. (2006) Discourse and participation in ESL face-to-face and written electronic conferences. Language Learning \& Technology, 10, pp. 67-86

Forman, E. A \& Cazden, C. B. (1985). Exploring Vygotskian perspectives on education: The cognitive value of peer interaction. In J. V. Wertsch, (Ed.), Culture, communication, and cognition: Vygotskian perspectives (pp. 323-247). New York: Cambridge University Press.

Fotos, S \& Brown, C. (Eds.). (2004). New Perspectives on CALL for Second and Foreign Language Classrooms. Mahwah, NJ: Lawrence Erlbaum Associates.

Fowler, F.J. (1988). Survey Research Methods, Second Edition. Newbury Park: Sage Publications.

Garrett, M., Nimri, M., Peterson, J., \& Barlow, M. (1995). Software evaluation: Project of Rice University. Retrieved May 17, 2000 from: http:// www.owinet.rice.edu/ling4l7/guide.html.

Gass, S. (1997). Input, interaction, and the second language learner. Rowley, MA: Newbury House.

Gass, S. M., \& Selinker, L. (2001). Second language acquisition: An introductory course. Mahwah, NJ: Erlbaum.

Gass, S. M., \& Varonis, E. M. (1994). Conversation interactions and the development of L2 grammar. Studies in Second Language Acquisition, 16, 283-302.

George, D., \& Mallery, P. (2003). SPSS for Windows step-by-step: A simple guide and reference $\left(4^{\text {th }}\right.$ ed. $)$. Boston: Pearson Education. 
Gonzalez-Bueno, M., \& Perez, L. C. (2000). Electronic mail in foreign language writing: A study of grammatical and lexical accuracy, and quantity of language. Foreign Language Annals, 33, 189-198.

Grace, C. (1998a). Personality type, tolerance of ambiguity, and vocabulary retention in CALL. CALICO Journal, 15, 19-45.

Grace, C. A. (1998b). Retention of word meanings inferred from context and sentencelevel translations: Implications for the design of beginning-level CALL software. Modern Language Journal, 82, 533-544.

Grace, C. A. (2000). Gender differences: Vocabulary retention and access to translations for beginning language learners in CALL. Modern Language Journal, 84, 214-224.

Gros, B. \& Spector, J. M. (1994). Evaluating automated instructional design systems: A complex problem. Educational Technology, 42, 37-46.

Grotjahn, R. (1987). On the methodological basis of introspective methods. In C. Faerch \& G. Kasper (Eds.), Introspection in second language research (pp. 5960). Clevedon, England: Multilingual Matters.

Hadfield, J. 1990. Intermediate Communication Games. Surrey: Thomas Nelson and Sons.

Hall, J. K., \& Verplaetse, L. S. (2000). Second and foreign language learning through classroom interaction. Mahwah, NJ: Erlbaum.

Halliday, M. K. (1970). Spoken and written language. Oxford: Oxford University Press. Hamayan, E., \& Tucker, E. (1980). Language input in the bilingual classroom and its relationship to second language achievement. TESOL Quarterly, 14, 453-468.

Han, Z-H. (2002). A study of impact of recasts on tense consistency in L2 output. TESOL Quarterly, 36, 543-572. 
Harley, B. (1992) Patterns of second alngauge development in French immersion. Journal of French Language Studies, 2, 159-183.

Hart, R. (1981). Language study and the Plato system. Studies in Language Learning, 3, 1-24.

Hatch, E. (1978). Discourse analysis and second language acquisition. In E. Hatch (Ed.), Second language acquisition: A book of readings (pp. 401-435). Rowley, MA: Newburry House.

Healey, D., \& Johnson, N. (1997a). A place to start in selecting software. CAELL Journal, 8(1). Retrieved in May 29, 2000 from: http:/www.ucs.orst.edu/healeyd/cj_software_selection.html

Higgins, J. (1988). Language, learners, and computers: Human intelligence and artificial unintelligence. Singapore: Longman.

Howatt, A. P. R. (1984). A History of English Language Teaching. Oxford: Oxford University Press.

Hsu, J.J., Chapelle, C., \& Thompson, A.D. (1993). Exploratory learning environments: what are they and do students explore? Journal of Educational Computing Research, 9, 1-15.

Huang, S. J. (1997). The Preliminary Study of the Indirect Use of Computer Simulation in EFL Teaching. Paper presented at the First International Conference of CALL. Naval Academy, Taiwan.

Huang, S. J. and Liu, H. F. (2000). Communicative Language Teaching in a Multimedia Language Lab. The InternetTESL Journal, 6.

Hubbard, P. L. (1987) Language teaching approaches, the evaluation of CALL software and design implementation. In W. Flint Smith (Ed.). Modern media in 
foreign language education: Theory and implementation (pp. 227-254).

Lincolnwood, IL: National Textbook Company.

Hubbard, P. L. (1988). An Integrated Framework for CALL courseware evaluation. CALICO Journal, 6, 51-73.

Hubbard, P. L. (1989). An integrated framework for CALL coursework evaluation. CALICO Journal, 6, 51-72.

Hubbard, P. L. (1992). A methodological framework for CALL courseware development. I Pennington, M. and Stevens, V. (Eds), Computers in applied linguistics. Clevedon: Multilingual Matters.

Hutchinson \& Waters (1987). Materials Evaluation (Chapter 9). In English for Specific Purposes: A learner-centered approach (96-106). New York: Cambridge Press.

Hymes, D. (1972). Models of the interaction of language and social setting. Journal of social issues, 23, 8-28.

Ikeda, N. (1999). Language learning strategies with sound-hints in computer-based drill. Journal of Computer Assisted Learning, 15, 312-322.

Irvine, S. E. (2000). What are we talking about? The impact of computer-mediated communication on student learning. (ERIC Document Reproduction Service No. ED444494).

Iwasaki, J., \& Oliver, R. (2003). Chatline interaction and negative feedback. Australian Review of Applied Linguistics, 17, 60-73.

Jakobsdottir, S., \& Hooper, S. (1995). Computer-assisted foreign language learning:

Effects of text, context, and gender on listening comprehension and motivation. Educational Technology Research and Development, 43, 43-59.

Janello, Pam. (1984). Software evaluation for the teacher of the English Language Arts. ERIC Digest. 
Jepson, K. (2005). Conversations and negotiated interaction in text and voice chat rooms. Language Learning \& Technology, 9, pp. 79-98.

Johanesen, K.J. \& Tennyson, R.D. (1983). Effect of adaptive advisement on perception in learer-controlled, computer-based instruction using a rule-learning task. Educational Communication and Technology, 31, 226-236.

Johns, T. \& King, P. (Eds.) (1991). Classroom concordancing. ELT Journal 4, 27-45.

Johnson, D. \& Johnson, R. (1991). Cooperative learning lesson structure. Edina, MN: Interaction Book Company.

Johnson, K. (1982). Communicative syllabus design and methodology. Oxford: Pergamon Institute of English.

Johnson, K. (2002). Designing Language Teaching Tasks. United Kingdom: Palgrave. Johnston, J., \& Milne, L. (1995). Scaffolding second language communicative discourse with teacher-controlled multimedia. Foreign Language Annals, 28, 315-336.

Jonassen, D. H. (1994). Technology as cognitive tools: Learners as designers. IT Forum Paper \#1. Retrieved May 30, 2000, from http://it.coe.uga.edu/itforum/paper1/paper1.html

Jones, C. \& Fortescue, S. (1987). Using computers in the language classroom. London: Longman.

Kamhi-Stein, L. (2000). Looking to the future of TESOL teacher education: Web-based bulletin board discussions in a methods course. TESOL Quarterly, 34, 423-455. Kang, S.-H., \& Dennis, J. R. (1995). The effects of computer-enhanced vocabulary on achievement of ESL grade school children. Computers in the Schools, 11, 2535.

Kasper, L. (2000). New technologies, new literacies: Focus discipline research and ESL learning communities. Language Learning and Technology, 4, 105-128.. 
Kearsley, G., Hunter, B., \& Seidel, R. J. (1983). Two decades of computer-based instruction projects: What have we learned? T.H.E. Journal, 10, 90-95.

Kelm, O. R. (1992). The use of synchronous computer networks in second language instruction: A preliminary report. Foreign Language Annals, 25, 441-545.

Kelm, O. R. (1995). E-mail discussion groups in foreign language education: Grammar follow-up. In M. Warschauer (Ed.), Telecollaboration in foreign language learning. Proceedings of the Hawai'i symposium, Honolulu, HI, 58-61.

Kelm, O. R. (1996). Applications of computer networking in foreign language education: Focusing on principles of second language acquisition. In M. Warschauer (Ed.), Telecollaboration in foreign language learning. Proceedings of the Hawai'l symposium, Honolulu, HI, 19-28.

Kenning, M. M., \& Kenning, M. J. (1990). Computers and language learning: current theory and practice. New York: Ellis Horwood.

Kern, R. (1995). Restructuring classroom interaction with networked computers: Effects on quantity and quality of language production. Modern Language Journal, 79, 457-476.

Kern, R. \& Warschauer, M. (2000). Theory and practice of network-based language teaching. In M. Warschauer \& R. Kern (Eds.), Network-based language teaching: Concepts and practice (pp. 154-178). New York: Cambridge University Press.

Kerr, J. (2001). Software evaluation. Retrieved in October 15, 2001 from http://www.ed.brocku.ca/ jkerr/sftwreva.htm

Kim, J.O., \& Mueller, C. (1978). Factor Analysis: Statistical Methods and Practical Issues. Newbury Park: Sage Publications. 
Kim, Y. (1998). The effect of a network computer-mediated discussion on subsequent oral discussion in the ESL classroom. Unpublished doctoral dissertation, University of Texas, Austin.

Kleinmann, H.H. (1987). The effect of computer-assisted instruction on ESL reading achievement. Modern Language Journal, 71, 267-276.

Krashen, S (1977). The monitor model for adult second language performance. In M. Burt, H. Dulay, \& M. Finocchiaro (Eds.), Viewpoints on English as a second language (pp. 152-161). New York: Regents.

Krashen, S. (1981). Second language acquisition and second language learning. Oxford: Pergamon.

Krashen, S. (1982). Principles and practice in second language acquisition. Oxford: Pergamon.

Krashen, S. (1985). The input hypothesis. New York: Longman.

Krashen, S. (1987). Applications of psycholinguistic research to the classroom. In M. Long \& J. Richards (Eds.), Methodology in TESOL: A book of readings (pp. 3344). New York: Newbury House.

Krashen, S. (1994). The Input Hypothesis and its rivals. In N. Ellis (Ed.), Implicit and explicit learning of languages (pp. 45-77). London: Academic Press.

Krashen, S. (2003). Explorations in Language Acquisition and Use. Portsmouth, NH: Heinemann.

Krashen, S. D., \& Terrell, T. (1983). The natural approach. Oxford: Pergamon.

Kubota, R. (1999). Word processing and WWW projects in a college Japanese language class. Foreign Language Annals, 32, 205-218.

Kumaravadivelu, B. 1994. "The postmethod condition: (E)merging strategies for second/foreign language teaching." TESOL Quarterly, 28, 27-48. 
Lantolf, J. (Ed.). (2000). Sociocultural theory and second language learning. Oxford, England: Oxford University Press.

Larsen-Freeman, D. (1986). Techniques and principles in language teaching. Oxford: Oxford University Press.

Larsen-Freeman, D. , \& Long, M. (1991). An Introduction to Second Language Acquisition Research. New York: Longman.

Laurillard, D. (1995). Multimedia and the changing experience of the learner. British Journal of Educational Technology, 26, 179-189.

Lee, L. (1997). Using Internet tools as an enhancement of C2 teaching and learning. Foreign Language Annals, 30, 410—427.

Lee, L. (1998). Going beyond classroom learning: Acquiring cultural knowledge via online newspapers and intercultural exchanges via on-line chat rooms. CALICO Journal, 16, 101-120.

Lee, L. (2004). Learners' perspectives on networked collaborative interaction with native speakers of Spanish in the US. Language Learning \& Technology, 8 , 83-100.

Leeman, J. (2000). Towards a new classification of input: An empirical study of the effect of recasts, negative evidence and enhanced salience on L2 development. Unpublished doctoral dissertation, Georgetown University, Washington DC.

Leeman, J. (2003). Recasts and second language development: beyond negative evidence. Studies in Second Language Acquisition, 25, 37-63.

Leu, J. D., Hillinger, M., Loseby, P. H., Balcom, M. L., \& Dinkin, J. (1998). Grounding the design of new technologies for literacy and learning in teachers' instructional needs. In D. Reinking, M. C. McKenna, L. D. Labbo, \& R. D. Kieffer. (Eds.). Handbook of literacy and technology. Transformations in a posttypographic world (pp. 203-220). Mahwah, NJ: Earlbaum. 
Levy, M. \& Hinckfuss, J. (1990). Program design and student talk. CAELL Journal, 1, 21-26.

Li, D. (1998). "It's always more difficult than you plan and imagine": Teachers' perceived difficulties in introducing the Communicative Approach in South Korea. TESOL Quarterly, 32, 677-703.

Liaw, M. (1997). An analysis of ESL children's verbal interaction during computer book reading. Computers in the Schools, 13, 55-73.

Liaw, M. (1998). Using electronic mail for English as a foreign language instruction. System, 26, 335-351.

Light, P. H. (1993). Collaborative learning with computers. In P. Scrimshaw (Ed.), Language, classrooms and computers (pp.155-159). London: Routledge.

Light, P.H., \& Mevarech, Z.R. (1992). Cooperative learning with computers: an introduction. Learning and Instruction, 2, 155-159.

Lightbown, P., \& Spada, M. (1990). Focus-on-form and corrective feedback in communicative language teaching. Studies in Second Language Acquisition, 12, 429-448.

Lightbown, P., \& White, L. (1987). The influence of linguistics theories on language acquisition research. Language Learning, 37, 483-510.

Lin, Y., \& Hedgcock, J. (1996). Negative feedback incorporation among highproficiency and low-proficiency Chinese-speaking learners of Spanish. Language Learning, 46, 567-611.

Liou, H.-C., Wang, S. H., \& Hung-Yeh, Y. (1992). Can grammatical CALL help EFL writing instruction? CALICO Journal, 10, 23-43.

Littlewood, W. (1981) Communicative Language Teaching. New York: Cambridge University Press. 
Liu, M. (1992). The effect of hypermedia-assisted instruction on second language learning: a semantic-network-based approach. Dissertation Abstracts International, A: The Humanities and Social Sciences, 53, 1134-A.

Liu, M. (1995). Contextual enrichment through hypermedia technology: Implications for second language learning. Computers in Human Behavior, 11, 439-450.

Liu, M., \& Reed, W. M. (1995). The effect of hypermedia-assisted-instruction on second language learning. Journal of Educational Computing Research, 12, 159-175.

Lomicka, L. (1998). "To gloss or not to gloss": An investigation of reading comprehension online. Language Learning and Technology, 1, 41-50.

Long, M. H. (1980). Input, interaction and second language acquisition. Unpublished doctoral dissertation, University of California, Los Angeles.

Long, M. H (1983). Linguistic and conversational adjustments to non-native speakers. Studies in Second Language Acquisition, 5, 177-193.

Long, M. H. (1985). Input and second language acquisition theory. In Gass, S. and Madden, C. (Eds.). Input in second language acquisition (377-393). Rowley, MA: Newbury House.

Long, M. H. (1989). Task, group, and task-group interactions. University of Hawai'i Working papers in ESL, 8, 1-26.

Long, M. H. (1991). Focus on form: A design feature in language teaching methodology. In K. de Bot, R. Ginsberg, \& C. Kramsch (Eds.), Foreign language research in cross-cultural perspective (pp. 39-52). Amsterdam: John Benjamins.

Long, M. (1996). The role of the linguistic environment in second language acquisition. In W. C. Ritchie \& T. K. Bhatia (Eds.), Handbook of research on language 
acquisition. Vol. 2: Second language acquisition (pp. 413-468). New York: Academic Press.

Long, M. \& Robinson, P. (1998). Theory, research and practice. In C. Doughty \& J. Williams (Eds.), Focus on form in classroom second language acquisition (pp. 15-41). Cambridge: Cambridge University Press.

Long, M. H. (2005). Current issues in TBLT. Proceedings of the TBLT 2005: International Conference on Task-Based Language Teaching, Leuven, Belgium, 2005, 21-23.

Long, M. H. (2005). The delivery of negative feedback in naturalistic, classroom, and artificial environments. Proceedings of the UNTELE conference, Compiegne, France, 2005, 24-26.

Long, M. H. (Ed.). (2005). Second language needs analysis. Cambridge: Cambridge University Press.

Long, M. H. (2006). Problems in SLA. Mahwah, NJ: Lawrence Erlbaum Associates.

Long, M. H., \& Porter, P. A. (1985). Group work, interlanguage talk, and second language acquisition. TESOL Quarterly, 19, 207-227.

Long, M. H., \& Robinson, P. (1998). Focus on form: Theory, research, and practice. In C. Doughty \& J. Williams (Eds.), Focus on form in classroom SLA (pp. 15-41). Cambridge, England: Cambridge University Press

Long, M. H., \& Sato, C. J. (1984). Methodological issues in interlanguage studies: An interactionist perspective. In A. Davies, C. Criper, \& A. Howatt (Eds.), Interlanguage (pp. 253-279). Edinburgh: Edinburgh University Press.

Long, M., Inagaki, S., \& Ortega, L. (1998). The role of implicit negative feedback in SLA: Models and recasts in Japanese and Spanish. Modern Language Journal, 82, 357-371. 
Lyster, R. (1998a). Negotiation of form, recasts explicit correction in relation to error types and learning repairs in L2 classrooms. Language Learning, 48, 183-213.

Lyster, R. (1998b). Recast, repetition and ambiguity in L2 classroom discourse. Studies in second language acquisition, 20, 51-81.

Lyster, R., \& Ranta, L. (1997). Corrective feedback and learner uptake: Negotiation of form in communicative classrooms. Studies in Second Language Acquisition, 19, 37-66.

Mackey, A. (1999). Input, interaction and second language development: An empirical study of question formation in ESL. Studies in Second Language Acquisition, $21,557-587$.

Mackey, A., \& Philp, J. (1998). Conversation interaction and second language development: Recasts, response and red herrings? Modern Language Journal, 82, 338-356.

Mackey, A., Oliver, R., \& Leeman, J. (2003). Interactional input and the incorporation of feedback: An exploration of NS-NNS and NNS-NNS adult and child dyads. Language Learning, 53, 35-66.

MacKinley, K. (1999). Planning to use e-mail to support the learning process? Retrieved December 10, 1999 from http://www.edfac.unimelb.edu.au/online-ed/ mailouts/1999/Sept6.html

Mark, S, Scot, A., \& Smith, R. (2002) Facilitating the collaborative design of flexible learning materials: Investigating the synthesis of content and multimedia knowledge and expertise. Australian Journal of Educational Technology, 18, 293-307.

McGroarty, M (1993) Cooperative learning and second language acquisition. In D. Holt (Ed.), Cooperative learning (pp. 19-46). Washington, DC: Center for Applied Linguistics. 
McLoughlin, C., \& Oliver, R. (1998). Maximizing the language and learning link in computer learning environments. British Journal of Educational Technology, 29, $125-136$.

Mehan, H. (1979). Learning Lessons. Cambridge, MA.: Harvard University.

Mercer, N. (1994). The quality of talk in children's joint activity at the computer. Journal of Computer Assisted Learning, 10, 24-32.

Meskill, C. (1993). ESL multimedia: a study of the dynamics of paired student discourse. System, 21, 323-341.

Meskill, C. (2000). Introduction to special issue of the Journal of Educational Computing Research: Research in computer assisted language learning. Journal of Educational Computing Research, 22, 239-242.

Meskill, C. (2002). Teaching and learning in real time: Media, technologies and language acquisition. Houston, TX: Athelson

Meskill, C., \& Mossop, J. (2000). Technologies use with ESL learners in New York State: Preliminary report. Journal of Educational Computing Research, 22, 265284.

Meunier, L. E. (1995/1996). Human factors in a computer assisted foreign language environment: The effects of gender, personality and keyboard control. CALICO Journal, 13, 47-72.

Mitra, A. (2002). Toward developing questionnaire items to measure effectiveness of computers in teaching. Journal of Educational Computing Research, 25, 381394.

Moroishi, M. (2001). Recasts and learner uptake in Japanese classroom discourse. In X. Bonch-Bruevich, W. J. Crawford, J. Hellermann, C.,Higgins, \& H. Nguyen (Eds.), The past, present and future of second language research. Selected 
proceedings of the 2000 Second Language Research Forum (pp. 197-208). Somerville, MA: Cascadilla Press.

Morris, F. (2002). Negotiation and recasts in relation to error types and learner repair. Foreign Language Annals, 35, 395-404.

Morris, F. (2005). Child-to-Child Interaction and Corrective Feedback in a Computer Mediated L2 Class. Language learning \& Technology, 9, $29-45$.

Müller-Hartmann, A. (2000). The role of tasks in promoting intercultural learning in electronic learning networks. Language Learning \& Technology, 4, 129-147.

Muniandy, A.V.A. (2002). Electronic-discourse (E-discourse): Spoken, written or a new hybrid? Australian Journal of TESOL, 17, 45-68.

Muranoi, H. (2000). Focus on form through interaction enhancement: Integrating formal instruction with a communicative task in EFL classrooms. Language Learning, 50, 617-673.

Murillo, D. (1991). Maximizing CALL effectiveness in the classroom. CAELL Journal, 2, 20-25.

Murray, L. \& Barnes, A. (1998). Beyond the "wow" factor - evaluating multimedia language learning software from a pedagogical viewpoint. System, 26, 249-259.

Nabei, T., \& Swain, M. (2002). Learner awareness of recasts in classroom interaction: A case study of an adult EFL student's second language learning. Language Awareness, 11, 43-62.

Nagata, N. (1996). Computer vs. workbook instruction in second language acquisition. CALICO Journal, 14, 53-75.

Nagata, N. (1997). The effectiveness of computer-assisted metalinguistic instruction: A case study in Japanese. Foreign Language Annals, 30, 187-200.

Nagata, N. (1998). Input vs. output practice in educational software for second language acquisition. Language Learning and Technology, 1, 23-40. 
Nagata, N. (1999). The effectiveness of computer-assisted interactive glosses. Foreign Language Annals, 469-479.

Natasi, B. K. and Clements, D. H. (1993). Motivational and social outcomes of cooperative computer education environments. Journal of Computing in Childhood Education, 4, 15-43.

Neu, J. \& Scarcella, R. (1991). Word processing in the ESL classroom: a survey of student attitudes. In P. Dunkel (Ed.), Computer-assisted language learning and testing , 169-187. Rowley, MA: Newbury House.

Nunan, D. (1992). Research methods in language learning. Cambridge, England: Cambridge University Press.

Nunan, D. (1999). Second language teaching and learning. Boston: Heinle \& Heinle.

Nutta, J. (1998). Is computer-based grammar instruction as effective as teacherdirected grammar instruction for teaching L2 structures? CALICO Journal, 16, 49-62.

Nystrom, N. (1983). Teacher-student interaction in bilingual classrooms: four approaches to error feedback. In H. W. Seliger \& M. H. Long (Eds.), Classroom oriented research in second language acquisition (pp. 169-188). Rowley, MA: Newbury House.

O'Malley, C. (1995). Designing computer support for collaborative learning. In C. O'Malley (Ed.) Computer supported collaborative learning (pp. 283-297). New York: Springer-Verlag.

Ocker, R. J., \& Yaverbaum, G. J. (1999). Asynchronous computer-mediated communication versus face-to-face collaboration: Results on student learning, quality, and satisfaction. Group Decision and Negotiation, 8, 427-440.

Odell, A. (1986). Evaluating CALL software. In G. Leech, \& C. Candlin (Eds.). Computers in English Language Teaching and Research: Selected papers form 
the 1984 Lancaster Symposium "Computers in English Language Education and Research" (pp.60-77). London: Longman.

Ogata, H., Feng, C., Hada, Y., \& Yano, Y. (2000). Online markup based language learning environment. Computers and Education, 34, 51-66.

Ohta, A. S. (2000). Rethinking recasts: A learner-centered examination of corrective feedback in the Japanese language classroom. In J. K. Hall \& L. S. Verplaetse (Eds.), Second and foreign language learning through classroom interaction (pp. 47-71). Mahwah, NJ: Erlbaum.

Ohta, A. (2001). Second language acquisition processes in the classroom: Learning Japanese. Mahwah, NJ: Lawrence Erlbaum Associates.

Oliva, M., \& Pollastrini, Y. (1995). Internet resources and second language acquisition: An evaluation of virtual immersion. Foreign Language Annals, 28, 551-563.

Oliver, R. (1995). Negative feedback in child NS-NNS conversation. Studies in Second Language Acquisition, 17, 459-481.

Oliver, R. (1998). Negotiation of meaning in child interactions. Modern Language Journal, 82, 372-386.

Oliver, R. (2000). Age differences in negotiation and feedback in classroom and pairwork. Language Learning, 50, 119-151.

Oliver, R. (2002). The patterns of negotiation for meaning in child interactions. Modern Language Journal, 86, 97-111.

O'Malley, C. (1995). Designing computer support for collaborative learning. In C. O'Malley (Ed.), Computer supported collaborative learning (pp. 283-297). New York: Springer-Verlag.

Ortega, L. (1997). Processes and outcomes in networked classroom interaction: Defining the research agenda for L2 computer-assisted classroom discussion. Language Learning \& Technology, 1, 82-93. 
Oskoz, A., \& Liskin-Gasparro, J. (2001). Corrective feedback, learner uptake, and teacher's beliefs: A pilot study. In X. Bonch-Bruevich, W. J. Crawford, J. Hellermann, C. Higgins, \& H. Nguyen (Eds.), The past, present and future of second language research Selected proceedings of the 2000 Second Language Research Forum (pp. 209-228). Somerville, MA: Cascadilla Press.

Osuna, M. (2000). Promoting foreign culture acquisition via the Internet in a sociocultural context. Journal of Educational Computing Research, 22, 323346.

Osuna, M., \& Meskill, C. (1998). Using the World Wide Web to integrate Spanish language and culture: A pilot study. Language Learning and Technology, 1, 7192.

Owston, R.D. \& Dudley-Marling, C. (1988). A criterion-based approach to software evaluation. Journal of Research in Computing in Education, 20. 231-248.

Panova, I., \& Lyster, R. (2002). Patterns of corrective feedback and classroom uptake in an adult ESL classroom. TESOL Quarterly, 36, 573-595.

Papert, S. (1993). The children's machine: Rethinking the school in the age of computers. New York: Basic Books.

Patten, Mildred L. (2002). Understanding research methods: An Overview of the essentials (3rd ed.). Los Angeles: Pyrczak Publishing.

Pea, R. D. (1987). The aims of software criticism: Reply to Professor Papert. Educational Researcher, 16, pp. 4-8.

Pea, R. D. (1992). Augmenting the discourse of learning with computer-based learning environments. In de Corte, E., Linn, M., Mandl, H., and Verschaffel, L. (Eds.), Computer-Based Learning Environments and Problem-Solving (pp, 87-99). New York: Springer-Verlag. 
Pellettieri, J. (1996). Network-based computer interaction and the negotiation of meaning in the virtual foreign language classroom. Unpublished manuscript, University of California at Davis.

Pellettieri, J. (2000). Negotiation in cyberspace: The role of chatting in the development of grammatical competence. In M. Warschauer \& R. Kerns (Eds.), Networkbased language teaching: Concepts and practice (pp. 59-86). Cambridge, England: Cambridge University Press.

Phillips, M. (1987). Communicative language learning and the microcomputer. London: British Council.

Phinney, M. (1991). Computer-assisted writing and writing apprehension in ESL students. In P. Dunkel (Ed.), Computer-assisted language learning and testing, 189-204. Rowley, MA: Newbury House.

Pica, T. (1983). Adult acquisition of English as a second language under different conditions of exposure. Language Learning, 33, 465-497.

Pica, T. (1993). Communication with second language learners: What does it reveal about the social and linguistic process of second language learning. In J. E. Alatis (Ed.), GURT 1992: Language, communication, and social meaning (pp. 435-464). Washington, D.C.: Georgetown University Press.

Pica, T. (1994). Research on negotiation: What does it reveal about second-language learning conditions, processes, and outcomes? Language Learning, 44, 493527.

Pica, T., \& Doughty, C. (1985). Input and interaction in the communicative language classroom: A comparison of teacher-fronted and group activities. In S. M. Gass \& C. G. Madden (Eds.), Input and second language acquisition (pp. 115-132). New York: Newbury House. 
Pica, T., Holliday, L., Lewis, N., \& Morgenthaler, L. (1989). Comprehensible output as an outcome of linguistic demands on the learner. Studies in Second Language Acquisition, 11, 63-90.

Pica, T., Kanagy, R., \& Faladun, J. (1993). Choosing and using communication tasks for second language instruction and research. In G. Crookes \& S. M. Gass (Eds.), Tasks and language learning: Integrating theory and practice (pp. 9-34). Clevedon: Multilingual Matters Ltd.

Pica, T., Lincoln-Porter, F., Paninos, D., \& Linnell, J. (1996). Language learner interaction: How does it address the input, output, and feedback needs of second language learners? TESOL Quarterly, 30, 59-84.

Piper, A. (1986). Conversation and the computer: A study of the conversational spinoff generated among learners of English as a foreign language working in groups. System, 14, 187-198.

Plass, J. L. (1998). Design and evaluation of the user interface of foreign language multimedia. Language Learning and Technology, 2(I), 35-45.

Plass, J. L., Chun, D. C., Mayer, R. E., \& Leutner, D. (1998). Supporting visual and verbal learning preferences in a second-language multimedia learning environment. Educational Psychology, 90(1), 25-36.

Poulsen, E. (1990). Evaluation of CALL from a classroom perspective. CAELL Journal, 1, 73-78.

Pujol, M. (1995/96). ESL interactions around the computer. CAELL Journal, 6, 2-11. Reeder, K., Heift, T, Roche, J., Tabyanian, S., Schlickau, S., \& Golz, P. (2004). Evaluating New Media in Language Development. In Fotos, S., \& Browne, C. (Eds.). New Perspectives on CALL for Second Language Classrooms (pp. 255278). Mahwah, NJ: Lawrence Erlbaum. 
Reeves, T.C. (1994). Systematic Evaluation Procedures for Interactive multimedia for Education and Training. In Reisman, S. (Ed.) Multimedia Computing: Preparing for the 21st century (pp.78-101). Harrisburg, PA: Idea Group

Reeves, T.C. (1997). Evaluation Tools. Retrieved September 26, 2002 from http://mime1.marc.gatech.edu/MMTools/ evaluation.html

Repman, J. (1993). Collaborative, computer-based learning: Cognitive and affective outcomes. Journal of Educational Computing Research, 9, 149-163.

Richard-Amato, P. A. (1996). Making it happen: Interaction in the second language classroom. White Plains, NY: Longman.

Richards, J. C. \& Rodgers, T. S. (1986). Approaches and Methods in Language Teaching. Cambridge: Cambridge University Press.

Robinson, G.L. (1989). The CLCCS CALL study: Methods, error feedback, attitudes, and achievement. In W.F. Smith (Ed.), Modern technology in foreign language education: Applications and projects (pp. 124-141). Lincolnwood, IL: National Textbook Company.

Rochelle, J. \& Teasley, S.D. (1995). The construction of shared knowledge in collaborative problem solving. In C. O'Mailley (Ed.), Computer supported collaborative learning. (pp. 69-97). New York: Springer-Verlag.

Salaberry, M. R. (1996). A theoretical foundation for the development of pedagogical tasks in computer mediated communication. Calico Journal, 14, 5-34.

Sassenrath, J. M. (1975). Theory and results on feedback and retention. Journal of Educational Psychology, 67, 894-899.

Sauro, S. (2001). The success of task type in facilitating oral language production in online computer mediated collaborative projects. Unpublished master's thesis. lowa State University, Ames. 
Sauro, S. (2004). Cyberdiscursive tug-of-war: Learner repositioning in a multimodal CMC environment. Working Papers in Educational Linguistics, 19, 55-72.

Savignon, S. (1983). Communicative competence: Theory and classroom practice. Reading, MA.:Addison-Wesley.

Savignon, S.J. 1991. Communicative Language Teaching: State of the Art. TESOL Quarterly, 25, 261-277.

Saxton, M. (1997). The contrast theory of negative input. Journal of Child Language, 24, 139-161.

Saxton, M., Kulcsar, B., Marshall, G. , \& Rupra, M. (1998). Long term effects of corrective input and experimental approach. Journal of Child Language, 25, 701-721.

Schaeffer, R.H. (1981). Meaningful practice on the computer: Is it possible? Foreign Language Annals, 14, 133-137.

Schank, R., \& Cleary, C. (1995). Engines for education. Mahwah, NJ: Lawrence Erlbaum.

Schcolnik, M., Kol, S., Abarbanel, J., Friedler, J., Heymans, Y., \& Tsafrir, Y. (1995/96). Multimedia reference materials in advanced EFL courses: A project report. CAELL Journal, 6, 34-38.

Scholfield, P. J. (2000). Evaluation of CALL software: Work in progress. Department of Language and Linguistics, University of Essex, UK. Retrieved December 17, 2004 from http://privatewww.essex.ac.uk/ scholp/calleval.htm.

Schueckler, L.M. \& Shuell, T.J. (1989). A Comparison of Software Evaluation Forms and reviews. Journal of Educational Computing Research, 5, 17-33.

Schultz, J. (1996). Computers and collaborative writing in the foreign language curriculum. Unpublished manuscript, University of California at Berkeley. 
Schumann, J. (1978). The acculturation model for second-language acqusition. In R. Ginvras (Ed.), Second language acquisition and foreign language teaching (pp. 27-50). Arlington, VA: Center for Applied Linguistics.

Sciarone, A., \& Meijer, P. (1993). How free should students be? A case from CALL: Compute assisted language learning. Computers and Education, 21, 95-102.

Seliger, H. (1977). Does practice make perfect? A study of interaction patterns and L2 competence. Language Learning, 27, 263-278.

Sengupta, S. (2001). Exchanging ideas with peers in network-based classrooms: An aid or a pain? Language Learning and Technology, 5, 103-134

Simpson, J. (2005). Conversational floors in synchronous text-based CMC discourse. Discourse Studies, 7, 337-361.

Sinclair, J. McH., and Coulthard, R. M. (1975). Towards an Analysis of Discourse. Oxford: Oxford University Press.

Sinclair, M. \& Smith, R. (2001). Developing Flexible Learning Materials Design Protocols, Using an ESL Example. Unpublished Report on a Central Queensland University Focus Grant project, Central Queensland University, Rockhampton.

Sinclair, M., Aldred, S., \& Smith, R. (2002). Facilitating the collaborative design of flexible learning materials: Investigating the synthesis of content and multimedia knowledge and expertise. Australian Journal of Educational Technology, 18, 293-307.

Smith, B. (2003). Computer-mediated negotiated interaction: An expanded model. The Modern Language Journal, 87, 38-54.

Smith, B. (2004). Computer-mediated negotiated interaction and lexical acquisition. Studies in Second Language Acquisition, 26, 365-398. 
Soh, B.-L., \& Soon, Y. P. (1991). English by e-mail: creating a global classroom via the medium of computer technology. ELT Journal, 45, 287-292.

Soo, K.-S., \& Ngeow, Y.-H. (1998). Effective English as a second language instruction with interactive multimedia: The MCALL project. Journal of Educational Multimedia and Hypermedia, 7, 71-89.

Sotillo, S. (2000). Discourse functions and syntactic complexity in synchronous and asynchronous communication. Language Learning and Technology, 4, 82-119..

Spada, N. (1997). Form-focused instruction and second language acquisition: A review of classroom and laboratory research. Language Teaching, 29, 1-15.

Spada, N., \& Lightbrown, P.M. (1993). How languages are learned. Oxford: Oxford University Press.

Stenson, N., Downing, B., Smith, J. \& Smith, K. (1992). The effectiveness of computerassisted pronunciation training. CALICO Journal, 9, 5-19.

Stern, H.H. 1992. Issues and Options in Language Teaching. Oxford: Oxford University Press.

Stieglitz, Ezra. (1997). Form for reviewing educational software. Unpublished manuscript.

Sullivan, N., \& Pratt, E. (1996). A comparative study of two ESL writing environments: A computer-assisted classroom and a traditional oral classroom. System, 29, 491-501.

Swain, M. (1985). Communicative competence: Some roles of comprehensible input and comprehensible output in its development. In S. Gass \& C. Madden (Eds.), Input in second language acquisition (pp. 235-253). Rowley, MA: Newbury House. 
Swain, M. (1995). Three functions of output in second language learning. In G. Cook \& B. Seidlhofer (Eds.), Principle and practice in applied linguistics: Studies in honour of H.G. Widdowson (pp. 125-144). Oxford: Oxford University Press.

Tella, S. (1991). Introducing international communications networks and electronic mail into foreign language classrooms (Research Report No. 95). Department of Teacher Education, University of Helsinki.

Tella, S. (1992a). Boys, girls and e-mail:aA case study in Finnish senior secondary schools (Research report No. 110). Department of Teacher Education, University of Helsinki.

Tella, S. (1992b). Talking shop via e-mail: a thematic and linguistic analysis of electronic mail communication (Research report No. 99). Department of teacher education, University of Helsinki.

Tella, S., \& Mononen-Aaltonen, M. (1998). Developing dialogic communication culture in media education: Integrating dialogism and technology. Helsinki: Media Education Publications. Retrieved February 10, 1999 from http://www.helsinki.fi/ tella/mep7.html

Tennyson, R. (1981). Use of adaptive information for advisement in learning concepts and rules using computer-assisted instruction. American Educational Research Journal, 18, 423-438.

Thaipakdee, S. (1992). Relationships among writing quality, attitudes toward writing, and attitudes toward computers in a computer-mediated technical writing class for English as a foreign language students. Dissertation Abstracts International, A: The Humanities and Social Sciences, 53, 1135-A.

Thompson, A. D., Simonsen, M. R., \& Hargrave, C. P. (1992). Educational Technology: A Review of Research. Washington DC: Association for Educational Communications and Technology. 
Thorn, W. J. (1995). Points to consider when evaluating interactive multimedia. The Internet TESL Journal, 2. Retrieved May 17, 2000 from:

http://www.aitech.ac.jp/-iteslj/Articles/ Thorn-EvalueConsider.html

Underwood, J. (1984). Linguistics, computers, and the language teacher: $A$

communicative approach. Rowley, MA: Newbury House.

Underwood, J. (1989). On the edge: intelligent CALL in the 1990s. Computers and the Humanities, 23 (1), 71-84.

Urbee, L. (1999). Classroom practice: MOO, WOO, and more - Language learning in virtual environments. In J. Egbert \& E. Hanson-Smith (Eds.), CALL environments: Research, practice, and critical issues (pp. 346-361). Alexandria, VA: TESOL.

Van Bussel, F. (1994). Design rules for computer aided learning of vocabulary items in a second language. Computers in Human Behavior, 10, 63-76.

Van Der Linden, E. (1993). Does feedback enhance computer-assisted language learning? Computers and Education, 21, 61-65.

Varonis, E. M., \& Gass, S. (1985). Nonnative/nonnative conversations: A model for negotiation of meaning. Applied Linguistics, 6, 71-90.

Verano, M. (1989). USAFA interactive study in Spanish. In W.F. Smith (Ed.), Modern technology in foreign language instruction (pp. 136-154). Lincolnwood, IL: National Textbook Company.

Vygotsky, L. S. (1978). Mind in society: The development of higher psychological processes . Cambridge, MA: Harvard University Press.

Walchowicz, K. A. and Scott, B. (1999). Software That Listens: It's Not a Question of Whether, It's a Question of How. CALICO Journal, 16, 253-276.

Wang, Y. M. (1993). E-mail dialogue journaling in an ESL reading and writing classroom. Unpublished doctoral dissertation, University of Oregon at Eugene. 
Warner, C. N. (2004). It's just a game, right? Types of play in foreign language CMC. Language Learning \& Technology, 8, pp. 69-87.

Warschauer, M. (1995) (Ed.), Virtual connections: Online activities and projects for networking language learners . Honolulu, Hawaii: University of Hawaii Second Language Teaching and Curriculum Center.

Warschauer, M. (1995/1996). Comparing face-to-face and electronic discussion in the second language classroom. CALICO Journal, 13, 7-26.

Warschauer, M. (1996b). Computer-assisted language learning: an introduction. In S. Fotos (Ed.), Multimedia Language Teaching (pp. 3-20). Tokyo: Logos.

Warschauer, M. (1997) Electronic literacies:ILanguage, culture, and power in online education. Unpublished doctoral dissertation, University of Hawai'i.

Warschauer, M. (2000). On-line learning in second language classrooms: An ethnographic study. In M. Warschauer \& R. Kerns (Eds.), Network-based language teaching: Concepts and practice (pp. 41-58). Cambridge, England: Cambridge University Press.

Warschauer, M. (2004). Technology and writing. In C. Davison and J. Cummins (Eds.), Handbook of English languaget teaching (pp. 176-199). Kluwer, Dordrecht, Netherlands.

Warschauer, M. (2005). Sociocultural Perspectives on CALL. In J. Egbert and G. M.

Petrie (Eds.) CALL Research Perspectives (pp.41-51). Mahwah, NJ: Earlbaum, Warschauer, M., \& Healey, D. (1998). Computers and language learning: An overview. Language Teaching, 31, 57-71.

Warschauer, M., \& Kern, R. (Eds.). (2000). Network-based language teaching:

Concepts and practice. Cambridge, England: Cambridge University Press.

Warschauer, M., \& Lepeintre, S. (1997). Freire's dream or Foucault's nightmare:

Teacher-student relations on an international computer network. In R. Debski, 
J. Gassin, \& M. Smith (Eds.), Language learning through social computing (pp. 67-89). Parkville, Australia: Applied Linguistics Association of Australia.

Warschauer, M., Shetzer, H., \& Meloni, C. (2000). Internet for English teaching. Washington, DC: TESOL.

Watts, C. 1989. Interactive video: what the students say, CALICO Journal, 7, 17-20.

Weasenforth, D., Biesenbach-Lucas, S. \& Meloni, C. (2002). Realizing Constructivist Objectives through Collaborative Technologies: Threaded Discussions. Language Learning \& Technology, 6, pp.58-86.

Weasenforth, D. , Meloni, C., \& Biesenbach-Lucas, S. (2005). Learner autonomy and course management software. In B. Holmberg, M. Shelley, \& C. White (Eds.). Distance education and language: Evolution and change (pp. 134-168). Clevedon, UK: Multilingual Matters.

Webb, N.M., Troper, J.D., \& Fall, R. Constructive activity and learning in collaborative small groups. Journal of Educational Psychology, 87, 406-42.

Wegerif, R. (1996). Collaborative learning and directive software. Journal of Computer Assisted Learning,_12, 22-32.

White, L. (1987). Against comprehensible input: The input hypothesis and the development of L2 competence. Applied Linguistics, 8, 95-110.

White, L. (1990). Second language acquisition and universal grammar. Studies in Second Language Acquisition, 12, 121-133.

Widdowson, H. G. (1978). Teaching language as communication. Oxford: Oxford University Press.

Willis, J. (1994). A Framework for task-based learning. England: Addison Wesley Longman Limited. 
Willis, J. (1996). A flexible framework for task-based learning. In J. Willis, \& D. Willis (Eds.). Challenge and Change in Language Teaching (pp. 52-62). Great Britain: Heinemann English Language Teaching.

Willis, J. and Willis, D..(2001). Task-based language learning. In Carter, R. and D. Nunan (Eds), The Cambridge Guide to Teaching English to Speakers of Other Languages (pp. 72-83). Cambridge: Cambridge University Press.

Wolach, A. H. (1994). Developing a computer program to facilitate language training. Computers in Human Behavior, 10, 541-557.

Yalden, Janice. 1987. The communicative syllabus: Evolution, design and implementation. Englewood Cliffs, NJ: Prentice-Hall.

Yang, S. C. (2001). Language learning on the world wide web: An investigation of EFL learners' attitudes and perceptions. Journal of Educational Computing Research, 24, 155-181.

Zhao, Y. (1996). Language learning on the world wide web: Toward a framework of network based CALL. Calico Journal, 14, 37-51.

Zhong, Y. X. \& Shen, H. Z. (2002). Where is the technology-induced pedagogy? Snapshots from two multimedia EFL classrooms. British Journal of Educational Technology, 33, 39-52. 